Maestría en Planificación y

Gestión de Procesos Comunicacionales

\title{
DERECHOS HUMANOS, POLITICAS PÚBLICAS Y UNIVERSIDAD
}

Sistematización de las experiencias de gestión implementadas por la Secretaría de Derechos Humanos de la Facultad de Periodismo y Comunicación Social de la Universidad Nacional de La Plata (2004-2014)

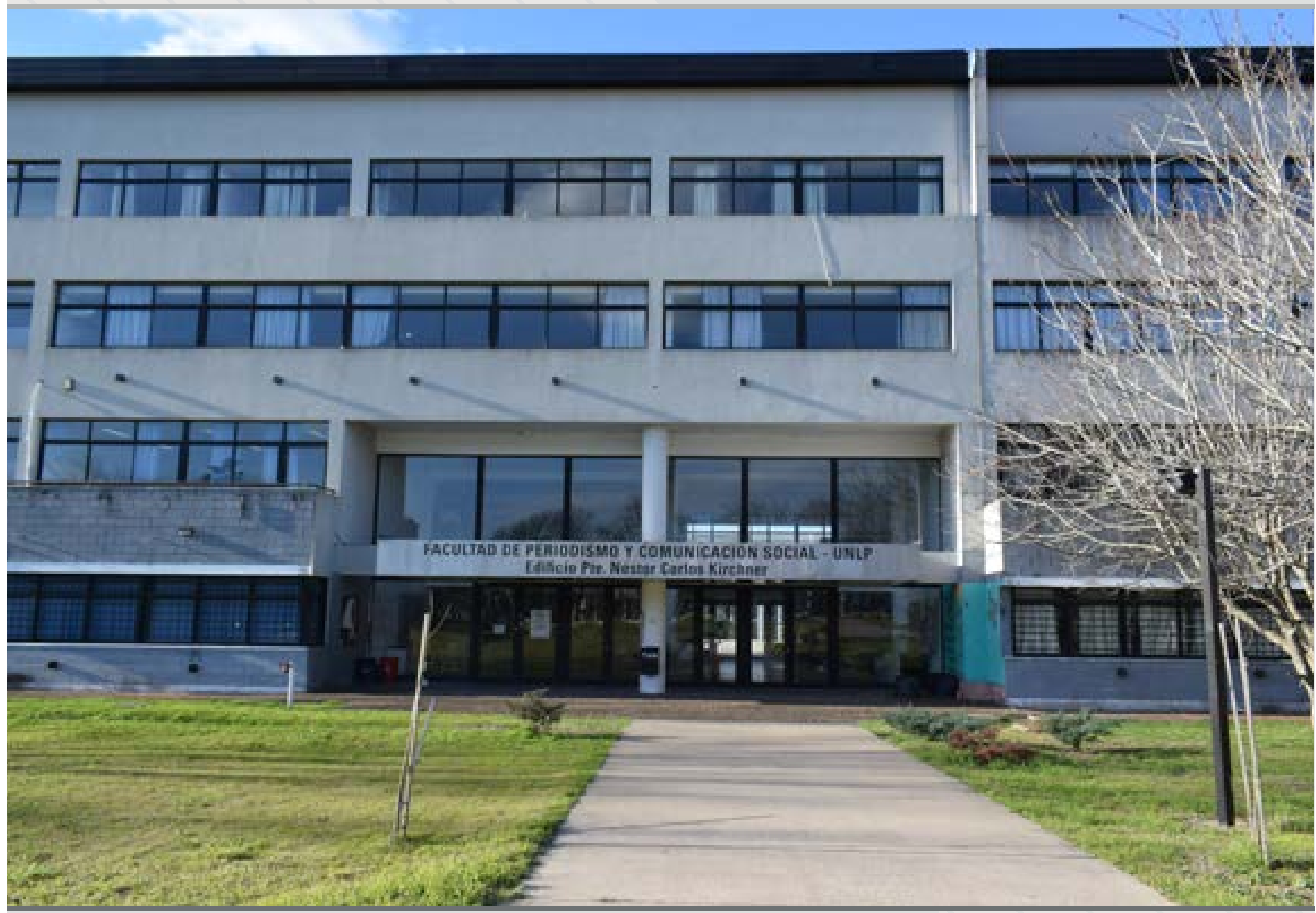




\section{DERECHOS HUMANOS, POLÍTICAS} PÚBLICAS Y UNIVERSIDAD

Sistematización de las experiencias de gestión implementadas por la Secretaría de Derechos

Humanos de la Facultad de Periodismo

y Comunicación Social de la Universidad Nacional de La Plata (2004-2014)

\section{DERECHOS HUMANOS, POLÍTICAS PÚBLICAS Y UNIVERSIDAD}

Sistematización de las experiencias de gestión implementadas por la Secretaría de Derechos Humanos de la Facultad de

Periodismo y Comunicación Social

de la Universidad Nacional de La Plata

(2004-2014)

Director:

German Retola

Codirectora:

Silvia Delfino

Revisión de estilo y normalización de referencias: Adela Ruiz

Maestría en Planificación y

Gestión de Procesos Comunicacionales (plangesco)

Facultad de Periodismo y Comunicación Social

Universidad Nacional de La Plata

Buenos Aires | Argentina 
A mi hija Guadalupe,

a mi amigo Miguel Bru

y a todes les compañeres de lucha.

\section{AGRADECIMIENTOS}

A Rosita Bru, a las Madres y Abuelas de Plaza de Mayo, y a las madres de víctimas de la violencia institucional en democracia, por tanto amor y por enseñarme el valor de la lucha y la solidaridad.

A mi mamá Neri y a mi familia, por estar siempre presentes y por darme la posibilidad de venir a La Plata a estudiar.

A mis compañeres de la Asociación Miguel Bru, por ser lo mejor que me pasó en la vida, porque les adoro. También a les que ya no están en la orga, pero pertenecieron y se fueron por diversos motivos, sepan que también les amo.

A mis amigues, porque sin elles no podría existir.

A la Facultad de Periodismo que me dio a mis amigues, me dio familia, me formó como persona y me incorporó a un proyecto político hermoso que transito con enorme orgullo y alegría.

A les compañeres del sindicato ADULP, por tanta paciencia, afecto y por bancar siempre en todas.

A los organismos y a las organizaciones de derechos humanos por apoyar la gestión y por hacerme parte de las luchas y los afectos.

A mis compañeres de la Secretaría de Derechos Humanos, y de todas las áreas de la Facultad, por tanta banca, tanta paciencia y tanto afecto.

A Germán Retola, mi director, a Angélica Sangronis y a Natalia Zapata, por ayudarme con la tesis. A Silvia Delfino, a Flavio Rapisardi y a Cristian Alarcón, por enseñarme tanto y ser fundamentales en los inicios de la gestión. 
PRÓLOGO, por Germán Retola

\section{Mirar hacia atrás para ganar el porvenir}

PRESENTACIÓN

INTRODUCCIÓN

Los orígenes: un modo de vida

CAPÍTULO I

\section{¿Dónde está Miguel?}

La desaparición

¿Dónde está Miguel?

La complicidad judicial

La búsqueda de justicia

Rosa: amor, lucha y solidaridad

El juicio oral

La Asociación Miguel Bru (amb)

La AMB en tiempos del kirchnerismo

\section{CAPÍTULO ॥}

\section{Condiciones para la creación}

53

de la Secretaría de Derechos Humanos

Los orígenes de la Facultad de Periodismo

La UNLP durante el terrorismo de Estado

La Facultad de Periodismo y la última Dictadura

La apertura democrática

La década ganada en derechos

\section{CAPÍTULO III}

\section{Fundamentos epistemológicos y metodología}

71

De la protección a la construcción de los derechos humanos

La comunicación como acción política

Los usos de la memoria

La epistemología de la esperanza

El diálogo de saberes

El instrumento metodológico

\section{CAPÍTULO IV}

El proceso vivenciado desde el diálogo de saberes

La Matriz de Sistematización: recuperación de los principales acontecimientos

2004 / 2007 - El inicio de la nueva política

2007 / 2010 - La consolidación del proyecto

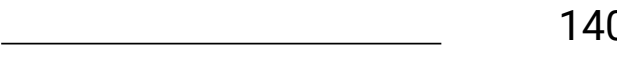

2010 / 2014 - Los nuevos desafíos

\section{REFLEXIONES FINALES}

\section{El rol de la universidad pública en materia}

\section{de políticas públicas en derechos humanos}

\section{REFERENCIAS Y FUENTES}

\section{ANEXO}

Carta de intención del proyecto

de Dirección de Derechos Humanos (FPYCS-UNLP) 


\section{PRÓLOGO}

MIRAR HACIA ATRÁS PARA GANAR EL PORVENIR

Prologar esta tesis es uno de esos lujos que te regala la vida. Esta Tesis de Maestría es el retazo de una historia, nuestra historia, la más difícil de contar, la que está cerca, la que llevamos incorporada, la que advertimos como huella que dejó marca en el camino cuando encontramos otras pisadas y vemos a las nuevas generaciones. Trabajar en su producción fue un viaje que me permitió recorrer el laberinto del pasado reciente, mientras veía, con orgullo, la tenacidad con la que Jorge hacía su trabajo.

Conocí a Jorge a principios de los noventa. No recuerdo la escena, pero puedo inferir que fue en el pasillo de 44 (hoy, la sede Miguel Bru de la Facultad). Tal vez haya sido en una plaza, tomando alguna cerveza en el cordón o volviendo en un micro desde Buenos Aires después de haber marchado por nuestros derechos, o en algún tren atestado de militantes y cargados de banderas. Ahora mismo, me viene la imagen de Miguel, borracho de todo (amor, cerveza, deseo, desparpajo, juventud), usando de tambor el techo del micro, cantando la marcha peronista, seguida por la internacional. Miguel Bru hermanaba con sus perfos, canciones y poesías.

¿Nos habremos conocido ahí con Jorge? Como dije, no recuerdo la escena exacta, pero estoy seguro del escenario: pasillo de 44, Plaza de Mayo, la placita redonda con el árbo en el medio, las marchas por el pase a Facultad, peñas, mucho cordón de vereda, mucha casa, mucha juventud, potencia, deseo, rock, mucho rock y política. Me viene la casa de calle 10, donde vivían Antonia y Caro, el patio interno, el balcón, los tilos. Toda una multitud circulaba por ahí; por supuesto, también Miguel. Una vez me confundí el colirio y quedé medio ciego, así que me llevaron -caminando, por supuesto- desde la casa de 10 hasta el hospital San Martín. Cuando llegamos a la esquina con encontramos con Miguel y, como Chempes ensayaba enfrente, derivamos en el ensayo. Nos alojábamos, circulaba afecto la emoción de cambiar el mundo, no como en un abstracto sino en la práctica concreta de nuestros propios modos de ser y de estar siendo jóvenes de Perio en La Plata.

¡Hemos marchado tantas veces por los derechos humanos de jóvenes! Jamás hubiéramos pensado, en ese entonces, que nos tocaría confeccionar la bandera que diría: «¿Dónde está Miguel?».

La memoria aparece así, de a flashes, y se va. Vuelve emocionada a brindar imágenes y se vuelve a ir, dejando sensaciones que impactan y que nos retuercen. Hace poco vi un posteo de Jorge, junto a Rosa, en una de las tantas búsquedas del cuerpo desaparecido de Miguel. Otra vez, una vez más, siempre presentes. La constancia y el valor de las madres, ser la gota que orada la piedra, la punta de lanza, poner el cuerpo estando ahí, siendo. Repetían y repito ahora: hay una recompensa por dar una pista certera sobre la ubicación del cuerpo de Miguel.
En definitiva, trabajar en esta tesis fue trabajar también con la memoria colectiva. Somos sujetos políticos colectivos que hemos transitado experiencias comunes que han sido fundamentales en nuestros procesos de subjetivación política, atravesando amor y violencia. De alguna manera, en nuestro colectivo político la historia de la Secretaría de Derechos Humanos condensa la historia misma de la Facultad y del país. Por eso esta tesis es también una tesis-archivo. No solamente porque guarda datos y reflexiones, sino porque nos permite comprender las condiciones de posibilidades de acción política con las que contamos, que no aparecieron mágicamente sino que son parte de un camino efectivamente andado, sinuoso y complejo, donde hubo cuerpos puestos a disposición de fortalecer la trama colectiva. En este caso, las posibilidades de pensar el mundo son estas, porque hubo otras antes, que son parte de un haber-saber político y social, pero también particular, singular.

Esta tesis, entonces, es una parte de una gran historia, que sigue su cauce y que se articula con una matriz de pensamiento emancipatorio que viene dando frutos en América Latina desde que comenzó la conquista imperialista. Tiene por objetivo contar la trayectoria de la Secretaría de Derechos Humanos de la Facultad de Periodismo y Comunicación Social de la UNLP. Si bien toca ese punto de la historia, está bueno siempre recordar toda la trama. Además de ser la primera secretaría de este tipo en una universidad pública, la relevancia de este trabajo está dada por el modo de construcción del relato que nos aporta Jorge.

Vamos a la tesis, sin más derivas. Primero, su decisión epistemológica: se basa en las epistemologías pluralistas, del sur, del barro, de la esperanza. Segundo, tiene un afán políticoacadémico, una concepción de memoria activa, en diálogo, y una noción benjaminiana de la historia y sus procesos. Un riesgo que tenía en su producción era el de contar una historia cargada de datos en un tiempo lineal, cuestión que a veces es difícil de desandar cuando se tienen tantos materiales y tanta cercanía con el complejo estudiado. ¿Cómo hacer para que no fuera una sucesión de informes de gestión? ¿Cómo alejarse lo suficiente para reordenar el campo material? ¿Cómo hacer para que sea reflexiva la propia práctica, cómo hacerla hablar?

Jorge estuvo dispuesto a lanzarse al mar de incertidumbres que deviene del vivenciar un proceso de construcción de conocimientos, donde no necesariamente se encuentra lo que une iba a buscar. En este sentido, tuvimos avances y retrocesos, y el proceso fue lo que debía ser: un subibaja de emociones y de preguntas.

Fue clave la selección del modelo de sistematización que Jorge adoptó para su proceso. Eligió la metodología propuesta por el Dr. Oscar Jara Holliday, educador popular de Costa Rica, lo cual requiere de un gran compromiso, porque su mirada está situada dentro de los métodos que requieren de una profunda implicancia con la investigación. Hubo tanta responsabilidad de Jorge para con el proceso que fue a formarse con el mismo Oscar Jara Holliday. De hecho, la decisión del recorte temporal surgió de los diálogos del tesista con Jara Holliday. Esta metodología forma parte de la matriz de pensamiento latinoamericana y 
También, podremos observar en la tesis cómo la Secretaría, a lo largo de su trayectoria, pudo hacer desplazamientos vitales para la construcción social de sentidos colectivos acerca de la lucha en derechos humanos. De esta forma, fue ampliando su gramática e incorporando actores, temas, problemas, escenarios y territorios de gestión desde donde aprehendimos nuevos horizontes de transformación.

Entonces, para cerrar y para abrir a una lectura posible de la tesis, quiero decir que, en este trabajo, vamos a intentar develar no solo los hechos de la realidad, sino las relaciones que fundaron los acontecimientos que se van a relatar. Por ello, leeremos una tesis cargada de voces otras: voces trans, voces migrantes, voces indígenas, voces privadas de su libertad, vidas de desaparecides, de madres que cargan pérdidas inconmensurables, de abuelas que aún buscan a sus nietes. Porque la lucha por los derechos humanos no está tejida solamente de palabras y de conceptos, sino de vida, de cuerpos, de relaciones, de la conflictividad de ser y de estar presentes en el mundo, luchando por la justicia social y epistémica que durante siglos nos viene siendo negada. Es una tesis para adelante, que mira hacia atrás para ganar el porvenir.
Tenemos el derecho a ser iguales cada vez que la diferencia nos inferioriza y a ser diferentes cuando la igualdad nos descaracteriza.

Boaventura de Sousa Santos (2005a)

Esta tesis sistematiza la experiencia de gestión de la Secretaría de Derechos Humanos de la Facultad de Periodismo y Comunicación Social (FPYCS) de la Universidad Nacional de La Plata (UNLP) durante el período 2004/2014. Este proceso se realiza mediante la metodología de sistematización de experiencias, propuesta por el educador popular Oscar Jara Holliday, referente latinoamericano en el tema, a los efectos de interpretarlas epistemológicamente desde el diálogo de saberes. El propósito del proyecto es hacer aportes reflexivos sobre las políticas de derechos humanos gestionadas desde la universidad pública con un enfoque comunicacional.

Cuando aludimos al enfoque comunicacional, tenemos que partir de definir al diálogo de saberes como una política central de la planificación y la gestión del proceso analizado. Un diálogo de saberes entre teorías y prácticas concretas en derechos humanos que tiene lugar en los procesos de planificación y de gestión en pos de construir nuevos sentidos que aporten positivamente a la transformación de la realidad académica y social. Se parte del hacer con les otres, del encuentro y el reconocimiento de la diversidad para construir propuestas, muchas inéditas hasta ese momento en las políticas de derechos humanos de la UNLP, como veremos más adelante. Construir saberes en procesos dialogados, supone compartir con les protagonistas las experiencias vividas, las trayectorias de vida y los procesos de construcción colectiva, para generar políticas que inclusive desestabilizan la cotidianeidad académica, en sentido positivo, y que favorecen, por sobre todas las cosas, la calidad de las propuestas políticas de gestión, más inclusivas, originales y multiculturales.

En un principio, la intención era abarcar la gestión desde sus inicios hasta la actualidad. No obstante, ese período resultaba demasiado extenso para analizarlo con la profundidad y la rigurosidad que este proceso requiere. Por esa razón, y por recomendación de Germán Retola y del propio Oscar Jara Holliday, el recorte temporal quedó comprendido entre los años 2004 y 2014.

Para esto, se partió de periodizar la historia de la Secretaría. Se establecieron tres períodos, signados por la coyuntura política nacional: $2004 / 2014$, este primer período se caracteriza por la consolidación del paradigma de gestión en un contexto favorable a los derechos humanos; 2014/2019, en este segundo período se produce un cambio de paradigma en el gobierno nacional respecto de los derechos humanos, en un contexto de ajuste y de represión; 2019/actualidad, en este tercer período, nuevamente, un gobierno nacional y 
popular, con un claro eje en la defensa de los derechos humanos, gana las elecciones

El proyecto abarca, en consecuencia, el primer periodo de gestión, un tiempo fundacional que comienza en 2004 cuando, por decisión unánime del Consejo Académico de la FPYCS se creó formalmente la Dirección de Derechos Humanos y se propuso mi nombre para ejercer el cargo de Director. ${ }^{1}$

Esta tesis se desarrolla en el marco de la Maestría en Planificación y Gestión de Procesos Comunicacionales (PLANGESCO), inscripta en el campo de estudios del cambio social, la comunicación popular y la pedagogía para el desarrollo, que busca formar comunicadores que, sobre la base de objetivos político-culturales, puedan diseñar, planificar y gestionar procesos de comunicación. En línea con este enfoque, la metodología desarrollada por Oscar Jara Holliday, que vertebra este escrito, resulta de estricta coherencia y pertinencia para la sistematización de experiencias realizada.

Durante el periodo estudiado, el horizonte de las acciones hallaba fundamentos en un contexto social de luchas por la ampliación y la universalización de un conjunto variado de derechos civiles, políticos, sociales, económicos y culturales, para su concreción y su accesibilidad en condiciones de igualdad. En ese escenario, el Estado gestionaba y acompañaba las luchas, incorporando a los organismos de derechos humanos, y a sus reclamos históricos, como parte central de la política. Este proceso provocó un cambio importante en las instituciones, entre ellas la Universidad: de ser históricamente formadora y productora de dirigentes intelectuales, se desplazaba hacia una institución garante y constructora de derechos y con políticas inclusivas de distinto tipo y en diferentes territorialidades (Sousa Santos, 2006)

La Dirección, primero, y la Secretaría, después, se nutrieron de saberes y de prácticas concretas y diversas. En la actualidad, y transcurrida más de una década de experiencias, creo que llegó el tiempo de la recapitulación, puesto que hasta este momento no se había Ilevado a cabo una organización sistemática del proceso de gestión que permitiera interpretar el curso de políticas que, además, exceden la institucionalidad universitaria debido a su articulación con la gestión general de la FPYCS, con la comunidad universitaria en general con organismos de derechos humanos, con actores y referentes de la sociedad civil, y con el Estado en todos sus niveles.

Partiendo de concebir la comunicación como matriz de la práctica y como estrategia para la acción política, es ese vacío en la historización lo que me impulsa a sistematizar las experiencia de gestión, proceso que inició con un conjunto de interrogantes a partir de los cuales se delinearon los objetivos que luego me permitieron hilar algunas reflexiones, desde la mirada PLANGESCO, sobre las relaciones entre comunicación / derechos humanos / políticas públicas / universidad

Desde esta perspectiva, el desarrollo de la tesis intenta construir respuestas para las siguientes preguntas:

1 Cargo que desempeñé durante el período 2004-2007 (Resolución 88/2004) y luego, como Secretario, en los períodos 2007-2010 y 2010-2014 (Resolución 87/2007).
¿De qué manera es factible sistematizar el proceso de gestión de la Dirección/ Secretaría de Derechos Humanos de la FPYcs de la UNLP desde el punto de vista de la comunicación como acción política?

Desde lo comunicacional, ¿en qué consistió la política de derechos humanos de la Dirección/Secretaría durante el período 2004-2014?

¿Cómo influyeron el contexto político y la política pública del Poder Ejecutivo en la gestión llevada a cabo?

Ante las luchas activas por los derechos, ¿cuáles fueron las transformaciones en los modos de articular la planificación con la gestión?

¿Con qué bases epistemológicas es factible reflexionar sobre las relaciones entre los derechos humanos, la comunicación, las políticas públicas y la universidad?

¿De qué modos y en qué medida la FPYcs dialogó con las formas organizacionales del país?

¿De qué manera es factible identificar las matrices de prácticas y de saberes que orientaron aquellos diálogos?

Frente a estos interrogantes, en el periodo estudiado identificamos ocho ejes que fueron fundamentales y articuladores de la gestión, a saber:

Pedagogía en comunicación y derechos humanos: para la formación de docentes y de estudiantes en las relaciones entre comunicación y derechos humanos, se desarrollaron proyectos de extensión, de producción y de investigación sobre la temática. En 2005, se planificó el seminario Comunicación y Derechos Humanos, que rápidamente se transformó en una asignatura por la que circuló una enorme cantidad de estudiantes, tanto en las cursadas de la sede central como en las diferentes extensiones áulicas. En 2012, se inició el dictado de la Maestría en Comunicación y Derechos Humanos, la primera oferta de posgrado específica sobre la materia en Latinoamérica.

Narrativas con perspectiva en derechos humanos: para que les estudiantes puedan aplicar esta perspectiva en su futuro desarrollo profesional del periodismo, se armaron seminarios específicos en la currícula de la carrera, charlas-debates con referentes periodísticos especialistas en la materia, congresos y numerosas jornadas tendientes a abordar la relación entre comunicación, exclusión e inclusión en la disputa del sentido sobre las representaciones sociales de lo que comunicamos.

- Memoria y Dictadura: se confeccionó el listado de víctimas del terrorismo de Estado de la Facultad y de la UNLP, que incluyó sus historias de vida; se organizaron actividades conjuntas con los organismos históricos de derechos humanos y se establecieron contactos con familiares, amigues y compañeres de las víctimas; se realizaron actos, charlas, muestras, murales alusivos y diversas producciones comunicacionales sobre los ex estudiantes de 
la Escuela Superior de Periodismo durante los años 1976-1983, entre las que destacan los relatos audiovisuales de Madres y Abuelas de Plaza de Mayo. Se inauguró la plaza de les desaparecides en la Facultad, se trabajó en el acompañamiento y en la divulgación de los Juicios de Lesa Humanidad y se participó de diferentes actividades convocadas con y desde diferentes espacios de derechos humanos de la ciudad.

- Violencia Institucional en democracia: junto con familiares de víctimas de la violencia institucional, se organizaron charlas, debates, actos y talleres; se realizaron murales alusivos, producciones comunicacionales e informes sobre la relación con la producción de noticias; y se acompañó en diversos juicios penales. Se trabajó, permanentemente, sobre el caso Miguel Bru y se creó la Dirección de Violencia Institucional, dependiente de la Secretaría.

- Diversidad sexual: se articuló con activistas del movimiento TLGBI, se fomentaron espacios de formación en cátedras y jornadas institucionales, se trabajó con la primera egresada trans en la FPYCs (posteriormente, docente y Doctora en Comunicación), se promovió el reconocimiento en las actas administrativas de la identidad auto-percibida (la Facultad es la primera del país y de Latinoamérica en asumir esta política), se participó del activismo político en visibilización y reclamos de vulneración de derechos, y se creó de la Dirección de Género y Diversidad, dependiente de la Secretaría.

- Derechos de las mujeres: en articulación con activistas y con referentes feministas, se incluyó esta temática específica en la cátedra Comunicación y Derechos Humanos, se organizaron charlas-debate, presentaciones de libros y actos, y se participó en marchas y en juicios sobre hechos de violencia de género.

- Pueblos indígenas: a partir del caso del estudiante Pascual Pichún Collonao, prófugo de la justicia chilena, se inició el trabajo en este eje específico. Se introdujeron en la currícula de la carrera materias sobre lenguas mapuche, quechua y guaraní, se realizaron jornadas sobre comunicación indígena y se incorporó el eje temático en el programa de la materia Comunicación y Derechos Humanos. Si bien no queda comprendido en el período delimitado para sistematizar la experiencia que se aborda en esta tesis, en 2016 se creó la Dirección de Pueblos Indígenas «Emilia Uscamayta Curi» y se instaló la Chakana (Cruz Andina) en el centro del patio de la Facultad, donde se realizan ceremonias con diversas comunidades indígenas.

- Educación superior en cárceles: en 2006, la Secretaría y el Ministerio de Justicia de la Provincia de Buenos Aires firmaron un convenio para el dictado de talleres de comunicación y para la realización de producciones periodísticas en las unidades penitenciarias para privades de libertad. En 2009, producto de un nuevo convenio entre la Facultad y el Ministerio de Justicia, se puso en marcha la extensión áulica Unidad 9 de La Plata, una experiencia de formación universitaria presencial en unidades carcelarias del Servicio Penitenciario Bonaerense. La Licenciatura en Comunicación Social se convirtió, así, en la primera carrera de la UNLP con cursadas intramuros y cuenta, en la actualidad, con más de 500 estudiantes en contextos de encierro.

$2 \quad$ A cargo de la Dirección, se designó como directora a la docente quechua Zulema Enríquez.
A su vez, al momento de ser analizado, este primer período se subdivide en tres momentos organizados en función de los sucesivos períodos de gestión institucional: 2004 al 2007 2007 al 2010 y 2010 al 2014

A partir de lo señalado, el objetivo general que guía el presente trabajo puede sintetizarse de la siguiente manera: sistematizar las experiencias de la gestión de la Secretaría de Derechos Humanos, con la finalidad de interpretarlas epistemológicamente y de contribuir con reflexiones sobre las relaciones entre derechos humanos, comunicación, políticas públicas y universidad.

En relación con la metodología, es preciso destacar la relevancia que tuvo la construcción de la matriz de sistematización cronológica con los principales acontecimientos para comprender el proceso vivenciado desde el diálogo de saberes y para trazar, luego, líneas de reflexión que problematizan el rol de la universidad pública en materia de políticas públicas en derechos humanos.

El documento está organizado de la siguiente manera: en la introducción, se presenta un breve recorrido sobre mis orígenes y sobre la trama de experiencias que marcaron la subjetividad colectiva de gran parte de mi generación; la relación con el tema abordado y el camino que me llevó a asumir la Dirección de Derechos Humanos de la FPYcs. En el primer capítulo se aborda la desaparición del estudiante Miguel Bru; la relación de este hecho con la vida político académica de la Facultad, por entonces, Escuela Superior de Periodismo; el proceso colectivo de búsqueda de justicia; el papel central de su madre Rosa Bru; y la creación de la Asociación Miguel Bru (AMB). En el segundo capítulo se ofrece un recorrido histórico sobre las condiciones que posibilitaron la creación de la Dirección de Derechos Humanos; los orígenes de la FPYCS y lo sucedido en la UNLP y en la Facultad durante el terrorismo de Estado; y lo que implicó la apertura democrática y los tiempos del kirchnerismo en la era de ampliación de derechos. En el tercer capítulo se desarrollan los fundamentos teórico-epistemológicos y los instrumentos metodológicos utilizados. En el cuarto capítulo se presenta la matriz de sistematización cronológica que da cuenta de los principales acontecimientos de la gestión en el período 2004-2014 y la comprensión del proceso vivenciado desde el diálogo de saberes. Por último, el apartado dedicado a las conclusiones incorpora una reflexión integral sobre los fundamentos teórico epistemológicos de la gestión y la visión a futuro de esta experiencia.

En cuanto a la escritura, frente a la temática de género se decidió utilizar la letra «e», con la intención de visibilizar las representaciones que cuestionan el binarismo sexo genérico hegemónico y de promover el uso de lenguaje inclusivo en la academia. Entendemos que esta es la mejor forma que hemos encontrado, al menos hasta el momento, para sentar una posición frente al complejo problema que encierra el patriarcado lingüístico y la heteronormatividad que históricamente se apoderó de la construcción simbólica que produce el lenguaje. Al mismo tiempo que cuestiona la arbitrariedad en el lenguaje, la letra «e» marca la falta de representaciones desde los modos de enunciarse. Entender a la lengua 
y al discurso como un terreno de disputa, conlleva considerar que lo que no se nombra se invisibiliza, se excluye, todo lo contrario al eje que articula toda nuestra gestión: la política inclusiva. La utilizamos, pues, con la intención de que su uso y su puesta en práctica sea una herramienta fundamental y efectiva para aportar al cambio social por el que tanto luchamos, y en donde todas, todos y todes estemos representades.

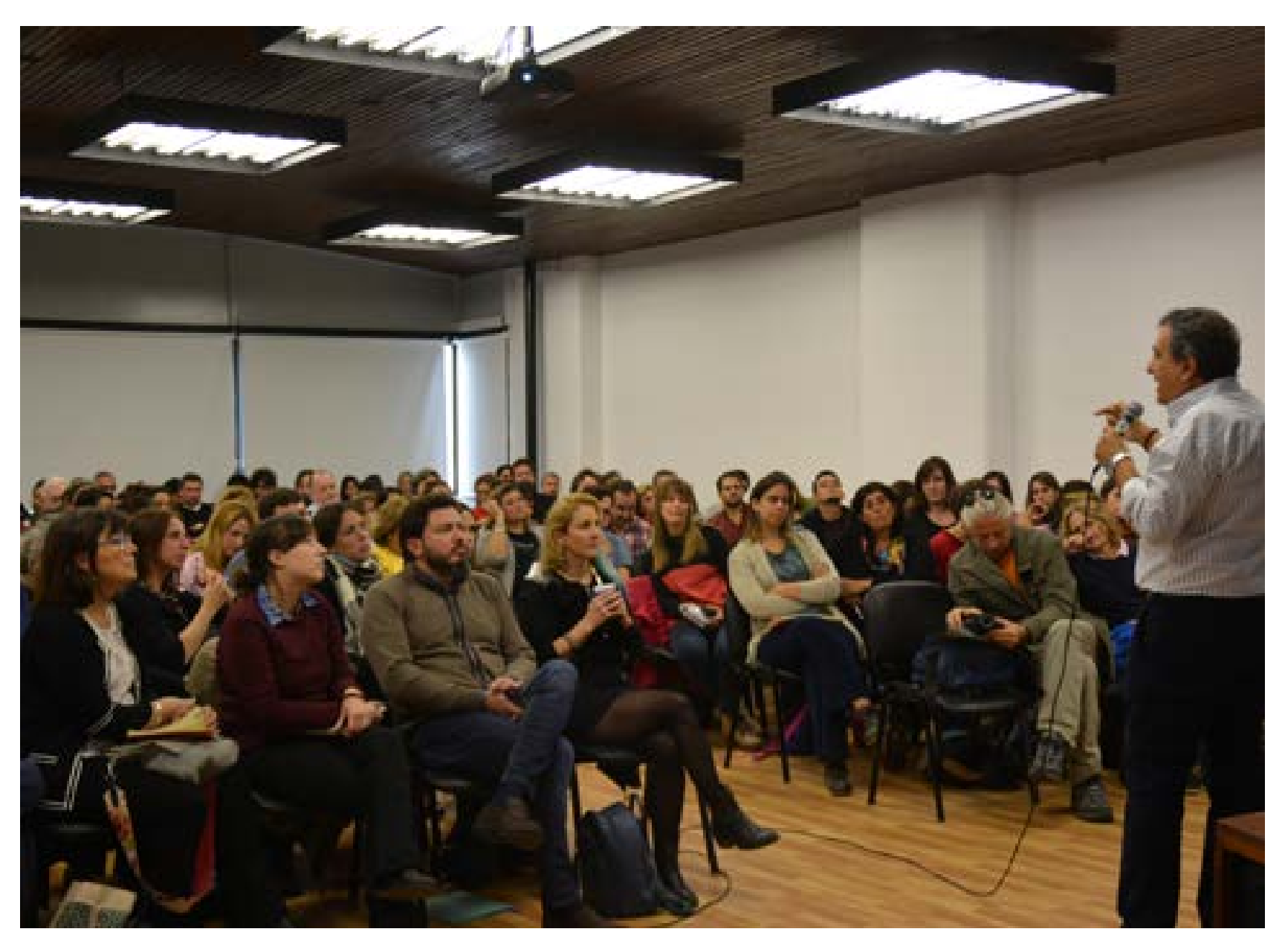

17

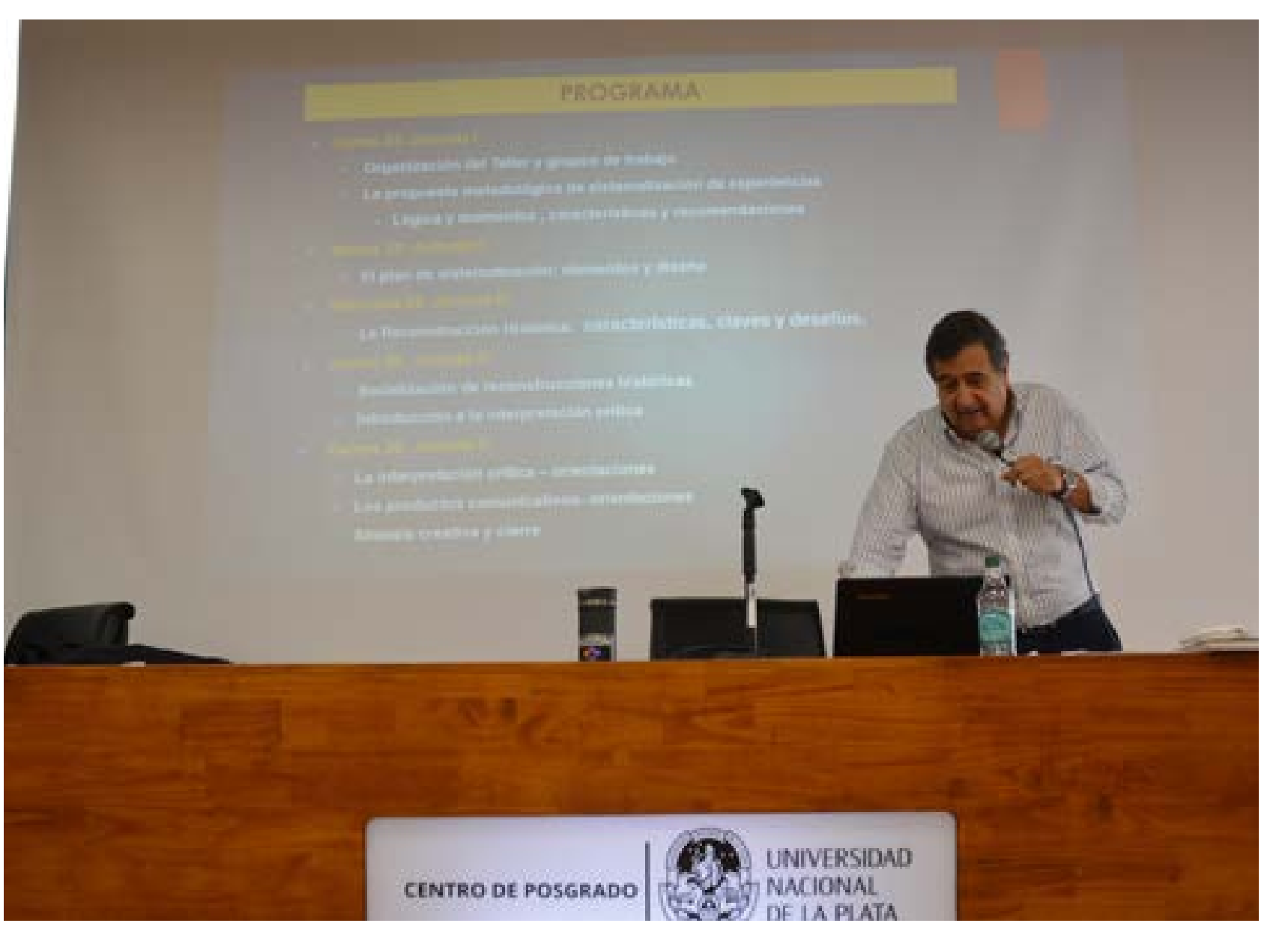



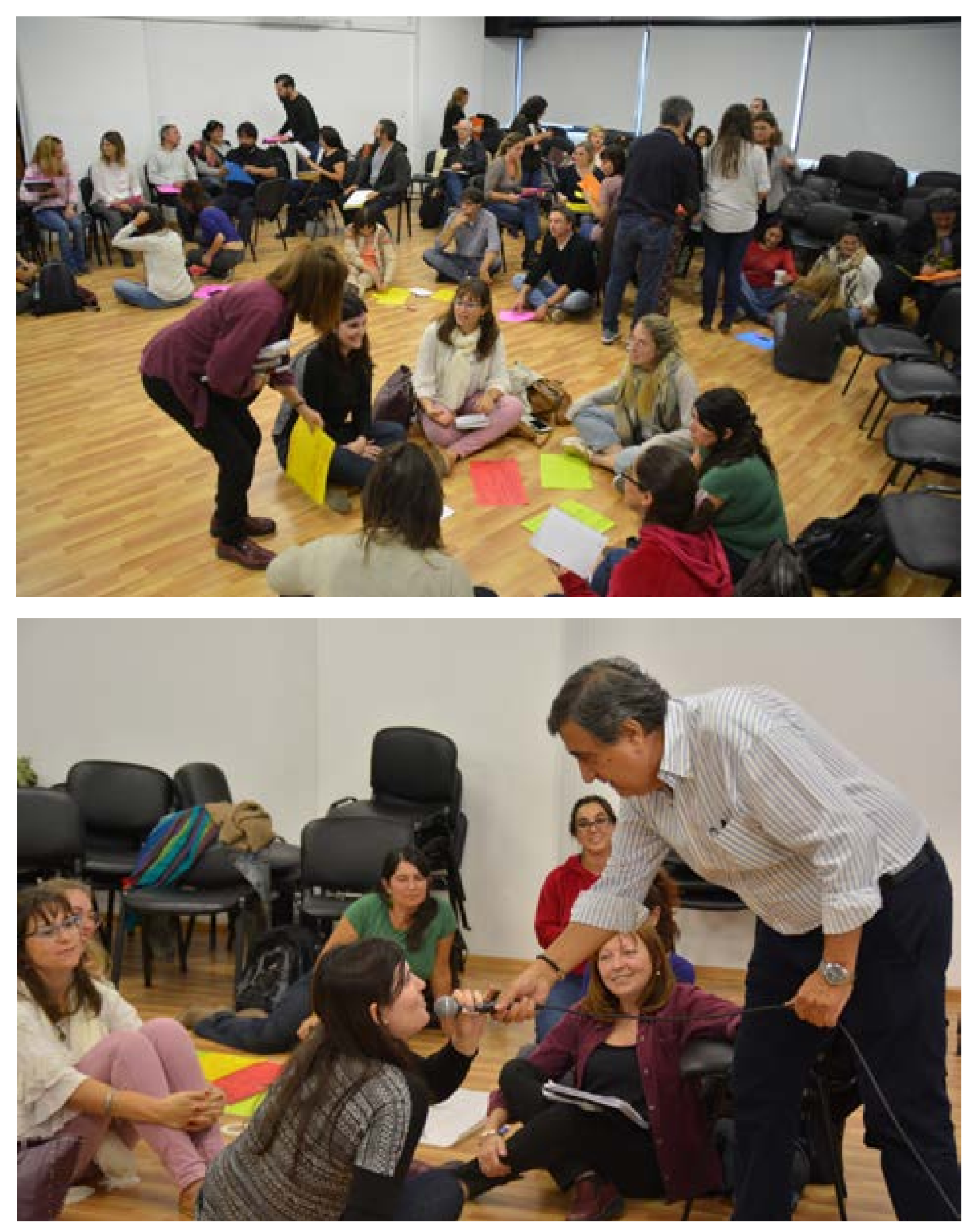

Curso "Extensión universitaria crítica y sistematización de las experiencias: explorando los modos de producción y circulación del conocimiento desde una perspectiva de ecología de saberes", dictado por Oscar Jara, en Abril de 2019, en la UNLP. Este curso del cual participé se transformó en un envión muy importante, poder compartir el proceso de formación en base a cuestiones relacionadas y planteadas en la tesis fue fundamental.
INTRODUCCIÓN

LOS ORÍGENES: UN MODO DE VIDA

Podrán cortar todas las flores pero no podrán detener la primavera.

Pablo Neruda

Soy clase 1968. Nací en Puerto San Julián, un pueblo de la provincia de Santa Cruz, que tenía 4.000 habitantes. Mi abuelo paterno era inmigrante. Llegó de Asturias, España, solo en un barco, con 18 años, y enseguida se fue a trabajar al sur. Allí se casó con mi abuela que ni siquiera había podido terminar la primaria. Tuvieron tres hijas, una de ellas mi mamá, quien tuvo que ir a cursar el secundario a Buenos Aires, porque en el pueblo no había ese nivel de estudios. Mi mamá se costeó los estudios trabajando en una verdulería y como niñera. Con el título secundario también se recibió de maestra y, con apenas 21 años, fue la directora más joven de la historia de la Escuela N. 4 Florentino Ameghino de Puerto San Julián, donde hice desde el jardín hasta sexto grado. Luego me mudé a Río Gallegos, porque a mi mamá la habían ascendido a inspectora.

Laúltima Dictadura cívico militareclesiásticapasó desapercibidaenmipueblo, históricamente antiperonista, al igual que mi familia. Nunca escuché fundamentos claros, pero en casa se notaba el odio hacia el peronismo. Sin embargo, siempre me llamó la atención que mi papá me enseñara a cantar la marcha peronista cuando apenas tenía cinco años. Falleció cuando yo tenía 14 años, por lo que lamento no haberle preguntado nunca por qué.

Viví la Guerra de Malvinas en Río Gallegos, hasta que a mediados de 1983 mi mamá se jubiló -con 25 años de servicio- y nos fuimos a Neuquén, donde terminé tercer año del secundario. En aquellas aulas me encontré con hijos e hijas de exiliados y exiliadas por la última Dictadura cívico militar eclesiástica. Un nuevo y apasionante mundo se abría ante mí, en el marco de la efervescencia de la democracia y del libro Nunca Más (1984), ${ }^{3}$ cuya lectura me permitió enterarme de las atrocidades cometidas por el terrorismo de Estado.

Comencé la militancia en el Peronismo Revolucionario (PR) y enseguida fundamos la Unión de Estudiantes Secundarios (UES) de Neuquén, con el convencimiento absoluto de que podíamos luchar por restituir el proyecto de país que la Dictadura había truncado. Desde el PR, me propusieron ir a militar a una villa neuquina, y ese trabajo, sumado a las lecturas sobre el movimiento peronista y sobre la historia argentina, determinó que empezara a vivir el amor por el peronismo.

$3 \quad$ Nunca Más (1984) recoge el informe emitido por la Comisión Nacional sobre la Desaparición de Personas (CONADEP) respecto de las desapariciones, las torturas y los asesinatos ocurridos en la Argentina durante la última Dictadura cívico militar eclesiástica (1976-1983). 
Pronto, las «Leyes del Perdón» ${ }^{4}$ truncaron nuestros sueños. Queríamos participar más en las discusiones y en la toma de decisiones del partido, pero nuestra cúpula política no compartía esa visión. Al poco tiempo, nos expulsaron a algunes de les compañeres sin justificaciones claras y ante esta situación decidimos irnos todes, con la sensación de que nos habían hecho «pisar el palito» de la salida.

De todos modos, continuaron las discusiones fragorosas sobre política en el ámbito universitario y la participación en las marchas (por ese entonces, había empezado la carrera de Comunicación Social en la Universidad Nacional del Comahue, en la ciudad de General Roca, Río Negro). En casa, las discusiones sobre política también eran muy intensas, pero mi mamá abandonó la ilusión de convencerme; de hecho, muchas veces no tenía respuesta para sus contradicciones, porque mis convicciones peronistas estaban ya demasiado fundamentadas.

A partir de las recomendaciones de amigues que estaban estudiando en La Plata, y con el apoyo de mi familia, decidí continuar mi formación en la Escuela Superior de Periodismo de la Universidad Nacional de La Plata (UNLP). El nivel de activismo y de discusión política que tenía lugar en las aulas me apasionó desde el primer momento, y así creció el compromiso político con las lecturas, la formación política y, por supuesto, la comunicación.

Recuerdo que fue muy impactante, casi estremecedor, entrar a la sala donde se hacían las fotocopias y ver un mural con flores, cada una con el nombre de las víctimas del terrorismo de Estado de la Escuela Superior, y la frase: «Podrán cortar todas las flores, pero no podrán detener la primavera», Pablo Neruda.

Esta Escuela me abrazaba, me cobijaba, y me daba la contención y la formación política que necesitaba. Empecé a hacerme de algunes amigues, pero cuando llegué era bastante tímido y me costaba socializar. No obstante, al poco tiempo conocí a una persona que era la antítesis de eso, se llamaba Miguel Bru, y podría decir que fue el primer amigo que hice en La Plata, un tipo bueno, generoso, alegre y de humor fresco. Escuchábamos música, jugábamos al fútbol, nos juntábamos a comer pizza y a tomar cerveza, discutíamos sobre periodismo y sobre periodistas desde una visión crítica de la realidad política nacional e internacional.

Íbamos a las peñas que se hacían en las diferentes unidades académicas de la UNLP. Nos divertíamos mucho, nos conteníamos y creíamos en la construcción de un mundo mejor que aquel en el que vivíamos, plagado de leyes de perdón, de violencia, de corrupción policial y con una gestión política fundada en la corrupción y en la ausencia de un Estado que garantizara los derechos básicos y fundamentales.

El concepto de modo de vida remite a una forma no natural, sino cultural,

política e histórica, sujeta a prácticas y a experiencias. El modo de vida,

$4 \quad$ Se conoce de este modo a las leyes de Punto Final (1986) y de Obediencia Debida (1987) mediante las cuales se impidió el juzgamiento de las condenas contra los autores de crímenes de lesa humanidad cometidos por el Estado durante la última Dictadura cívico militar eclesiástica (1976-1983). además, y según Tatián (2009), se relaciona con una ética, entendida esta en forma similar al sentido spinoziano: el acto de ser «causa de nosotros mismos» y de desplegar nuestra «potencia de existir» (Retola, 2018, p. 95)

En 1993, el secuestro, la tortura y la desaparición de Miguel, uno de los mejores amigos que me dio la vida, fue para todes sus amigues y sus compañeres un golpe, un sacudón muy fuerte; tanto, que cambió nuestras vidas para siempre. Fue «el año en el que perdimos la alegría», como dice siempre una compañera y amiga de esas épocas.

El proceso colectivo de búsqueda de justicia por Miguel fue inmenso. Sus amigues y compañeres dejamos trabajo, diversión, estudio, todo de lado, para dedicar el día entero a diseñar la estrategia comunicacional, la movilización y para sostener y acompañar a su familia. Y esta Facultad fue la que nos dio contención institucional: nos juntábamos desde las 7 u 8 de la mañana, diseñábamos y activábamos la lucha, y nos íbamos a altas horas de la noche; en general, a seguir en reuniones en la casa de algún compañere para planificar lo que vendría.

Muy pronto, este proceso se convirtió en una de las búsquedas de justicia más significativas desde la apertura democrática. Y no solo en La Plata, porque llegamos a todo el país e, inclusive, al exterior. Los pedidos de informes que diversos estamentos internacionales (la embajada de los Estados Unidos, Amnesty Internacional, etc.) hacían al gobierno argentino lo constituyeron en un momento bisagra en la lucha contra el «Gatillo fácil» 5 en el país.

En esa búsqueda de justicia nos acompañó un sinnúmero de personas y de organizaciones que marcarían el futuro destino político de la gestión. En ese proceso, conocí personalmente a las Madres y las Abuelas de Plaza de Mayo, que desde entonces nos aconsejan y nos acompañan, a familiares de detenides desaparecides por razones políticas, a hijes de desaparecides (en ese momento, aún no existía formalmente la agrupación HIJos), a familiares de víctimas de la violencia institucional, a la familia del periodista José Luis Cabezas, de Maximiliano Albanese, de Andrés Nuñez, de Walther Bulacio, de Sebastián Bordón, de Mariano Wittis y de Ezequiel Demonty.

También nos acompañaban organizaciones de derechos humanos como el Centro de Estudios Legales y Sociales (CELS), la Coordinadora contra la Represión Policial e Institucional (CORREPI), la Asamblea Permanente por los Derechos Humanos (APDH) de La Plata, y numerosas personalidades del mundo político, legislativo, de la militancia platense y de la Universidad. Ese proceso colectivo, acompañado por una movilización pública de gran magnitud, junto con las mencionadas relaciones y articulaciones, fue muy reconocido y me fue convirtiendo en un referente político en materia de derechos humanos en La Plata $y$, fundamentalmente, en el mundo universitario.

De todos modos, continuaba viviendo profesionalmente del periodismo. Había realizado una $5 \quad$ Se conoce de este modo al uso abusivo y fuera de la ley, por parte de las fuerzas de seguridad, de armas de fuego, generalmente presentada por la policía como una acción accidental o de legitima defensa y que ocasiona muerte de una persona. 
pasantía en el diario El Día y hacía trabajos freelance para ATC, para Televisión Selectiva (el canal del diario El Día) y para Crónica TV. En 1996, Crónica TV me incorporó como empleado de planta permanente y fue para este canal que, tres años después, me tocó cubrir el juicio oral y público por la desaparición de Miguel.

Ese mismo año, rendí los seis finales que debía para recibirme de licenciado en Comunicación Social y me convertí en el primer universitario de mi familia, un logro que me dio mucha satisfacción.

En 2000 ingresé al área audiovisual de la Facultad, a la vez que realizaba investigaciones periodísticas para América TV, BBC de Londres y Telemundo, y en 2002 comencé a trabajar como productor personal de Juan Castro para Kaos en la Ciudad, en aquel momento, el programa top de Canal 13. En ese camino, nunca abandoné la militancia ni el reclamo de justicia por Miguel, intentando siempre vincular mi tarea periodística con el mundo de los derechos humanos.

Casi al mismo tiempo del suicidio de mi jefe, Juan Castro, y en el marco de una saturación importante del mundo del periodismo televisivo, en 2004, me ofrecieron la Dirección de Derechos Humanos de la Facultad de Periodismo y Comunicación Social. Un desafío y una responsabilidad muy grande: podría combinar mi tarea militante en materia de derechos humanos con mi trabajo profesional.

Desde el principio, tuve mucho acompañamiento político y conté con el apoyo de actores estratégicos, de organismos y organizaciones de derechos humanos, y de la militancia política de diversos sectores y partidos políticos que respetaban mi trayectoria en la búsqueda de justicia por Miguel. Pero también, y fundamentalmente, sentí el apoyo unánime desde todos los claustros de la Facultad.

Al principio, no faltaron activistas y miembros de organizaciones que me miraron con un poco de recelo por no encuadrar en sus grupos políticos, pero en poco tiempo, con mucho trabajo y con el cuerpo puesto en la gestión, eso se fue solucionando.

Como afirma Germán Retola, director de esta tesis, «la subjetividad es la presencia de la sociedad en el individuo, es el acto de organización compleja que emerge de la relación de sujeto con el mundo y con los demás. La subjetividad se construye en un proceso a partir de los vínculos con los otros, con las instituciones y con las significaciones imaginarias sociales» (Retola, 2018, p. 14)

Tenía una premisa fundamental: desde el diálogo de saberes, articular las políticas de la Facultad con los organismos de familiares de víctimas de la Dictadura, con organizaciones de derechos humanos, con víctimas de violaciones a los derechos humanos y con militantes políticos. Desde una perspectiva de construcción de derechos, me involucré no solo con temas relacionados con el genocidio ocurrido durante la última Dictadura, sino también con las violaciones a los derechos humanos desde la apertura democrática y con los cotidianos reclamos de justicia; es decir, con los derechos humanos entendidos desde su diversidad y

\section{con una mirada integral.}

Es importante señalar mis orígenes como comunicador, como militante y como profesional, porque este trabajo pretende correrse de una perspectiva de construcción de conocimiento objetivista para asumir un enfoque de producción de conocimiento que pone de relieve tanto a les sujetes cognoscentes como a los procesos de subjetivación política derivados de lo vivenciado en las prácticas a sistematizar.

Por eso este trabajo se inicia destacando la trama que conecta las experiencias: aque joven militante de secundaria, el mural con la poesía de Neruda, Miguel y las actividades de búsqueda de justicia, entre tantos otros hechos, personas y organizaciones que hicieron posible la práctica de gestión que se describe en estas páginas y que, sin duda, supo nutrirse de estos aconteceres. 


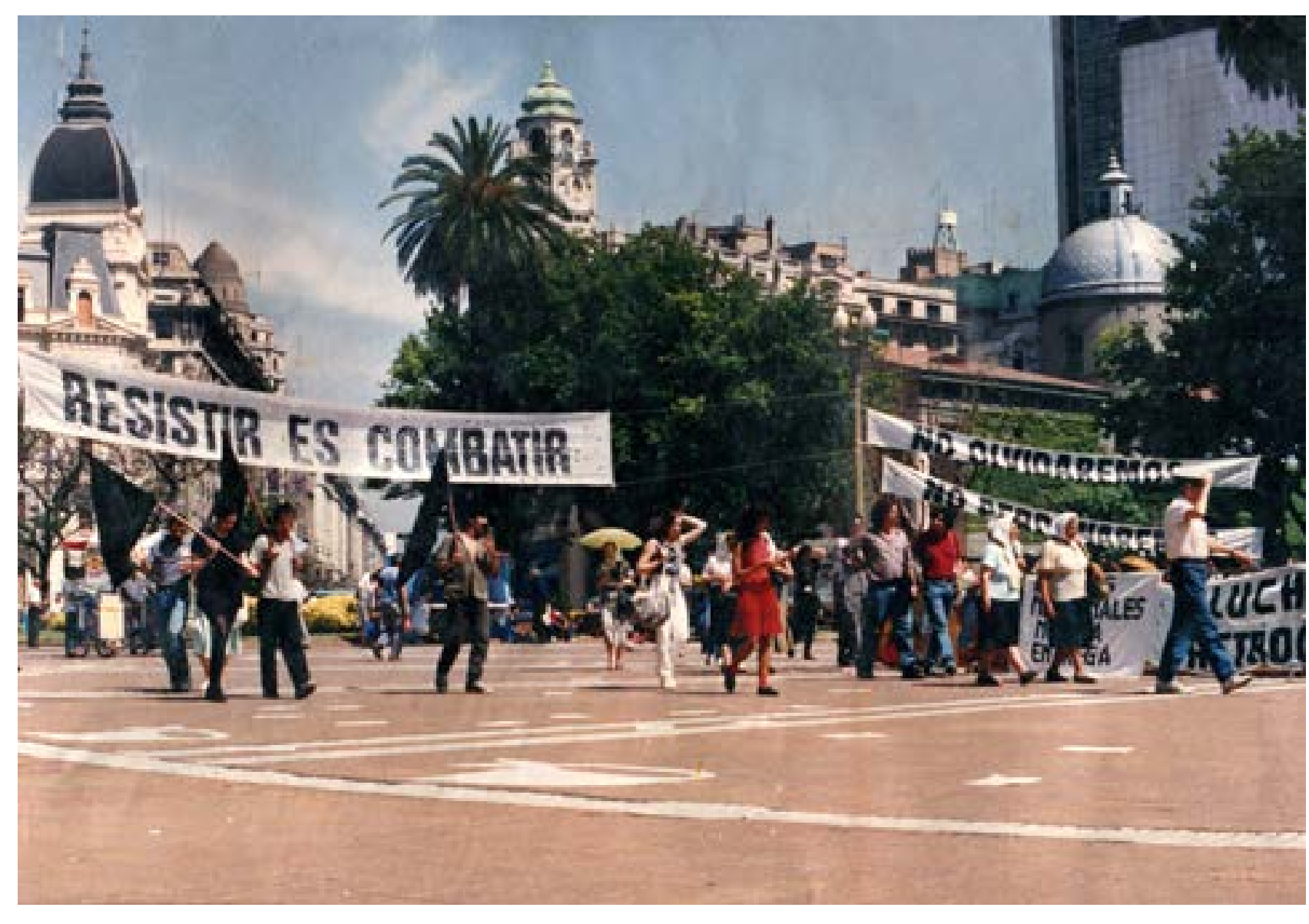

\section{¿ DONDE ESTA? MIGUEL AARCHA $20-8.16$ Q2.}
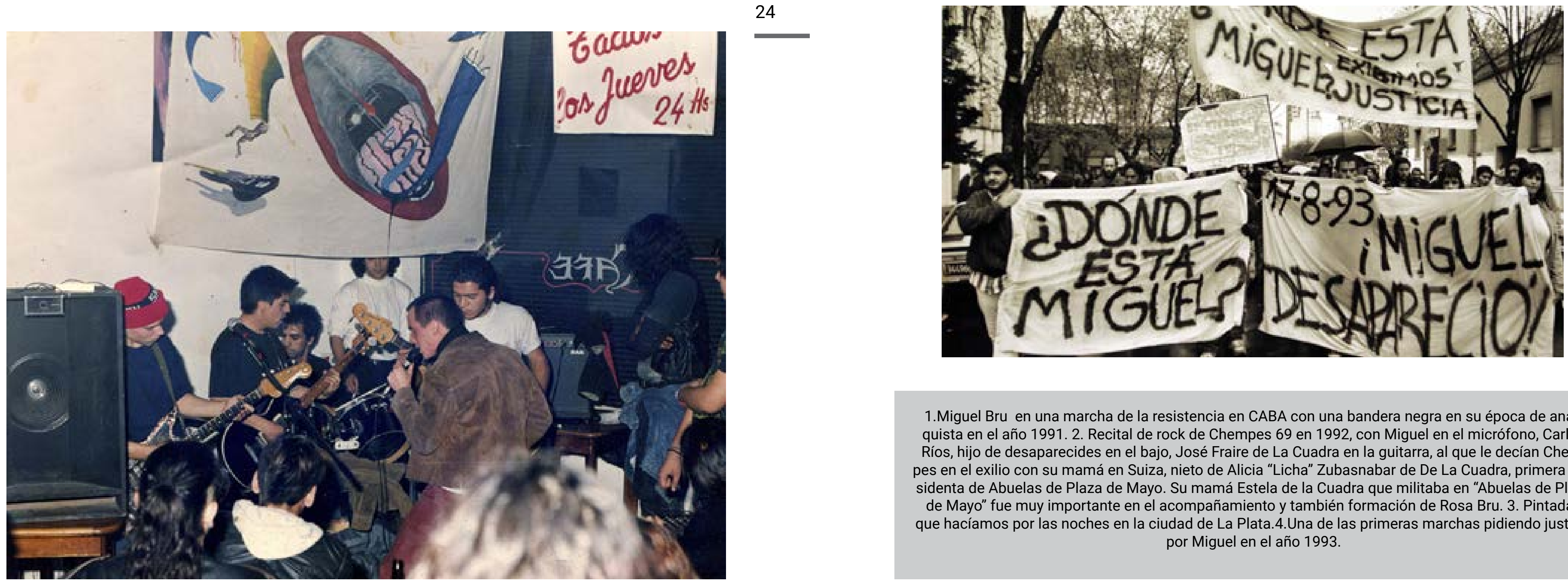

Miguel Bru en una marcha de la resistencia en CABA con una bandera negra en su época de anar1.Miguel Bru en una marcha de la resistencia en CABA con una bandera negra en su época de anarRíos, hijo de desaparecides en el bajo, José Fraire de La Cuadra en la guitarra, al que le decían Chempes en el exilio con su mamá en Suiza, nieto de Alicia "Licha" Zubasnabar de De La Cuadra, primera prepidenta de Abuelas de Plaza de Mayo. Su mamá Estela de la Cuadra que militaba en "Abuelas de Plaza de May" fue muy importante en el acompañamiento y también formación de Rosa Bru 3. Pintadas que hacíamos por las noches en la ciudad de La Plata 4 Una de las primeras marchas pidiendo justicia por Miguel en el año 1993. 


\section{CAPÍTULO I}

\section{¿DÓNDE ESTÁ MIGUEL?}

En este capítulo se describen los hechos sobre la desaparición de Miguel Bru, estudiante de la Escuela Superior de Periodismo de la Universidad Nacional de La Plata (UNLP), para entender cómo se produce la práctica de organización colectiva de reclamo de justicia y para analizar los entramados desarrollados para lograr que se llegue a la verdad sobre su desaparición. Cómo decanta esta lucha en la creación de la Asociación Civil Miguel Bru, la manera en que las experiencias organizativas gestan modos de hacer y la manera en la que estos se relacionan, potencian y fortalecen la práctica política desarrollada en la gestión llevada adelante por la Secretaría de Derechos Humanos de la Facultad de Periodismo y Comunicación Social de la UNLP.

\section{La desaparición}

El 17 de agosto de 1993 constituyó un antes y un después en la historia de los derechos humanos en la Facultad y en toda la sociedad argentina: desaparece el estudiante Miguel Bru, tras ser detenido y torturado por agentes policiales de la Comisaría $9 .^{\circ}$ de la ciudad de La Plata. Tenía 23 años, era mi amigo y compañero de ingreso en la promoción 89 de la Escuela Superior de Periodismo (ESP) de la Universidad Nacional de La Plata (UNLP).

Al momento de su desaparición, Miguel vivía en una casa tomada en el barrio El Mondongo de La Plata, con varies integrantes de Chempes 69, su banda de música punk. El nombre surgió porque uno de los integrantes, José Fraire De La Cuadra, nieto de Licha De La Cuadra, la primera presidenta de Abuelas de Plaza de Mayo, se había exiliado en Suiza, luego de la desaparición de su padre y sus tíos, y como era el año del Mundial 78 en ese país lo habían apodado «Chempes», en alusión al goleador argentino Mario Kempes. Cuando sucedió lo de Miguel, su mamá, Estela, también miembro de Abuelas, fue fundamental en la formación y en el acompañamiento de Rosa.

En general, las letras de las canciones las escribía Miguel, que era el cantante de la banda. Algunos versos alusivos de sus letras dan cuenta de cómo pensábamos y éramos:

A esta mierda digo no, algún día venceremos. Cada cual se va a ocupar, de que todo salga bien. Sí, ya sé, y yo te entiendo, es difícil no es un juego. Hagámoslo ahora, el futuro es nuestro.

No te importan más los desaparecidos, no te importa más si yo perdí a un amigo. No te importa más, amigo del indulto, tu vida es un insulto.
Esa casa, ubicada en calle 69 entre 1 y 115, era el lugar donde vivían, ensayaban y hacían reuniones. En esa propiedad, también habían sido víctimas de dos allanamientos ilegales, muy violentos y a punta de pistola, por parte del personal de la Comisaría $9 .^{\circ}$ de La Plata: en el primero, se presentaron violentamente con la excusa de que los vecinos habían denunciado ruidos molestos -nunca se supo quién fue el denunciante-; en el segundo, adujeron el supuesto robo a un kiosco, aunque tampoco nunca apareció esa denuncia. La policía jamás reconoció estos hechos. Una constante en la historia argentina: la fuerza policial nunca reconoce los hechos o, mejor dicho, oculta sus irregularidades, sus delitos y sus crímenes.

En los allanamientos, los policías rompieron instrumentos y se llevaron detenides a algunes amigues, sin encontrar rastro alguno de lo que supuestamente buscaban. Miguel creyendo que se protegía y que pondría un freno a estas situaciones, luego de consultarlo con su madre, denunció al personal policial. Desde entonces, comenzó a ser víctima de un hostigamiento constante, de insultos y de persecuciones en auto a paso de hombre, inclusive, en presencia de su novia y sus amigues. Lo amenazaban diciendo que si no retiraba la denuncia lo matarían.

La maquinaria criminal policial ya estaba en marcha.

Lamentablemente, en ese momento no tomábamos conciencia del peligro. Cuando Migue nos relataba las amenazas, lo normalizábamos como parte de las prácticas policiales de las que éramos víctimas en esa época, por el solo hecho de ser jóvenes, escuchar rock y querer vivir en libertad. Siempre nos preguntamos qué hubiera pasado si hubiéramos tomado conciencia de lo que significaban las amenazas o de lo peligrosa que era esa gente. Tal vez, las cosas hubieran sido distintas.

La culpa es una sensación que recorre el entorno más allegado a las víctimas, es algo que siempre escucho y que me conmueve cuando se acercan a solicitar ayuda a la Asociación Miguel Bru.

El 15 de agosto de 1993, Miguel fue a cuidar la casa de una pareja amiga que vivía en el campo, en la localidad de Bavio, a 50 kilómetros de la ciudad de La Plata y, desde entonces, no volvimos a verlo. Su ropa y su bicicleta aparecieron prolijamente ubicadas a la orilla del Río de la Plata, cerca de la propiedad que Miguel cuidaba. Me enteré de su desaparición el sábado 21 de agosto, en el torneo de fútbol interno de Periodismo donde jugábamos en el mismo equipo. A partir de entonces, comenzamos con lo que primero fueron sospechas y luego certezas: Miguel era otra víctima del atroz accionar del personal policial de la Argentina; en este caso, de la policía bonaerense.

Recuerdo una experiencia bastante macabra, que refleja la injusticia, la desesperación, la desolación y la impotencia que sentíamos en el momento. El domingo 22 de agosto, fuimos a buscarlo a Punta Blanca, el lugar donde había aparecido la ropa, una selva marginal con mucho pantano. De repente, llegó la policía, nos indagó como si sospechara de nuestra culpabilidad, y se llevó a un compañero a la comisaría para revisar sus antecedentes. 
Mientras tanto, la policía no quería tomar la denuncia por la desaparición en ninguna de las comisarías por las que peregrinaba su madre. Y tampoco quiso buscarlo.

Recuerdos fuertes y oscuros, como esa noche, a poco de la desaparición, en la que luego de una reunión la policía golpeó violentamente la puerta de mi casa, gritando: «Es la policía». Tuvimos miedo, nunca abrimos y con mi compañera siempre nos preguntamos qué hubiera pasado si hacíamos lo contrario. Recuerdo las sensaciones que me corrían por el cuerpo cuando íbamos a reconocer gente a los hospitales, por si se trataba de Miguel. Pero no había tiempo para detenerse en esas cosas, la víctima era Miguel, en primer lugar, $y$, después, su familia.

También viene a mi memoria el día que fuimos a la casa de Rosa para decirle que necesitábamos un abogado. Ella nos contestó: «¿Para qué, si ya hay un juez investigando?». La duda le duró muy poco, porque enseguida comprendió lo que estaba sucediendo. Recupero esta anécdota, que Rosa siempre cuenta en sus charlas, para dar cuenta de la importancia de nuestro rol ante los hechos, en relación con el acompañamiento a familiares de las víctimas. Una lección que aprendimos, que fue clave en este caso, y que en la actualidad tratamos de poner en práctica desde la acción política que llevan adelante tanto la Asociación Miguel Bru como la Secretaría de Derechos Humanos de la Facultad de Periodismo y Comunicación Social de la UNLP.

\section{¿Dónde está Miguel?}

Desde ese trágico 17 de agosto, sus familiares, amigues y compañeres nos preguntamos: ¿DÓNDE ESTÁ MIGUEL? Un interrogante desesperado que pronto se convirtió en la consigna en torno a la cual nos convocamos y desde la cual encaramos un proceso colectivo de lucha por justicia y de denuncia contra el poder policial, judicial y político. Con esa consigna se le dio visibilidad al caso, nos movilizamos, pintamos banderas y titulamos volantes y comunicados de prensa que se repartían en lugares públicos, en plazas, en facultades y en los barrios.

Ante la profunda tristeza por la pérdida de un ser tan querido, fue central el rol del grupo más cercano de amigues. Cursábamos juntos, nos reuníamos de noche para divertirnos, nos ayudábamos con las mudanzas, formábamos grupos de estudio, festejábamos cumpleaños, construíamos parejas, compartíamos viviendas, vacaciones, entre otras acciones que constituían nuestra vida cotidiana.

Nuestro compañero Cristian Alarcón, quien con su investigación periodística en el diario Página/12 fue uno de los principales impulsores para que se supiera la verdad, escribió:

Miguel era parte de una gran banda que sabía pasarla bien, aunque golpeada, solía caminar en zigzag en grandes patios llenos de rock cuando éramos universitarios y estudiábamos periodismo en lo que llamábamos la Escuelita. Solíamos escaparnos irresponsablemente de las clases aburridas para seguir el ritmo de la ciudad donde en esa época los pibes no querían dormirse y todo devenía en festejo, ruidos de baterías punkis, cierta nube de precoz desesperanza mezclada con la candidez y la virginidad más desenfadada que haya conocido (Jaunarena, 2005, p. 78).

Era mucha la bronca contra el poder político por su complicidad y muy difícil convivir con la idea de que a nuestro amigo le habían hecho lo mismo que se hacía durante la última Dictadura. Era tremendamente doloroso e indignante y nos causaba mucha impotencia, porque entrada la democracia pensábamos que esas prácticas, tema de militancia permanente desde la apertura democrática y que nos había marcado a fuego como generación, eran parte del pasado. Con el correr de los años, entendimos que las prácticas de represión y la corrupción eran y son una constante a lo largo de toda la historia de las fuerzas de seguridad en la Argentina, sin que ningún proyecto político haya podido aportar una solución concreta.

Las prácticas de violaciones a los derechos humanos, perpetradas por las fuerzas armadas durante la última Dictadura cívico militar eclesiástica, continuaban enquistadas en las fuerzas policiales, al tiempo que la ausencia de justicia la convertían en una corporación plagada de hechos corruptos y violentos. Eran moneda corriente, por esos tiempos, las detenciones por averiguación de antecedentes, sobre todo de jóvenes, que luego eran sometides a provocaciones, malos tratos y torturas que llegaron, incluso, hasta el asesinato y, como en el caso de Miguel, a la desaparición del cuerpo.

Por esos años, se sucedieron una serie de hechos de extrema violencia policial que llenaron numerosas páginas de la prensa, y que generaron marchas y movilizaciones en reclamo de justicia. Solo para mencionar algunos casos:

- Andrés Núñez (1960-1990), desaparecido y asesinado por policías en la Brigada de Investigaciones de La Plata, su cuerpo fue encontrado cinco años después en el campo de un policía. Es el primer hecho de desaparición forzada de personas en democracia.

- Maximiliano Albanesse (1973-1990), torturado y asesinado por un policía de la ciudad de Berisso en la puerta de un boliche bailable en La Plata.

-Walter Bulacio (1973-1991), asesinado por policías federales a la salida de un recital.

Cristian Guardatti (1971-1992), asesinado y desaparecido por la policía de Mendoza.

Para entonces, empero, muches de nosotres teníamos formación política y experiencia de militancia o de diversas formas de activismo. De allí que para preservar nuestra identidad y para darnos cohesión como colectivo, compañeres y amigues formamos la Comisión de familiares, amigos y compañeros de Miguel, encabezada por Rosa Bru. Con esa denominación firmábamos documentos y volantes, lo que nos daba cierta seguridad en momentos de mucha vulnerabilidad para nosotres, ya que nos estábamos metiendo contra la corporación policial de la Bonaerense. 

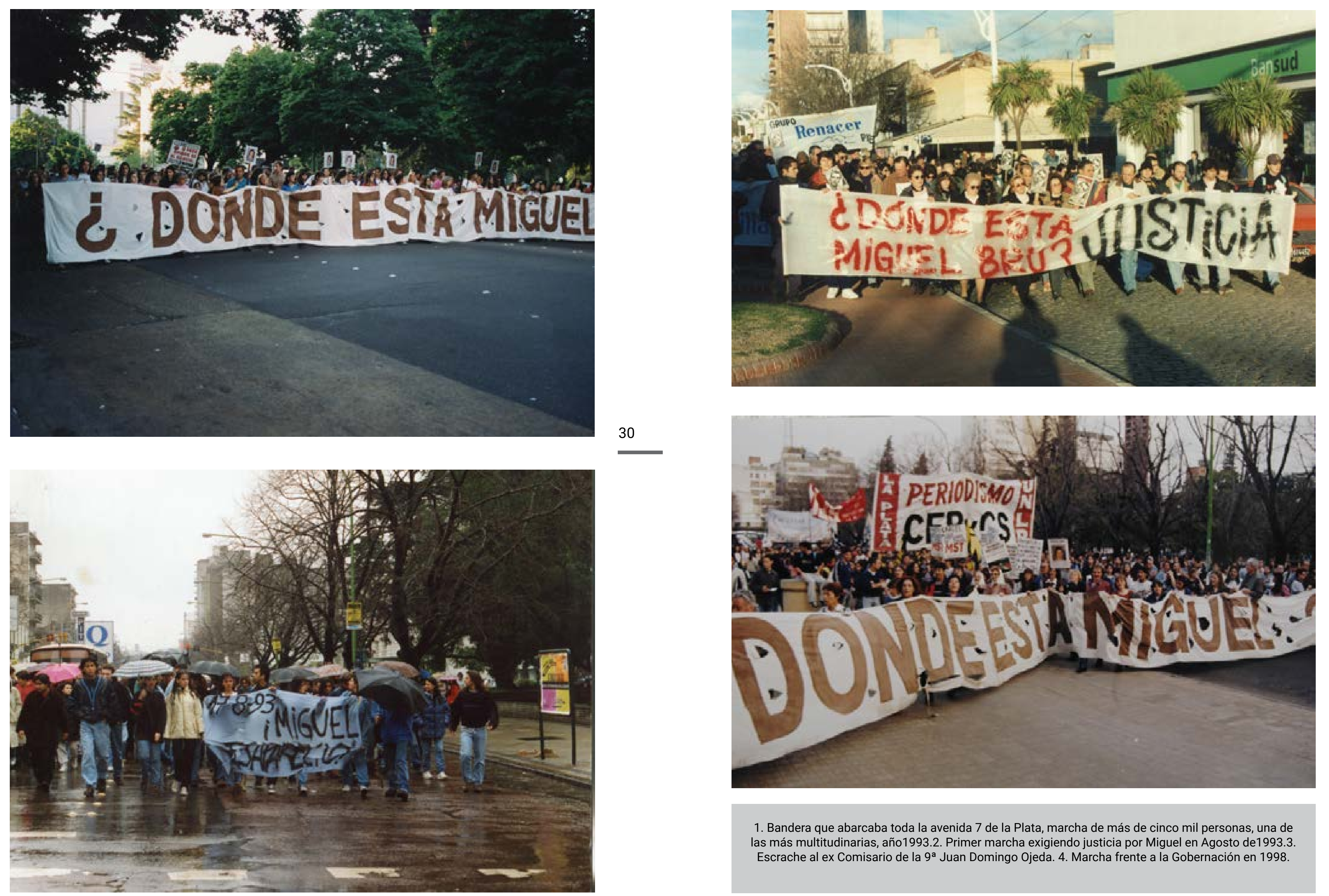

31

1. Bandera que abarcaba toda la avenida 7 de la Plata, marcha de más de cinco mil personas, una de las más multitudinarias, año1993.2. Primer marcha exigiendo justicia por Miguel en Agosto de1993.3. Escrache al ex Comisario de la 9a Juan Domingo Ojeda. 4. Marcha frente a la Gobernación en 1998. 


\section{La complicidad judicial}

Los policías tenían a su favor un hecho clave: la complicidad judicial. En un principio, nos llamó la atención que el juez de la causa, Amílcar Vara, se negara a vincular la desaparición de Miguel con la actividad del personal policial y que públicamente asegurara: «Mantengo la íntima convicción de que Bru está vivo». En otra declaración a la prensa, más propia de un genocida que de un juez de la democracia, afirmó: «No hay nada que permita manifestar que la desaparición es un delito». ${ }^{6}$

En su oficina del juzgado, varias personas escucharon frases tales como «mirá lo que parece en esta foto, seguro que era homosexual y drogadicto». Incluso, sin fundamento alguno, llegó a decirle a Rosa Bru: «Sospecho que se ha ido con alguna chica a Brasil». Este tipo de expresiones también fueron escuchadas por las madres de las víctimas de la última Dictadura cívico militar eclesiástica cuando golpeaban las puertas de los militares para pedirles explicaciones sobre la desaparición de sus hijes. Con argumentos similares, durante muchos años, el inconsciente social argentino se trabajó con frases del tipo «en algo andará» o «por algo será», con las que se intentaba justificar crímenes aberrantes.

El juez Vara no volcaba en los expedientes las declaraciones que vinculaban a los policías con el hecho. Mantenía la carátula de la causa como «Averiguación de paradero» y, por ende, no le permitía a Rosa Bru intervenir como «particular damnificado», alegando que «si no hay cuerpo, no hay delito». Otra constante de nuestra historia: la misma carátula de las causas judiciales de nuestres desparecides durante la última Dictadura cívico militar eclesiástica y también, la de Jorge Julio López, desaparecido en La Plata en 2006, luego de declarar en e juicio por delitos de lesa humanidad contra el genocida Miguel Osvaldo Etchecolatz.

En tanto, Pedro Klodczyk, el entonces Jefe de la Policía de la Provincia de Buenos Aires - cuyo nombre se asocia en la actualidad a la llamada «maldita policía»-, declaró ante los medios de comunicación: «No hay ningún nexo que permita vincular el accionar de personal policial con la desaparición de Bru», ${ }^{8}$ pese a las declaraciones de familiares y de amigues que señalaban que Miguel era permanentemente amenazado por efectivos policiales. En las declaraciones durante el juicio, tampoco hubo ningún policía de los que esa noche estuvieron en la Comisaría 9. ${ }^{\circ}$ que recordara alguna irregularidad.

Sin embargo, esos fundamentos comenzaron a caerse a medida que se aportaban más pruebas que comprometían a los agentes policiales.

Finalmente, conseguimos que Vara fuera sometido a un Jurado de Enjuiciamiento y, tras comprobarse que había cometido irregularidades en 26 causas en las cuales estaba involucrado personal policial que había sido beneficiado, destituido como juez. La denuncia,

$6 \quad$ Declaraciones extraídas del documental «¿Dónde está Miguel?» (2000).

$7 \quad$ Pedro Anastasio Klodczyk (1940-2000) fue el Jefe de la Policía bonaerense que más tiempo estuvo en el cargo. Designado en diciembre de 1991 por el gobernador Eduardo Duhalde, fue obligado a renunciar en 1996 en medio de un escándalo de denuncias de todo tipo.

8 Declaración extraída del documental «¿Dónde está Miguel?» (2000). realizada por la Comisión de familiares, compañeros y amigos de Miguel, se sintetizaba en la siguiente consigna: «No hay maldita policía sin maldito poder judicial». Vara, empero, nunca fue juzgado por la justicia ordinaria, ya que sus ex colegas se excusaban alegando incompatibilidad.

A lo largo de nuestra historia, el accionar judicial por acción u omisión es una constante en las causas sobre violaciones a los derechos humanos, así como el denominado «espíritu de cuerpo» en el accionar de las fuerzas de seguridad, que supone el encubrimiento y la complicidad cuando un miembro comete una irregularidad, sin importar su gravedad. Sobre ambos ejes hace hincapié el trabajo de nuestra actual Secretaría. 

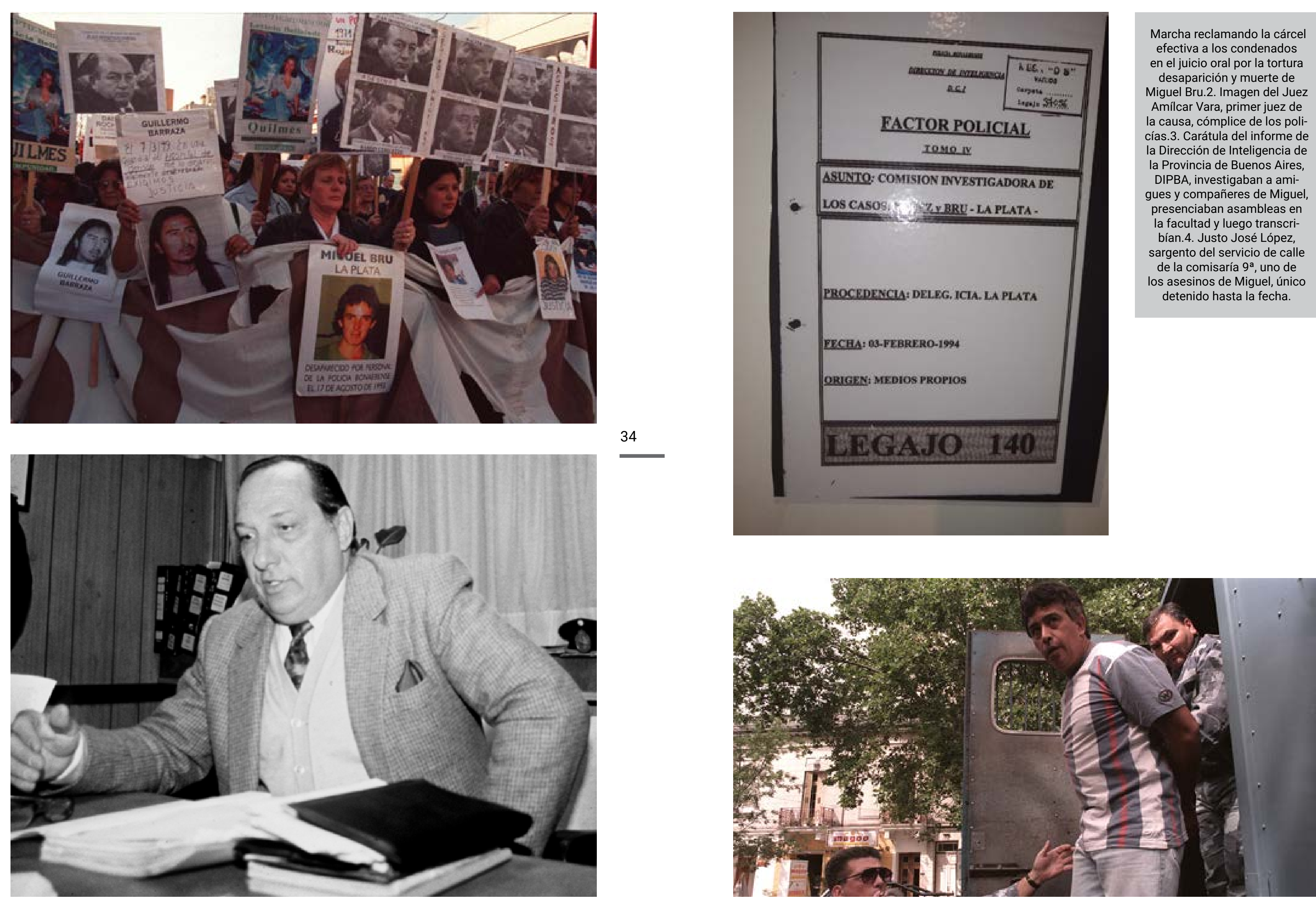


\section{La búsqueda de justicia}

La policía, sin embargo, no había tenido en cuenta un hecho fundamental: Miguel era un pibe pobre, sí, pero era estudiante de una universidad pública y, específicamente, de una unidad académica movilizada por sus estudiantes y sus docentes, acostumbrades a participar en marchas en defensa de los derechos humanos y a posicionarse frente a la lucha por el derecho a estudiar y a enseñar, problemáticas de ese contexto político.

La por entonces ESP era una de las más movilizadas. Había sido una de las cinco unidades académicas cerradas por la última Dictadura cívico militar eclesiástica, con casi la mitad de la población académica desaparecida, asesinada y exiliada. Los debates políticos que allí se producían eran reconocidos por toda la comunidad universitaria, por lo que contábamos con un bagaje experiencial organizativo desde donde partir para discutir las estrategias a seguir.

Teníamos que ser muy estratégicos en nuestro discurso para desmontar y para denunciar el aparato judicial corrupto. En ese marco, desde la ESP desarrollamos una estrategia para difundir y para presionar a través de los medios de comunicación. El primer programa de televisión al que llevamos la foto de Miguel fue «Anochecer con Mauro Viale», emitido por ATC. No lo veíamos como un modelo de periodismo, todo lo contrario, pero lo hicimos como estrategia para darle difusión masiva al caso, pensando en que así podíamos ejercer presión sobre los sectores de poder y contribuir a la aparición de algún testigo o del mismo Miguel. Pronto, la «ingeniería» mediática que armamos ocupó un lugar clave para presionar al poder político-policial, para difundir el hecho y para crear conciencia social.

Las decisiones se tomaban en asambleas que realizábamos en la ESP, siempre respetando que la última palabra la tuviera la familia de Miguel. Con las movilizaciones en el espacio público y mediante la estrategia mediática-les compañeres y amigues de Miguel ya teníamos experiencia profesional en medios masivos--, el hecho rápidamente tomó relevancia pública y miles de personas marcharon por las calles para acompañar el pedido de justicia. Esto, sin duda, puso a prueba nuestra capacidad político-comunicacional.

La ESP era una especie de base de operaciones desde donde se organizaba la lucha Empezamos a elaborar un sinnúmero de documentos políticos y periodísticos directos y punzantes, que mezclaban la fuerza, la ternura y el dolor sincero de una madre con la narrativa, la formación y la juventud de estudiantes de Periodismo. Fundamentales, en este sentido, fueron las publicaciones de nuestro compañero Cristian Alarcón y del periodista Pablo Morosi, quienes con sus investigaciones lograron que el diario Página/12 se hiciera eco del tema.

Finalmente, producto de las masivas movilizaciones y de la difusión que le dábamos a estas situaciones, conseguimos parte del objetivo. Lo aprendido en cuanto a la estrategia discursiva y a ponerle el cuerpo a la lucha -sobrellevando el dolor que suponía tomar real dimensión de lo que significaba la desaparición de Miguel-, fueron hechos clave que marcaron la forma de hacer política de la futura Secretaría de DDHH y que incidieron en la decisión de las autoridades de la Facultad de darme la responsabilidad de conducirla.

Desde entonces, y hasta la actualidad, el eje periodismo-derechos humanos-prácticas organizacionales es trascendental para nuestra propuesta pedagógica y de acción política.

\section{Rosa: amor, lucha y solidaridad}

Siempre digo que Miguel se fue pero me dejó muchos nuevos hijos e hijas.

Rosa Bru

La mamá de Miguel, Rosa Schonfeld de Bru, cumplió un rol clave y fundamental para llegar a la sentencia condenatoria. Nuevamente, como una constante en la historia argentina, una madre encabeza la búsqueda de justicia por su hijo. Sin duda, la dulzura, la solidaridad y la empatía que todos veíamos en Miguel las había heredado de ella. Cuanto más la conocíamos, más nos convencíamos de que teníamos una líder muy especial. Nos enseñó muchísimo, y su sacrificio, energía, fuerza y lucidez aún son conmovedores.

Recuerdo esos domingos maravillosos en los que extrañar a la familia se hacía más llevadero porque íbamos a la casa de Miguel, que vivía con su mamá, su papá y sus hermanes. Jugábamos al fútbol en el baldío del fondo, comíamos tallarines caseros que cocinábamos entre todes, bajo la supervisión de Rosa que los amasaba, y que generosamente compartía la mesa familiar con les amigues de su hijo. Me hacía mucha gracia que Miguel le dijera «la bruja». Era muy divertido y el amor de esa madre nos cobijaba a todes.

Rosa fue parte de nuestra crianza, nos mejoró muchísimo. Convertir ese tremendo dolor en fuerza para la lucha fue fundamental. Como dijo el ex juez de la Suprema Corte de Justicia de la Nación, Raúl Zaffaroni, cuando en 2006 leyó la laudatio en la entrega del premio Doctor Honoris Causa de la UNLP: «Esa vida que se llevaron de su hijo, y que la puso en el escenario de la lucha, salvó muchas vidas más». ${ }^{9}$ En la actualidad, Rosa es una referente de los derechos humanos reconocida en todo el país.

Durante 100 días, Rosa estuvo acampando en una casilla frente al tribunal de Casación de La Plata, hasta que finalmente logró la detención efectiva de los policías que habían desaparecido a Miguel. Por ese espacio circularon estudiantes, militantes, personalidades de derechos humanos y referentes de la política. Hasta el mismísimo León Gieco pasó un día a saludarla y sellaron una relación que sería trascendental para la futura conformación de la Asociación Miguel Bru.

El ejemplo de lucha y de solidaridad de Rosa nos marcó para siempre, y aún nos sigue sorprendiendo. Para la gestión de la Secretaría -y me atrevo a decir, de toda la Facultadsu aporte y su acompañamiento son fundamentales. Rosa ocupa un lugar central en 9 Distinción propuesta por la Secretaría de Derechos Humanos de la FPYCS. 
nuestra política. Siempre responde a las convocatorias de les estudiantes. Jamás falla ni falta, pase lo que pase. Tiene un amor y una empatía muy especial por les jóvenes que estudian en nuestra institución, y la comunidad académica toda le demuestra su amor y su acompañamiento en forma permanente.

En el reclamo por justicia, la madre de la víctima ocupa un lugar único y central, ya nos lo enseñaron muy bien nuestras Madres y Abuelas de Plaza de Mayo. Por esto, en la actualidad para la Asociación, es un eje clave -casi una condición sine qua non- poder trabajar en los diversos casos para lograr el empoderamiento de las madres de las víctimas.

\section{El juicio oral}

Se suele decir que «el delito perfecto no existe». Gracias a las declaraciones de seis detenidos en la Comisaría 9. ${ }^{\circ}$ que oficiaron de testigos del caso, pudo saberse que Miguel fue ingresado en esa seccional el 17 de agosto de 1993, entre las 19 y las 21 horas. Los presos, al escuchar los gritos, espiaron por las ventanas de sus celdas y vieron cómo era torturado hasta la muerte, en la sala de guardia, con la práctica denominada «submarino seco»; esto es, golpes en el estómago con una bolsa de nylon en la cabeza que produce asfixia, un método también utilizado durante la última Dictadura cívico militar eclesiástica. No obstante, como el testimonio de los privados de libertad no era tenido en cuenta, o no hubiera sido suficiente, se realizó una pericia caligráfica sobre el libro de guardia de la seccional, en donde se asienta la entrada y la salida de detenidos. Gracias a la pericia caligráfica realizada por el Instituto Balseiro, ${ }^{10}$ se descubrió que el nombre de Miguel Bru había sido escrito y luego borrado. En el lugar, encima del borrón, aparecía el nombre de otro detenido, José Luis Fernández.

Uno de los presos alojados en la Comisaría 9. era Horacio Suazo, que increpaba a los policías gritándoles: «Qué le hicieron a ese pibe» y los amenazaba con denunciarlos. Meses después, una vez liberado, en un operativo con pruebas «armadas», Horacio fue asesinado Pero antes, tuvo una idea que sería reveladora: habló sobre el hecho con su hermana, Celia Giménez, quien luego le contó a Rosa lo que había escuchado de labios de su hermano. Para tener constancia del testimonio, y luego de buscarla incansablemente durante varias noches de vigilia, Rosa la encontró y la registró con un grabador que le habíamos prestado y que llevaba escondido en la cartera (al estilo de la tradición del periodismo investigativo).

Pocos días después, evaluamos que lo mejor era entregar la cinta a un diario para que publicara el relato en la tapa. Al juez no le quedó más remedio que detener a los policías y excusarse de la causa para ser sometido a juicio, ya que tampoco había volcado en los expedientes el testimonio brindado por Celia luego de la muerte de su hermano. «Ella era prostituta y no quise embarrar la causa», eran las explicaciones que el ex juez le daba a

$10 \quad$ Entidad académica argentina de alto nivel que funciona en las instalaciones del Centro Atómico Bariloche 1955 , forma profesionales en física y en ingeniería.

\section{Rosa}

Sin un juez corrupto al frente de la investigación penal, y con la presión ejercida por el estado público que había tomado el caso, las pruebas se sumaban y se convertían en irrefutables. La estructura del sistema represivo empezaba a tambalear. En 1995, luego de la declaración de los testigos, la justicia dictó la prisión preventiva a uno de los policías, el sargento Justo López, que tenía numerosas denuncias por abusos y por violencias de todo tipo en la dependencia de Asuntos Internos de la fuerza. Finalmente, en 1996, se ordenó la detención del subcomisario Walter Abrigo, el comisario Juan Domingo Ojeda y los efectivos Jorge Gorosito y Ramón Cerecetto.

En mayo de 1999 comenzó el juicio oral y público. En él fueron condenados a prisión perpetua los policías, ex integrantes del servicio de calle, Justo José López y Walter Abrigo, acusados de tortura seguida de muerte, privación ilegal de la libertad y falta a los deberes de funcionario público. El cuerpo de Miguel sigue sin aparecer, pero su muerte pudo comprobarse a través de pruebas indirectas. El cuerpo del delito puede configurarse sin la aparición del cadáver ya que se consideran otros elementos de juicio como, en este caso, la pericia caligráfica sobre el libro de guardia, los testimonios de los detenidos en la Comisaría 9. y los testigos de las amenazas que Miguel recibía.

En 2003, la Suprema Corte de Justicia de la provincia de Buenos Aires dejó firme la condena a ambos ex funcionarios policiales. El entonces titular de la Comisaría 9.', Juan Domingo Ojeda, fue condenado a dos años de cumplimiento efectivo de la pena, pero recuperó su libertad con solo ocho meses de prisión, al igual que el oficial Ramón Cerecetto, que era quien había borrado y reescrito el libro de guardia.

Lamentablemente, hay algo muy doloroso que no se pudo dilucidar en el juicio: qué hicieron con el cuerpo de Miguel. Teníamos muchas expectativas de que se supiera la verdad y de que nos dijeran dónde está, pero hasta el día de hoy los asesinos siguen torturándonos con su ausencia. El policía Abrigo murió en la cárcel de un infarto y López continúa preso en Sierra Chica por salir, y con el beneficio de la libertad transitoria.

En la actualidad, desde la Asociación Miguel Bru continuamos exigiendo el procesamiento del personal policial que estaba en servicio en la Comisaría 9. la noche del 17 de agosto de 1993, por considerar que son cómplices del hecho, y repudiamos que nunca se llevara adelante la investigación penal al primer juez que entendió en la causa, Amílcar Vara, que falleció sin ser juzgado. 


\section{La Asociación Miguel Bru (AMB)}

El ideólogo de la Asociación es León. Vino a tocar a La Plata y quería saber qué hacíamos.

Fue él quien dijo: "Vamos a hacer una asociación para que otros casos no estén solos», porque no todos tienen una facultad detrás como teníamos nosotros.

Rosa Bru

En 2002 se creó la Asociación Miguel Bru (AMB), que tuvo como uno de sus principales impulsores al cantautor León Gieco, padrino de la Asociación, y en un principio fuerza fundamental con sus recitales benéficos. La entidad se formó con la intención de institucionalizar el trabajo que se venía realizando, fundamentalmente por parte de Rosa de acompañamiento a los familiares de víctimas que buscaban justicia y que, al no recibir respuestas del Estado, iban a pedirle ayuda.

La principal razón social era, y sigue siendo, defender los derechos humanos de las personas frente a la violencia institucional, y, particularmente, los abusos policiales. Se patrocinan algunas causas, se asesora en otras, se acompaña a los familiares en la búsqueda de justicia, se visibilizan los hechos y se realiza un trabajo territorial de empoderamiento y de formación en estrategias de defensa frente a la violencia institucional.

La experiencia de la organización en relación con la búsqueda de justicia por Miguel, e patrocinio y el acompañamiento en la gestión de justicia, la formación como vehículo de inclusión y el empoderamiento son ejes fundamentales para la AMB. Desde lo metodológico, otro importante antecedente fueron los años de trabajo en Isla Maciel, un barrio de Dock Sud ubicado en el partido de Avellaneda, provincia de Buenos Aires, donde, a poco tiempo de creada la Asociación, comenzamos a trabajar sobre casos de «Gatillo Fácil».

Este hecho marcó un antes y un después en la vida de la organización, ya que fue nuestro primer trabajo territorial en una zona de exclusión social. La Isla está conformada por veinte manzanas que se ubican al lado del Riachuelo, frente al barrio de La Boca. Es el asentamiento urbano más antiguo de ese distrito y tiene alrededor de 8.000 habitantes. En 2000, el antiguo escenario de conventillos y ranchos de chapa y madera, y pequeñas fábricas y astilleros, dio lugar a un desolado panorama con portones de fábricas cerradas, paredes derruidas y marginación social.

En este contexto, la falta de perspectivas de futuro y la ausencia del ejercicio de los derechos básicos eran una característica central. La exclusión social no solo se advertía en la producción social de estereotipos sobre sus identidades -al mostrarlos como una amenaza social, como protagonistas de prácticas marginales y sin posibilidades futuras-, sino también en la propia dificultad para superar el estigma de la discriminación y la desvalorización social, y en la convicción de sus habitantes sobre la limitación de sus capacidades y sus derechos.
Como objetivo central, buscábamos promover que el proceso colectivo era fundamental para que pudieran empoderarse y reclamar por sus derechos. Teníamos talleres de panadería y gracias a que un panadero nos donó las máquinas, les niñes hacían pan dulce, pan, prepizzas entre otros productos que llevaban con alegría a sus casas. También contábamos con talleres sobre salud y ejercicio de derechos humanos.

Trabajamos con las madres del lugar y las acompañamos en casos de búsqueda de justicia y en diversas gestiones relacionadas con las situaciones sociales que padecían. Con ellas constituimos la Comisión de Derechos Humanos de la Isla, con el objetivo fundamental de que juntas y movilizadas pudieran poner un freno a los atropellos policiales que sufrían. Como anécdota ilustrativa de este proceso, hace poco tiempo, con motivo de conmemorar el cierre de año, me reuní con una de nuestras líderes, en la sede de Parque Patricios, y me contó que cuando había problemas llamaban a la comisaría de la Isla y se presentaban como de la Asociación Miguel Bru, a modo de acción estratégica para frenar los abusos policiales.

Se montó un taller de fotografía, generosamente dictado por amigues que trabajaban en el diario Página/12; un taller sobre derechos humanos, del cual formé parte; y un talle sobre periodismo, desde el que se editó Ojos y voces de la Isla, un libro con fotos y textos realizados por adolescentes.

Este trabajo territorial, que se sostuvo durante más de cinco años, fue una experiencia sumamente difícil y enriquecedora, y representó un momento bisagra: con muy pocos recursos logramos llegar a un lugar arrasado por la crisis económico social de los años ochenta, noventa y principios de 2000. Enseguida, entendimos la primera lección territorial: debíamos trabajar con los niñes desde más chiques, para no llegar tarde, cuando ya habían sido víctimas del sistema represivo. Debíamos trabajar en el empoderamiento, la prevención y la promoción de derechos, para que no sean presas de las garras del sistema punitivo de Estado. 


\section{La Casa de Cultura y Oficios}

En 2006, y en directa relación con el trabajo realizado en la Isla Maciel, se fundó la «Casa de Cultura y Oficios Miguel Bru», sede de Parque Patricios de la Asociación, que tiene como finalidad generar un espacio de contención para jóvenes en situación de vulnerabilidad social de la zona sur de la Ciudad Autónoma de Buenos Aires (CABA) y del Conurbano bonaerense, promoviendo su inclusión social mediante la capacitación en oficios con miras al fortalecimiento de su empleabilidad y a la promoción de espacios culturales.

Las actividades y los talleres que comprende el proyecto, y que se sostienen a través de los años, son: informática, diseño, periodismo, cocina, peluquería, música, radio y video comunitario; todos ellos, atravesados por la promoción y el empoderamiento en derechos humanos e implementados con herramientas y con recursos que fuimos adquiriendo mediante concursos, proyectos, subsidios y mucha militancia. También se ha dictado el plan FinEs, ${ }^{11}$ se ha trabajado con personas en situación de calle y de vulnerabilidad, y se ha acompañado en el cumplimiento de causas contravencionales denominadas probation. ${ }^{12}$

En este sentido, el proyecto tiene dos ejes vertebrales: por un lado, el desarrollo de diversos talleres de capacitación en oficios y en expresión artística; por otro, la participación de les jóvenes en un espacio común que integre los distintos talleres y donde se favorezca el conocimiento mutuo, la pertenencia al espacio, la construcción conjunta del proyecto y la educación integral a través de talleres centrados en salud, educación, trabajo y comunicación.

Todos estos trabajos formaron parte de muestras y de charlas constantes en nuestra comunidad académica, y en numerosas oportunidades les jóvenes de la Isla vinieron a la Facultad y participaron de diversas jornadas y actividades.

\section{La AMB en tiempos del kirchnerismo}

Vengo a proponerles un sueño: reconstruir nuestra propia identidad como pueblo y como Nación. Vengo a proponerles un sueño, que es la construcción de la verdad y la justicia. Vengo a proponerles un sueño que es volver a tener una Argentina con todos y para todos.

Néstor Kirchner (2003)

En el proyecto político de los gobiernos kirchneristas, la ampliación de los derechos humanos ocupó un lugar trascendental, con objetivos relativos a derechos civiles, políticos, económicos, sociales y culturales. Entre 2003 y 2015, desde la AMB, dialogamos con el Estado, ya no a través de la protesta y el reclamo como lo habíamos hecho hasta el momento,

11 Plan para finalizar los estudios primarios y secundarios implementado por el gobierno nacional en 2008. 12 La probation es una oportunidad que se otorga a aquellas personas que nunca antes habían cometido un delito. Es la suspensión del proceso con la condición de que la persona cumpla con reglas de conducta. sino a partir de articular políticas de seguridad y de desarrollo territorial en relación con la inclusión social.

Junto con los organismos históricos de derechos humanos, pasamos a ser parte de la política de Estado. Rosa Bru integró, primero, la Comisión Antiimpunidad dependiente de Ministerio del Interior y, luego, la Secretaría de Derechos Humanos de la Nación, entidad que patrocinaba, asesoraba y acompañaba a familiares de todo el país en los reclamos de justicia frente a los hechos de violencia institucional por parte de las fuerzas de seguridad.

Formaban ese equipo de trabajo varias madres y familiares con quienes compartíamos la lucha por justicia contra el «Gatillo Fácil» y la impunidad:

\Dolores Demonty, mamá de Ezequiel, que tenía 19 años cuando fue asesinado a manos de la Policía Federal, el 14 de septiembre de 2002 en el Puente Alsina, tras ser torturado y obligado a tirarse a las aguas del Riachuelo por un grupo de efectivos policiales. Fue encontrado siete días después flotando debajo del puente.

\Miriam Medina y Luis Bordón, padres de Sebastián, asesinado el 12 de octubre de 1997 por la policía de Mendoza, mientras estaba allí de viaje de egresados. En el juicio oral se dio por probado que el chico, de 18 años, luego de ser detenido, escapó del destacamento. Cuando los policías Daniel Gómez, Roberto Gualpa y Alejandro Cubillos, que salieron a buscarlo en un patrullero, lo encontraron, le dieron una paliza feroz que lo dejó inconsciente. Las pericias demostraron que el joven agonizó durante varios días, en un lugar nunca precisado, hasta que murió de hambre y sed. Ninguna de las heridas sufridas previamente era mortal.

\Gustavo Melmann, papá de Natalia, secuestrada en 2001 por un grupo de policías de la bonaerense a la salida de un boliche en Miramar. La llevaron a una casa en las afueras de la ciudad para celebrar el cumpleaños de uno de ellos: la violaron, la golpearon y la mataron. En el cuerpo de la adolescente, de 15 años, había rastros genéticos de cinco personas y un vello púbico tenía el ADN del ex sargento Ricardo Panadero.

\Linda Vázquez, mamá de Mariano, asesinado el 23 de marzo de 1995, mientras miraba un partido de fútbol con un grupo de amigos en el parque de un monoblock del barrio porteño de Villa Pueyrredón. En medio de un ataque a balazos perpetrado por desconocidos, Mariano, de 17 años, recibió un disparo mortal. Los asesinos nunca fueron hallados.

\Raquel Wittis, mamá de Mariano, asesinado en 2000 cuando la policía decidió tirar a matar al auto donde lo llevaban como rehén tras un asalto a la sucursal del Banco Itaú, en Beccar Raquel no solo pidió justicia por su hijo sino, también, por Darío Riquelme, el joven que había participado en el asalto y que fusilaron junto con Mariano.

Las madres de víctimas, tanto de la Dictadura como de la democracia, ocupan un ro fundamental en la gestión de la Secretaría y son parte activa de la vida institucional de la Facultad. A diario, recorren nuestros claustros académicos, dan charlas, son fuentes de 
consulta para la realización de trabajos prácticos, obras artísticas y diversas producciones comunicacionales.

Estas prácticas organizacionales se convirtieron en un eje fundamental de la AMB y de la política de gestión de la Secretaría de Derechos Humanos de la Facultad. La movilización, la lucha colectiva y las prácticas comunicacionales de reclamo son, además, ejes centrales en materia pedagógica y de acompañamiento por parte de nuestra comunidad académica.

En 2015, a partir del cambio de rumbo del nuevo gobierno, en la Asociación seguimos sosteniendo, con mucho amor y militancia, los talleres y el trabajo en las causas por violencia institucional. En 2016, no obstante, tuvimos que devolver la oficina por no poder afrontar los costos de alquiler y de mantenimiento.

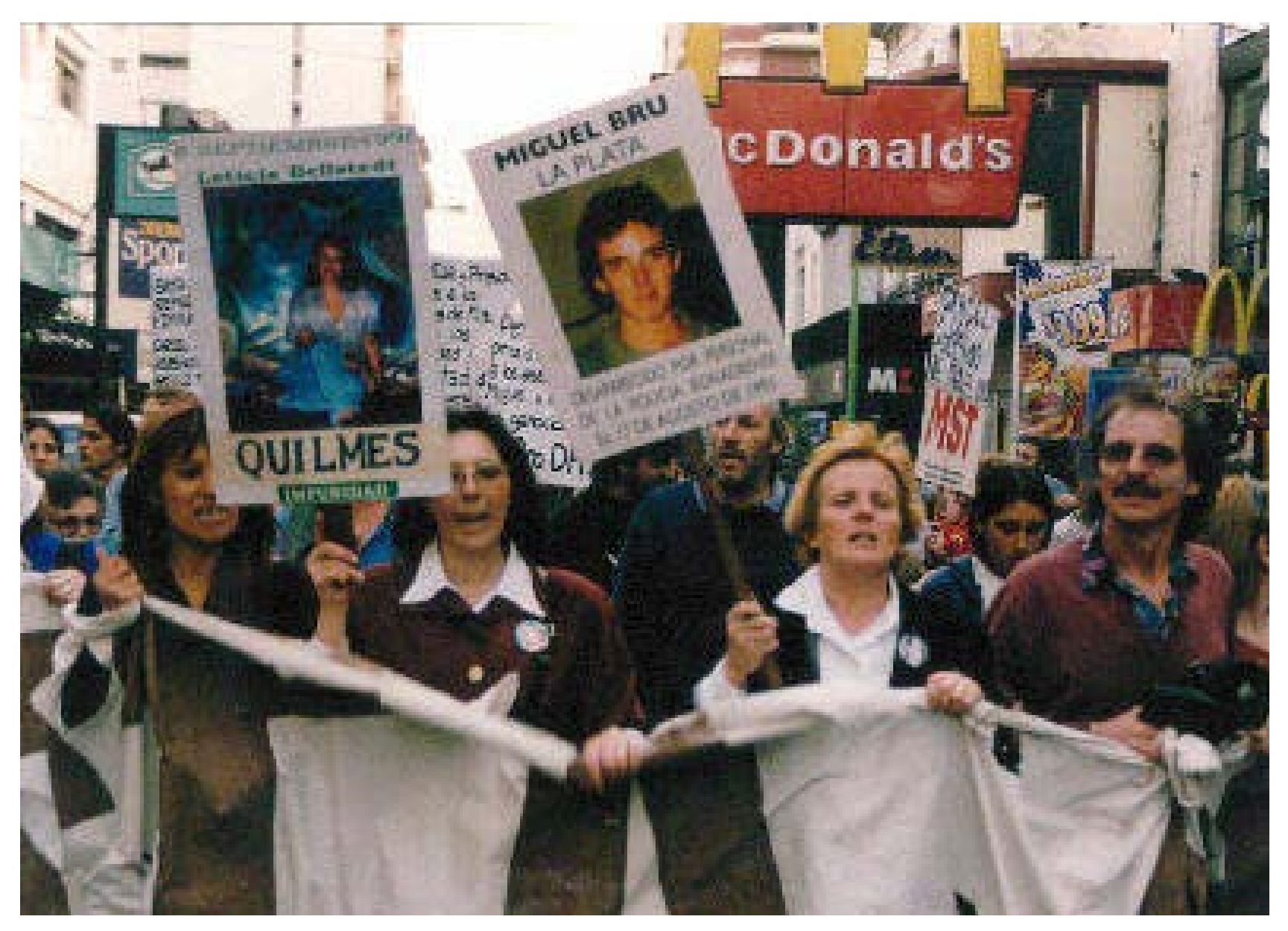

Marcha encabezada por Rosa y acompañada a su lado por Mirna, esposa de Andrés Nuñez víctima de Violencia institucional en La Plata y Lalo, papá de Maximiliano Albanese, de 17 años, otra víctima de la bonaerense en el año 1990.2. Rosa acampando afuera del tribunal de Casación de la provincia durante 100 días en el año 2000 , pidiendo cárcel efectiva para los asesinos de Miguel.3. Marcha en reclamo de justicia encabezada por Rosa.4. Festejo en los tribunales platenses luego de la sentencia condenatoria en el jury de enjuiciamiento al Juez Vara.

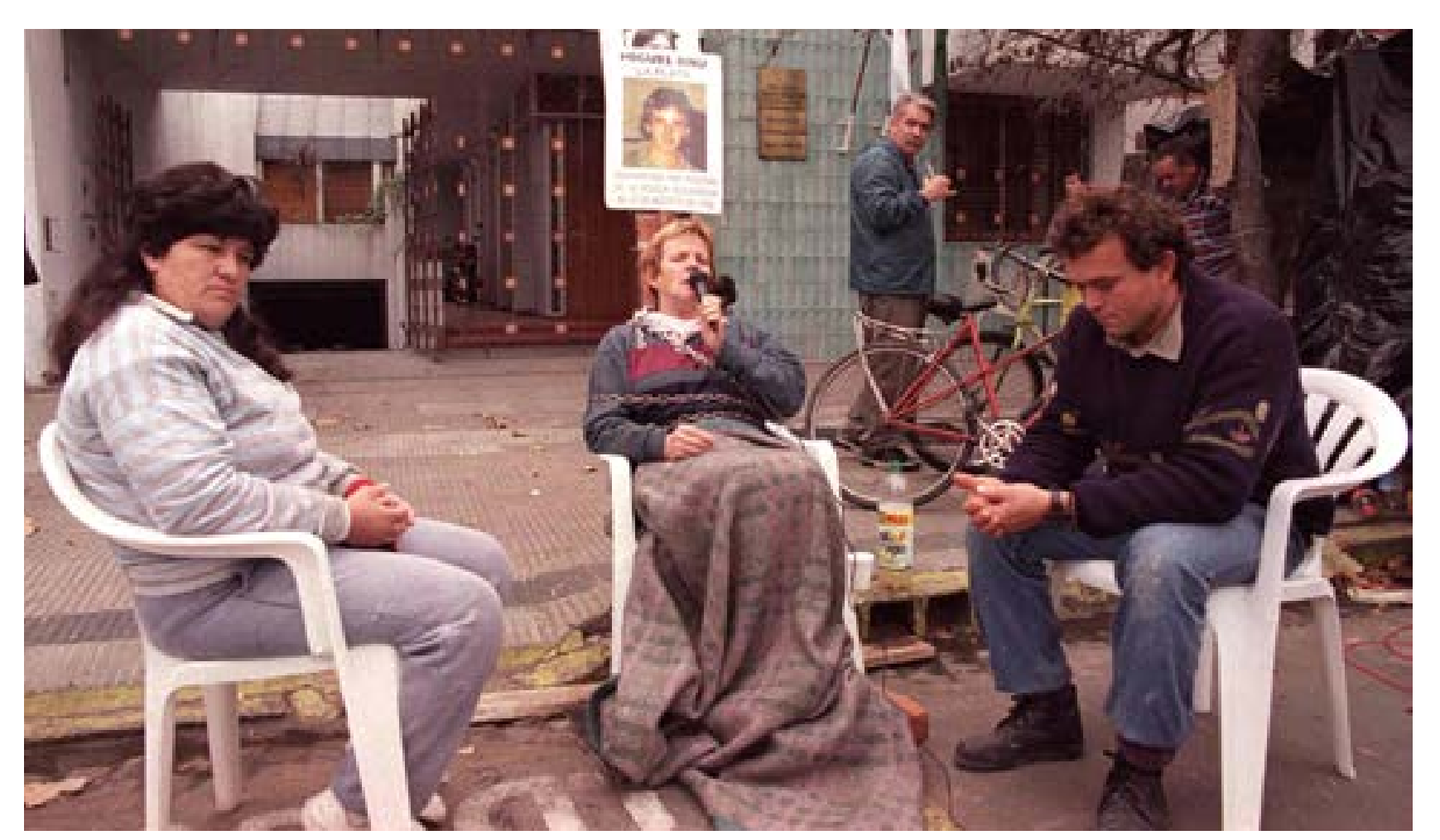

45 

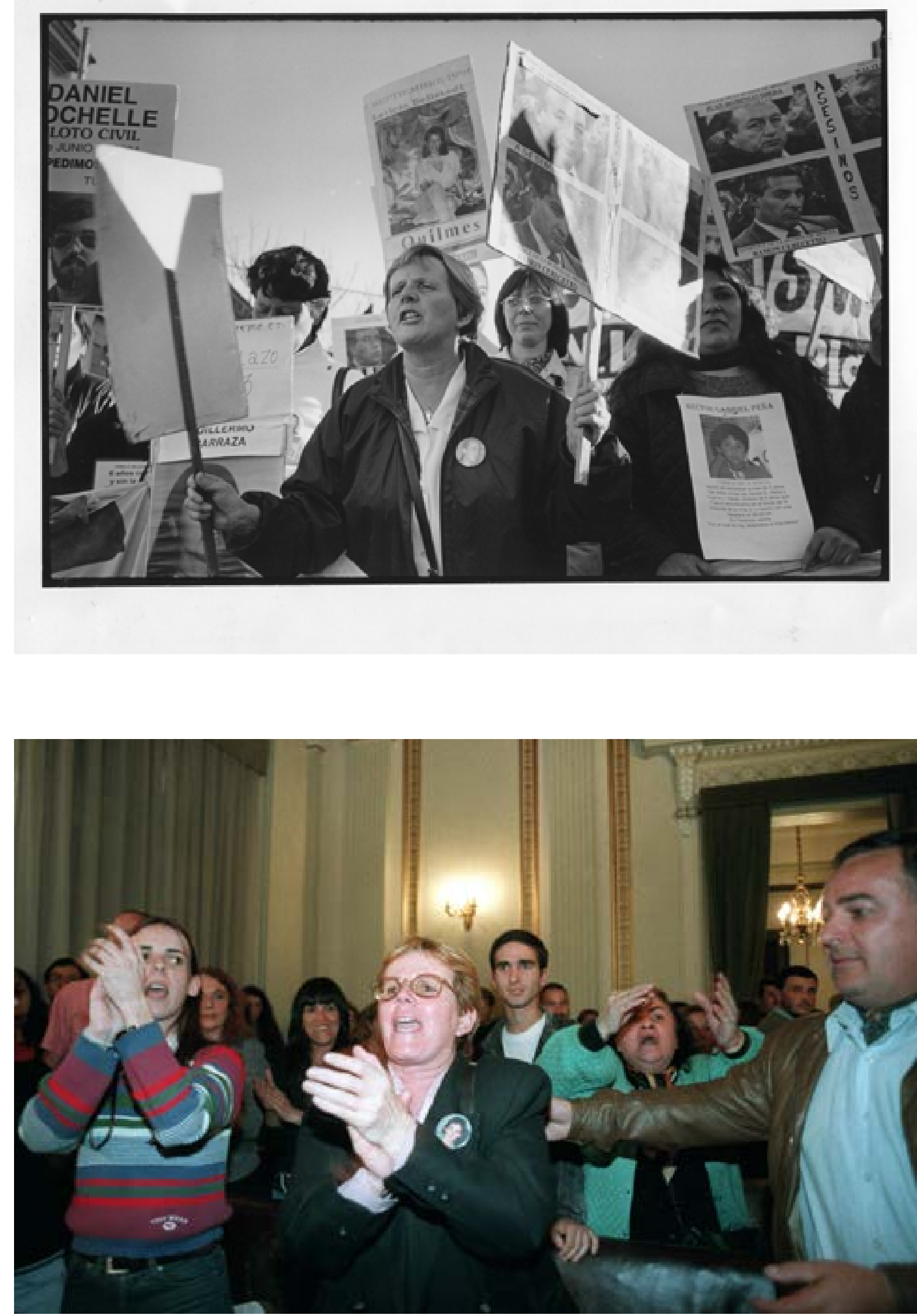

\section{El futuro llegó}

La Facultad de Periodismo y Comunicación Social ocupó siempre un lugar preponderante en la búsqueda de justicia por Miguel, a quien familiares, amigues y compañeres recordamos como una persona extremadamente solidaria y generosa, a la que le gustaba la música y el fútbol; hijo y hermano muy afectuoso, gran amigo y compañero; un tipo comprometido políticamente, que no soportaba los atropellos y que amaba la libertad por sobre todas las cosas.

En la actualidad, la sede ubicada en Avenida 44, entre 8 y 9, lleva el nombre «Miguel Bru, Memoria y Justicia» y cuenta con dos murales que decoran la fachada: uno con Miguel y otro con Rosa. La muralista y artista plástica platense Cristina Terzaghi y su equipo donaron generosamente su arte para que Miguel permaneciera presente en el edificio que lo vio transitar como estudiante. La inauguración, realizada al cumplirse 12 años de su desaparición, fue el primer acto con una enorme masividad realizado por la Secretaría de Derechos Humanos.

En nuestra comunidad académica, la memoria de Miguel se actualiza en todo momento: las Tesis y los Trabajos Integradores Finales de estudiantes, las charlas en el Curso de Ingreso, los trabajos prácticos para distintas asignaturas, los debates en congresos y jornadas, las muestras y producciones periodísticas de todo tipo con eje en la desaparición de Miguel, forman parte de la cotidianeidad de la institución.

En agosto de 2000 se estrenó el documental «¿Dónde está Miguel?», una coproducción del Área Audiovisual de la Facultad y la Comisión de familiares, amigos y compañeros de Miguel, del cual participé como productor general, guionista y director. Los medios de comunicación, tanto locales como nacionales, se hicieron eco de la realización y pronto se convirtió en un suceso muy importante. En 2001, fue ganador en el rubro derechos humanos del VIII Festival Latinoamericano de Cine y Video de Rosario, y seleccionado para ser proyectada en el IV Festival internacional de Cine y Video de Derechos Humanos de Buenos Aires (DERHUMALC); en 2002, recibió el premio a mejor dirección, otorgado por la Red de Facultades de Comunicación de la Argentina (REDCOM).

En la Facultad, Rosa está presente en los actos institucionales y participa de charlas con ingresantes y con estudiantes de la carrera. Ella es un símbolo de la lucha por los derechos humanos, en la Universidad Nacional de La Plata, en la ciudad y en todo el país. «La lucha de Rosa Bru y de Miguel ha salvado a miles de chicos de que los mate la policía», afirmó León Gieco en una entrevista con los estudiantes del taller de Medios de la Asociación Miguel Bru, luego del recital que dio a beneficio de esa institución el 14 de junio de 2015 en el Teatro Argentino de La Plata.

Durante ese concierto, que fue también un homenaje a Rosa, la Facultad le entregó el premio Rodolfo Walsh por su lucha contra la violencia institucional. Gieco destacó que la mamá del estudiante platense desaparecido en 1993 es una «resiliente», porque transformó su 
tragedia personal en un emblema de justicia, y aseguró: «Quién iba a saber que ella iba a luchar toda su vida, que se iba a convertir en alguien popular, alguien que si se para frente a una comisaría es un dolor de cabeza para los policías. Y lo hizo saliendo a la calle, si no se plantaba con ese trailer frente a Tribunales yo no hubiera ido a saludarla porque no la hubiera visto».

$\sim$

La experiencia que retomo en esta tesis formó una mirada sobre los derechos humanos que marcó la línea política y metodológica que se puso en práctica a partir de la creación de la Dirección de Derechos Humanos, primero, y de la Secretaría de Derechos Humanos, en la actualidad.

En ese camino de búsqueda de justicia por Miguel y como militante de causas de derechos humanos, me convertí en referente de varios espacios políticos que integro, entre ellos, la Facultad de Periodismo y Comunicación Social, con cinco períodos de gestión al frente de la Secretaría de Derechos Humanos, y la Asociación de Docentes de la Universidad de La Plata (ADULP), donde tengo a cargo, desde el 2009, la Secretaría de Derechos Humanos.

Del mismo modo, lo aprendido y puesto en práctica en el marco de la Comisión de familiares, amigos y compañeros de Miguel, luego Asociación Migue Bru, fue fundamental como política para relacionarnos, en un diálogo de saberes, con organismos históricos de derechos humanos como el Centro de Estudios Legales y Sociales (CELS), la Asamblea Permanente por los Derechos Humanos (APDH), y Madres y Abuelas de Plaza de Mayo, y con organismos creados luego de la apertura democrática como H.I.J.O.S., OTRANS, Hogar del Padre Cajade, Justicia por Luciano Arruga, Fundación Construyendo Conciencia, Asociación Anahí, Familiares de detenides desaparecides por razones políticas, etcétera.

También nos permitió integrar espacios como la Mesa por los Derechos Humanos de La Plata, la Asamblea de Justicia por Emilia, el Foro por la libertad de Ixs presxs políticxs, y el Frente Social y Político Carlos Cajade. Asimismo, articulamos y somos parte de organizaciones políticas creadas por el kirchnerismo, como La Cámpora. ${ }^{13}$

Esta tesis pretende dar cuenta de esa trama de intercambios de saberes y de prácticas, así como de toda la experiencia puesta al servicio de una propuesta pedagógica, tanto para el grado, con la cátedra de Comunicación y Derechos Humanos, como para el posgrado, mediante la implementación de la primera Maestría en Comunicación y Derechos Humanos en Latinoamérica. Este modo de institucionalización de lo aprendido y el desafío de profundizar saberes y prácticas es la guía de un proceso tan bisagra en la historia de nuestra Facultad por lo innovadora y por el resultado de la gestión.

13 Organización kirchnerista fundada en 2006.

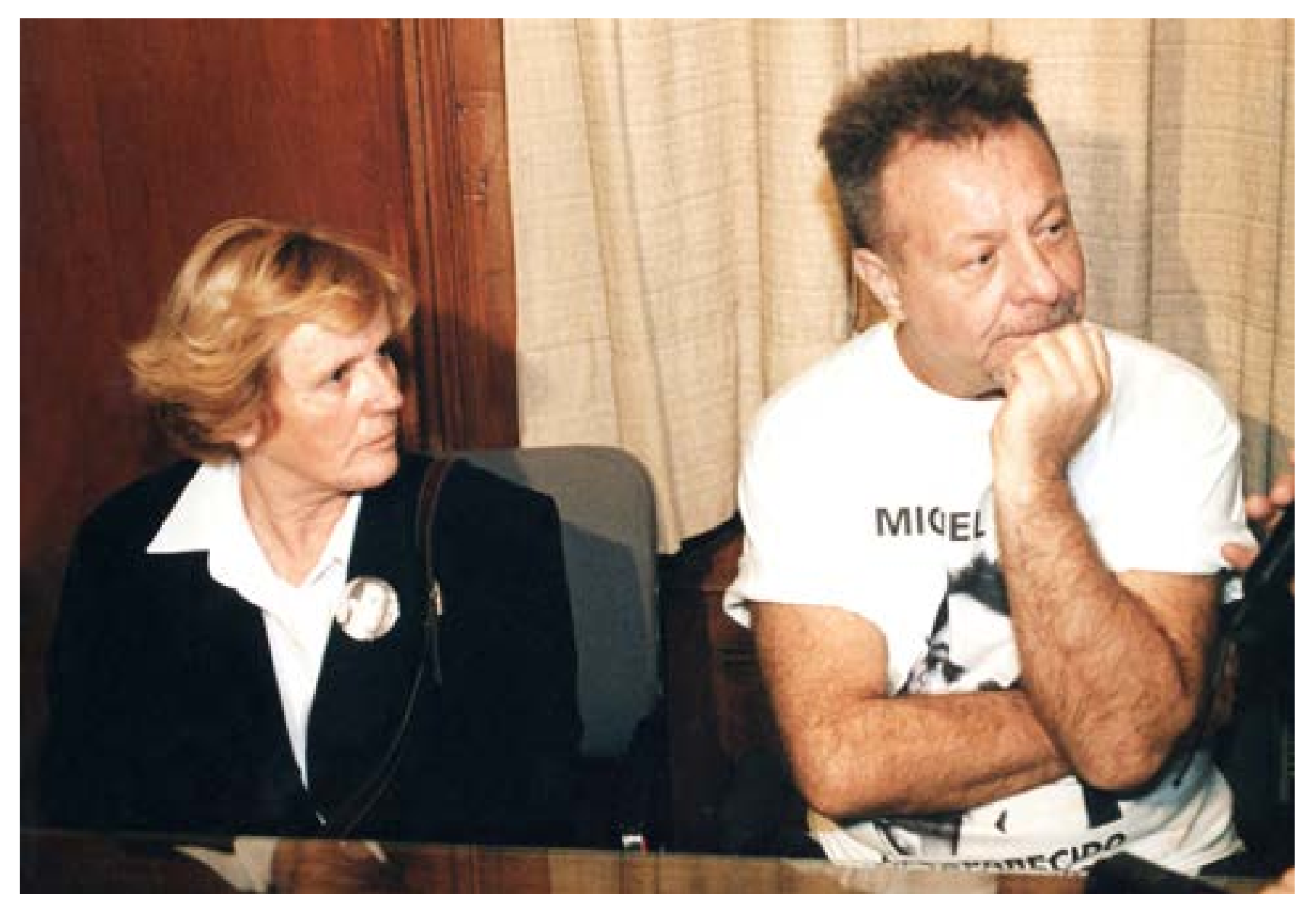

48

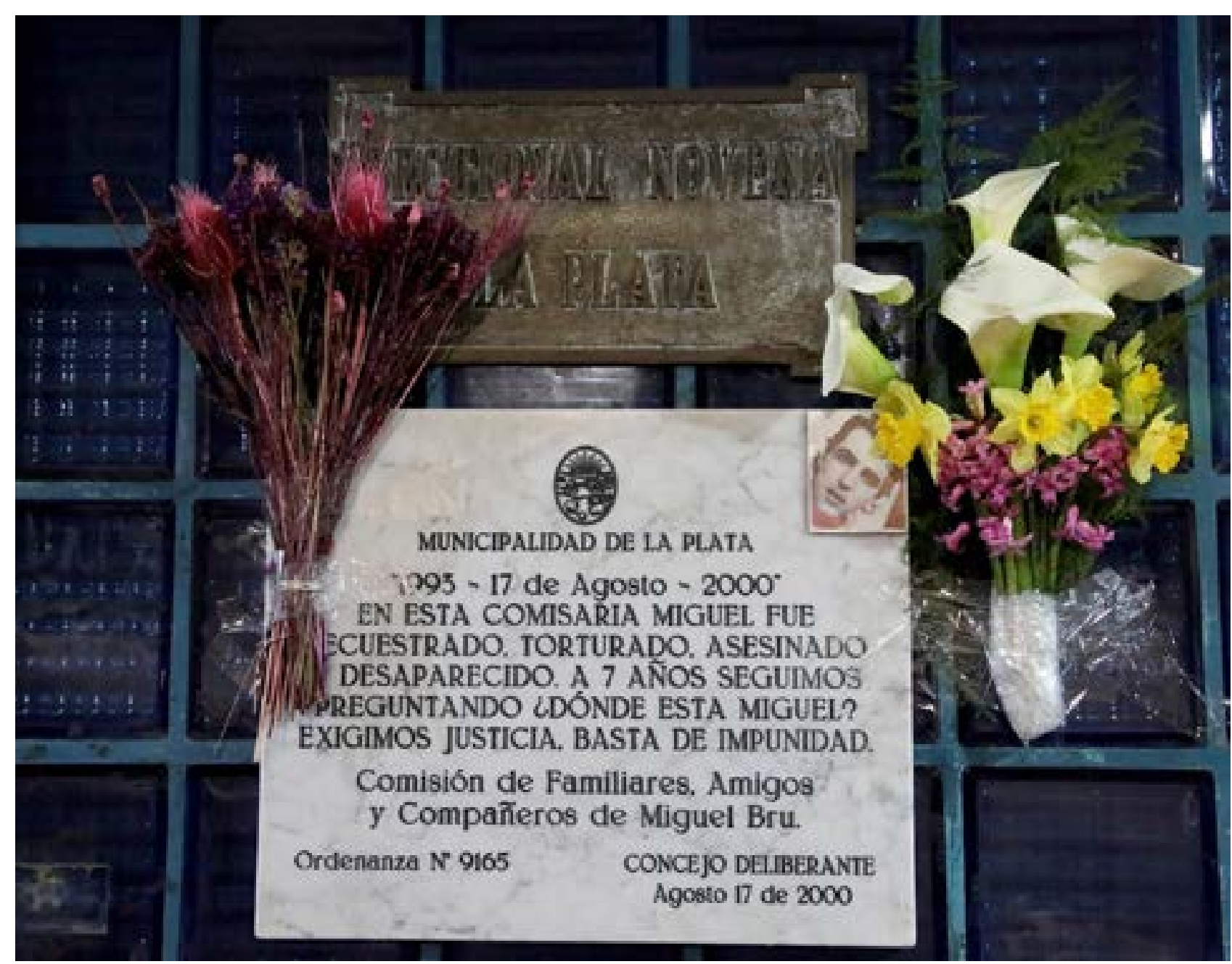



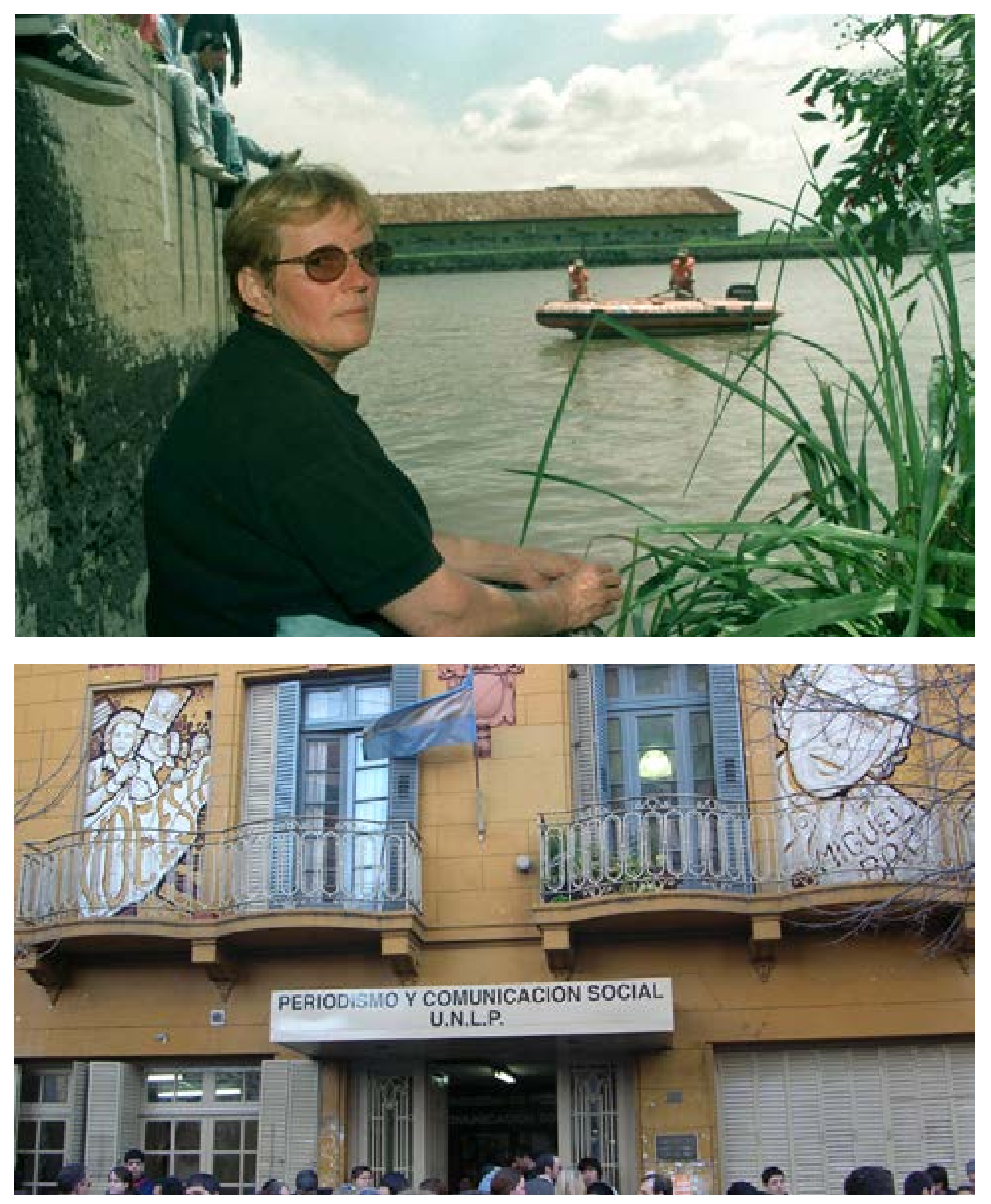

Rosa en conferencia de prensa con León Gieco antes del recital en el rectorado de la Universidad de la Plata, en el año 1997.2.Placa puesta por el Concejo Deliberante de la Municipalidad de La Plata en la comisaría 9a en el año 2000.3.Búsqueda de Miguel en el Río de La Plata, hasta el día de hoy se contabilizan 39 procedimientos en este sentido sin ningún resultado positivo.4. Inauguración de los murales sobre Rosa y Miguel Bru, realizados por la artista Cristina Terzaghi, en la fachada de la Facultad en la sede de calle 44 entre 8 y 9 en el año 2005.

\section{JUSTICIA \\ POR}

ARIEL CANNIZZO

MUERTO EL 22/10/11

ALAS SER DETENIDO POR 4 POUICIAS

EN LA COMISARIA TERCERA DE BERISSO

JUICIO - ALEGATOS

11/4 - 9:30HS

TOC: 856 Y 57 (LA PLATA)

\section{BASTA DE TORTURAY}

SON JUZGADOS:

DELACANAL ROBERTO PERCUOCO, ERNESTO CONTI,Y JOSÉ ANTONIO CÁCERE

(8)

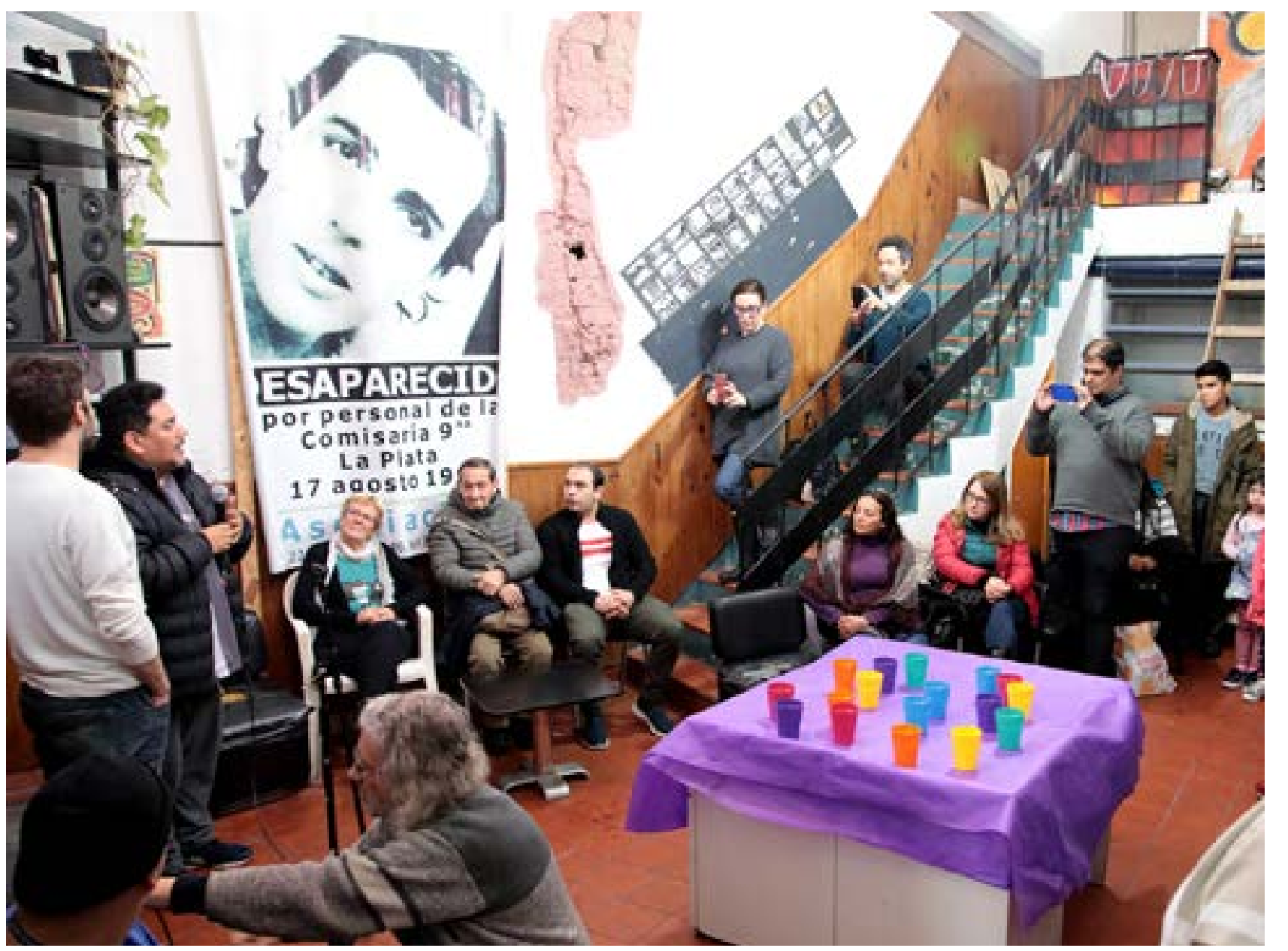



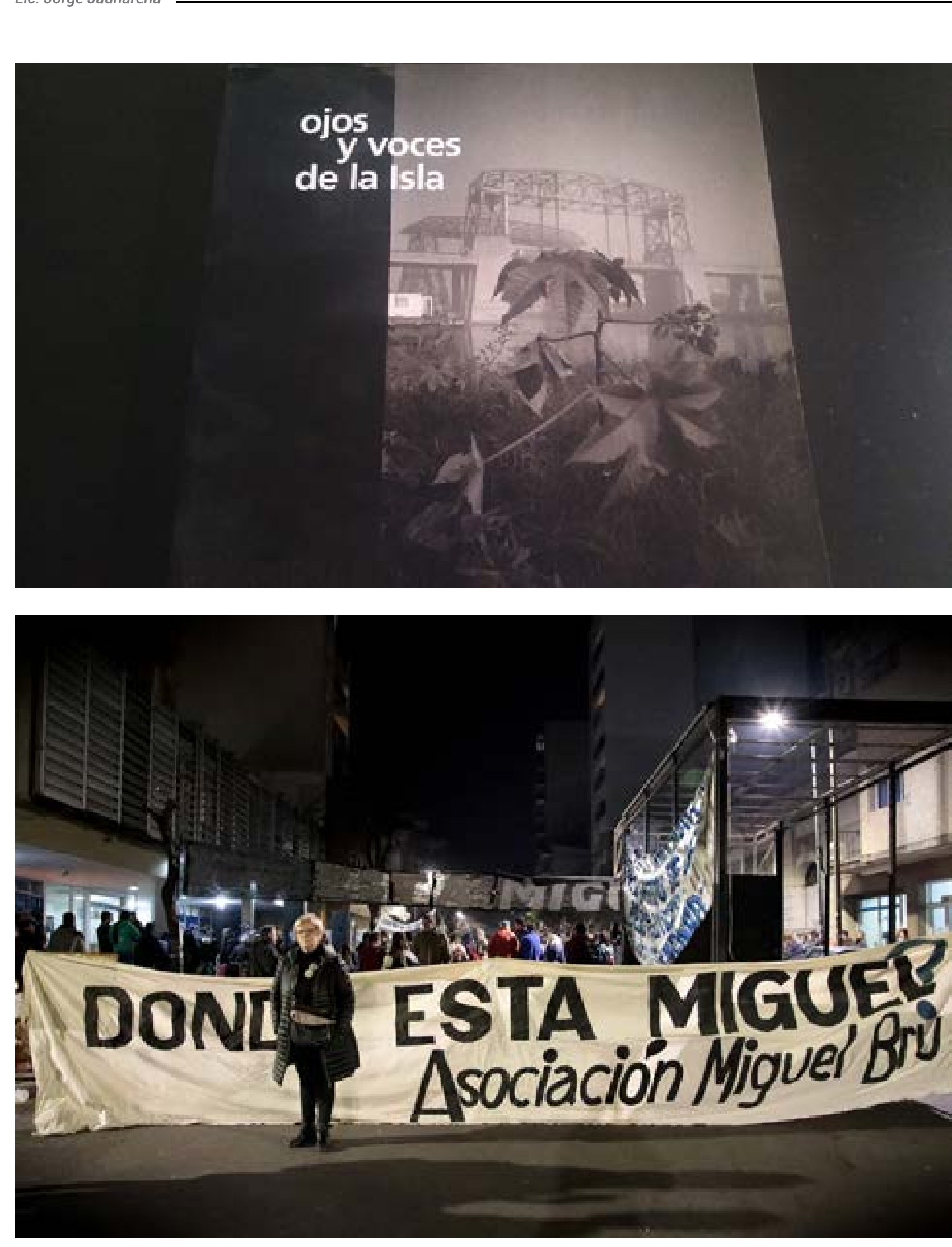

Para explicar la creación y el proceso de gestión de la Secretaría de Derechos Humanos de la Facultad de Periodismo y Comunicación Social, es preciso conocer y comprender las condiciones que la hicieron posible. Para ello, en este capítulo se presentan algunos aspectos referidos a la historia de la Facultad que contribuyen a entender este proceso, haciendo hincapié en la fundación, en el terrorismo de Estado, en el proceso de consolidación democrática, y en el momento de afianzamiento y de ampliación de derechos.

\section{Los orígenes de la Facultad de Periodismo}

Tanto entonces como ahora creo que el periodismo es libre o es una farsa sin términos medios.

Rodolfo Walsh (1957)

La Facultad de Periodismo y Comunicación Social nació, como tal, el 24 de octubre 1994 pero los estudios sobre periodismo en la ciudad de La Plata se remontan a algunas décadas atrás, precisamente, a 1934. En aquellos años, fueron los denominados «periodistas de oficio» quienes vislumbraron y sintieron la necesidad de encauzar el aprendizaje de la actividad a través de estudios sistemáticos proclives al desarrollo de una conciencia crítica y de una formación universal e integral. En el seno del Círculo de Periodistas de la Provincia de Buenos Aires surgió la inquietud de fundar una Escuela Superior de Periodismo.

Desde estos inicios y a lo largo de la historia, la formación de periodistas y de comunicadores, en general, y de la propia Facultad, en particular, se enmarca en un claro encuadre sobre el rol político-social del periodista que, con diferentes perspectivas político-académicas, permanecerá en los distintos períodos de la institución. La cuestión del entramado político tendrá relevancia en la toma de definiciones con respecto a la elección de las materias que constituyen los planes de Estudio, a la conformación de la planta docente y a los principios formativos que se enuncian.

5.Juicio de Ariel Canizzo. 6. Casa de Cultura y Oficios de la Asociación Miguel Bru en Parque Patricios, CABA.7. "Ojos y Voces de la Isla", libro con textos y fotos realizado por adolescentes en el marco del trabajo territorial de la AMB en la Isla Maciel de Avellaneda.8. Vigilia en la Comisaría Novena a 26 años de la desaparición de Miguel.

Manuel Elicabe (1885-1959), hombre crítico de su tiempo y de espíritu progresista, dirigió los primeros cursos de la Escuela Superior de Periodismo y luchó por la defensa de la libertad de prensa, enfrentándose al poder político de turno y marcando una historia de compromiso social y político con la construcción de una sociedad más justa.

El 26 de marzo de 1954, la Universidad Nacional de La Plata (UNLP) aceptó hacerse cargo 
de la Escuela Argentina de Periodismo. Los considerandos fueron claros: la escuela universitaria debía encuadrar la formación de los periodistas dentro de las necesidades de la Ley Universitaria y, en particular, como una «labor permanente de bien público, siempre en defensa de los intereses del pueblo y forjadora de una conciencia nacional». Para ello, la Universidad Eva Perón, por Resolución 155, resolvió «dar por nombre de Presidente General Juan Perón a la Escuela de Periodismo de la Universidad».

\section{La UNLP durante el terrorismo de Estado}

La Universidad que queremos es parte inalienable del país que anhelamos.

Federación Universitaria de la Revolución Nacional (1973)

En el período que va de mayo de 1973 a septiembre de 1974, con la asunción de Jorge Taiana como ministro de Educación de la Nación, las universidades expresaron la vocación de reconstrucción y de renovación nacional. El momento más alto de dicha expresión se alcanzó en marzo de 1974, con la sanción de la Ley Nacional 20654 de las Universidades Nacionales. El artículo primero enunciaba lo siguiente:

Las Universidades Nacionales son comunidades de trabajo que integran el sistema nacional de educación en el nivel superior con el fin de impartir enseñanza, realizar investigación, promover la cultura nacional, producir bienes y prestar servicios con proyección social y, haciendo los aportes necesarios y útiles al proceso de liberación nacional, contribuir a la solución de los grandes problemas argentinos (Ley 20654, Título I, art. 1).

Los antecedentes de la Revolución Cubana, la Noche de los Bastones Largos ${ }^{14}$ y el Cordobazo ${ }^{15}$ profundizaron la lucha por un país con justicia social desde diversos sectores universitarios en coordinación con los sectores populares. En este marco, no puede dejar de mencionarse a Rodolfo Achem (estudiante de abogacía), a Carlos Miguel (médico veterinario y docente de esa unidad académica) y a Ernesto Ramírez (Secretario General de la Asociación de Trabajadores de la Universidad, ATULP), fundamentales en la UNLP para poner en marcha, a partir de 1973, «La Universidad al servicio del Pueblo». Este proyecto concebía a la educación y a la universidad al servicio de la transformación social y le 14 El 29 de julio de 1966, el presidente de facto Juan Carlos Onganía sancionó el Decreto 16.912 que dio lugar a la intervención de las universidades. Lo sucedido ese dia se denomina "La Noche de los Bastones Largos» en alusión a los bastones con los cuales la Policía Federal reprimió y desalojó violentamente a profesores y a estudiantes de cinco facultades de la Universidad de Buenos Aires (UBA), que se oponían a la decisión del gobierno de facto de intervenir las casas de altos estudios y anular el régimen de gobierno.

15 El Cordobazo fue un levantamiento obrero estudiantil contra la Dictadura de Juan Carlos Onganía, que tuvo lugar el 29 y 30 de mayo de 1969. otorgaba un corte nacional y popular, mediante la multiplicación de becas, de albergues estudiantiles y de comedores a los que, hasta ese momento, las clases populares no tenían acceso. La misión social, entonces, era clara y concreta.

Pero aquellos movimientos sociales crispaban a los sectores que veían amenazados sus intereses. En este contexto, el 8 de octubre del 1974, Achem y Miguel fueron secuestrados y asesinados por la Triple A. ${ }^{16}$ Poco tiempo después, la UNLP se cerró temporalmente, cortando el proceso transformador que quedaría definitivamente destruido con la denominada Misión Ivanisevich (en alusión al nuevo ministro de Educación nombrado por la presidenta Isabel Perón, que anunciaba «combatir la conjura internacional -subversiva y marxista- a la que estaba expuesta la universidad»). Se daba inicio, así, a los años más oscuros y trágicos de nuestra historia universitaria.

Párrafo aparte merece el mítico comedor universitario, construido en 1951 por la Fundación Eva Perón. Recordado por los intensos debates políticos que allí se daban y como un lugar de encuentro de los distintos claustros universitarios, fue cerrado en noviembre de 1973 luego de la explosión de una bomba colocada por la Triple A que lo destruyó casi por completo.

En 1975, la represión prohibía los actos y las asambleas de los centros de estudiantes y con la Misión Ivanisevich empezaron las cesantías por motivos políticos. A fines de ese año, fue asesinado por la Triple A el arquitecto Carlos de la Riva, quien encabezaba la Asociación de Docentes que había comenzado a organizarse en 1972

La UNLP estuvo cerrada desde octubre de 1974 hasta abril de 1975, y ese período fue utilizado para «depurar» a docentes «indeseables». La tarea continuaría, se perfeccionaría y se extendería durante el autodenominado «Proceso de Reorganización Nacional» ${ }^{17}$-que derrocó a Isabel Perón-, llegando a declarar cesantes por ausentismo a docentes que habían sido secuestrados por los grupos de tareas o que no concurrían a dar clases porque temían ser secuestrados o asesinados. En todas las facultades había personal policial servicios de civil; algunos uniformados, incluso, solían presenciar las clases.

La lógica del exterminio se estableció sobre un cruento sistema represivo aplicado contra todos los que tuvieran ideas distintas al régimen. La consigna era detener, torturar y eliminar incluso se utilizó el Plan Cóndor, ${ }^{18}$ en cooperación con los países limítrofes. Se cerraron carreras (Sociología, Antropología, Psicología, Cine, Mural y Periodismo), se liquidaron cátedras, grupos de trabajo, investigaciones, proyectos de extensión y toda experiencia académica ligada a concepciones democráticas de la producción de conocimiento; por el

16 La Alianza Anticomunista Argentina (AAA), llamada Triple A, fue un grupo parapolicial de la Argentina que, durante el tercer gobierno de Juan Perón, entre 1973 y 1976, asesinó a artistas, sacerdotes, intelectuales, políticos de izquierda, estudiantes, historiadores y sindicalistas, además de utilizar como métodos las amenazas, as ejecuciones y la desaparición forzada de personas.

17 Así denominaron las Fuerzas Armadas a la Dictadura cívico militar eclesiástica que provocó un genocidio de Estado entre 1976 y 1983.

18 El denominado Plan Cóndor fue una coordinación represiva entre los servicios de inteligencia de las dictaduras que gobernaban los países del Cono Sur (Argentina, Chile, Uruguay, Brasil, Paraguay, Bolivia) en coordinación con los Estados Unidos y su Agencia Central de Inteligencia (CIA). 
contrario, se fomentó el desarrollo de una cultura académica individualista y corporativa. Según los listados oficiales, el saldo en la UNLP es de más de 750 víctimas directas, un gran número de exiliades y un sinnúmero de renuncias docentes (UNLP, 2020).

Desde la apertura democrática, nos encontramos recorriendo la incesante lucha por la memoria, la verdad y la justicia, en relación con lo sucedido durante el período del terrorismo de Estado en nuestro país, que se inició en 1974 y que culminó en 1983, repudiando y pidiendo justicia por aquellos hechos que pretendieron matar ideales y terminar con los intentos de crear una universidad ligada a la justicia social y al desarrollo productivo nacional.

\section{La Facultad de Periodismo y la última Dictadura}

Recuerdos

Me recuerdo la tarde en que te vi y tus ojos me gustaron y me senté a tu lado y conversamos, y quién sabe si no fue la calidez de tu voz que me sedujo.. Hoy te recuerdo y no te olvido, y te siento en los hijos y en los nietos y escribo en tu memoria compañera con la imagen de una tumba que no encuentro.

Sin embargo, no hay lugar en el cual no estés presente $y$, aunque yo esté muy lejos, en otra realidad geográfica y humana, estás en el recuerdo de nosotros, y en todos los que te conocieron compañera. Marita periodista, Marita guerrillera.

Marita secuestrada, violada, asesinada. Marita, sentiste el dolor de la tortura y la incertidumbre de saber si habíamos logrado escapar a la muerte atormentaba tus noches de cautiva.

Marita que te matan! Aun así tus labios no delatan.. Después de tanto tiempo de calvario, prisionera y vejada. Sólo queda el instante frente a los asesinos que apagarán la llama de tu vida compañera.. Sólo queda un instante, $y$, antes que te lo quiten, antes que te lo roben entre risas de sangre, la imagen de los hijos, en esos claros ojos habrán de acompañar tu silencio de muerte.

Te quitaron la vida asesinos sedientos, lacayos del sistema de explotación y odios y escondieron tu cuerpo, como otros tantos cuerpos,

para borrar tu nombre y desaparecer... Creyeron.. Pero aquí, en la memoria de lucha de nuestro continente

¿ESTÁN TODOS PRESENTES!

Julio Coronel ${ }^{19}$

Junto con los objetivos establecidos y con la organización de la currícula, el Plan de Estudios de 1972 fue el primero que propuso una formación en comunicación social vinculada a la transformación social en una sociedad «dependiente». Periodistas, investigadores y profesores tenían, además de su rol específico en los medios, un objetivo superior: transformar la sociedad argentina. Como asegura Carlos Ciappina (2015), «la revolución no era solo un tema de los alumnos. A principios de los setenta, también comenzaba a vibrar un nuevo Plan de Estudios. Ese el Plan con el que se encontrará en 1976 la Dictadura militar» (p. 132).

En marzo de 1976, la Escuela Superior de Periodismo, una de las unidades académicas que más se caracterizaba por la participación política, fue cerrada y, en octubre, puesta bajo la dependencia de la Facultad de Ciencias Jurídicas y Sociales. En junio de ese año, el interventor desaparecida el 27 de enero de 1977. 
de la UNLP, el Capitán de Navío Eduardo Luis Saccone, dispuso la conformación de una Comisión Especial destinada a delinear el nuevo proyecto educativo de la institución. Dos meses después, el profesor Daniel Alfredo Pabón fue nombrado como director de la Escuela Superior de Periodismo. Les docentes de periodismo que no habían sido perseguidos, lo eligieron «porque al ser docente de la Escuela Naval suponían que les brindaría la confianza de sus superiores» (Vestfrid, 2005, s/p). Años más tarde, en una entrevista, Pabón relata:

Los militares querían cerrarla directamente, no sabían qué hacer con la carrera. Habían recibido la orden de que había que cerrarla y la expresión era «porque había un nido de bolches». Allá por el mes de junio, el interventor, capitán Saccone, nos llamó a los últimos que habíamos ido a pedirle por la Escuela y nos dijo que sacarla de la esfera de Derecho no se podía, porque Derecho se llamaba Facultad de Ciencias Jurídicas y Sociales, por lo cual la Escuela quedaba bajo su dependencia. Acerca del Plan 1972, dijo que era para formar subversivos (Vestfrid \& Guillermo, 2007, p. 97).

Tal como fue establecido por el gobierno nacional, a partir de 1977 se implementaron en todas las carreras de las universidades públicas los cursos de ingreso eliminatorios. Además, se explicitó la cantidad de ingresantes que debía admitir cada unidad académica y se estipuló el porcentaje de alumnos extranjeros (Barba, 1998).

Me acuerdo que nos habíamos anotado 300 personas y que finalmente entramos treinta y pico. La escuela había estado cerrada durante todo 1976 y reabrió en 1977. Cuando rendimos el examen, funcionaba en 10 entre 54 y 55 , en el primer piso de una casa vieja. Me acuerdo que arriba, en el descanso de la escalera que da al primer piso, había soldados con armas largas... (Marisa Álvarez, ingresante de 1977) [Vestfrid \& Guillermo, 2007, p. 131].

Una de las cosas que me llamó la atención y me quedó como un recuerdo fotográfico es la imagen del día en el cual empecé el curso de ingreso. Ese edificio donde cursábamos tenía una escalerita muy chiquita y me acuerdo que había soldados de ambos lados. Nosotros tuvimos que pasar entre ellos, teníamos el edificio ocupado (Nancy Fernández, ingresante de 1978) [Vestfrid \& Guillermo, 2007, p. 132].

En mi materia, tenía a uno de los servicios escuchándome toda la clase. Yo le tomaba el pelo haciéndolo opinar sobre el periodismo. En cada clase había un servicio, un hombre que no podía disimular que había estado acatando órdenes toda su vida... (Teódulo Domínguez, profesor) [Vestfrid \& Guillermo, 2007, p. 143].
Durante su administración, desaparecieron y asesinaron -sobre un total estimado de 200 personas- más de 35 docentes, estudiantes y graduades. Fue tal el silenciamiento que, hasta entrada la democracia, la Escuela Superior de Periodismo nunca salió a la calle con ningún producto periodístico ni académico.

Listado de víctimas del terrorismo de Estado de la Escuela Superior de Periodismo de la Universidad Nacional de La Plata

Ricardo Emir AIUB SALOMON, Julio Alberto ALVAREZ CAVAROZZI, Horacio Félix BERTHOLET CARDOSI, Néstor Alejandro BOSSI, Ricardo Antonio DIAZ ANSELMI, Rodolfo Daniel ELIAS ZAPPELLINI, Roberto Nando FALIVENE GONZALEZ, María Cristina FERNÁNDEZ, Jorge Horacio FOULKES DINSEN, María Teresa GRUJIC ALBARENQUE de CORONEL, Julio Eduardo GUSHIKEN KISHIMOTO, Alejandro Enrique GUTIÉRREZ PENETTE, Silvia Elvira IBAÑEZ de BARBOSA, Sergio KARAKACHOFF, Mercedes Isabel MAIZTEGUI, Héctor Marcelo MARGHETICH BROUSSIAN, Elsa Delia MARTÍNEZ DUTHIL DE RAMÍREZ ACHINELLI, Susana Beatriz MEDINA CARDOZO de BERTHOLET, Mario Miguel MERCADER, Liliana Edith MOLTENI, Victorio Graciano PERDIGHE MILLIA, Rafael Antonio PEDREIRA CARRATALA, Guillermo Ernesto SAVLOFF SAEDLER, Nélida Ofelia VILLARINO BOLENTINI, Sergio ZURITA BROCCHI, Silvio FRONDIZI, José Guillermo ESPINOZA PESANTES, Pablo Andrés GELSTEIN BARETIC, Jorge Rodolfo HARRIAGUE FITZ GERALD, Carlos Eduardo ISHIKAWA MAYEYOSHIMOTO, Juan Carlos JORDAN VERCELLONE, Luis Norberto MACOR SORIA, Norberto Juan ORLANDO TILOT.

Compañeres detenides desaparecides: ¡Presentes, ahora y siempre! 


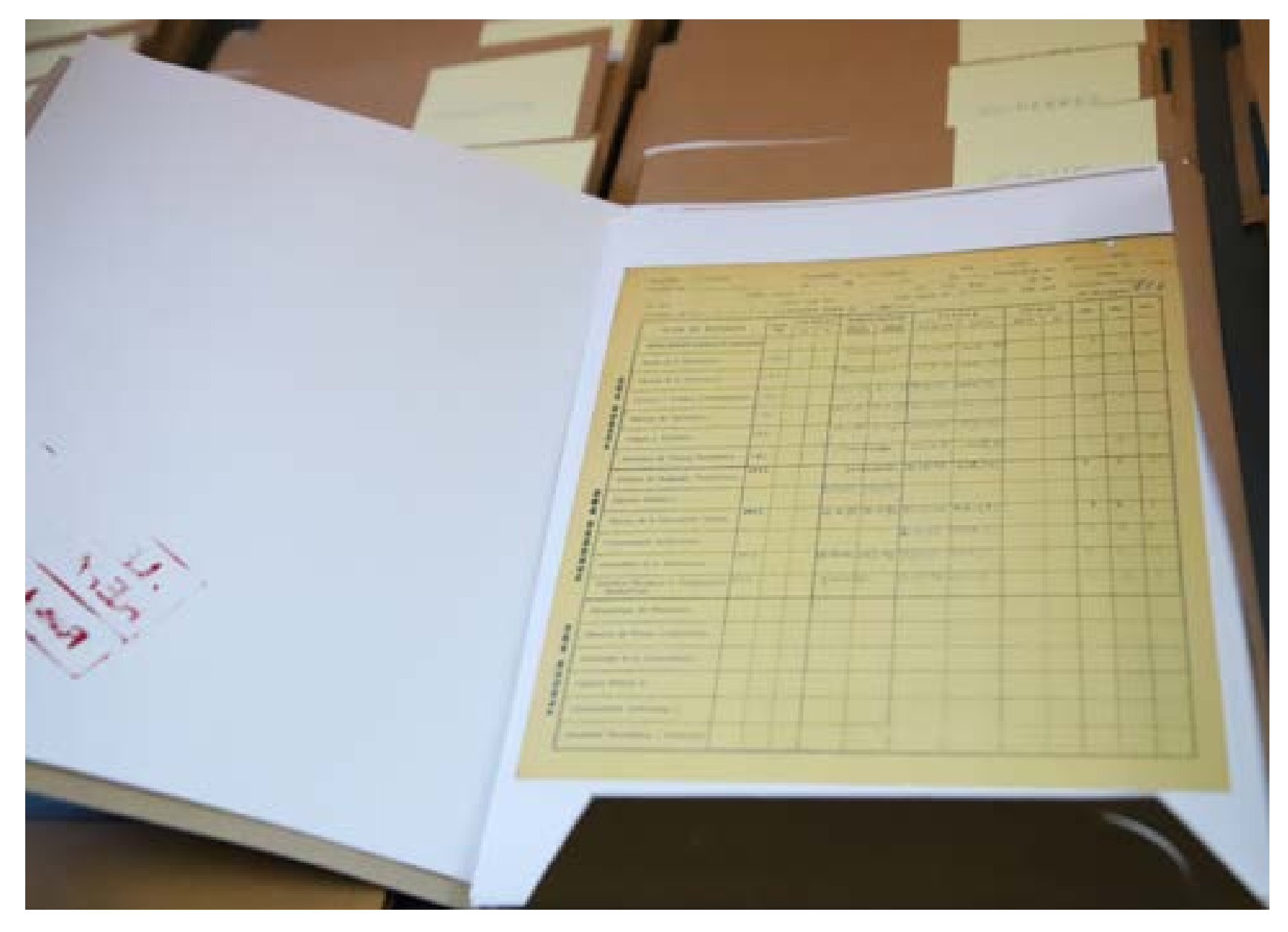

60

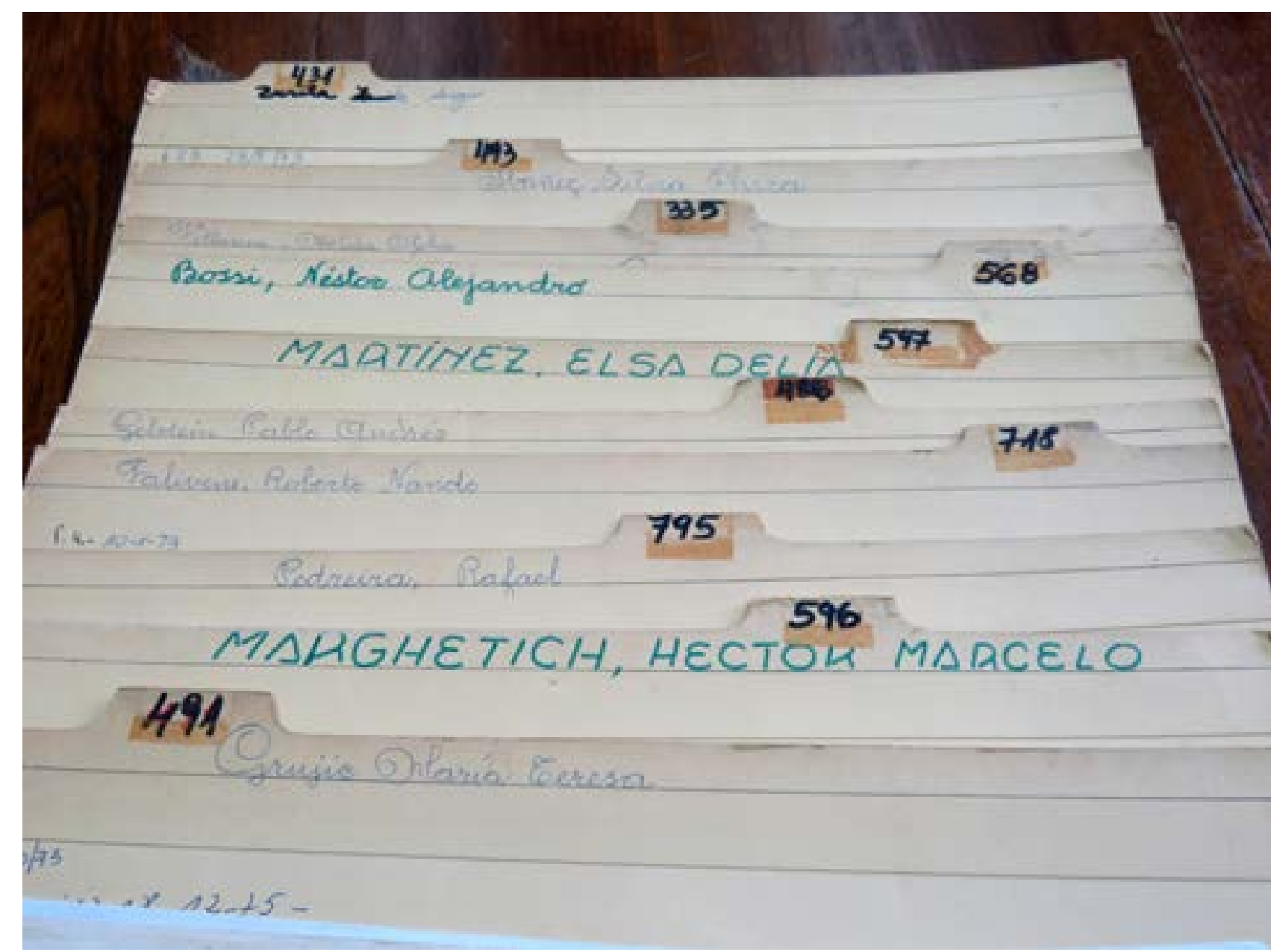

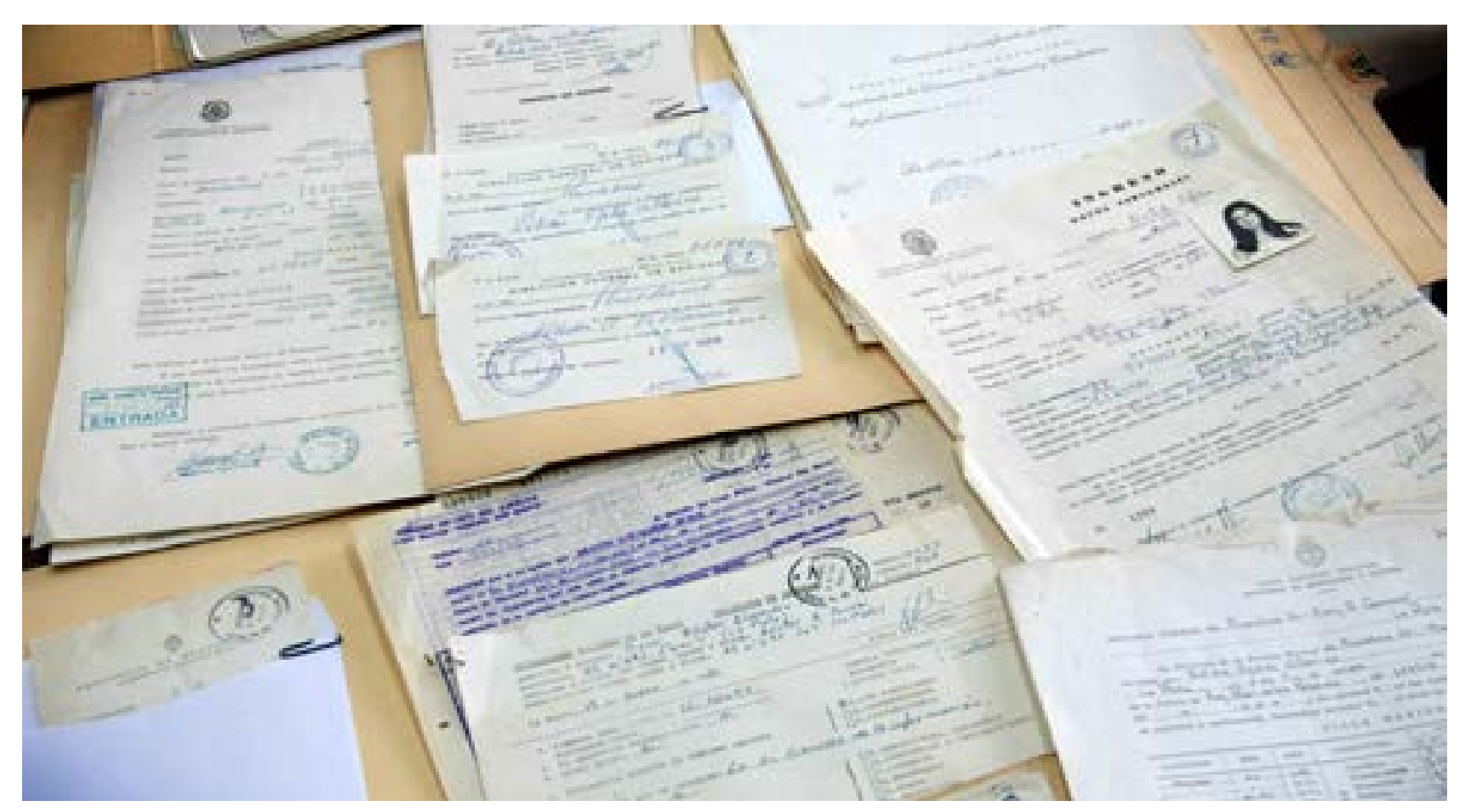

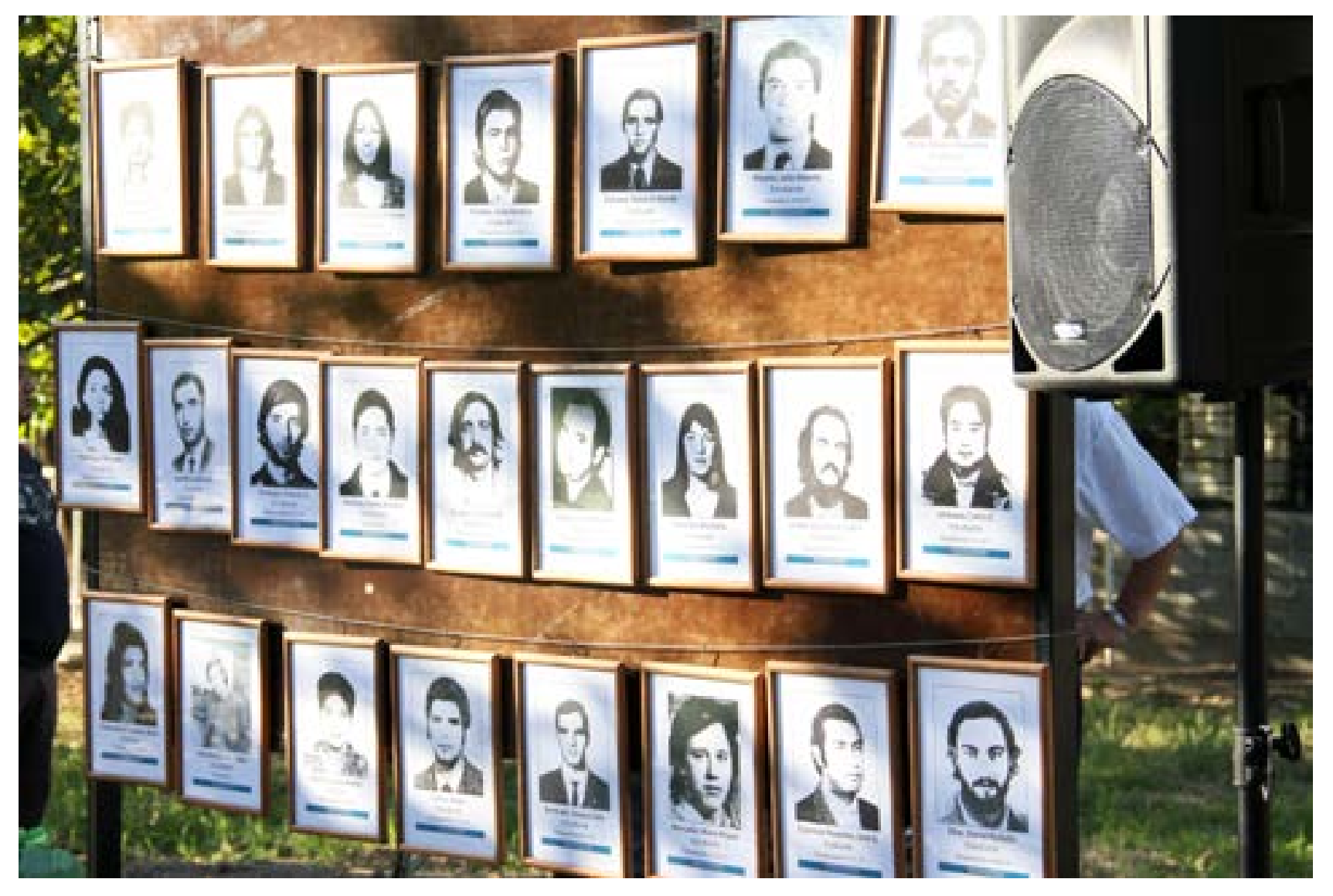

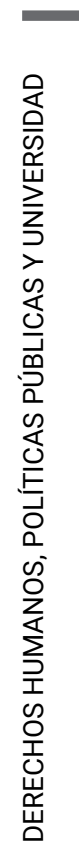

Certificado analítico de Pablo Guelstein, desaparecido de la FP y CS. UNLP, las actas iniciales eran muy precarias y figuraban dos desaparecidos distintos uno Pablo Guelstein y otro Pablo Barretic, investigando descubrimos que eran la misma persona con doble apellido.2. Fichas de les desparecides por el Terrorismo de Estado de la FP y CS. UNLP.3. cuadros de les desaparecides en la inauguración de la sede Néstor Kirchner de la FP y CS.4Documentación de las víctimas del terrorismo de Estado de la FP y CS. 

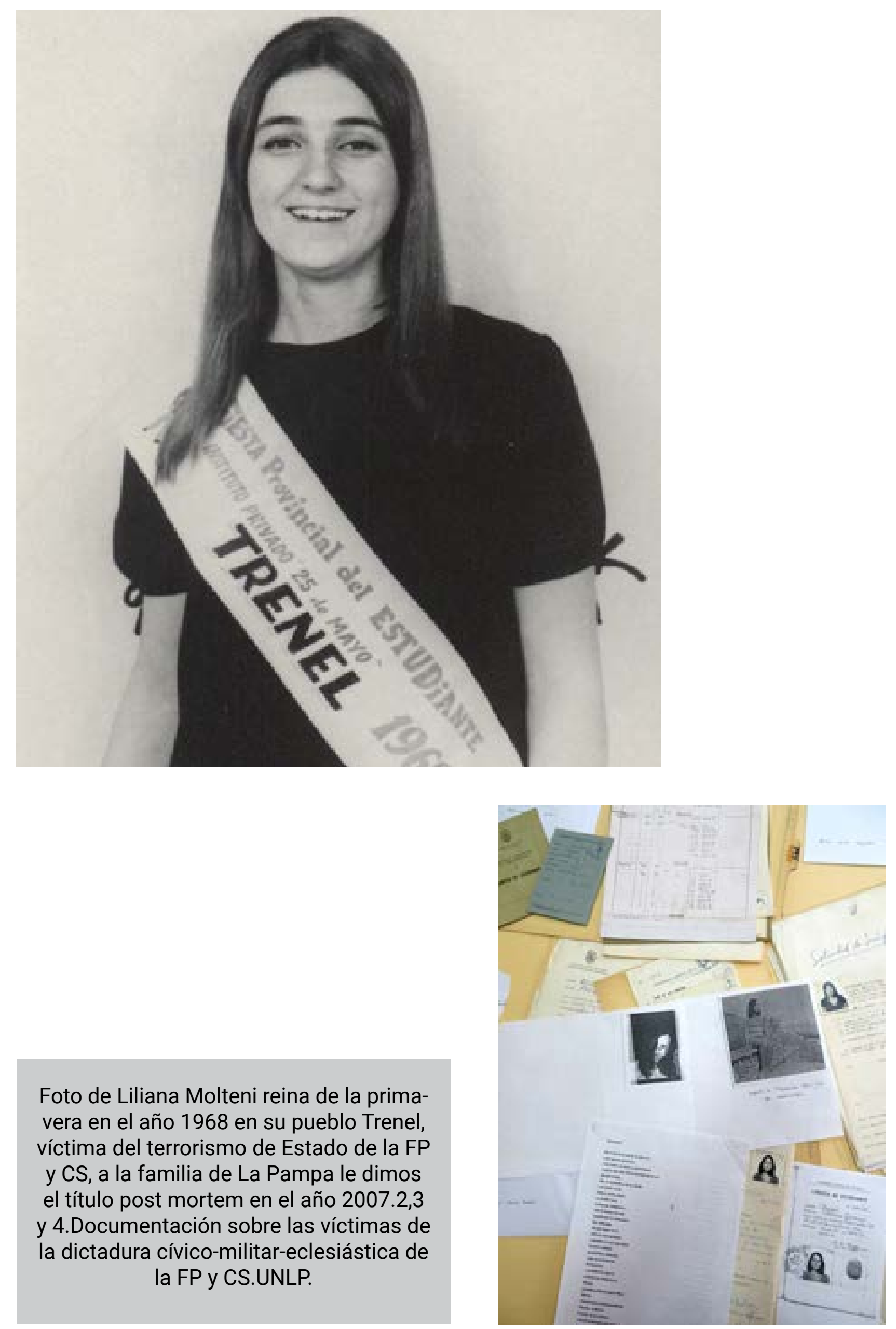

Foto de Liliana Molteni reina de la primavera en el año 1968 en su pueblo Trenel, víctima del terrorismo de Estado de la FP y CS, a la familia de La Pampa le dimos

el título post mortem en el año 2007.2,3

y 4.Documentación sobre las víctimas de la dictadura cívico-militar-eclesiástica de la FP y CS.UNLP.

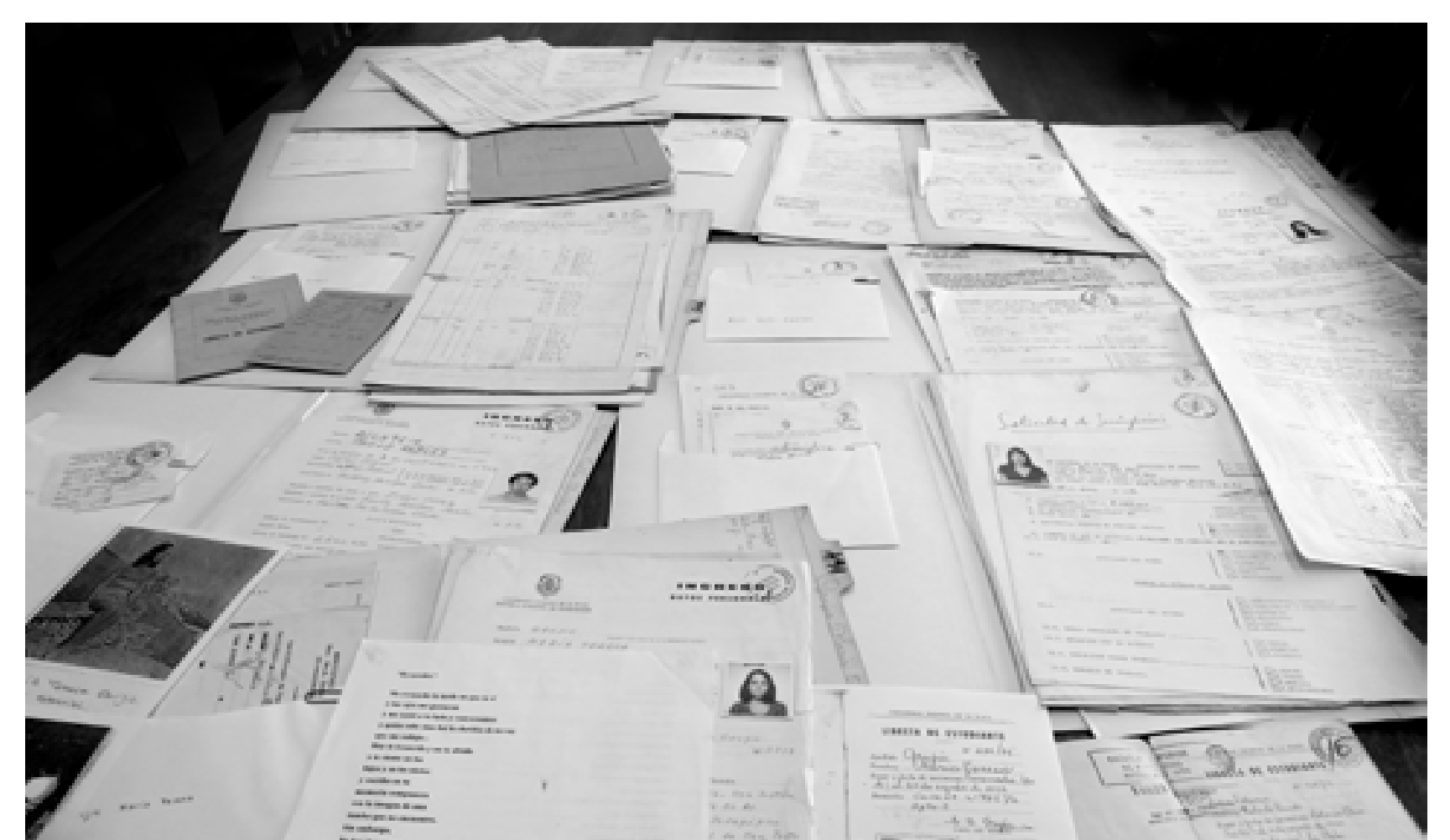

\section{a}

2.

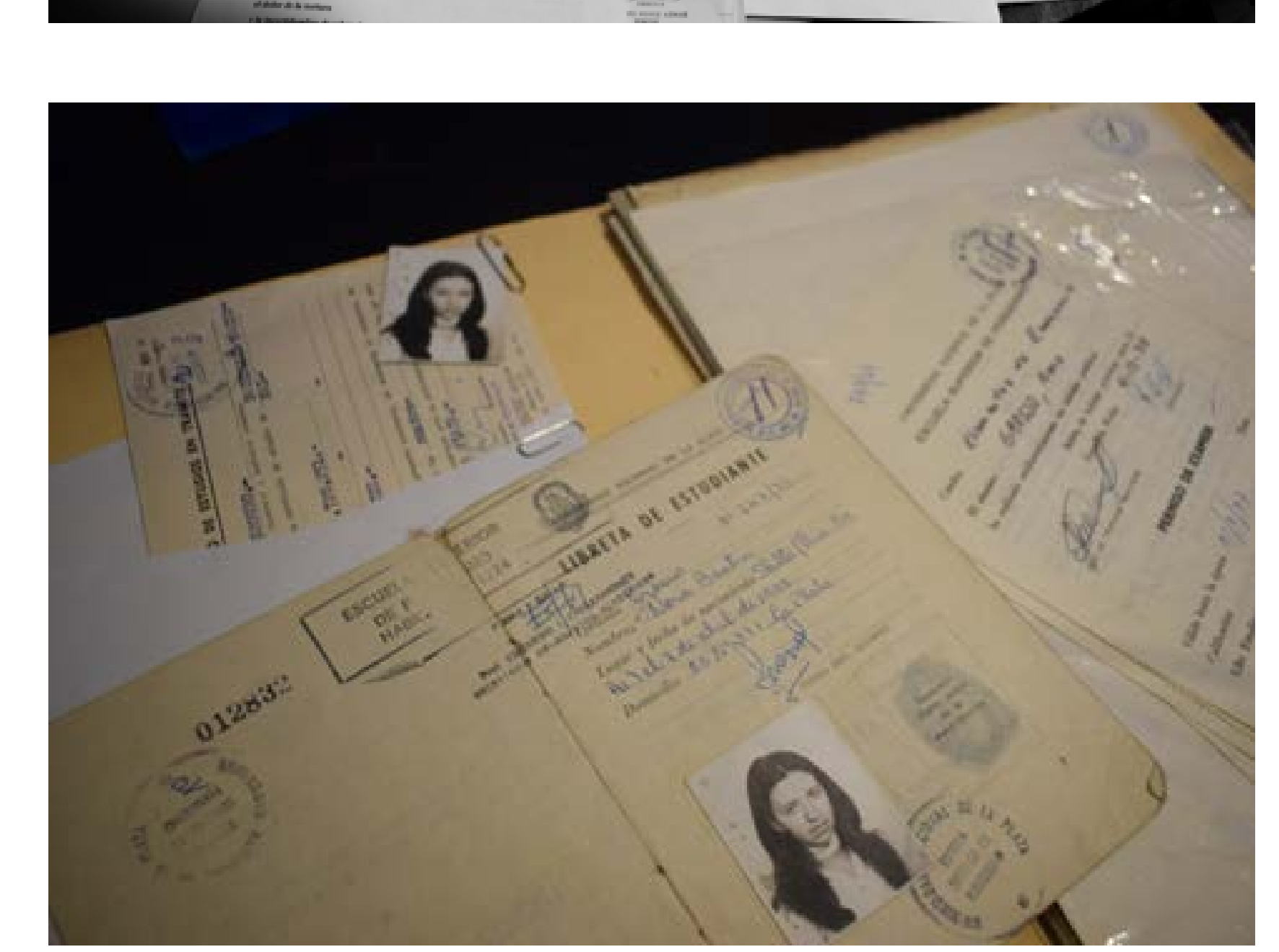




\section{La apertura democrática}

Entre las muchas formas de luchar por la memoria, la UNLP ha confeccionado listados con las víctimas de la última Dictadura cívico militar eclesiástica en las distintas unidades académicas, ha colocado placas, realizado murales y monumentos, y llevado a cabo actos que son parte de la vida cotidiana en los espacios públicos de la ciudad. Tras la apertura democrática, también la Escuela Superior de Periodismo participó con su presencia activa e intelectual en los principales hechos de la política local, provincial y nacional, caracterizándose, nuevamente, por la militancia, el activismo y el debate político en todos los ámbitos.

En los primeros años, nos encontramos en un contexto de cierta fragilidad democrática puesto que los gestores de la última Dictadura genocida -tanto militares como sectores del poder económico que financiaron y que hicieron enormes negocios durante la Dictaduracontinuaban caminando en la impunidad. A esto se sumaba el contexto latinoamericano con dictaduras que todavía proliferaban en todo el continente. Frente a esto, y en un acto que determinaba una firme decisión política, Raúl Alfonsín, a solo cinco días de asumir la presidencia, creó la Comisión Nacional sobre la Desaparición de Personas (CONADEP), con el objetivo de investigar las violaciones a los derechos humanos perpetradas por el terrorismo de Estado. La decisión de llevar adelante el Juicio a las Juntas Militares ya estaba tomada, y la comisión, cuya función era aportar pruebas, recibió miles de declaraciones y de testimonios, y verificó la existencia de cientos de lugares clandestinos de detención en todo el país. Con el informe se publicó el libro Nunca Más, ${ }^{20}$ que cosechó muchas críticas por parte de la militancia de Derechos Humanos debido a que en el prólogo, escrito por Ernesto Sábato, se avalaba la «teoría de los dos demonios». ${ }^{21}$ En el Juicio a las Juntas, realizado en 1985, el fiscal, Julio César Strassera, cerró su alegato con la misma expresión: «Nunca Más».

Pero, pronto, la triste realidad desnudó lo que venía: las leyes de Punto Final (1986) y de Obediencia debida (1987), que generaron el repudio total de muchos sectores de la sociedad; entre ellos, de los claustros académicos. Desde todos los sectores -estudiantiles, docentes y no docentes-, había un estado de movilización constante en reclamo de justicia y contra la impunidad del terrorismo de Estado.

En consonancia con lo que sucedía en el país, hacia el interior de la Universidad tampoco tenía lugar el proceso de reparación que pretendíamos, sino todo lo contrario. Respecto de los cesanteados por la última Dictadura, en diciembre de 1984, mediante la ordenanza 162 , se ordenó la reincorporación de docentes y de no docentes cesanteades, prescindibles u obligades a renunciar por motivos políticos, gremiales o conexos, reconociéndoles los cargos que tenían entre los años 1976 y 1983. No obstante, el plazo para presentar las $20 \quad$ Editado por Eudeba, en 1984.

21 Esta teoría pone en la misma escala los actos perpetrados por las Fuerzas Armadas durante la última Dictadura con los de las organizaciones revolucionarias de la época, intentando proponer que fue una guerra y no un genocidio de Estado. solicitudes era el 18 de marzo del siguiente año. Sí, isolo tres meses!, con las dificultades que acarreaba, por ejemplo, para quienes estaban en el exilio.

No pueden dejar de mencionarse en esta etapa, signada por los gobiernos neoliberales del peronista Carlos Menem y del radical Fernando De la Rúa, los intentos por modificar la Ley 24521 de Educación Superior (LES) que buscaban privatizar la educación pública y que mantuvieron a la comunidad académica universitaria en estado de alerta y de movilización permanentes. Cuando el por entonces presidente de la UNLP, Luis Ángel Lima, impulsó la modificación del Estatuto para introducir la LES, permitir la reelección en los mandatos y el arancelamiento, todo el arco estudiantil buscó impedir la votación en la Asamblea Universitaria del 20 de febrero de 1996.

Además de generalizar el arancel, Lima pretendía vender los servicios de investigación, de extensión y de enseñanza, los tres pilares fundamentales de la Universidad. Había riesgo de que la Universidad se volviera funcional a las grandes empresas y que la educación excluyera a los sectores más vulnerables de la sociedad. Ese 20 de febrero volvió a escribirse otra página negra para el estudiantado: la policía (muchos de civil) reprimió brutalmente a los integrantes de la Asamblea. Un total de 237 estudiantes fueron detenides en la sede de la Infantería de la Provincia de Buenos Aires, ubicada en calles 1 y 60 (con el morbo agregado de que, durante la última Dictadura, allí había funcionado uno de los centros clandestinos de detención). Recuerdo la imagen de Rosa Bru y de Hebe de Bonafini poniendo el cuerpo en defensa de les detenides.

Otra muestra de la lentitud en el proceso de justicia al interior de la Universidad -una de las instituciones públicas más castigadas por el terrorismo de Estado en número de víctimases que recién en 2008, al reformularse el Estatuto, se agregó en el Preámbulo:

La UNLP reafirma su compromiso con los valores democráticos y republicanos y por ello sostiene que no podrán incorporarse y/o permanecer en ella, en cualquier desempeño, aquellas personas involucradas en violaciones a los derechos humanos y/o terrorismo de Estado (UNLP, 2008, p. 4)

En ese sentido, a partir de la nulidad de las «Leyes del Perdón», la UNLP participa como querellante en los juicios de lesa humanidad y acompaña a las organizaciones de derechos humanos, transformándose en un ámbito público que promueve el proceso de Memoria, Verdad y Justicia. ${ }^{22}$

No obstante, retrocediendo en el tiempo, un hecho marcaría a fuego la vida institucional de la Facultad: el 17 de agosto de 1993, en plena democracia, el alumno de tercer año, Miguel Bru, fue secuestrado ilegalmente, torturado hasta la muerte y luego desaparecido por la policía bonaerense.

22 Memoria, Verdad y Justicia es la denominación que se utiliza para dar cuenta de los procesos que culminan en los juicios por delitos de lesa humanidad llevados a cabo contra los responsables de las violaciones a los derechos humanos en el marco del terrorismo de Estado (1976 y 1983). 
Sus asesinos, los policías Abrigo y López, entre otros, tenían 20 años cuando ingresaron en la policía que por ese entonces comandaba el general Ramón Camps. Indudablemente, en la muerte y en la desaparición de Miguel mucho tuvieron que ver las leyes de Punto Final (1986) y de Obediencia Debida (1987), que impidieron revisar en esos años de democracia la actuación de las fuerzas de seguridad durante la última Dictadura. Lo importante es que lo que definió la condena y la cárcel para los dos policías asesinos fue la movilización social y la lucha constante de todos los claustros universitarios, con el acompañamiento fundamental de las Madres y las Abuelas de Plaza de Mayo.

Esta triste carga implica para nuestra institución una lucha constante en busca de verdad y justicia, desde aquel momento hasta la fecha. Desde lo cotidiano, en los trabajos de estudiantes y de docentes, se ven las producciones relacionadas con la desaparición de Miguel y con las víctimas de la última Dictadura. En nuestra Plaza de la Memoria hay un monolito con el listado completo de las víctimas, igual que en el aula anfiteatrada, donde se ofrecen fragmentos de sus historias de vida. Es un tema con el que se trabaja permanentemente desde la currícula de las cátedras y en los proyectos de investigación, en las diversas charlas, en la participación en los juicios, actos y marchas. Se intenta mantener viva la memoria, con la convicción de que implica verdad y que a la verdad no debiera implicar otra cosa que no sea la justicia. La sede de calle 44 de la Facultad lleva el nombre de Miguel Bru, con una placa en la puerta que lo recuerda y con un mural de él y su mamá en la fachada del edificio.

\section{La década ganada en derechos}

La defensa de los derechos humanos ocupa un lugar central en la nueva agenda de la República Argentina. Somos hijos de las Madres y Abuelas de Plaza de Mayo. $Y$ por ello insistimos en apoyar de manera permanente el fortalecimiento del sistema internacional de protección de los derechos humanos y el juzgamiento y la condena de quienes los violen.

Néstor Kirchner (2003)

Desde el retorno de la democracia, junto con las Madres y las Abuelas de Plaza de Mayo, los organismos de derechos humanos, y numerosas organizaciones sociales y políticas, hemos levantado la bandera de los derechos humanos para consolidar el Estado democrático que tenemos en la actualidad. En 2002, mediante la Ley Nacional 25633, se instituyó el 24 de Marzo como Día Nacional de la Memoria por la Verdad y la Justicia «en conmemoración de quienes resultaron víctimas del proceso iniciado en esa fecha del año 1976». En 2006, otra ley estableció la condición de feriado de la fecha.

Los gobiernos de Néstor Kirchner (2003-2007) y de Cristina Fernández (2007-2015) abrieron la autodenominada «era de ampliación de derechos», en alusión a la ejecución de políticas de restitución y de ampliación de derechos humanos.

Durante los gobiernos de Néstor Kirchner y de Cristina Fernández de Kirchner (2003-2015) en la Argentina hubo grandes inversiones en materia edilicia, en investigación y en extensión, también se gestó una importante articulación entre las políticas públicas y las universidades del país. [...] En esta etapa de las universidades públicas argentinas, se entendió que la calidad de la educación superior es pluridimensional y que se debía abordar en todos sus elementos, funciones y actividades [...] se dio cuenta de un proyecto de universidad cercano al territorio, con incentivos a las tareas de formación, de investigación, de extensión y de transferencia integradas a un proyecto de país. Implementado por el Proyecto Nacional, Popular y Democrático del kirchnerismo, las universidades asumieron roles y desafíos promotores de profundas transformaciones académicas, docentes y extensionistas que, a mi parecer, impactaron en la configuración de nuevas subjetividades docentes y estudiantiles, configurando nuevos desafíos (Retola, 2018, p. 142).

A esta ampliación de derechos se la reconoce por la reconstrucción de verdades, la promoción de la memoria colectiva, el hallazgo de nietos que faltan y la reparación de tantas heridas que dejó el terrorismo de Estado, y que por las «Leyes del Perdón» no estaban saldadas en nuestra democracia. La nulidad de estas leyes y los juicios de lesa humanidad -con el consiguiente procesamiento y cárcel a los genocidas-, acompañados por políticas de memoria que incluyeron demarcación de sitios, museos, obras artísticas, reivindicación de historias de víctimas y la creación del Banco Nacional de Datos Genéticos para la búsqueda de niñes apropiades durante la Dictadura trajeron mucha paz, no solo a los familiares de las víctimas sino a la enorme mayoría de la sociedad, en un acto reparatorio de profunda civilidad.

Muchos sectores sociales y los organismos de derechos humanos nos sentimos parte activa de ese momento histórico. En el marco de un proyecto nacional y popular, hemos militado con fuertes convicciones por mayor justicia social, por la democracia y por la Argentina.

En efecto, en esta «era de ampliación de derechos», iniciada en 2003, encontramos una política de gobierno clave para avanzar en la conquista de una gran cantidad de derechos sociales, económicos y culturales, entre los que se destacan:

- Juicios por delitos de lesa humanidad: retomados luego de la derogación de las leyes de Punto Final (1986) y de Obediencia Debida (1987), se convirtieron en política de Estado. Hasta 2014, concluyeron 21 juicios en todo el país, en los cuales se condenó con sentencia firme a 92 genocidas por delitos cometidos contra 558 víctimas. En la provincia de Buenos Aires, se llevaron a cabo siete juicios en los que se condenó a 40 represores que suman, desde 1983, un total de 559 condenados. 
- Comisión Nacional por el Derecho a la Identidad (CONADI): organismo encargado de recibir denuncias o información que permita alcanzar la restitución de la identidad de niñes desaparecides y de bebés robados al nacer de madres en cautiverio. Hasta 2020, el trabajo de la CONADI ha permitido restituir la identidad de 130 nietes.

- Iniciativa Latinoamericana para la Identificación de Personas Desaparecidas: campaña que procura establecer los lugares donde fueron enterradas en forma clandestina las personas detenidas desaparecidas durante la última Dictadura. Una vez que estos lugares son encontrados, se realizan las excavaciones para desenterrar los restos óseos y poder identificarlos. Finalmente, los restos son restituidos a los familiares para que puedan realizar homenajes y darle digna sepultura.

- Archivo Nacional de la Memoria (ANM): organismo público que se encarga de preservar los testimonios que integran la CONADEP y los testimonios que se reciben a diario en la Secretaría de Derechos Humanos de la Nación. El ANM se encarga, además, de digitalizar los documentos, los testimonios y la información que muestren el accionar del terrorismo de Estado, para que las futuras generaciones puedan resguardar y mantener viva la memoria.

- Red Federal de Sitios de Memoria: identifica y señaliza los lugares que el terrorismo de Estado utilizó para detener, torturar y matar personas. Uno de los más emblemáticos es el Espacio Memoria y Derechos Humanos de la ex Escuela de Mecánica de la Armada (ESMA) donde funcionó el centro clandestino de detención, tortura y exterminio que fue símbolo del terrorismo de Estado. ${ }^{23}$ El espacio, recuperado en 2004, es considerado una referencia nacional e internacional en temas de políticas públicas de memoria, de promoción de valores democráticos y de defensa de los derechos humanos.

Centro de Asistencia a Víctimas de Violaciones de Derechos Humanos «Dr. Fernando Ulloa»: ofrece acompañamiento y asistencia integral a víctimas del terrorismo de Estado, a sus familiares, y a víctimas-testigos y querellantes que participen en los juicios por delitos de lesa humanidad.

- Programas de participación y acceso a la justicia: otorgan la posibilidad de votar a los 16 años, en vez de a los 18. Centros de Acceso a la Justicia (CAJ) para los sectores más marginados de la sociedad con recepción de denuncias y atención ciudadana.

- Trabajo y diversidad sexual: se protegen y se promueven los derechos de la población LGTBI en el ámbito laboral. Las personas que consideran que son discriminadas por su orientación sexual o por su identidad de género en su ámbito laboral son informadas sobre sus derechos y se las vincula con el Instituto Nacional contra la Discriminación, la Xenofobia y el Racismo (INADI)

- Matrimonio igualitario: garantiza a todas las personas el derecho al matrimonio, con independencia de que les contrayentes sean del mismo o de diferente sexo.

- Identidad de género: permite solicitar la rectificación registral del sexo, el nombre de pila y

23 Entre 1976 y 1983, pasaron por allí cerca de 5.000 personas detenidas desaparecidas. la imagen registrados en el DNI, cuando estos no coincidan con la identidad de género auto percibida por la persona solicitante.

- Rescate y acompañamiento a víctimas de trata de personas: recibe denuncias y cuenta con un equipo de psicólogos, trabajadores sociales y abogados que acompañan a las víctimas desde el momento del rescate o de la huida del lugar de explotación.

- Ley Nacional 26485 de Protección Integral para Prevenir, Sancionar y Erradicar la Violencia contra las Mujeres.

- Línea 137 para la Atención a Víctimas de Violencia Familiar: línea gratuita que funciona las 24 horas, todos los días del año, a la que se puede llamar ante una situación de violencia familiar, para recibir orientación y asistencia profesional.

- Línea 144 para la Atención de Consultas sobre Violencia de Género: brinda contención, información y asesoramiento sobre recursos existentes en materia de prevención de la violencia contra las mujeres y de asistencia a quienes la padecen.

Finalización de Estudios Primarios y Secundarios (FINES): plan de finalización de estudios destinado a personas de 18 años o más que terminaron de cursar, como alumnos regulares, el último año de la educación primaria o secundaria y adeudan materias.

- Apoyo para la escolaridad de estudiantes pertenecientes a pueblos originarios: aplicado tanto para estudios primarios como secundarios.

- Becas universitarias: destinadas a estudiantes de bajos recursos que aspiren o que estén cursando una carrera de grado del campo de las ciencias de la salud, humanas y sociales, en una universidad nacional o instituto universitario nacional.

- Patrocinio gratuito a personas y grupos discriminados: destinado a toda persona o grupo que haya sido víctima de un acto o una práctica discriminatoria.

- Lucha contra la impunidad: busca mitigar los efectos que generan la violencia institucional y la injusticia. Cuenta con profesionales de distintas disciplinas y familiares de víctimas que acuerdan vías de acción con las personas denunciantes para encaminar apropiadamente la demanda de justicia.

- Participación comunitaria en seguridad: promueve la participación activa de la comunidad en la elaboración y el control de políticas públicas en seguridad a través de la creación de espacios de intercambio denominados "mesas barriales», destinadas a buscar acuerdos para lograr mayor seguridad, más prevención y mejor trabajo policial e incentivar formas de convivencia solidarias y fraternas.

- Atención de casos y situaciones de derechos humanos en el ámbito de la jurisdicción Defensa: destinado a las personas que tomen conocimiento de un hecho que pueda significar la vulneración de derechos humanos por parte de personal militar o civil de la Defensa.

-Asignación Universal por Hijo (AUH): suma mensual no remunerativa que se paga por cada 
hije menor de 18 años o con discapacidad, sin límite de edad, a las familias que no cuentan con ingresos formales.

- Asignación por embarazo: beneficio que se abona mensualmente a las mujeres embarazadas sin cobertura de obra social.

- TV Digital Abierta (TDA): garantiza el acceso universal a la televisión de aire en alta definición sin necesidad de pagar abonos ni paquetes especiales, con una variada programación y nuevas señales que ponen al alcance de todos contenidos de entretenimiento, educativos, culturales y regionales, a través de sus señales documentales, deportivas, infantiles, musicales e informativas.

- Radicación de extranjeros: permite y facilita el acceso a la radicación en la Argentina.

- Ley Nacional de 26160 de relevamiento territorial: prohíbe los desalojos y exige llevar adelante relevamientos sobre las comunidades indígenas.

- Conectar Igualdad: una iniciativa lanzada en 2010, durante la presidencia de Cristina Fernández de Kirchner, que entrega netbooks a estudiantes de escuelas primarias y secundarias de todo el país.

\section{CAPÍTULO III}

\section{FUNDAMENTOS EPISTEMOLÓGICOS Y METODOLOGÍA}

\section{De la protección a la construcción de los derechos humanos}

Los documentos internacionales que siguieron a la Declaración Universal de los Derechos Humanos (1948) tienden a consolidar, cada vez más claramente, los deberes de los Estados para con los derechos de las personas. En 2005, la Comisión de Derechos Humanos presentó al Alto Comisionado de las Naciones Unidas (ONU) el documento «La función del buen gobierno en la promoción de los derechos humanos», donde insta a los Estados a realiza «esfuerzos para identificar y afianzar prácticas de buen gobierno» (p. 98), consciente, por un lado, «de que una gestión transparente, responsable, consecuente y participativa, sensible a las necesidades y las aspiraciones de la población, en particular los miembros de los grupos vulnerables y marginados, es el fundamento del buen gobierno» (p. 293) y, por otro, «de que la existencia de un poder judicial independiente e imparcial [...] es una condición esencial para el buen gobierno y la protección de los derechos humanos» (p. 294).

Esta postura se convierte en una premisa fundamental para llevar adelante políticas inclusivas que incorporen en los claustros académicos a sectores que tenían vedada su entrada. Como sostiene Eduardo Luis Duhalde (2007), ${ }^{24}$ al referir a políticas públicas en derechos humanos es preciso «conceptualizarlos y referenciarlos en políticas concretas, de lo contrario, son meras abstracciones» (p. 32).

Las políticas públicas en materia de Derechos Humanos comprenden los conceptos más amplios en materia de enunciación de los Derechos Humanos, estos son: los derechos civiles, políticos, económicos, sociales, culturales. La acción no es obra de una Secretaría específica de Estado, sino que la transversalidad de los derechos humanos, el carácter general que tienen en relación con las funciones del Estado, hacen que todas las áreas, en su propia acción, cuando cumplen con su obligación social, están poniendo en práctica los derechos fundamentales [...] que constituyen la base del Estado de Derecho (Duhalde, 2007, p. 32).

Se alude, de este modo, a la creación conjunta de una política de protección y de reparación, en la que deben participar el Estado y la totalidad de los miembros de la sociedad, pero, además y muy fundamentalmente, en una política activa de construcción de derechos. La política activa de construcción de derechos fue bandera fundamental de la Secretaría de Derechos Humanos de la Facultad de Periodismo y Comunicación Social (en adelante, la

24 Eduardo Luis Duhalde asumió como Secretario de Derechos Humanos de la Nación en mayo de 2003, y continuó en este cargo hasta su fallecimiento, en abril de 2012 . 
Secretaría), apoyada en una política de Estado y en una institución que la sustentaba.

En 2011, Martín Gras, ${ }^{25}$ en un congreso llevado a cabo en Chaco, ${ }^{26}$ inició su exposición llamando a convertir los compromisos internacionales, las decisiones del gobierno local y las demandas sociales en políticas públicas enfocadas desde los derechos humanos, y puntualizó que estas debían estar dotadas de sus correspondientes herramientas de planificación, gestión y desarrollo de recursos humanos. Desde su propuesta, son tres los elementos centrales que se juegan en una perspectiva de derechos humanos: el bienestar general, la lógica política y los sujetos de derecho (Gras, 2011)

La Secretaría ha asumido el planteo de Gras (2011): no restringirse al sistema jurídico positivizado, sino dotarse también de herramientas de planificación, gestión, capacitación y desarrollo de recursos humanos para el desarrollo de la política. La política activa de protección, de reparación y de construcción de derechos fue una bandera fundamental de la Secretaría.

En los procesos de gestión de políticas públicas, de acuerdo con la propuesta de Antoni Fernández (2006), se pueden apreciar los siguientes momentos:

\begin{tabular}{|c|c|}
\hline FASE DEL PROCESO & TIPO DE ANÁLISIS \\
\hline $\begin{array}{l}\text { 1. Identificacion del problema } \\
\text { ventrada en la agenda }\end{array}$ & Estructuración del problema o definición \\
\hline 2. Formulación de alternativas & Anticipación de los efectos de las diferentes \\
\hline $\begin{array}{l}\text { 3. Decisión } \\
\text { 4.Implementación } \\
\text { 5. Evaluacion }\end{array}$ & $\begin{array}{l}\text { Recomendacion o prescripción } \\
\text { Monitorilacion o descripcion } \\
\text { Evaluacion }\end{array}$ \\
\hline
\end{tabular}

Para Oscar Oszlak y Guillermo O’Donnell (1976), las políticas públicas «son un conjunto de iniciativas y de respuestas, manifiestas o implícitas, que observadas en un momento histórico y en un contexto determinado permiten inferir la posición del Estado frente a una cuestión que atañe a sectores significativos de la sociedad» (p. 113). Esta definición hace alusión explícita a una concepción relacional de las políticas, lo que implica la existencia de actores y de intereses diversos.

Podemos entender la política pública como resultado político; es decir, que las acciones y las decisiones de los gobiernos son esencialmente desenlaces, consecuencia de compromisos y de negociaciones entre actores de distintas posiciones jerárquicas que «configuran campos de relaciones sociales (relaciones de poder, que implican relaciones de fuerza en la producción instrumental y simbólica)» (Díaz, 1998, p. 78).

Las políticas públicas se relacionan con las funciones que cumplen las instituciones del Estado en la sociedad de acuerdo con las condiciones que establece el modelo o el proyecto

$25 \quad$ Martín Gras es ex miembro de la Secretaría de Derechos Humanos de la Nación, docente universitario y sobreviviente de la ex Escuela de Mecánica de la Armada (ESMA).

26 VI Congreso Argentino de Administración Pública «Gobernabilidad Democrática y Desarrollo Económico con Equidad Social», realizado en Resistencia, Chaco, del 6 al 8 de julio de 2011. político de gobierno.

Una aproximación para abordar los distintos momentos de las políticas públicas la ofrecen María Laura Pagani y Matías Manuele (2020):

- El momento inicial se identifica como la agenda de gobierno, compuesta por «el conjunto de problemas, demandas, cuestiones, asuntos que los gobernantes han seleccionado y ordenado como objetos de acción y, más propiamente, como objetos sobre los que han decidido que deben actuar o han considerado que tienen que actuar» (Aguilar Villanueva, 1993, p. 29)

- Una vez que el gobierno decide hacerse cargo de un problema, comienza el proceso de formulación de alternativas para proporcionar las soluciones. Las alternativas son opciones de política o cursos de acción alternativos, o las diferentes estrategias de intervención.

- Al momento de tomar decisiones sobre las estrategias para solucionar o para menguar el problema deben tenerse en cuenta su viabilidad y su legitimidad política.

- A continuación, viene la etapa de implementación, que constituye la puesta en acción, la ejecución de la decisión tomada en el momento anterior. Hay que prestar atención a las cuestiones burocráticas que, muchas veces, pueden perjudicar la solución.

- La evaluación, que originariamente se entendía como una etapa final y de balance sobre los resultados de la política pública, más recientemente es concebida como un proceso de carácter permanente que acompaña todo el ciclo de la política (diagnóstico, proceso resultados e impacto) y que implica el análisis del cumplimiento de las actividades y el logro de los resultados. De este modo, se la considera como acciones que generan aprendizaje institucional, ya que brindan información relevante para la posterior toma de decisiones para la implementación de posibles ajustes sobre las políticas

En efecto, lo primero que se me propone para crear la Secretaría (en ese momento Dirección), fue redactar un documento que delineara los objetivos políticos y las estrategias metodológicas de la gestión. Las autoridades me pidieron que siguiera los parámetros que orientaban el trabajo llevado a cabo desde mi organización política de base -por decirlo de alguna manera-, que era la Asociación Miguel Bru, pero también me pidieron que tuviera en cuenta que este espacio no sería una organización de derechos humanos, sino parte de una institución pública universitaria. La premisa fundamental fue la incorporación de otras voces, de un mundo diverso de actores en la construcción y la gestación de la política pública universitaria, siempre desde el diálogo de saberes.

\section{La comunicación como acción política}

En la Facultad de Periodismo y Comunicación Social de la UNLP, nos referimos a la comunicación en términos de "acción política», porque entendemos que comunicarse - 
en el sentido experiencial- es vincularse, poner en común, compartir e intercambiar. La comunicación, construida desde el diálogo de saberes, es un elemento clave en la gestión política de la Secretaría. La comunicación es asumida como un trabajo absolutamente relacionado con lo cultural, transformado en producción de mensajes, en manejo de instrumentos o canales, en construcción de estrategias informativas y en desarrollo de políticas para las prácticas organizacionales, en, desde y con les otres, para poner en práctica estrategias pedagógicas, de reclamo de justicia, de difusión y de organización para la práctica política, el vínculo y la inclusión; para habilitar la escucha, intercambiar, aprender. Fundamentalmente, entendemos a la comunicación como un campo de disputa permanente por la producción social de sentido.

En cuanto a la relación entre derechos humanos y comunicación, Rossana Reguillo (1998) plantea que esta alude a una relación cultural, «se trata fundamentalmente del debate entre la inclusión y la exclusión» (p. 1), y no solo de «una cuestión de visibilidad y de acceso a los circuitos de la comunicación masiva, por parte de los grupos y los sectores sociales que coexisten hoy en condiciones de desigualdad» (p. 17). Es decir, la comunicación no se reduce a los medios de comunicación sino que es el espacio donde se disputan sentidos sociales. En esta lucha, los actores con mayor poder simbólico pueden posicionar determinadas narrativas socioculturales como las que alimentan, por ejemplo, imaginarios sobre les jóvenes pobres como causantes de la inseguridad, sobre les indígenas como salvajes o no modernos, las trans o travestis vinculadas a la prostitución y el narcotráfico, etcétera.

De esta manera, como señala la autora, no alcanza solo con multiplicar los canales de acceso a los grandes medios por parte de los sectores excluidos «si todo ello no va acompañado de una profunda revolución simbólica que altere de manera radical nuestra mirada, es decir nuestra manera de entender el mundo» (Reguillo, 1998, p. 23). Tampoco si no se abre y se gana el debate entre la inclusión y la exclusión que encierra la perspectiva de comunicación y derechos humanos para que estos sectores logren la legitimación de la palabra propia.

[...] el mejor antídoto contra la violación sistemática a los derechos humanos desde la comunicación estriba en la posibilidad de intervenir directamente en la ruptura de las representaciones asumidas como «orden natural» $y$ develar así el disfrazamiento simbólico que construye a ciertos actores y ciertos espacios para representar acciones que se rechazan (Bartra, 1996), convirtiendo la desigualdad estructural en un problema de diferenciación cultural (Reguillo, 1998, s/p)

La comunicación representa el espacio donde cada quien pone en juego sus posibilidades de construirse con otres. La comunicación, entendida como disputa por el sentido y hecho cultural, como espacio de interacción entre sujetos y como práctica social. Esta perspectiva resulta clave para la comprensión de la comunicación como hecho y matriz cultural. Por eso, es pertinente valerse de una categoría elaborada por Alcira Argumedo (1996): las matrices de pensamiento. «El punto de partida de una matriz de pensamiento está dado por la forma en que concibe a lo social. El concepto de sociedad conlleva una determinada visión acerca de la naturaleza humana y es el núcleo de los esquemas de pensamiento» (Argumedo, 1996, p. 79)

Las matrices de pensamiento son formas de sistematizar concepciones del mundo, idearios y aspiraciones. Expresan procesos sociales, políticos, económicos y culturales, y tienden a inferir en las realidades y en los conflictos. Incluyen valores y criterios, definiciones, postulados y métodos, pero no constituyen la única forma de conocimiento social.

El concepto «matriz de pensamiento» es fundamental para identificar los parámetros que determinan cómo se construye el conocimiento sobre la realidad y, en función de ello, gestionar su transformación. Sobre los aconteceres académicos, Argumedo (1996) señala que se hace una lectura de los contextos político-culturales de cada época, y remarca que en las ciencias sociales las corrientes hegemónicas no permiten que emerjan todas las voces de los protagonistas de la historia. Al momento de pensar la historia popular de América Latina y la nuestra propia, la autora advierte: «Internarse en las sendas de la memoria - de la memoria colectiva o individual- es algo que conmociona, que nos hace preguntar sobre las infinitas combinaciones de azares cuyas leyes entrelazan las vidas personales con las historias sociales» (Argumedo, 1996, p. 7).

La autora se refiere a una matriz latinoamericana de pensamiento popular, encabezada por líderes populares, al tiempo que señala que los contextos políticos culturales de cada época hacen una lectura propia sobre los aconteceres académicos. «Planteamos un concepto de totalidad que, sin caer en totalizaciones reduccionistas, sea capaz de develar los silencios de las corrientes hegemónicas en la ciencias sociales y de hacer emerger las voces de otros protagonistas de la historia» (Argumendo, 1996, p. 77).

Esas voces que emergen abren lugares de visibilidad y de inclusión que, especialmente en el campo académico, habían sido vedados. Tal fue el objetivo de la gestión de la Secretaría: introducir, entrelazar esas voces en y con los claustros académicos, y pensar una universidad al servicio de todo el pueblo como la que habían proyectado les compañeres de los setenta antes de los años de plomo del terrorismo de Estado.

Precisamente, una de las primeras políticas de gestión de la Secretaría tuvo por objetivo incluir voces excluidas de los claustros universitarios, para lo cual el gobierno nacional creaba el contexto apropiado. El ejemplo cabal es que Rosa Schonfeld de Bru -que a duras penas había llegado a completar la escuela primaria-, en 2006 fue distinguida por la Universidad Nacional de La Plata con el título "Doctora Honoris Causa». El hecho, impensable en épocas anteriores, en las que tal nombramiento se destinaba a eruditos del establishment académico, marcó la línea política de la Facultad, fundada en las epistemologías del barro y en el diálogo de saberes.

Los hechos históricos que atravesaron nuestra experiencia política, sumados a la 
formación teórica en una Facultad marcada por un pasado de luchas y de fuertes debates políticos, instalaron en la gestión de la secretaría prácticas concretas de valoración de los derechos humanos. Las matrices de pensamiento, en efecto, nos permiten encontrar rupturas y continuidades históricas en el debate político de nuestro tiempo; son formas de reelaboración y de sistematización conceptual de determinados modos de percibir el mundo que se desarrollan en procesos históricos y en experiencias políticas determinadas.

\section{Los usos de la memoria}

En la política de gestión desarrollada por la Secretaría el significado del concepto memoria es muy importante, sobre todo teniendo en cuenta la visión dinámica con que la ponemos en práctica, íntimamente ligada con las matrices de pensamiento que la motorizan y con la disputa simbólica por el sentido que la define. La memoria es inevitable, es una necesidad histórica, un imperativo ético y un recurso político, no solo en función del pasado (para recordar, saber lo que pasó y que se haga justicia), sino también en función del futuro (para que no vuelva a suceder). La memoria implica verdad y la verdad no debería implicar otra opción que no sea la justicia (el norte de nuestras luchas).

Memoria e historia se construyen desde los interrogantes y las necesidades del presente, pero la primera tiene un distintivo singular, «llama», «despierta», reorganiza lo vivido, aquello experimentado directamente desde y con el cuerpo. La memoria arranca de una inscripción hecha en el cuerpo individual o social, de una «marca» que incluso ha desaparecido de la superficie, permanece allí como un desconector y conector de la memoria (Calveiro, 2005, p. 33).

Desde la Secretaría, tratamos de recuperar los relatos memoriales de las víctimas y los hechos, que cumplen la importante tarea de poner en relación el pasado con el futuro a través del presente. La memoria es una fuerza trascendental para la transformación de las sociedades y para el cambio de rumbo de la historia, debido a que consigna huellas, impresiones, marcas y fracturas en las vidas de los pueblos y de los individuos. Está hecha de narraciones plurales diversas, cuya selección y posterior almacenamiento permitirán resaltar aquello que le dará sentidos individuales y colectivos, y actuar con intencionalidad política frente al futuro.

Al hablar de memoria nos referimos a lo comunicativo, lo dramático, lo sociológico, lo colectivo, lo histórico y lo práctico como diferentes dimensiones sobre las que reflexionar. En este sentido, Elizabeth Jelin (2013) sostiene:

Las marcas institucionales, territoriales y simbólicas explícitamente ancladas en el pasado reciente de violencia y de represión han proliferado en el mundo contemporáneo. Se trata de expresiones producidas por actores y por movimientos sociales diversos y por políticas estatales que responden a las demandas de estos actores sociales; algunas veces, surgen de iniciativas gubernamentales propias. La justificación de estas manifestaciones es diversa, e incluye procesos individuales y grupales (expresión y elaboración de sufrimientos vividos, solidaridad con víctimas, homenaje a quienes ya no están) y argumentaciones y creencias que ligan el «deber de memoria» con la construcción de futuros más democráticos, sin violencias. En este segundo caso, el énfasis está puesto en la preocupación por los legados y por la transmisión a las nuevas generaciones, lo que podríamos llamar la dimensión «pedagógica» de la memoria (p. 129).

Esta dimensión pedagógica y un tiempo de políticas públicas con fuerte acento en el proceso de memoria -como el que atravesaba el país durante el período seleccionado-, son claves que aportan para explicar la sistematización de esta experiencia.

Si bien Jelin (2013) sostiene que nadie nos puede asegurar que el simbolismo se mantenga en el tiempo o que pase a formar parte del mobiliario urbano, es en esa disputa y en esa lucha permanente por el sentido donde tiene lugar el debate, y así como la única forma de garantizarlo está en nosotres, la tarea fundamental es demarcar esas huellas. Esta disputa simbólica fue la denominada «batalla cultural» que todes entendimos que debíamos militar más que nunca a partir de un gobierno que sentíamos nos representaba y la encabezaba, con Néstor Kirchner, primero, y con Cristina Fernández, luego.

La instalación del paradigma de los derechos humanos en los años setenta en el mundo, todo el conjunto de organizaciones y de activismo que reclama por los crímenes cometidos durante las dictaduras, es caracterizado y denominado movimiento de derechos humanos. Como consecuencia, al menos en la Argentina, la expresión «derechos humanos» quedó pegada a la dictadura. Pero es sabido que la noción de derechos humanos es mucho más amplia, y la pregunta que queda abierta es bajo qué condiciones la atención prestada a la memoria de las dictaduras ayuda u obstruye la aceptación social y estatal de una concepción amplia de los derechos humanos, que incorpore una perspectiva universal de derechos civiles y políticos, pero también económicos, sociales y culturales, individuales pero también de incidencia colectiva (Jelin, 2013, p. 135)

Esta situación fue una constante a lo largo de nuestra historia: trabajar la política de derechos en su amplitud y diversidad, que, sin dudas, se vio beneficiada por la «era de ampliación de derechos» de la política de gobierno y, muy fundamentalmente, por la decisión política de juicio y castigo a los genocidas. Sin duda, ver a los responsables de crímenes de lesa 
humanidad caminando impunemente, suponía una traba muy importante para pensar en otra diversidad de derechos colectivos y en sus políticas de memoria (violencia institucional en democracia, Malvinas, comunidades indígenas, próceres de nuestra historia, mujeres, diversidad sexual, personas privadas de libertad, etc.). Como sostiene Michael Pollak (1989), una acción de las memorias colectivas no desde una visión pasiva o dada, sino sobre sus procesos de construcción simbólica. Esto implica incorporar a distintos actores sociales marginados y excluidos a las disputas y a las negociaciones de sentidos de su propio pasado

Les argentines se han dado, sobre todo a partir de la lucha de los organismos de derechos humanos, su propia construcción y reconstrucción de la memoria tras el genocidio de la última Dictadura cívico militar eclesiástica. Los procesos que han preservado el recuerdo y que han evitado el olvido de las víctimas de la represión son complejos y de un doble movimiento, en el que el olvido suele colarse por entre las diversas fuerzas que aportan en pos del recuerdo. El compromiso, como motor de la recuperación de la memoria, se hace necesario en toda la comunidad universitaria.

Al respecto, Raquel Robles (2004), hija de desaparecidos, miembro y cofundadora de la agrupación H.I.J.O.S., sostiene:

No es posible tener la memoria de una persona con recuerdos, tan pocos, tan breves, tan frágiles. Entonces, hay que empezar la ardua tarea de reconstruir quiénes fueron esas personas que fueron mis padres. Qué querían, qué les gustaba, qué eran además de papá y mamá, cuál era su lucha, quiénes sus compañeros, por qué cosas se peleaban, qué canciones les gustaban, qué libros leían, qué cosas odiaban, qué los convocaba. Una tarea que está más cerca del periodismo de investigación que de las preguntas que una hija hace a sus padres.

Y una sociedad que tiene treinta mil desaparecidos debe darse también esta tarea. Debe saber dónde yacen sus muertos, quiénes eran esos muertos cuando estaban vivos; porque ninguna sociedad podrá sobrevivir si no se les da identidad a sus muertos, si no es capaz de resucitar la memoria de los que no están. ${ }^{27}$

Las víctimas directas e indirectas nunca renuncian a sus exigencias de verdad y justicia ni los pueblos que han vivido épocas de horror y de desesperanza deponen su derecho a saber, y como la memoria es inevitable, muchas veces, reaparece en el devenir de las ciudades, a veces en forma de libros, de fotografías, de cine, en fin, de manifestaciones artísticas. La memoria siempre ha servido como estrategia política para exorcizar el olvido

27 Discurso brindado por Raquel Robles en la mesa académica «Memoria, verdad y reparación», en el marco del intercambio cultural «Buenos Aires y Medellín se miran y se encuentran», realizado en Medellín, Colombia, en y para construir algún futuro deseable. En palabras de Jelin (2013):

El pasado es un objeto de disputa, donde actores diversos expresan y silencian, resaltan y ocultan distintos elementos para la construcción de su propio relato. Lo que encontramos es una lucha por las memorias, lucha social y política en la que se dirimen cuestiones de poder institucional, simbólico y social. A su vez, los fenómenos de memoria se manifiestan en distintos planos de la vida social: el plano institucional, el cultural, el subjetivo (p. 141).

\section{La epistemología de la esperanza}

Al comprender la comunicación como el análisis de los modos en los que se disputa la construcción social de sentidos, Florencia Saintout y Andrea Varela (2014) se posicionan filosóficamente desde una epistemología de la esperanza que, en sintonía con las epistemologías del sur planteadas por Boaventura de Sousa Santos, da cuenta de los modos emancipadores de las sociedades que van a contrapelo de lo que parecería, para algunes, un ineludible destino latinoamericano.

Tal vez sea el momento de pensar en una epistemología de la esperanza.

Un punto de vista que no solo vea lo que se ha destruido y lo que falta, sino

lo que está naciendo en un sentido emancipador. Que vea aquello que no había muerto, que estaba como murmullo o como hormigueo silencioso, amordazado, moviéndose subterráneamente. 0 que por momentos estaba quieto, que simplemente esperaba. O que aparece como nuevo, como creación y como excepción. Como tiempo emergente (Saintout \& Varela, 2014, p. 113).

Ese planteo nos guía para construir un modelo académico que recupera teorías disruptivas, a partir de asumir las diversas culturas como sujetos de conocimiento, en encuentros y en intercambios que ponen en común cosmovisiones, saberes y prácticas emergentes del territorio. Como sostiene Vanesa Arrúa (2006): «Los diálogos entre diferentes saberes y perspectivas ["otras voces", "otras ideas", "otros sentidos"] son la oportunidad de alcanzar síntesis novedosas; aportes más concretos en los procesos de "encuentro con lo propio"» (p. 24).

Efectivamente, esto es lo que se hizo en el desarrollo de la política de la Secretaría, a lo largo de la gestión. Desde los ejes «Memoria y Dictadura», «Violencia Institucional en democracia», «Periodismo con perspectiva en derechos humanos», «Derechos de la mujeres», "Diversidad sexual», «Pueblos indígenas» y «Extensión áulica en cárceles», siempre articulamos con les propies protagonistas la escucha, el diálogo de saberes y la valoración de otros modos de estar en el mundo. 


\section{El diálogo de saberes}

El diálogo de saberes ha sido clave en el proceso de planificación y de gestión de la Secretaría. La premisa guía es que «todos los sujetos son sujetos de conocimiento». Desde esta perspectiva, las biografías y los saberes producidos en medio de diferentes realidades y experiencias son valorados como académicamente fundamentales para la construcción de nuevos sentidos.

Fue necesario sortear una importante resistencia: lo que De Sousa Santos (2006) llama la «monocultura». Se trata de la naturalización - propia de la ciencia occidental- de las diferencias que ocultan jerarquías, a la que hay que sustituir por «ecologías del saber» que eviten «epistemicidios» (la muerte de conocimientos alternativos).

La primera [resistencia] es la monocultura del saber y del rigor: la idea de que el único saber riguroso es el saber científico y que, por lo tanto, otros conocimientos no tienen la validez ni el rigor del conocimiento científico. Esta monocultura reduce de inmediato, contrae el presente, porque elimina mucha realidad que queda afuera de las concepciones científicas de la sociedad, porque hay prácticas sociales que están basadas en conocimientos populares, conocimientos indígenas, conocimientos campesinos, conocimientos urbanos, pero que no son evaluados como importantes o rigurosos. Y como tal, todas las prácticas sociales que se organizan según este tipo de conocimientos no son creíbles, no existen, no son visibles (De Sousa Santos, 2006, p. 23).

Al respecto, en Paraíso (2018), Retola afirma:

Todavía persisten las huellas de la colonia en nuestros modos de conocer y de construir el mundo. Existe una participación en la construcción de conocimientos que aún es dependiente de modelos, teorías, nociones y métodos pensados en Europa o en Estados Unidos. Esa dependencia, es claro, detiene la emancipación. Desde hace siglos, los modos de hacer ciencia han estado supeditados a paradigmas europeizantes, consolidando una epistemología descontextualizada de las culturas latinoamericanas ( $p$. 122).

Lo anterior puede graficarse mediante una frase de Joaquín V. González, fundador de la Universidad de La Plata: «Felizmente, las razas inferiores han sido excluidas de nuestro conjunto orgánico; por una razón o por otra, nosotros no tenemos indios en una cantidad apreciable, ni están incorporados a la vida social argentina» (en Retola, 2018, p. 122).

En el primer momento de la gestión, tuvimos que trabajar internamente con docentes y con estudiantes desde una ecología más amplia de saberes, «para que el saber científico pueda dialogar con el saber laico, con el saber popular, con el saber de los indígenas, con el saber de las poblaciones urbanas marginales, con el saber campesino, etc.» (De Sousa Santos, 2006, p. 26).

En esta línea, desde la Secretaría incorporamos, desde un principio, la política indígena de la mano de Pascual Pichún Collonao, estudiante de la Facultad, ciudadano mapuche, hijo de un Lonko (cacique, jefe de la comunidad), que estaba prófugo de la justicia chilena porque le habían aplicado la "Ley Antiterrorista» ${ }^{28}$ en el marco de reclamos a una empresa multinacional de Temuco por la tierra de su comunidad; la instalación de la Chakana (cruz andina), de la mano de la familia de nuestra estudiante indígena Emili Uscamayta Curi, en el centro neurálgico del patio de la facultad; la capacitación en periodismo con perspectiva de derechos humanos, que organizamos con la APDH La Plata, solo para mencionar algunos de los ejemplos que desarrollaremos en el capítulo siguiente.

No hay ninguna cultura que sea completa, y entonces hay que hacer traducción para mirar la diversidad sin relativismo, porque los que estamos comprometidos con cambios sociales no podemos ser relativistas. Pero hay que captar toda la riqueza para no desperdiciar la experiencia, ya que sólo sobre la base de una experiencia rica, no desperdiciada, podemos realmente pensar en una sociedad más justa (De Sousa Santos, 2006, p. 34).

En esa línea, incorporamos muchos diálogos:

- con Flavio Rapisardi, especialista del Instituto Nacional contra la Discriminación, la Xenofobia y el Racismo (INADI) en cuestiones de exclusión y de discriminación;

- con Antonia Portaneri, quien fuera miembro del área Mujer de la Cancillería Argentina y, actualmente, vicepresidenta de Télam, la Agencia Nacional de Noticias;

- con Madres y Abuelas de Plaza de Mayo, H.I.J.O.S., víctimas y familiares de víctimas del terrorismo de Estado, para confeccionar actas de nuestres desparecides y proyectar una política institucional en materia de memoria y Dictadura;

- con Claudia Vásquez Haro, estudiante, luego docente y militante trans, para construir en conjunto y bajo su conducción la política de diversidad;

- con Rosa Schonfeld de Bru, y otras madres y padres de víctimas de la violencia institucional en democracia, para delinear y para construir la política de ese eje;

- con privades de libertad, para construir juntes la política de inclusión educativa en cárceles;

28 La Ley 18314, que determina conductas terroristas y fija su penalidad, más conocida como «Ley Antiterrorista», es una ley chilena que tiene por objeto tipificar conductas o delitos terroristas y establecer penas Augusto Pinochet el 16 de mayo de 1984, es una ley muy criticada debido a que se usa para criminalizar a las comunidades mapuches. 
- con periodistas con perspectiva de derechos humanos, para producir relatos y noticias.

- con Zulema Enríquez, docente quechua, para que encabece la Dirección de Pueblos Indígenas de la Facultad.

Esto nos permitió hacer ecología de saberes hacia el interior de la Universidad, una especie de extensión universitaria a la inversa, en vez del concepto tradicional de llevar la universidad hacia afuera, la ecología de saberes supone «traer otros conocimientos hacia adentro de la universidad» (De Sousa Santos, 2005, p. 38)

Tal vez no se sepa con certeza, advierte De Sousa Santos (2006), si los derechos humanos actuales «son un legado de las revoluciones modernas o las ruinas de esas revoluciones, $s$ tras ellos hay una fuerza revolucionaria de emancipación o una fuerza contrarrevolucionaria» (p. 30). Pero a la pregunta acerca de si los derechos humanos son funcionales a las luchas de los excluidos, la gestión llevada adelante por la Secretaría de Derechos Humanos de la Facultad de Periodismo y Comunicación Social -casi de manera contrahegemónica- ha podido ampliar derechos hacia lo colectivo y lo comunitario.

\section{El instrumento metodológico}

Nuestro conocimiento de la experiencia nunca se agota. Es más, un proceso de sistematización ya va a formar parte de la experiencia y por lo tanto será un nuevo factor de aprendizaje.
Muchas veces las conclusiones de una sistematización de experiencia se convierten en base de un plan de acción futura.

Oscar Jara Holliday (2018)

La metodología utilizada fue la sistematización en correlación con la experiencia. Se trata, de acuerdo con Oscar Jara Holliday (2018), de un proceso de reflexión y de interpretación teórica «sobre la práctica y desde la práctica, desde las condiciones particulares de nuestra realidad compleja y diversa» (p. 27), que se desarrolla mediante la reconstrucción y el ordenamiento de «experiencias que son colectivas, están en permanente movimiento y abarcan un conjunto de dimensiones objetivas y subjetivas de la realidad históricosocial» (p. 52). Y agrega: extraer aprendizajes y compartirlos, "posibilita que los sujetos de las experiencias podamos, gracias a la sistematización, apropiarnos críticamente de su sentido» $(2018$, p. 62)

La sistematización, como señala Jara Holliday (2018), pese a que puede tener muchos objetos de interés, tiene un carácter preciso. En efecto, la sistematización no permite generalizaciones ni universalizaciones, pero sí posibilita un primer nivel de teorización básica y un diálogo crítico con el conocimiento teórico. Al mismo tiempo, Jara Holliday (2018) sostiene que la sistematización de experiencias trasciende las situaciones particularistas y da cuenta de los aspectos que conforman en sí toda una globalidad que permite abordarlos

\section{e interpretarlos.}

En tal sentido, la sistematización propone comunicar y difundir las experiencias, dar cuenta de sus relaciones con procesos similares, compartirlas en forma práctica con universos más amplios, desarrollar programas y proyectos de gestión similares, y ordenar las acciones, los procesos y las vivencias.

[Mediante] la sistematización trabajamos con experiencias particulares, necesitamos contar con criterios rigurosos de aproximación a la realidad histórico-social, que tengan validez y confiabilidad. Un camino metodológico que incluya instrumentos adecuados que permitan reconstruir y describir de la manera más concreta, detallada y precisa posible; pero no para terminar allí, sino para poder hacer una interpretación, lo cual supone una postura teórica y epistemológica que valora tanto lo descriptivo como lo interpretativo (Jara Holliday, 2018, p. 77)

Producir conocimientos profundos y críticos de la realidad a través de la sistematización de experiencias se consigue, en efecto, con tres núcleos fundamentales: la historia, la cronología y las condiciones subyacentes que atravesaron las experiencias.

Se trata de una interpretación de la lógica de dicho proceso: de cómo y por qué los distintos factores objetivos y subjetivos se relacionaron de determinada manera a lo largo de la experiencia; cuáles fueron los factores más activos y determinantes, cuáles los más dependientes o secundarios; qué continuidades, discontinuidades, contradicciones y rupturas se dieron en el proceso y por qué se dieron. Qué fases o etapas tuvo la experiencia y por qué fue posible que se pasara de una a otra. Sistematizar significa clasificar, ordenar datos e informaciones, pero cuando se investigan procesos sociales se amplía su significado en razón de interpretar críticamente las experiencias para orientarlas hacia un futuro con perspectiva transformadora (Jara Holliday, 2018, p. 61)

En palabras de Germán Retola (2018), «la sistematización ofrece condiciones para reflexionar sobre las perspectivas que fecundan las prácticas de transformación, y así las fortalece y las reorienta en nuevos sentidos que, en comunicación con otras prácticas, incluyen los enfoques de género y de etnicidad como también la multiculturalidad y lo intergeneracional» (p. 223).

La sistematización de experiencias toma en cuenta la dinámica de los procesos históricos y sociales en los que intervienen de manera interrelacionada, inédita e irrepetible, factores objetivos y subjetivos (situaciones particulares, acciones intencionadas, reacciones, intuiciones, percepciones, interpretaciones, emociones.) 
Produce un conocimiento que potencia la propia práctica con un sentido transformador. Se trata de una mirada a la experiencia vivida pero no para quedarse en el pasado, sino para proyectarse hacia el futuro. Es una producción de conocimiento para la acción transformadora, que es posible en la medida que comprendemos mejor el entramado de relaciones que explican nuestro quehacer. Al poder identificar los factores que las dificultan o facilitan, así como las principales fuerzas en tensión, los protagonistas de las prácticas obtenemos nuevas o mejores pistas de cómo y dónde enfatizar para producir cambios, superar resistencias, generar sinergias, enfrentar otras propuestas y tendencias y, así, proyectar nuevos horizontes de más largo alcance o de más amplia perspectiva. En ese sentido, potencia nuestras capacidades y responsabilidades como personas, como sujetos protagonistas de la historia que queremos edificar (Jara Holliday, 2018, p. 63)

Jara Holliday (2018) propone, los siguientes momentos en la sistematización

- Realizar la reconstrucción histórica.

Ordenar y clasificar la información.

Reconstruir de forma ordenada lo que sucedió, tal como pasó

- Identificar etapas, cambios, momentos significativos de todo el proceso.

- Clasificar la información disponible de acuerdo con algunas categorías o variables.

Organizar la información de forma clara y visible.

Basarse en todos los registros posibles.

Determinar las categorías y las variables para ordenar.

Realizar análisis y reflexiones críticas.

Para sistematizar las experiencias de la Secretaría se aplica la matriz de reconstrucción histórica propuesta por Jara Holliday (2018). En ella se identifican los siguientes datos: fecha, actividad, participantes, objetivos, metodología, resultados, contextos y fuentes. En tanto, las fuentes que proveen a la matriz son: documentos políticos, adhesiones a actividades, notas periodísticas, producciones comunicacionales (gráficas, audiovisuales y radiales), proyectos de extensión y de investigación gestionados por la Secretaría, entrevistas e informes de gestión presentados ante el Consejo Directivo de la Facultad. Estos insumos se transforman en un aporte invalorable para establecer la línea de tiempo y el desarrollo temático de cada eje de trabajo de la gestión para explicar, a partir de ahí, el entramado que la constituye y para dar cuenta de las situaciones subyacentes que la hicieron posible.

\section{CAPÍTULO IV}

\section{EL PROCESO VIVENCIADO}

\section{DESDE EL DIÁLOGO DE SABERES}

La Ecología de Saberes es traer otros conocimientos hacia adentro de la universidad.

Boaventura de Sousa Santos (2005)

La trama de relaciones que subyace a la matriz de sistematización del proceso de gestión de la Secretaría de Derechos Humanos de la Facultad de Periodismo y Comunicación Social parte fundamentalmente, de la articulación con los territorios para promover el cambio social. No solo para pensarlos, como sostiene Boaventura de Sousa Santos (2005), en el sentido tradicional de la extensión universitaria de ir hacia ellos, sino en el sentido inverso, para pensar cómo esos diversos actores territoriales se apropian y se incluyen dentro de los claustros universitarios.

Para este tipo de política pública universitaria, es fundamental establecer un diálogo de saberes ya que el proceso comunicacional ocupa un lugar trascendental, que permite que las diversas comunidades se incluyan en un intercambio dialogado, se construya ciudadanía y se compartan los conocimientos y las experiencias.

Teniendo en cuenta el objetivo de realizar una interpretación de la experiencia de esta política de gestión, para analizarla, difundirla y mejorarla, el primer paso fue construir una matriz de sistematización que permita ordenar, precisar y reconstruir, en este caso cronológicamente, las características de cada período de gestión.

Fue clave para su desarrollo el curso-taller de sistematización de experiencias dictado por el educador popular Oscar Jara Holliday en la Universidad Nacional de La Plata, en abril de 2019. Construir una matriz de sistematización implica un esfuerzo de clasificación, de búsqueda de materiales, de construcción de un camino metodológico que permita pasar de la descripción concreta, detallada y precisa a la interpretación. Supone una postura teórica y epistemológica que valora tanto lo descriptivo como lo interpretativo y que se realiza sobre la base de un ordenamiento y de una reconstrucción organizada del proceso a analizar. Ese es el sentido de insumo que aporta la confección de una matriz de sistematización cronológica, a partir de la cual tomar distancia para desarrollar el análisis.

La exposición que aquí se presenta se divide en tres etapas, delimitadas por las tres gestiones que abarca el periodo estudiado (las dos primeras, de tres años de duración, y la tercera, de cuatro años) y se organiza en función de los principales ejes temáticos trabajados y señalados: Pedagogía en comunicación y derechos humanos, Narrativas con perspectiva en derechos humanos, Memoria y dictadura, Violencia Institucional en democracia, Diversidad sexual, Derechos de las mujeres, Educación en cárceles y Pueblos indígenas.

Resta señalar que el desarrollo de los ejes no supone un orden de prioridad, ya que todos tienen la misma importancia y se complementan.

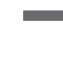


Desarrollo de la Matriz de Sistematización

1er Periódo de gestión

\begin{tabular}{|c|c|c|c|c|c|c|c|}
\hline Fecha & Actividad & Participantes & Objetivos & Metodología & Resultado & Contexto & Fuentes \\
\hline 2004 & $\begin{array}{l}\text { Se crea la Dirección de } \\
\text { DDHH en la FP y CS. }\end{array}$ & $\begin{array}{l}\text {-Director de DDHH } \\
\text {-Decano } \\
\text {-Consejo Directivo FP y CS. } \\
\end{array}$ & $\begin{array}{l}\text {-Desarrollar políticas de } \\
\text { DDHH en y desde la } \\
\text { Universidad Pública en la } \\
\text { Facultad de periodismo y } \\
\text { Com Social }\end{array}$ & $\begin{array}{l}\text {-Escritura y presentación } \\
\text { del proyecto. } \\
\text {-Ponerlo en diálogo con } \\
\text { decanato. } \\
\text { - Votación y aprobación en } \\
\text { el Consejo Directivo. }\end{array}$ & $\begin{array}{l}\text {-Se aprueba el proyecto de } \\
\text { creación de la Dirección de } \\
\text { DDHH de la FP y CS. UNLP } \\
\text {-Me nombran Director }\end{array}$ & $\begin{array}{l}\text {-Presidencia Néstor Kirchner, } \\
\text { convierte a los DDHH en } \\
\text { política de Estado. } \\
\text {-Nulidad de las leyes del } \\
\text { perdón (2003) } \\
\text {-incorpora a los organismos } \\
\text { y a las organizaciones de } \\
\text { DDHH a la política pública. }\end{array}$ & $\begin{array}{l}\text {-Documento de creación de } \\
\text { Dirección de DDHH. } \\
\text {-entrevistas } \\
\text { - Resolución (no } 88 / 2004) \\
\text { del CD de la FP y CS. } \\
\text { UNLP. }\end{array}$ \\
\hline 2004 & $\begin{array}{l}\text { Curso extracurricular de } \\
\text { Periodismo y Derechos } \\
\text { Humanos La Plata, dirigido a } \\
\text { alumnes avanzades de la Lic. } \\
\text { En Comunicación Social. }\end{array}$ & $\begin{array}{l}\text {-Organizado por Dirección de } \\
\text { DDHH de la Facultad de } \\
\text { Periodismo y Comunicación y } \\
\text { APDH La Plata, Asamblea } \\
\text { Permanente por los DDHH } \\
\text {-Estudiantes avanzados de la } \\
\text { carrera de Licenciatura en } \\
\text { Comunicación Social } \\
\text { - Activistas y periodistas } \\
\text { profesionales especialistas en } \\
\text { las temáticas: Edna Ricceti, } \\
\text { Madre de Plaza de Mayo y } \\
\text { Jaime Glüzmann de la APDH } \\
\text { La Plata. } \\
\text { Ricardo Rajendorfer, periodis- } \\
\text { ta y escritor. } \\
\text { Enrique Symms, periodista y } \\
\text { escritor. } \\
\text { Néstor Maldonado, periodista } \\
\text { y miembro del Sindicato de } \\
\text { Prensa Bonaerense. } \\
\text { Victoria Guinsberg. Periodista } \\
\text { de Página } 12 \text {. } \\
\text { Hernán Brienza, periodista y } \\
\text { escritor. } \\
\text { Rosa Bru y Alberto Mendoza, } \\
\text { integrantes de la Asociación } \\
\text { Miguel Bru. } \\
\text { Flavio Rapisardi. Politólogo y } \\
\text { Profesor en Filosofía de la } \\
\text { UBA. } \\
\text { Liliana Daunes. Periodista y } \\
\text { escritora. } \\
\text { Cecilia Cerasso, Secretaría de } \\
\text { Planificación y gestión para la } \\
\text { comunidad. }\end{array}$ & $\begin{array}{l}\text { Desarrollar capacidades } \\
\text { para practicar periodismo } \\
\text { con perspectiva de DDHH } \\
\text { en los siguientes temas : } \\
\text { Historia de los organismos } \\
\text { de DDHH, Violencia } \\
\text { Institucional-policial,Cri- } \\
\text { minalización de la pobreza, } \\
\text { Conflictos laborales en el } \\
\text { ejercicio de la profesión, la } \\
\text { cobertura de noticias de } \\
\text { DDHH, el caso Von } \\
\text { Wernich, el caso Bru, } \\
\text { discriminación y diversida- } \\
\text { des culturales, Género y } \\
\text { medios de comunicación, } \\
\text { comunicación Alternativa } \\
\text { y Derechos Humanos. }\end{array}$ & $\begin{array}{l}\text { Consistió en } 11 \text { encuentros } \\
\text { de tres horas cada uno, } \\
\text { durante los meses de } \\
\text { Septiembre, Octubre y } \\
\text { Noviembre, en donde se } \\
\text { abordaron los temas } \\
\text { mencionados. Les estudian- } \\
\text { tes tenían que elegir un tema } \\
\text { dictado y elaborar una nota } \\
\text { periodística, para la aproba- } \\
\text { ción del curso, además de } \\
\text { tener el } 80 \% \text { de asistencia. } \\
\text { Les especialilstas en cada eje } \\
\text { temático daban una charla y } \\
\text { luego se pasaba al espacio de } \\
\text { preguntas. }\end{array}$ & $\begin{array}{l}\text { Un gran número de asisten- } \\
\text { tes al seminario. } \\
\text {-afianzamiento de los lazos } \\
\text { con la Asamblea Permanente } \\
\text { de DDHH de La Plata. } \\
\text {-Lucas Miguel, secretario de } \\
\text { prensa de APDH, es el que } \\
\text { va a dictar el eje memoria y } \\
\text { dictadura en el futuro } \\
\text { seminario de Com y DDHH. } \\
\text {-Una alumna, Luciana } \\
\text { Burgos, quien realiza el } \\
\text { mejor trabajo final del } \\
\text { seminario es elegida para ser } \\
\text { becada de la Dirección de } \\
\text { DDHH y pasa a trabajara en } \\
\text { la oficina. } \\
\text { - La articulación permite } \\
\text { fomentar la comunicación y } \\
\text { por ende la relación de la } \\
\text { Facultad, con activistas y } \\
\text { periodistas referentes a nivel } \\
\text { nacional en esas temáticas } \\
\text { específicas de periodismo y } \\
\text { DDHH }\end{array}$ & $\begin{array}{l}\text { Se cumple un año de la } \\
\text { asunción de Nestor Kirchner } \\
\text { y su política de gobierno } \\
\text { genera un profundo debate } \\
\text { en materia de DDHH y } \\
\text { también como parte del } \\
\text { mismo, el periodismo con } \\
\text { perspeciva de DDHH. }\end{array}$ & Informes de Gestión. \\
\hline
\end{tabular}




\begin{tabular}{|c|c|c|c|c|c|c|c|}
\hline Fecha & Actividad & Participantes & Objetivos & Metodología & Resultado & Contexto & Fuentes \\
\hline $2004 / 2007$ & $\begin{array}{l}\text { Armado del listado de } \\
\text { víctimas del Terrorismo de } \\
\text { Estado de la FP y CS. }\end{array}$ & $\begin{array}{l}\text {-Madres y Abuelas de Plaza } \\
\text { de Mayo. } \\
\text {-Familiares de detenidos } \\
\text { desaparecidos } \\
\text {-Hijes de víctimas } \\
\text { - integrantes de la Dir. de } \\
\text { DDHH, FP y CS. }\end{array}$ & $\begin{array}{l}\text {-Aportar a la reconstrucción } \\
\text { de la memoria colectiva de lo } \\
\text { acontecido con el Terrorismo } \\
\text { de Estado en la Facultad. } \\
\text {-Vincular a la facultad con los } \\
\text { organismos de DDHH } \\
\text {-Vincular a la facultad con les } \\
\text { familiares de las víctimas } \\
\text {-Vincular a la facultad con ex } \\
\text { estudiantes de esa época. }\end{array}$ & $\begin{array}{l}\text {-Entrevistas a familiares de } \\
\text { víctimas } \\
\text {-Lectura de material bibliográfi- } \\
\text { co. } \\
\text {-Entrevistas con ex alumnes. } \\
\text {-Revisar fichas y libros de } \\
\text { actas administrativas. } \\
\text {-Revisión deactas de denun- } \\
\text { cias de organismos de DDHH } \\
\text { (APDH La Pata) } \\
\text {-Reuniones con Madres y } \\
\text { Abuelasde Plaza de Mayo de } \\
\text { La Plata. }\end{array}$ & $\begin{array}{l}\text { Se completaron los listados } \\
\text {-Se recogió información } \\
\text { sobre nuestras víctimas } \\
\text {-Nos conectamos con los } \\
\text { familiares y conmpañeres de } \\
\text { estudies y de militancia. } \\
\text {-Articulamos la actividad } \\
\text { con los organismos históri- } \\
\text { cos de DDHH }\end{array}$ & $\begin{array}{l}\text {-Comienzan los juicios y las } \\
\text { condenas a los genocidas. } \\
\text {-Los organismos históricos y } \\
\text { las organizaciones de } \\
\text { DDHH se incorporan a las } \\
\text { políticas de Estado } \\
\text {-Empieza la denominada } \\
\text { "época de restitución de } \\
\text { derechos". }\end{array}$ & $\begin{array}{l}\text {-Madres y Abuelas de Plaza de } \\
\text { Mayo } \\
\text {-Hijes de víctimas del } \\
\text { Terrorismo de Estado. } \\
\text {-Bibliografia } \\
\text {-APDH la Plata } \\
\text {-Compañeres de militancia y } \\
\text { familiares de las víctimas de la } \\
\text { Facultad. } \\
\text {-Ex alumnes } \\
\text {-Actas administrativas de la } \\
\text { Facultad. }\end{array}$ \\
\hline $2004 / 2007$ & $\begin{array}{l}\text { Acto por el aniversario de la } \\
\text { desaparición de Miguel Bru. } \\
\text { Reforzar institucionalmente la } \\
\text { memoria y la historia de lucha } \\
\text { en la búsqueda de justicia por } \\
\text { nuestro estudiante Miguel Bru } \\
\text { (torturado, asesinado y } \\
\text { desaparecido por la policía } \\
\text { bonaerense el } 17 / 8 / 1993 \text { ) }\end{array}$ & $\begin{array}{l}\text {-Rosa Bru } \\
\text {-Integrantes de la Asoc. Miguel } \\
\text { Bru } \\
\text {-Dirección de DDHH FP } \\
\text { y CS. } \\
\text {-Equipo de gestión de la } \\
\text { Facultad } \\
\text {-Alumnes, docentes y no } \\
\text { docentes. } \\
\text {-Comunidad universitaria en } \\
\text { general, militantes, organismos } \\
\text { y organizaciones politicas y } \\
\text { sociales, gremios universitarios. } \\
\text {-Referentes y familiares de } \\
\text { víctimas de la Violencia } \\
\text { Institucional en democracia. }\end{array}$ & $\begin{array}{l}\text {-Fortalecer el proceso de } \\
\text { memoria por la desaparición } \\
\text { de Miguel Bru y por la lucha } \\
\text { por justicia de la comunidad } \\
\text { universitaria en general y la } \\
\text { FP en particular. } \\
\text {-Fortalecer el vínculo de la } \\
\text { facultad con Rosa Bru, con } \\
\text { la Asoc. miguel Bru y con } \\
\text { familiares de víctimas de } \\
\text { la VI. }\end{array}$ & $\begin{array}{l}\text {-Actos, charlas, movilizacio- } \\
\text { nes. } \\
\text {-Incorporación del tema a } \\
\text { las cátedras. } \\
\text {-Mural } \\
\text {-Muestras de producciones } \\
\text { periodísticas. } \\
\text {-Muestras de trabajos } \\
\text { territoriales de la Asoc. Bru }\end{array}$ & $\begin{array}{l}\text {-Mural en la fachada de la } \\
\text { facultad. } \\
\text {-Fortalecimiento, en el } \\
\text { alumnado, de la historia de } \\
\text { Miguel Bru } \\
\text {-Trabajos prácticos, produc- } \\
\text { ciones comunicacionales y } \\
\text { tesis sobre Miguel Bru y la } \\
\text { violencia institucional } \\
\text {-El tema desarrollado en } \\
\text { seminarios y cátedras. } \\
\text {-Título de Dra. Honoris } \\
\text { Causa de la Universidad a } \\
\text { Rosa Bru. }\end{array}$ & $\begin{array}{l}\text {-Visibilización mediática de } \\
\text { la problemática sobre } \\
\text { Violencia Institucional, VI en } \\
\text { democracia. } \\
\text {-Se forma la Comisión } \\
\text { antiimpunidad dependiente } \\
\text { del Minissterio del IIterior de } \\
\text { la Nación, con familiares de } \\
\text { víctimas de la VI. }\end{array}$ & $\begin{array}{l}\text {-Producciones comunicacio- } \\
\text { nales. } \\
\text { - Familiares, amigxs y } \\
\text { compañeres de Miguel. } \\
\text {-Especialistas en materia de } \\
\text { DDHH } \\
\text {-Docmentos } \\
\text {-Discursos } \\
\text {-Informes de gestión }\end{array}$ \\
\hline $2004 / 2007$ & $\begin{array}{l}\text { Armado del Seminario de } \\
\text { Comunicación y DDHH. }\end{array}$ & $\begin{array}{l}\text {-Familiares de víctimas de } \\
\text { violaciones a los DDHH en } \\
\text { democracia y dictadura. } \\
\text {-Referentes en DDHH } \\
\text {-Especialistas en las áreas de } \\
\text { género, diversidad, juicios de } \\
\text { Lesa Humanidad, normativas } \\
\text { en DDHH } \\
\text {-Periodistas que trabajan la } \\
\text { perspectiva en DDHH } \\
\text {-Miembros de comunidades } \\
\text { indígenas } \\
\text {-Colectivo GLTBBT } \\
\text {-Personas con discapacidad }\end{array}$ & $\begin{array}{l}\text {-Vincular referentes en } \\
\text { DDHH con la comunidad de } \\
\text { la FP y CS. } \\
\text {-Trabajar en formación en } \\
\text { DDHH con estudiantes de la } \\
\text { facultad. } \\
\text {-Trabajar los DDHH desde } \\
\text { una perspectiva comunicacio- } \\
\text { nal. } \\
\text {-Integrar a los diferentes } \\
\text { territorios y comunidades al } \\
\text { proyecto académico político. }\end{array}$ & $\begin{array}{l}\text {-Seminario interdisciplinario de } \\
\text { la carrera de Licenciatura en } \\
\text { Comunicación Social, 4hs. } \\
\text { semanales. }\end{array}$ & $\begin{array}{l}\text { - Se enriqueció la formación } \\
\text { en DDHH de alumnes y } \\
\text { docentes. } \\
\text {-Se fortaleció el vínculo con } \\
\text { referentes y familiares de } \\
\text { víctimas con la F P. } \\
\text {-Se multiplicaron las } \\
\text { producciones comunicacio- } \\
\text { nales en DDHH por parte } \\
\text { de alumnes. } \\
\text {-Les alumnes se empezaron } \\
\text { a incorporar en las distintas } \\
\text { actividades cotidianas de la } \\
\text { Dirección de DDHH. }\end{array}$ & $\begin{array}{l}\text {-La política de Estado de } \\
\text { restitución de derechos y los } \\
\text { avances en el proceso de } \\
\text { justicia por lo acontecido en } \\
\text { temas de Lesa Humanidad } \\
\text { hacen que se amplíe la } \\
\text { agenda de derechos.. }\end{array}$ & $\begin{array}{l}\text { Informes de gestión, programas } \\
\text { de la materia. }\end{array}$ \\
\hline
\end{tabular}




\begin{tabular}{|c|c|c|c|c|c|c|c|}
\hline Fecha & Actividad & Participantes & Objetivos & Metodología & Resultado & Contexto & Fuentes \\
\hline 2007 & $\begin{array}{l}\text { Se crea la Secretaría de } \\
\text { DDHH }\end{array}$ & $\begin{array}{l}\text {-Director de DDHH } \\
\text {-equipo de gestión en DDHH } \\
\text {-Comunidad académica de la } \\
\text { FP y CS. } \\
\text {-Decano } \\
\text {-Consejo Directivo }\end{array}$ & $\begin{array}{l}\text {-Reforzar la política de } \\
\text { DDHH de la facultad. } \\
\text {-Jerarquizar el área de DDHH } \\
\text { de la Facultad. } \\
\text {-Multiplicar acciones en } \\
\text { DDHH. }\end{array}$ & $\begin{array}{l}\text {-Acompañamiento y ejecución } \\
\text { de politicias sociales en DDHH } \\
\text {-Participación y acompañamien- } \\
\text { to a organismos, organizaciones } \\
\text { de DDHH y de víctimas de } \\
\text { violaciones a los DDHH. } \\
\text {-Talleres barriales de empodera- } \\
\text { miento en DDHH. } \\
\text {-Capacitación a docentes, } \\
\text { alumnes y no docentes. } \\
\text {-Realización de producciones } \\
\text { comunicacionales en DDHH. } \\
\text {-Realización de documentos. } \\
\text {-Realización de proyectos de } \\
\text { investigación y extensión. } \\
\text {-Articulación permanente con } \\
\text { actores extra académicos } \\
\text { referentes en la búsqueda de } \\
\text { justicia y los DDHH }\end{array}$ & $\begin{array}{l}\text {-Rejerarquización del área. } \\
\text { Incremento y multiplicidad de } \\
\text { actividades desde la diversidad } \\
\text { de Derechos. } \\
\text {-Incremento de espacios de } \\
\text { formación académica en } \\
\text { DDHH } \\
\text {-Incremento de producciones } \\
\text { comunicacionales en DDHH } \\
\text {-Incremento de producciones } \\
\text { e investigaciones de les } \\
\text { alumnes. } \\
\text {-Incremento en la participa- } \\
\text { cín de movilizaciones } \\
\text { sociales. } \\
\text {-Mejoramiento de la estructu- } \\
\text { ra de la oficina (mas computa- } \\
\text { doras, espacio y personal) }\end{array}$ & $\begin{array}{l}\text { La amplición de Derechos } \\
\text { por parte de la politica de } \\
\text { estado del Gobierno de } \\
\text { Nestor Kirchner es notoria y } \\
\text { hay una perspectiva integral } \\
\text { de derechos. La política } \\
\text { pública en restitución de } \\
\text { DDHH, fundamentalmente } \\
\text { sociales, económicos y } \\
\text { culturales sigue avanzzando. }\end{array}$ & $\begin{array}{l}\text { Resolución de Consejo } \\
\text { Directivo }\end{array}$ \\
\hline $2005 / 2006$ & $\begin{array}{l}\text { Primeros diálogos institucio- } \\
\text { nales con el ministerio de } \\
\text { Justicia para formalizar la } \\
\text { inserción de la Facultad en el } \\
\text { territorio carcelario. Se firma } \\
\text { el primer convenio e inicio de } \\
\text { talleres de producción gráfica } \\
\text { y radiofónica en unidades ( } 3 \text {, } \\
8,9,18,24,26,28,31,33,34, \\
36 \text { y } 51 \text { ) dirigidos a internos y } \\
\text { talleres de comunicación } \\
\text { institucional dirigidos a } \\
\text { gagnntes del SPB. (Servicio } \\
\text { Penitenciario Bonaerense) }\end{array}$ & $\begin{array}{l}\text { Ministerio de Justicia PBA } \\
\text { Decanato, Sec de Extensión de } \\
\text { la FPyCS, Sec DDHH FP y } \\
\text { CS. A los talleres se suman } \\
\text { docentes, claustro estudiantil, } \\
\text { graduadxs, Asociación La } \\
\text { Cantora [capacitación], } \\
\text { Colectivo de Investigación y } \\
\text { Acceso a la Justicia (capacita- } \\
\text { ción), Asociacion Miguel Bru } \\
\text { (capacitación). Ministerio de } \\
\text { Justicia PBA y Servicio } \\
\text { Penitenciario Bonaerense. Las } \\
\text { denuncias sobre violaciones a } \\
\text { los DDHH se tramitaban a } \\
\text { través de la Comisión Provin- } \\
\text { cial de la Memoria CPM. } \\
\text { Asesoramiento permanente } \\
\text { con el CUD (Centro universi- } \\
\text { tario de Devoto). Privados y } \\
\text { privadas de libertad de cárceles } \\
\text { del SPB. }\end{array}$ & $\begin{array}{l}\text {-Reforzar el acceso a } \\
\text { derechos con esta política } \\
\text { de inclusión educativa de } \\
\text { nuestra facultad. Potenciar } \\
\text { el Derecho a la educación } \\
\text { con les privades de libertad. } \\
\text {-Potenciar las capacidades } \\
\text { expresivas y el derecho a la } \\
\text { comunicación. Posibilitar el } \\
\text { dictado de la carrera en las } \\
\text { cárceles y el acceso de } \\
\text { privadxs de libertad a } \\
\text { nuestra sede. }\end{array}$ & $\begin{array}{l}\text {-Talleres cuatrimestrales de } \\
\text { producción gráfica y } \\
\text { radiofónica en unidades }(3, \\
8,9,18,24,26,28,31,33, \\
34,36 \text { y } 51 \text { ) dirigidos a } \\
\text { internos y talleres de } \\
\text { comunicación institucional, } \\
\text { dirigidos a agentes del SPB } \\
\text { se suman estudiantes } \\
\text { avanzades, docentes, } \\
\text { graduades, organizaciones } \\
\text { para la formación. Se } \\
\text { realizan producciones: CD, } \\
\text { revistas y un libro. Este } \\
\text { primer convenio es bianual } \\
\text { 2006//2008. }\end{array}$ & $\begin{array}{l}\text {-Se firma el convenio entre el } \\
\text { ministerio de justicia y la FP } \\
\text { y CS, antes hubo que } \\
\text { firmarlo con la UNLP como } \\
\text { indica el reglamento. } \\
\text {-Docentes y alumnnes de la } \\
\text { facultad dieron talleres en } 16 \\
\text { unidades penitenciarias del } \\
\text { SPB, fue el antecedente de } \\
\text { nuestra carrera con modali- } \\
\text { dad de cursada en la cárcel. } \\
\text {-Mas privades de libertad se } \\
\text { anotaron en la carrera para } \\
\text { cursar en nuestra sede. La } \\
\text { cárcel entró realmente en } \\
\text { nuestra facultad y viceversa. } \\
\text { Se multiplicaron las produc- } \\
\text { ciones del alumnado sobre } \\
\text { privades de libertad y } \\
\text { cárceles. Se visualizan las } \\
\text { producciones periodísticas } \\
\text { de privades de libertad. }\end{array}$ & $\begin{array}{l}\text { Recién se incorporaba a } \\
\text { instancias de Adriana } \\
\text { Puiggrós el capítulo Educa- } \\
\text { ción en ámbitos de privación } \\
\text { de libertad a la Ley de } \\
\text { Educación Nacional. }\end{array}$ & $\begin{array}{l}\text { Docentes coordinadores que } \\
\text { estaba en esas reuniones, } \\
\text { convenio entre el ministerio } \\
\text { de justicia y la Facultad de } \\
\text { Periodismo, informes de } \\
\text { gestión. }\end{array}$ \\
\hline
\end{tabular}




\begin{tabular}{|c|c|c|c|c|c|c|c|}
\hline Fecha & Actividad & Participantes & Objetivos & Metodología & Resultado & Contexto & Fuentes \\
\hline 2006 & 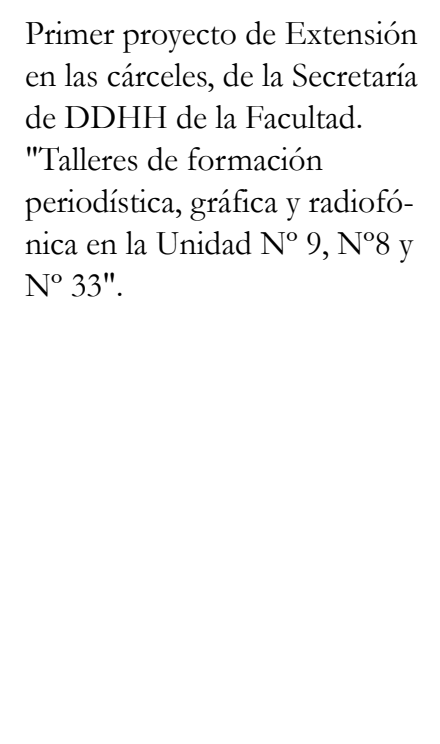 & $\begin{array}{l}\text { Alumnes, docentes y gradua- } \\
\text { dxs de la FP y CS, integrantes } \\
\text { del Ministerio de Justicia PBA, } \\
\text { Asociación Miguel Bru y } \\
\text { Grupo de Estudios de } \\
\text { Educación en Cárceles, } \\
\text { GESEC, privades de libertad } \\
\text { de las unidades } N^{\circ} 9,8 \text { y } 33 \text {. } \\
\text { Integrantes de la Secretaría de } \\
\text { DDHH de la FP y CS UNLP. }\end{array}$ & $\begin{array}{l}\text { Potenciar a la Secretaría de } \\
\text { DDHHH en materia de } \\
\text { proyectos de extensión. } \\
\text { Involucrar a la totalidad de la } \\
\text { Scere de DDHH en activida- } \\
\text { des en relación a educación } \\
\text { en cárceles. Fortalecer y } \\
\text { multiplicar los vínculos de la } \\
\text { Facultad con privades de } \\
\text { libertad. Construir narrativas } \\
\text { comunicacionales de privadxs } \\
\text { de libertad. Poder costear las } \\
\text { producciones gráficas y } \\
\text { radiales con mensajes de } \\
\text { privades de libertad. Promo- } \\
\text { ver la inslución educativa de } \\
\text { privades de libertad }\end{array}$ & $\begin{array}{l}\text { Talleres de producción } \\
\text { gráfica y radial en las } \\
\text { Unidades penales } \mathrm{N}^{\circ} 9 \text { de } \\
\text { varones y } \mathrm{N}^{\circ} 33 \text { de mujeres, } \\
\text { encuentros semanales } \\
\text { durante un año donde se } \\
\text { desarrollaron las capacidades } \\
\text { expresivas y las herramientas } \\
\text { tecnológicas para realizar un } \\
\text { libro con publicaciones } \\
\text { gráficas y radiales. }\end{array}$ & $\begin{array}{l}\text { Realización un libro ( } 100 \\
\text { publicaciones) con publica- } \\
\text { ciones gráficas y con dos } \\
\text { CDs con programa radial en } \\
\text { el interior del mismo. El } \\
\text { libro se llamó "Comunica- } \\
\text { ción en cárceles, una } \\
\text { herramienta para el cambio" }\end{array}$ & $\begin{array}{l}\text { Ya habíamos firmado el } \\
\text { convenio entre la FP y CS y } \\
\text { el Ministerio de justicia, lo } \\
\text { cual nos facilitaba el ingreso } \\
\text { a las unidades penitenciarias } \\
\text { y el acceso a centros de } \\
\text { estudiantes, a les alumnes y } \\
\text { las aulas para realizar los } \\
\text { talleres. }\end{array}$ & $\begin{array}{l}\text { Publicación de extensión } \\
\text { sobre proyectos otorgados, el } \\
\text { libro "Comunicación en } \\
\text { cárceles una herramienta } \\
\text { para el cambio". }\end{array}$ \\
\hline 2006 & $\begin{array}{l}\text { Encuentro y primeros } \\
\text { diálogos institucionales con } \\
\text { Claudia Vasquez Haro, alumna } \\
\text { trans, en el marco del semina- } \\
\text { rio de Com y DDHH }\end{array}$ & $\begin{array}{l}\text { Docente Jorge Jaunarena, } \\
\text { alumnes del seminario, alumna } \\
\text { trans Claudia Vasquez Haro, } \\
\text { decano de la FP y CS. }\end{array}$ & $\begin{array}{l}\text { Poder incluir el derecho a la } \\
\text { identidad de género autoperci- } \\
\text { bido en las actas administrativas } \\
\text { de la Facultad de Periodismo y } \\
\text { Comunicación Soc. de la } \\
\text { UNLP, pensando en llevarlo } \\
\text { luego a la UNLP en general e } \\
\text { instalar el tema en la agenda } \\
\text { política, académica y mediática } \\
\text { del pás, para lograr materiali- } \\
\text { zarlo en una ley que reconozca } \\
\text { la identidad de género en el } \\
\text { DNI. }\end{array}$ & $\begin{array}{l}\text { A partiir de revisar jurispru- } \\
\text { dencia de casos similares en } \\
\text { otros ámbitos, desarrollar } \\
\text { conjuntamente con Claudia } \\
\text { Vasquez el proyecto formal } \\
\text { y escrito para que se } \\
\text { presente la nueva normativa } \\
\text { sobre la ley de identidad de } \\
\text { género autopercibido, en el } \\
\text { Consejo Directivo de la } \\
\text { Facultad para su aprobación. } \\
\text { Ir dialogando con las } \\
\text { autoridades de la Facultad } \\
\text { para obtener apoyo político. }\end{array}$ & $\begin{array}{l}\text { Conocernos y empezar a } \\
\text { articular políticas con } \\
\text { Claudia Vasquez, recolección } \\
\text { de información e inicio del } \\
\text { armado del proyecto de } \\
\text { respeto por la identidad de } \\
\text { género en nuestras actas } \\
\text { administrativas. Instalar el } \\
\text { tema del derecho a la } \\
\text { identidad de género autoper- } \\
\text { cibido en nuestra facultad. } \\
\text { Inclusión social educativa. } \\
\text { Claudia Vasquez empieza a } \\
\text { dar el módulo sobre diversi- } \\
\text { dad sexual en el seminario. }\end{array}$ & $\begin{array}{l}\text { Presidencia de Nestor } \\
\text { Kirchner, era de ampliación } \\
\text { de DDHH. En varias } \\
\text { entrevistas el presidente } \\
\text { empieza a hablar de restitu- } \\
\text { ción de DDHH e inclusión } \\
\text { social para personas LGBTI } \\
\text { en nuestro país. }\end{array}$ & $\begin{array}{l}\text { Claudia Vasquez, Jorge } \\
\text { Jaunarena, programas del } \\
\text { seminario de Comunicaciòn } \\
\text { y DDHH. }\end{array}$ \\
\hline
\end{tabular}




\begin{tabular}{|c|c|c|c|c|c|c|c|}
\hline Fecha & Actividad & Participantes & Objetivos & Metodología & Resultado & Contexto & Fuentes \\
\hline 2006 & $\begin{array}{l}\text { Título de Doctora Honoris } \\
\text { Causa de la UNLP a Rosa Bru. }\end{array}$ & $\begin{array}{l}\text { Asociación Miguel Bru, Rosa } \\
\text { Bru, autoridades de la FP y CS. } \\
\text { Y del rectorado de la UNLP } \\
\text { (rector Gustavo Azpiazu), } \\
\text { todas las representaciones } \\
\text { estudiantiles, graduades y } \\
\text { docentes de la UNLP, gremios } \\
\text { ADULP y ATULP, Secretaría } \\
\text { de DDHH FP y CS. UNLP, } \\
\text { organismos de DDHH, Estela } \\
\text { Carlotto, Raúl Zaffaroni, } \\
\text { organizaciones políticas y } \\
\text { sociales. Familiares de víctimas } \\
\text { y referentes de la lucha contra } \\
\text { la violencia institucional. }\end{array}$ & $\begin{array}{l}\text { Reconocer a Rosa Bru como un } \\
\text { referente instalado en la historia } \\
\text { de los DDHH de la Universi- } \\
\text { dad. Mantener viva la memoria } \\
\text { y difundir lo que pasó con el } \\
\text { estudiante Miguel Bru. }\end{array}$ & $\begin{array}{l}\text { Presentar la idea a las } \\
\text { autoridades de la Facultad, } \\
\text { presentar la propuesta en el } \\
\text { Consejo Superior de la } \\
\text { UNLP para su votación. } \\
\text { Organización y realización } \\
\text { del acto de entrega del título. } \\
\text { Invitación a referentent y } \\
\text { especialistas. Invitación a la } \\
\text { comunidad en general. } \\
\text { Difusión periodística. }\end{array}$ & $\begin{array}{l}\text { Rosa Bru es elegida Doctora } \\
\text { Honoris Causa de la UNLP. } \\
\text { Hecho que tuvo una enorme } \\
\text { repercusión política y } \\
\text { periodística. Se profundiza la } \\
\text { difusión del caso y el vínculo } \\
\text { de Rosa con la Facultad y la } \\
\text { UNLP en general. }\end{array}$ & $\begin{array}{l}\text { El gobierno nacional crea la } \\
\text { comisión anti impunidad con } \\
\text { familiares referentes de la } \\
\text { lucha contra la violencia } \\
\text { institucional y abogades } \\
\text { especialistas, para acompañar } \\
\text { familiares en la búsqueda de } \\
\text { justicia que tengan situacio- } \\
\text { nes similares en todo el país. }\end{array}$ & $\begin{array}{l}\text { Videos, notas periodísticas, } \\
\text { fotos, discursos, informes de } \\
\text { gestión. }\end{array}$ \\
\hline $2004 / 2007$ & $\begin{array}{l}\text { Conmemoración del aniversa- } \\
\text { rio de la tortura seguida de } \\
\text { muerte y desaparición de } \\
\text { Miguel Bru. }\end{array}$ & $\begin{array}{l}\text { Asociación Miguel Bru, Rosa } \\
\text { Bru, autoridades de la FP y CS. } \\
\text { Y del rectorado de la UNLP, } \\
\text { todas las representaciones } \\
\text { estudiantiles, graduades y } \\
\text { docentes de la UNLP, gremios } \\
\text { ADULP y ATULP, Secretaría } \\
\text { de DDHH FP y CS. UNLP, } \\
\text { unidades académicas de la } \\
\text { UNLP, estudiantes, graduades, } \\
\text { docentes y no docentes, } \\
\text { militantes políticos y sociales. } \\
\text { Familiares de víctimas de } \\
\text { violencia institucional. }\end{array}$ & $\begin{array}{l}\text { Mantener viva la memoria y } \\
\text { difundir lo que pasó con } \\
\text { nuestro compañero el estudian- } \\
\text { te Miguel Bru. Vincular a la } \\
\text { Asociación Miguel Bru y las } \\
\text { tareas que realiza con la } \\
\text { Universidad. Difundir la } \\
\text { problemática de la Violencia } \\
\text { Institucional en Argentina. }\end{array}$ & $\begin{array}{l}\text { Realización de muestras, } \\
\text { charlas, disertaciones. Invitar } \\
\text { referentes, familiares de } \\
\text { víctimas. Convocatoria. } \\
\text { Difusión. }\end{array}$ & $\begin{array}{l}\text { Vinculación de la Facultad y } \\
\text { la UNLP con la historia de } \\
\text { Miguel y la Asociación } \\
\text { Miguel Bru. Difusión del } \\
\text { caso. Difusión de la proble- } \\
\text { mática de la Violencia } \\
\text { Institucional. Articulación } \\
\text { con familiares de vícimas, } \\
\text { organismos y organizaciones } \\
\text { de DDHH. }\end{array}$ & $\begin{array}{l}\text { La violencia institucional } \\
\text { ocupa un lugar destacado en } \\
\text { la agenda de derechos de la } \\
\text { política de gobierno en } \\
\text { nuestro país. }\end{array}$ & $\begin{array}{l}\text { Videos, notas periodísticas, } \\
\text { fotos, discursos, informes de } \\
\text { gestión. }\end{array}$ \\
\hline $2004 / 2006$ & $\begin{array}{l}\text { Proyecto de Extensión } \\
\text { Observatorio - Contralor de } \\
\text { Noticias Informativas sobre } \\
\text { Jóvenes "en Situación de } \\
\text { Delito". }\end{array}$ & $\begin{array}{l}\text { Asociación Miguel Bru, } \\
\text { Dirección de DDHH de la } \\
\text { Facultad de Periodismo y } \\
\text { Comunicación Social, Area } \\
\text { Queer de la Facultad de } \\
\text { Filosofía y Letras de la } \\
\text { Universidad de Buenos Aires, } \\
\text { Federación Argentina LGBT. }\end{array}$ & $\begin{array}{l}\text { Producir un libro sobre un } \\
\text { observatorio de la producción } \\
\text { de noticias informativas sobre } \\
\text { Jóvenes en situación de delito, } \\
\text { desde una perspectiva de } \\
\text { defensa y promoción de } \\
\text { DDHH y de políticas contra la } \\
\text { represión y discriminación en } \\
\text { articulación con un trabajo en } \\
\text { red de activistas de organiza- } \\
\text { ciones de la sociedad civil y } \\
\text { desde la interdisciplinariedad de } \\
\text { las Universidades. }\end{array}$ & $\begin{array}{l}\text { Investigación interdisciplina- } \\
\text { ria durante } 6 \text { meses en los } \\
\text { diarios Hoy y El Día de La } \\
\text { Plata, Clarín, La Nación y } \\
\text { Crónica de medios naciona- } \\
\text { les durante los meses de } \\
\text { septiembre, octubre, } \\
\text { noviembre, diciembre de } \\
2004 \text { y enero y febrero de } \\
2005 \text {,análisis de noticias } \\
\text { gráficas en donde les } \\
\text { jóvenes aparecen como } \\
\text { víctimas o victimarios. }\end{array}$ & $\begin{array}{l}\text { Publicación del libro con el } \\
\text { análisis y conclusiones de la } \\
\text { investigación sobre "Obser- } \\
\text { vatorio - Contralor de } \\
\text { Noticias Informativas sobre } \\
\text { jóvenes en Situación de } \\
\text { Delito (Informe Final } \\
\text { 2006)". }\end{array}$ & $\begin{array}{l}\text { El debate sobre el rol de los } \\
\text { medios y la democratización } \\
\text { de la información, en cuanto } \\
\text { formadores de opinión cobra } \\
\text { cada vez mayor relevancia. El } \\
\text { rol del periodismo en el } \\
\text { debate sobre la inseguridad } \\
\text { (principal hecho de temor en } \\
\text { la agenda sociall). Se empieza } \\
\text { a hablar sobre una nueval ley } \\
\text { de comunicación plural y } \\
\text { democrática, que visibilice } \\
\text { otras voces que no tienen } \\
\text { lugar en la agenda actual. }\end{array}$ & $\begin{array}{l}\text { Publicación : Observatorio - } \\
\text { Contralor de Noticias } \\
\text { Informativas sobre jóvenes } \\
\text { "en Situación de Delito" } \\
\text { (Informe Final 2006). } \\
\text { Informes de gestión. }\end{array}$ \\
\hline
\end{tabular}




\begin{tabular}{|c|c|c|c|c|c|c|c|}
\hline Fecha & Actividad & Participantes & Objetivos & Metodología & Resultado & Contexto & Fuentes \\
\hline $2005 / 2006$ & $\begin{array}{l}\text { Conferencia de prensa con } \\
\text { Pascual Pichún Collonao que } \\
\text { se presenta en la Facultad } \\
\text { comentando su situación, } \\
\text { totalmente injusta, que pesa } \\
\text { sobre él un pedido de extradi- } \\
\text { ción de Chile, que lo ayude- } \\
\text { mos a pedir refugio político y } \\
\text { que además pretende estudiar } \\
\text { nuestra carrera universitaria. } \\
\text { Organizamos una conferencia } \\
\text { de prensa desde la Facultad } \\
\text { (Noviembre de 2005) }\end{array}$ & $\begin{array}{l}\text { Integrantes de comunidades } \\
\text { indígenas, Pascual Pichún } \\
\text { Collonao, Dirección de } \\
\text { DDHH FP y CS, Liga } \\
\text { Argentina por los Derechos } \\
\text { del Hombre, comunidad } \\
\text { académica de la FP y CS. }\end{array}$ & $\begin{array}{l}\text { Visibilizarar la situación de } \\
\text { Pascual Pichum prófugo de la } \\
\text { Justicia chilena desde } 2003 \text {, } \\
\text { cuando fue condenado a cinco } \\
\text { años de presidio, conjuntamen- } \\
\text { te con otros miembros de la } \\
\text { comunidad Mapuche, en un } \\
\text { juicio claramente irregular, } \\
\text { autor del atentado incendiario a a } \\
\text { un camión en } 2002 \text { en las } \\
\text { cercanías del pueblo donde } \\
\text { habitaba (en la zona de } \\
\text { Temuco, Chile), durante una } \\
\text { manifestación mapuche, en } \\
\text { protesta por la ocupación de } \\
\text { tierras por parte de empresas } \\
\text { trasnacionales, caso por el cual } \\
\text { además fue conminado a pagar } \\
\text { una indemnización superior a } \\
\text { los } 11.300 \text { dólares, pena que va } \\
\text { en sentido contrario a lo } \\
\text { recomendado por normativas } \\
\text { internacionales en DDHH. Le } \\
\text { aplicaron la ley antiterrorista de } \\
\text { Pinochet, que entreo otras cosas } \\
\text { no le permitía derecho a la } \\
\text { defensa. }\end{array}$ & $\begin{array}{l}\text { Convocatoria a una conferencia } \\
\text { de prensa conjuntamente con } \\
\text { las comunidades mapuches, } \\
\text { Pascual y el abogado para dar a } \\
\text { conocer la injusta situación. }\end{array}$ & $\begin{array}{l}\text { Se visibilizó el caso, tomó } \\
\text { repercusión pública, se } \\
\text { entabló una muy buena } \\
\text { relación con las organizacio- } \\
\text { nes indígenas, también con } \\
\text { Pascual y su familia, se } \\
\text { formalizó su ingreso a la } \\
\text { Facultad y a colaborar en la } \\
\text { Dirección de DDHH de la } \\
\text { FP y CS para desarrollar } \\
\text { políticas sobre pueblos } \\
\text { indígenas para adentro de } \\
\text { nuestra unidad académica y } \\
\text { para el afuera tb. }\end{array}$ & $\begin{array}{l}\text { Gobierna Michelle Bachelett } \\
\text { en Chile y era complejo que } \\
\text { un gobierno de centro } \\
\text { izquierda, como se autopro- } \\
\text { clamaba, pida una extradi- } \\
\text { ción al kirchnerismo con la } \\
\text { buena sintonía que existía } \\
\text { entre ambos. En el } 2006 \text { el } \\
\text { kirchnerismo vota el } \\
\text { proyecto de ley de releva- } \\
\text { miento indigena. }\end{array}$ & $\begin{array}{l}\text { Pascual Pichún, google } \\
\text { información, informe } \\
\text { de gestión. }\end{array}$ \\
\hline 2006 & $\begin{array}{l}\text { Presentación del libro "La } \\
\text { gesta del nombre Propio", } \\
\text { informe sobre la situación de } \\
\text { la comunidad travesti en la } \\
\text { Argentina". }\end{array}$ & $\begin{array}{l}\text { Lohana Berkins, referente y } \\
\text { activista comunidad LGTBT, } \\
\text { Josefina Fernández, antropólo- } \\
\text { ga y activista feminista, } \\
\text { Marlene Wayar, referente y } \\
\text { activista comunidad LGTBT } \\
\text { Jorge Junnarena, Director de } \\
\text { DDHH FP y CS. }\end{array}$ & $\begin{array}{l}\text { Dar a conocer la situación trans } \\
\text { y travesti en la Argentina, } \\
\text { comunidad absolutamente } \\
\text { avasallada y vulnerada en sus } \\
\text { derechos. }\end{array}$ & $\begin{array}{l}\text { Presentación del libro con } \\
\text { disertantes y panel de preguntas } \\
\text { en la FP y CS UNLP. }\end{array}$ & $\begin{array}{l}\text { Visibilización del libro y la } \\
\text { realidad del colectivo travesti } \\
\text { en la Argentina, aula llena en } \\
\text { nuestra facultad, se comien- } \\
\text { za a instalar y a trabajar, } \\
\text { además, la temática en } \\
\text { nuestra institución. }\end{array}$ & $\begin{array}{l}\text { Era de reparación de } \\
\text { derechos producto de la } \\
\text { política de Gobierno de } \\
\text { Nestor Kirchner, los } \\
\text { reclamos de la diversidad } \\
\text { sexual ganan visibilidad. }\end{array}$ & $\begin{array}{l}\text { Informe de gestión, notas } \\
\text { periodísticas en la web. }\end{array}$ \\
\hline 2005 & $\begin{array}{l}\text { Organización de las jornadas } \\
\text { "Jóvenes, Derechos Humanos } \\
\text { y Violencia. Presentacion del } \\
\text { caso Walter Bulacio, sentencia } \\
\text { de la Corte Interamericana de } \\
\text { Derechos Humanos y el } \\
\text { compromiso asumido por el } \\
\text { Estado Argentino". }\end{array}$ & $\begin{array}{l}\text { Participaron el Lic. Edgardo } \\
\text { Binstock, Secretario de } \\
\text { DDHH de la Provincia de } \\
\text { Buenos Aires; Sr. Remo } \\
\text { Carlotto, Diputado Nacional; } \\
\text { Sara Derotier de Cobacho, } \\
\text { Subsecretaria de DDHH de la } \\
\text { Provincia de Bs. As. }\end{array}$ & $\begin{array}{l}\text { Presentacion del caso Walter } \\
\text { Bulacio, sentencia de la Corte } \\
\text { Interamericana de Derechos } \\
\text { Humanos y el compromiso } \\
\text { asumido por el Estado } \\
\text { Argentino. }\end{array}$ & $\begin{array}{l}\text { Disertación y charla debate } \\
\text { en la sede de la Facultad. }\end{array}$ & $\begin{array}{l}\text { Difusión del caso Bulacio, } \\
\text { del entramado de la búsque- } \\
\text { da de justicia, y de la } \\
\text { sentencia de la Corte } \\
\text { Interamericana de DDHH } \\
\text { con repecto al mismo. }\end{array}$ & $\begin{array}{l}\text { Las instituciones y autorida- } \\
\text { des del Estado empiezan a } \\
\text { cumplir con las demanadas } \\
\text { de los estamentos locales e } \\
\text { internacionales en DDHH, } \\
\text { como por ejemplo en el caso } \\
\text { Bulacio. }\end{array}$ & Informe de gestión. \\
\hline
\end{tabular}




\begin{tabular}{|c|c|c|c|c|c|c|c|}
\hline Fecha & Actividad & Participantes & Objetivos & Metodología & Resultado & Contexto & Fuentes \\
\hline 2005 & $\begin{array}{l}\text { Organización de la Conferen- } \\
\text { cia "Compromisos de la } \\
\text { Argentina, Compromisos con } \\
\text { las Mujeres". Presentación de } \\
\text { la Campaña Nacional } \\
\text { "Conocé tus Derechos para } \\
\text { Poder Ejercerlos". }\end{array}$ & $\begin{array}{l}\text { Disertaron: Embajadora } \\
\text { Juliana Di Tullio, Representa- } \\
\text { ción Especial para temas de la } \\
\text { Mujer en el Ámbito Interna- } \\
\text { cional, Ministerio de Relacio- } \\
\text { nes Exteriores, Comercio } \\
\text { Internacional y Culto. Arq. } \\
\text { Cristina Álvarez Rodríguez, } \\
\text { Presidenta del Instituto } \\
\text { Cultural de la Provincia de } \\
\text { Buenos Aires. Sra. Estela } \\
\text { Barnes de Carlotto, Presidenta } \\
\text { de Asociación Abuelas de } \\
\text { Plaza de Mayo. }\end{array}$ & $\begin{array}{l}\text { Dar a conmocer los puntos } \\
\text { centrales de la situación de los } \\
\text { Derechos de las Mujeres en } \\
\text { nuestro país y además difundir } \\
\text { los lineamientos de la Campaña } \\
\text { Nacional, diseñada por el } \\
\text { gobierno junto a organizacio- } \\
\text { nes y referentes, para promover } \\
\text { los derechos de las mujeres. }\end{array}$ & $\begin{array}{l}\text { Disertación y charla debate } \\
\text { en el salón del Consejo } \\
\text { Superior en la casa Matriz } \\
\text { del rectorado de la UNLP }\end{array}$ & $\begin{array}{l}\text { Difusión del tema, articula- } \\
\text { ción de políticas en DDHH } \\
\text { con la Dirección de DDHH } \\
\text { de la UNLP y en términos } \\
\text { de derechos de las mujeres } \\
\text { afianzamiento de los lazos } \\
\text { con la representante de } \\
\text { cancillería del gobierno } \\
\text { argentino para los derechos } \\
\text { de las mujeres. Instalarnos } \\
\text { como referentes de la } \\
\text { temática en la UNLP y en la } \\
\text { sociedad platense. }\end{array}$ & $\begin{array}{l}\text { Argentina se posiciona y } \\
\text { compromete fuertemente en } \\
\text { el ámbito nacional e interna- } \\
\text { cional en cumplir con la } \\
\text { restitución y ampliación de } \\
\text { derechos de género. }\end{array}$ & $\begin{array}{l}\text { Afiches, informe de gestión. } \\
\text { Entrevista a Antonia } \\
\text { Portaneri (cancillería, } \\
\text { representación de la mujer en } \\
\text { Argentina y en el mundo) }\end{array}$ \\
\hline $2005 / 2007$ & $\begin{array}{l}\text { Programa radial "de Igual a } \\
\text { Igual" }\end{array}$ & $\begin{array}{l}\text { Integrantes de la Dirección de } \\
\text { DDHH de la Facultad, } \\
\text { alumnes y graduades, conjun- } \\
\text { tamente con la Asociación } \\
\text { Miguel Bru. }\end{array}$ & $\begin{array}{l}\text { Difundir la temática de } \\
\text { Derechos Humanos en su } \\
\text { amplitud, con un programa de } \\
\text { la Dirección de DDHH en FM } \\
\text { Universidad. Tener un canal de } \\
\text { difusión propio hacia la } \\
\text { comunidad desde la Dirección } \\
\text { de DDHH de la FP y } \\
\text { CS.UNLP. }\end{array}$ & $\begin{array}{l}\text { Un programa semanal de } \\
\text { radio, de una hora de } \\
\text { duración, en la FM de radio } \\
\text { Universidad de La Plata. }\end{array}$ & $\begin{array}{l}\text { El programa se convirtió en } \\
\text { un referente en materia de } \\
\text { DDHH dentro de la radio y } \\
\text { nos permitió incorporar la } \\
\text { herramienta comunicacional } \\
\text { a la dirección, por el mismo } \\
\text { pasaron varies compañeres } \\
\text { que podían desarrollar } \\
\text { temáticas espećícicas. }\end{array}$ & $\begin{array}{l}\text { Desarrollo de las temáticas en } \\
\text { ddhh desde una visión integral } \\
\text { de la Dirección de DDHHH de } \\
\text { la facultad y enorme avance en } \\
\text { polítcas de ddhh como } \\
\text { política de Estado del } \\
\text { gobierno en el ámbito } \\
\text { nacional. } \\
\text { un lugar DDHH importante ocupap la } \\
\text { agenda mediática }\end{array}$ & $\begin{array}{l}\text { Programas, informes de } \\
\text { gestión. }\end{array}$ \\
\hline 2005 & $\begin{array}{l}\text { Mural de la artista Cristina } \\
\text { Terzaghi, en la fachada de la } \\
\text { sede de calle } 44 \text { de la Facultad } \\
\text { con la imágen de Rosa Bru y } \\
\text { de Miguel Bru." }\end{array}$ & $\begin{array}{l}\text { Asociación Miguel Bru, } \\
\text { Madres y Abuelas de Plaza de } \\
\text { Mayo de La plata, militancia } \\
\text { universitaria, organismos y } \\
\text { referentes de DDHH, } \\
\text { comunidad académica en } \\
\text { general, equipo de gestión de } \\
\text { la Facultad de Periodismo. }\end{array}$ & $\begin{array}{l}\text { Mantener viva la memoria de lo } \\
\text { que pasó con Miguel Bru y de } \\
\text { la lucha por la búsqueda de } \\
\text { justicia }\end{array}$ & $\begin{array}{l}\text { Realización de dos murales } \\
\text { en la fachada de la facultad } \\
\text { de Periodismo, por el equipo } \\
\text { de la muralista Cristina } \\
\text { Terzaghi, e inauguración del } \\
\text { mismo con un acto en la } \\
\text { calle, afuera de la sede y en } \\
\text { el interior de la Facultad se } \\
\text { inauguró una muestra con } \\
\text { fotos y relatos de jóvenes de } \\
\text { la Isla Maciel de Avellaneda } \\
\text { en el marco de los talleres } \\
\text { que daba en ese lugar la } \\
\text { Asociación Miguel Bru.. }\end{array}$ & $\begin{array}{l}\text { Mural en la fachada, el acto } \\
\text { fue muy masivo y emotivo. }\end{array}$ & $\begin{array}{l}\text { Se iniciaba la denominada } \\
\text { "era de los derechos } \\
\text { humanos", como se denomi- } \\
\text { naba a la política del } \\
\text { gobierno de Nestor Kirchner } \\
\text { en ese sentido. }\end{array}$ & $\begin{array}{l}\text { Página web de la Asociación } \\
\text { Miguel Bru y de la Facultad } \\
\text { de Periodismo de la UNLP, } \\
\text { informes de gestión, notas } \\
\text { periodísticas. }\end{array}$ \\
\hline $2004 / / 2007$ & $\begin{array}{l}\text { Armado de listado de } \\
\text { desaparecides de la UNLP }\end{array}$ & $\begin{array}{l}\text { Víctimas del terrorismo } \\
\text { de Estado, dirección de } \\
\text { ddhh de la UNLP, } \\
\text { Secretaria de ddhh de } \\
\text { Periodismo, madres de } \\
\text { plaza de Mayo de La } \\
\text { Plata, familiares de } \\
\text { víctimas. }\end{array}$ & $\begin{array}{l}\text { Confeccionar los listados } \\
\text { de víctimas del terrorismo } \\
\text { de Estado de la UNLP en } \\
\text { el marco del proceso de } \\
\text { memoria verdad y justicia } \\
\text { de nuestro país. }\end{array}$ & $\begin{array}{l}\text { Reuniones periódicas de } \\
\text { intercambio de informa- } \\
\text { ción, revisión de legajos y } \\
\text { actas administrativas, } \\
\text { información de familiares } \\
\text { y comnpañeres. }\end{array}$ & $\begin{array}{l}\text { Listados con historias de } \\
\text { las víctimas en el portal de } \\
\text { la UNLP y monumento a } \\
\text { les desaparecides en el } \\
\text { patio del rectorado de la } \\
\text { UNLP. }\end{array}$ & $\begin{array}{l}\text { Proceso de memoria verdad y } \\
\text { justicia. En } 2003 \text { el Congreso } \\
\text { de la Nación declarata la } \\
\text { nulidad de las leyes de Punto } \\
\text { Final y Obediencia Debida } \\
\text { algunos jueces comenzaron a } \\
\text { declarar inconstitucionales } \\
\text { aquellos indultos referidos a } \\
\text { crímenes de lesa humanidad y } \\
\text { a reabrir los casos. }\end{array}$ & $\begin{array}{l}\text { Directora de DDHH de la } \\
\text { UNLP, portal de la } \\
\text { Universidad, libro Huellas, } \\
\text { secretario de DDHH FP y } \\
\text { CS UNLP. }\end{array}$ \\
\hline
\end{tabular}




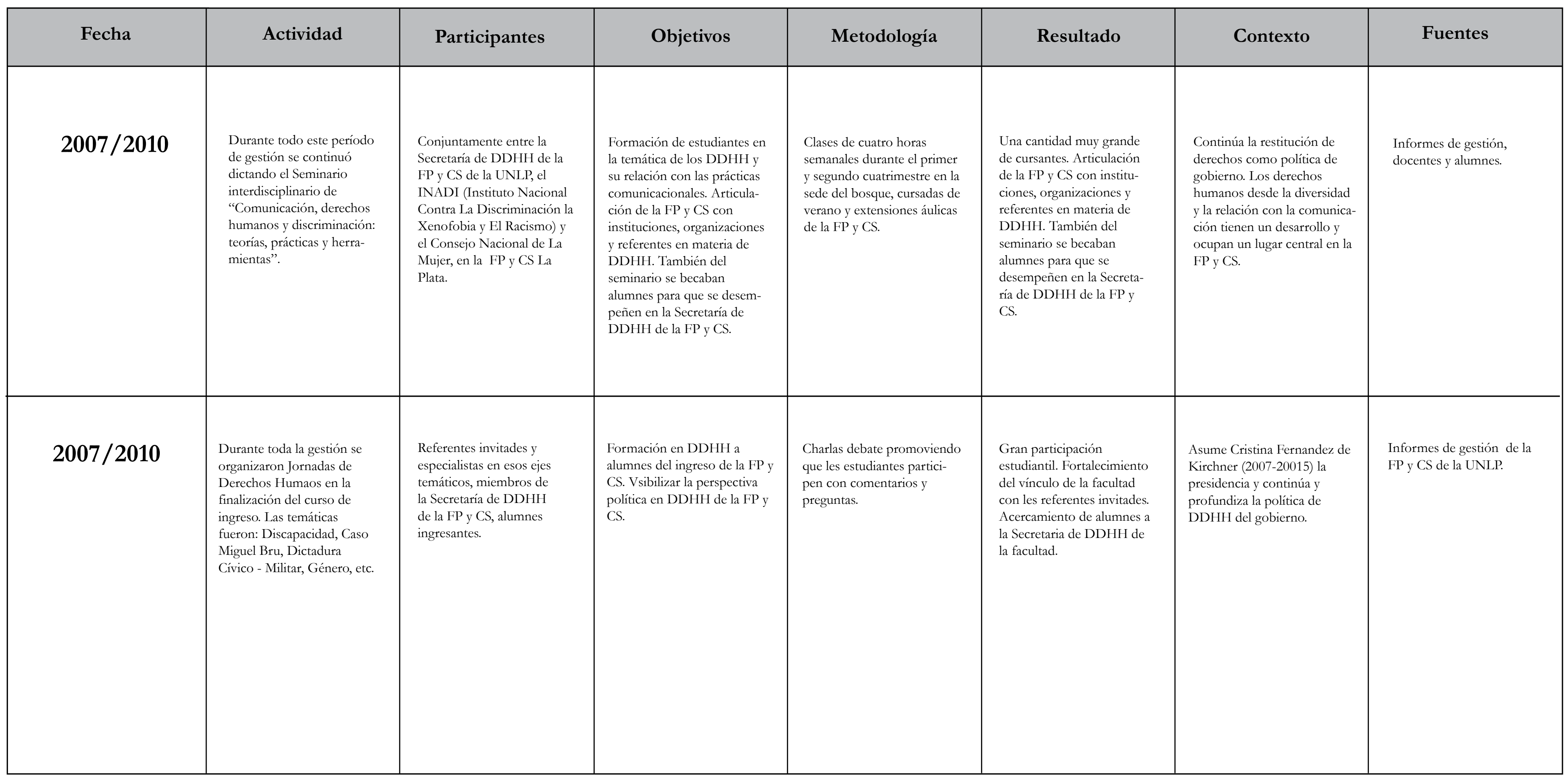




\begin{tabular}{|c|c|c|c|c|c|c|c|}
\hline Fecha & Actividad & Participantes & Objetivos & Metodología & Resultado & Contexto & Fuentes \\
\hline 2007 & $\begin{array}{l}\text { Acto al cumplirse } 30 \text { años } \\
\text { de la desaparición de } \\
\text { Rodolfo Walsh, inaugura- } \\
\text { ción de obra escultórica en } \\
\text { la plaza San Martín de La } \\
\text { Plata. }\end{array}$ & $\begin{array}{l}\text { Organizado por la Secretaría } \\
\text { de DDHH de la Provincia de } \\
\text { Buenos Aires y la Dirección } \\
\text { de DDHH de la FP y CS. } \\
\text { Participaron Lorena Riesgo, } \\
\text { pta. de la comisión de } \\
\text { DDHH de la Municipalidad } \\
\text { de La Plata, Madres y } \\
\text { Abuelas de Plaza de Mayo, } \\
\text { Felipe Solá Gobernador de la } \\
\text { Provincia de Buenos Aires, } \\
\text { H.I.J.O.S. La Plata, autorida- } \\
\text { des de la Universidad } \\
\text { Nacional de La Plata y de la } \\
\text { FP y CS de la UNLP, } \\
\text { comunidad académica, Rosa } \\
\text { Bru, referentes de DDHH, } \\
\text { militantes, organizaciones } \\
\text { políticas y organismos, ONG } \\
\text { Asociación Civil "Hom- } \\
\text { bre-Barro-Fuego" (realizado- } \\
\text { res de la escultura). }\end{array}$ & $\begin{array}{l}\text { Hacer un acto y una escultura } \\
\text { por la memoria del periodista } \\
\text { Rodolfo Walsh, al cumplirse el } \\
30 \text { aniversario de su desapari- } \\
\text { ción. }\end{array}$ & $\begin{array}{l}\text { Hacer una escultura en } \\
\text { alusión al escritor y periodis- } \\
\text { ta Rodolfo Walsh, encargarle } \\
\text { la obra a la ONG de } \\
\text { escultores "Hombre-Ba- } \\
\text { rro-Fuego", en la misma se } \\
\text { ve en una silla la cara de } \\
\text { Rodolfo Walsh y una } \\
\text { máquina de escribir, en el } \\
\text { centro de nuestra ciudad y } \\
\text { enfrente del club de Ajedrez } \\
\text { donde Walalsh practicaba. } \\
\text { Realización de un acto } \\
\text { público en la Plaza San } \\
\text { Martín para la inauguración } \\
\text { del monolito. }\end{array}$ & $\begin{array}{l}\text { Acto con enorme concu- } \\
\text { rrencia, de hecho también } \\
\text { participó como orador el } \\
\text { gobernador de la provincia, } \\
\text { Felipe Solá, también } \\
\text { muchas Madres y Abuelas } \\
\text { de Plaza de Mayo estuvie- } \\
\text { ron presentes, y mucha } \\
\text { presencia de la Facultad de } \\
\text { Periodismo, inauguración } \\
\text { del monolito emplazado en } \\
\text { la Plaza San Martín de La } \\
\text { Plata. }\end{array}$ & $\begin{array}{l}\text { El secretario de DDHH de la } \\
\text { Provincia de Buenos Aires es } \\
\text { un conocido militante de } \\
\text { DDHH, con la esposa y el } \\
\text { hermano asesinados por la } \\
\text { dictadura cívico militar, él } \\
\text { exiliado y su mamá una de las } \\
\text { fundadoras de Madres de } \\
\text { Plaza de Mayo. En la } \\
\text { Secretaría de DDHH de la } \\
\text { Nación, estaba Eduardo Luis } \\
\text { Duhalde, abogado de presos } \\
\text { políticos durante el terroris- } \\
\text { mo de Estado, militinte } \\
\text { peronista y durante el exilio } \\
\text { por la dictadura Cívico militar } \\
\text { de nuestro país se dedicó, } \\
\text { desde el extranjero, a } \\
\text { dennunciar y visibilizar las } \\
\text { atrocidades que se cometían } \\
\text { en nuestro país. }\end{array}$ & $\begin{array}{l}\text { Informe de gestión } \\
\text { presentado en el Consejo } \\
\text { Directivo por la Dirección } \\
\text { de DDHH, organizadores } \\
\text { del evento (Jorge Jaunare- } \\
\text { na, Isidoro Harispe). } \\
\text { Google. }\end{array}$ \\
\hline 2007 & $\begin{array}{l}\text { Se vota en el Consejo } \\
\text { Directivo la creación de la } \\
\text { Secretaría de DDHH de la } \\
\text { Facultad de Periodismo y } \\
\text { Comunicación Social. }\end{array}$ & $\begin{array}{l}\text { Director, a partir de ahora } \\
\text { Secretario de DDHH de la } \\
\text { FP y CS. Equipo de gestión } \\
\text { en DDHH, comunidad } \\
\text { académica de la FP y CS. } \\
\text { Decano, Consejo Directivo } \\
\text { de la FP y CS. }\end{array}$ & $\begin{array}{l}\text { Reforzar la politica de } \\
\text { DDHH de la facultad, } \\
\text { jerarquizar el área de DDHH } \\
\text { de la facultad, multiplicar } \\
\text { acciones en DDHH. }\end{array}$ & $\begin{array}{l}\text { Articulación de políticas } \\
\text { públicas en DDHH desde el } \\
\text { diálogo de saberes, acompa- } \\
\text { ñamiento y ejecución de } \\
\text { políticas sociales en DDHH, } \\
\text { participación y acompaña- } \\
\text { miento a organismos, } \\
\text { organizaciones de DDHH y } \\
\text { de víctimas de violaciones a } \\
\text { los DDHH, talleres barriales } \\
\text { de empoderamiento en } \\
\text { DDHH, Capacitación a } \\
\text { docentes, alumnes y no } \\
\text { docentes, realización de } \\
\text { producciones comunicacio- } \\
\text { nales en DDHH, realización } \\
\text { de documentos, realización } \\
\text { de proyectos de investiga- } \\
\text { ción y extensión, articula- } \\
\text { ción permanente con actores } \\
\text { extra académicos referentes } \\
\text { en la búsqueda de justicia y } \\
\text { los DDHH. }\end{array}$ & $\begin{array}{l}\text { Se multiplica y desarrollan } \\
\text { las actividades de la } \\
\text { Facultad en materia de } \\
\text { DDHH, se entablan redes } \\
\text { de articulación con } \\
\text { organizaciones del Estado y } \\
\text { la sociedad civil. Se articula } \\
\text { desde el dílogo de saberes } \\
\text { con referentes, organismos } \\
\text { y organizaciones desde una } \\
\text { visión integral de derechos. } \\
\text { Se multiplican las activida- } \\
\text { des, relaciones instituciona- } \\
\text { les y se siguen incorporan- } \\
\text { do actorxs de la comunidad } \\
\text { que no tenían cabida en los } \\
\text { claustros académicos. }\end{array}$ & $\begin{array}{l}\text { Los Derechos Humanos } \\
\text { siguen siendo prioridad como } \\
\text { política de gobierno, se } \\
\text { multiplican y se jerarquizan } \\
\text { las áreas de DDHH en las } \\
\text { áreas institucionales de } \\
\text { gobierno y también en la } \\
\text { universidad. }\end{array}$ & $\begin{array}{l}\text { Informe de gestión, } \\
\text { resolución }\left(\mathrm{n}^{\circ} 087 / 2007\right) \\
\text { del Consejo Directivo de } \\
\text { la FP y CS. UNLP. }\end{array}$ \\
\hline
\end{tabular}




\begin{tabular}{|c|c|c|c|c|c|c|c|}
\hline Fecha & Actividad & Participantes & Objetivos & Metodología & Resultado & Contexto & Fuentes \\
\hline $2007-2010$ & $\begin{array}{l}\text { Programa de radio De Igual } \\
\text { a Igual; AM Radio Univers- } \\
\text { dad de La Plata (continua- } \\
\text { ción). }\end{array}$ & $\begin{array}{l}\text { Dirección de DDHH FP y } \\
\text { CS, alumnes, graduades y } \\
\text { docentes de la FP y CS. } \\
\text { Entrevistadss: Horacio } \\
\text { Vertbisky; Lilia Ferreyra; } \\
\text { Osvaldo Bayer; Raúl } \\
\text { Zaffaroni; Rubén López } \\
\text { (Hijo de Jorge Julio Lópeze); } \\
\text { Dora Bravo (Alumna de } \\
\text { Carlos Fuentealba); Alba } \\
\text { Martino; (Madre de Plaza de } \\
\text { Mayo); Estela Carlotto } \\
\text { (Presidenta Abuelas de Plaza } \\
\text { de Mayo); Verónica Piccone } \\
\text { (Directora de DDHH del } \\
\text { Rectorado de la UNLP por } \\
\text { Homenaje de UNLP a 30 } \\
\text { años de Madres); Antonio } \\
\text { Fenoy (Marcha Pibes del } \\
\text { Pueblo); Walter Oviedo } \\
\text { (Presidente Centro de } \\
\text { estudiantes Unidad ); julio } \\
\text { Ferrer (autor del libro } \\
\text { "Osvaldo Bayer INTI- } \\
\text { MO-Conversaciones con el } \\
\text { eterno libertario"); Nilda } \\
\text { Eloy; Norberto Liwsky (Dir. } \\
\text { Programa de Asistencia a } \\
\text { Testigos avalado por la } \\
\text { ONU, CODESEDH); } \\
\text { Guadalupe Godoy,(abogada } \\
\text { de la querellla del juicio a Von } \\
\text { Wernich); Félix Croux (fiscal } \\
\text { del juicio a Von Wernich); } \\
\text { Roberto Cipriano (Comité } \\
\text { Contra la Tortura); ;tc. }\end{array}$ & $\begin{array}{l}\text { Difundir la política de Dere- } \\
\text { chos Humanos de la Secretaría. } \\
\text { Información en relación a los } \\
\text { ddhh a nivel local y nacional. } \\
\text { Trabajar en relación a la } \\
\text { comunicación con perspectiva } \\
\text { en DDHH. }\end{array}$ & $\begin{array}{l}\text { Entrevistas a especialistas } \\
\text { en Derechos Humanos. } \\
\text { Entrevistas a referentes y } \\
\text { víctimas de violaciones a los } \\
\text { DDHH en dictadura y } \\
\text { democracia. Investigaciones } \\
\text { periodísticas. Desarrollo de } \\
\text { columnas y editoriales } \\
\text { periodísticas sobre determi- } \\
\text { nadas temáticas en relación } \\
\text { a los DDHH. }\end{array}$ & $\begin{array}{l}\text { Logramos consolidar el } \\
\text { programa como referencia } \\
\text { en nuestra ciudad y en radio } \\
\text { universidad como espacio } \\
\text { de DDHH. }\end{array}$ & $\begin{array}{l}\text { Desarrollo del proceso de } \\
\text { Memoria Verdad y Justicia. } \\
\text { Notorio avance en materia de } \\
\text { DDHH en nuestro país. }\end{array}$ & $\begin{array}{l}\text { Informes de gestión. } \\
\text { Programas grabados. } \\
\text { Equipo realizador del } \\
\text { programa. }\end{array}$ \\
\hline $2007 / 2008$ & $\begin{array}{l}\text { Proyecto Comunicación en } \\
\text { Cárceles. }\end{array}$ & $\begin{array}{l}\text { Dirección de DDHH FP y } \\
\text { CS; equipo de gestión, } \\
\text { Ministerio de Justicia de la } \\
\text { Provincia de Bunenos Aires; } \\
\text { internos de Unidades } \\
\text { Penitenciarias de la Provincia } \\
\text { de Bs, As. ( } 8 \text { y } 33 \text { de Los } \\
\text { Hornos; } 18 \text { de Gorina, } 9 \text { de } \\
\text { La Plata; } 24 \text { de Florencio } \\
\text { Varela; } 28,36 \text { y } 51 \text { de } \\
\text { Magdalena; } 26 \text { de Olmos; } 3 \\
\text { de San Nicolás) y agentes del } \\
\text { SPB.. }\end{array}$ & $\begin{array}{l}\text { Promover el derecho a la } \\
\text { educación en las cárceles. } \\
\text { Potenciar la comunicación y } \\
\text { las capacidades expresivas y } \\
\text { al finalizar este primer } \\
\text { convenio con la implemen- } \\
\text { tación de la carrera de } \\
\text { Comunicación Social en las } \\
\text { cárceles del SPB. }\end{array}$ & $\begin{array}{l}\text { Talleres de producción } \\
\text { periodística (Radial y } \\
\text { Gráfica) en } 15 \text { unidades de } \\
\text { la Provincia de Buenos } \\
\text { Aires. }\end{array}$ & $\begin{array}{l}\text { Publicación de diarios y } \\
\text { programas radiales al } \\
\text { finalizar cada taller. Se } \\
\text { potenciaron los lazos entre } \\
\text { la Facultad de Periodismo } \\
\text { de la UNLP y les privades } \\
\text { de libertad. }\end{array}$ & $\begin{array}{l}\text { En el marco del Convenio } \\
\text { entre la FP y CS con el } \\
\text { Ministerio de Justicia de la } \\
\text { Provincia de Buenos Aires. }\end{array}$ & $\begin{array}{l}\text { Informe de gestión, } \\
\text { integrantes de la Secre de } \\
\text { DDHH de la FP y CS. } \\
\text { UNLP. Diarios y } \\
\text { programas radiales con } \\
\text { las producciones } \\
\text { realizadas por lxs } \\
\text { privades al finalizar cada } \\
\text { taller. Convenio entre el } \\
\text { Ministerio de Justicia de } \\
\text { la provincia de Bs As y la } \\
\text { FP y CS. }\end{array}$ \\
\hline
\end{tabular}




\begin{tabular}{|c|c|c|c|c|c|c|c|}
\hline Fecha & Actividad & Participantes & Objetivos & Metodología & Resultado & Contexto & Fuentes \\
\hline 2007 & $\begin{array}{l}\text { Presentación del libro } \\
\text { "Medios de Comunicación y } \\
\text { Discriminación: Desigual- } \\
\text { dad de clase, diferencias de } \\
\text { identidades, expresiones de } \\
\text { género y orientaciones } \\
\text { sexuales en los medios de } \\
\text { comunicación". }\end{array}$ & $\begin{array}{l}\text { El Área Queer de la Facultad } \\
\text { de Filosofía y Letras de la } \\
\text { Universidad de Buenos Aires } \\
\text { (UBA), la Cátedra de } \\
\text { Comunicación y Derechos } \\
\text { Humanos de la Facultad de } \\
\text { Periodismo y Comunicación } \\
\text { de la Universidad Nacional } \\
\text { de La Plata (UNLP), el } \\
\text { Proyecto Antirrepresivo de la } \\
\text { Secretaría de } \\
\text { Extensión de la Facultad de } \\
\text { Ciencias de la Educación de } \\
\text { la Universidad Nacional de } \\
\text { Entre Ríos (UNER), el } \\
\text { Observatorio de Medios de } \\
\text { la Unión de Trabajadores de } \\
\text { Prensa de Buenos Aires } \\
\text { (UTPBA), la Federación } \\
\text { Argentina de Lesbianas Gays } \\
\text { Bisexuales y Trans (FAL- } \\
\text { GBT) y la Liga } \\
\text { Argentina por los Derechos } \\
\text { del Hombre (LADH) }\end{array}$ & $\begin{array}{l}\text { Analizar la cobertura } \\
\text { periodística y los problemas } \\
\text { relacionados con desigualdad } \\
\text { de clase y diferencias por } \\
\text { edad, entias, géneros, } \\
\text { identidades de géneros y } \\
\text { orientaciones y prácticas } \\
\text { sexuales no normativas, } \\
\text { problematizar sobre discursos } \\
\text { discriminatorios que ayudan a } \\
\text { legitimar ideologias represivas } \\
\text { vinculadas con xenofobia, } \\
\text { racismo, sexismo, homofobia, } \\
\text { lesbofobia, travestofobia y } \\
\text { transfobia. }\end{array}$ & $\begin{array}{l}\text { Acto en la FP y CS con la } \\
\text { disertación del Lic. Jorge } \\
\text { Jaunarena, integrantes del } \\
\text { área Queer de la UBA y de } \\
\text { la Liga Argentina por los } \\
\text { Derechos Humanos. }\end{array}$ & $\begin{array}{l}\text { Presentación del informe n } \\
\text { el marco de una sala repleta } \\
\text { de alumnxs, docentes y } \\
\text { graduades. }\end{array}$ & $\begin{array}{l}\text { Era de ampliación de } \\
\text { Derechos y también de un } \\
\text { creciente debate sobre el rol } \\
\text { de los medios de comunica- } \\
\text { ción y su incidencia en la } \\
\text { opinión de las audiencias. }\end{array}$ & $\begin{array}{l}\text { Informes de gestión, } \\
\text { Google, libro. }\end{array}$ \\
\hline 2007 & $\begin{array}{l}\text { Coordinación del número } \\
53 \text { de la revista Tram(p)as } \\
\text { de la Comunicación y la } \\
\text { Cultura: "Comunicación y } \\
\text { derechos Humanos. La } \\
\text { búsqueda de justicia, } \\
\text { historias de ayer y de hoy". }\end{array}$ & $\begin{array}{l}\text { Con la participación de } \\
\text { Eugenio Zaffaroni, Eduardo } \\
\text { Luis Duhalde, Lilia Ferreira, } \\
\text { Horacio Verbitsky, Adelina } \\
\text { Alayes, Estela Carlotto, Rosa } \\
\text { Bru, Jorge Jaunarena, } \\
\text { comunidad académica; } \\
\text { equipo de gestión; entre } \\
\text { otros. }\end{array}$ & $\begin{array}{l}\text { Desde esta publicación } \\
\text { académica promover y } \\
\text { difundir los debates actuales } \\
\text { en materia de DDHH. } \\
\text { Interactuar con referentes } \\
\text { de la políitica Nacional en } \\
\text { materia de derechos } \\
\text { humanos y difundir las } \\
\text { principales políticas de } \\
\text { DDHH de ese momento en } \\
\text { Argentina. La coordinación } \\
\text { de la publicación estuvo a } \\
\text { cargo del Secretario de } \\
\text { DDHH de la FP y CS. } \\
\text { UNLP. }\end{array}$ & $\begin{array}{l}\text { A cada une de les referentes } \\
\text { menciondes en el punto } 3 \mathrm{se} \\
\text { le pidió un artículo de } \\
\text { elaboración propia sobre } \\
\text { algún eje en derechos } \\
\text { humanosos. Publicación } \\
\text { gráfica y también digital. }\end{array}$ & $\begin{array}{l}\text { Publicación del número } 53 \\
\text { de la revista Tram(p)as de la } \\
\text { Comunicación y la Cultura: } \\
\text { "Comunicación y derechos } \\
\text { Humanos. La búsqueda de } \\
\text { justicia, historias de ayer y } \\
\text { de hoy". }\end{array}$ & $\begin{array}{l}\text { Era de ampliación de } \\
\text { derechos humanos. Los } \\
\text { temas establecidos en la } \\
\text { publicación tienen que ver } \\
\text { con nuevas discusiones y } \\
\text { conceptualizaciones de } \\
\text { DDHH en nuestro país. } \\
\text { Nuevos debates que se abren } \\
\text { durante la presidencia de } \\
\text { Nestor Kirchner. }\end{array}$ & $\begin{array}{l}\text { Página web de la FP y CS. } \\
\text { Informe de gestión. } \\
\text { Publicación de Tram(p)as } \\
\text { N}^{\circ} 53\end{array}$ \\
\hline
\end{tabular}




\begin{tabular}{|c|c|c|c|c|c|c|c|}
\hline Fecha & Actividad & Participantes & Objetivos & Metodología & Resultado & Contexto & Fuentes \\
\hline 2007 & $\begin{array}{l}\text { Presentación del libro } \\
\text { "Mujeres dirigentes } \\
\text { indígenas. Relatos e } \\
\text { Historias de Vida", publica- } \\
\text { do por la Secretaría de } \\
\text { Cultura de la Nación. }\end{array}$ & $\begin{array}{l}\text { Dirección de DDHH; equipo } \\
\text { de gestión; Carmelo Sardinas } \\
\text { presidente de la comunidad } \\
\text { Minkáakuy Tawantinsuyupaq y } \\
\text { profesor de Quechua de la } \\
\text { Universidad de La Matanza y } \\
\text { de la UBA; Patricia González, } \\
\text { representante de la Comuni- } \\
\text { dad Mocovi de Berisso } \\
\text { integrante de la primera } \\
\text { familia que llegó desde } \\
\text { Chaco. }\end{array}$ & $\begin{array}{l}\text { Acompañar y visibilizar la } \\
\text { lucha y resistencia de las } \\
\text { comunidades aborígenes del } \\
\text { territorio Argentino desde } \\
\text { una perspectiva de género. } \\
\text { El libro contiene relatos de } \\
\text { mujeres dirigentes indígenas } \\
\text { de la Argentina. Su objetivo } \\
\text { es el de fomentar el respeto } \\
\text { a la diversidad cultural y } \\
\text { promover el conocimiento } \\
\text { de los pueblos indígenas al } \\
\text { divulgar su historia y los } \\
\text { procesos por los que } \\
\text { atraviesan en la actualidad, } \\
\text { desde la perspectiva de } \\
\text { mujeres que luchan por el } \\
\text { bienestar de sus pueblos. }\end{array}$ & $\begin{array}{l}\text { Mesa debate en la FP y CS } \\
\text { con integrantes de diferentes } \\
\text { comunidades indígenas. }\end{array}$ & $\begin{array}{l}\text { Presentación del libro y } \\
\text { posterior debate. Fortaleci- } \\
\text { miento del vínculo de la } \\
\text { Facultad con las comunida- } \\
\text { des indígenas y también } \\
\text { con la Secretaría de Cultura } \\
\text { de la Nación. Involucra- } \\
\text { miento de nuestra comuni- } \\
\text { dad estudiantil en la } \\
\text { temática. }\end{array}$ & $\begin{array}{l}\text { Década de ampliación de } \\
\text { derechos. }\end{array}$ & Informe de gestión. \\
\hline 2007 & $\begin{array}{l}\text { Participación como } \\
\text { miembro de la Red Nacio- } \\
\text { nal de Investigadoras/es } \\
\text { sobre discriminación del } \\
\text { INADI (Instituto Nacional } \\
\text { contra la Discriminación, la } \\
\text { Xenofobia y el Racismo). }\end{array}$ & $\begin{array}{l}\text { Referentes de Universidades } \\
\text { nacionales, especialistas del } \\
\text { INADI, representantes de } \\
\text { observatorios de comunica- } \\
\text { ción y discriminación. }\end{array}$ & $\begin{array}{l}\text { Desde diferentes institucio- } \\
\text { nes y organizaciones de la } \\
\text { sociedad civil trabajamos } \\
\text { temas en relación a la } \\
\text { discriminación y los medios } \\
\text { de comunicación. Se } \\
\text { investiga, se producen } \\
\text { informes y se trabaja en la } \\
\text { publicación y difusión de la } \\
\text { problemática. }\end{array}$ & $\begin{array}{l}\text { Estudios y seguimiento de } \\
\text { medios, realización de } \\
\text { informes, formación y } \\
\text { divulgación sobre la } \\
\text { problemática y como } \\
\text { abordarla }\end{array}$ & $\begin{array}{l}\text {. Informes y divulgación. } \\
\text { Investigación. Deconstruc- } \\
\text { ción de prácticas discrimi- } \\
\text { natorias. Vinculación con } \\
\text { instituciones que trabajan la } \\
\text { temática. Vinculación con } \\
\text { el INADI. }\end{array}$ & $\begin{array}{l}\text { Era de ampliación de } \\
\text { derechos en el marco del } \\
\text { gobierno de Nestor Kirchner } \\
\text { donde se jerarquizó el } \\
\text { INADI y se multiplicaron sus } \\
\text { actividades. }\end{array}$ & $\begin{array}{l}\text { Informe de Gestión. } \\
\text { Página web INADI. }\end{array}$ \\
\hline 2007 & $\begin{array}{l}\text { Acto de entrega del título de } \\
\text { grado pos mortem a los } \\
\text { padres y hermana de Liliana } \\
\text { Molteni en la ciudad de La } \\
\text { Pampa. (graduada de la } \\
\text { FPyCS, desaparecida junto a } \\
\text { su pareja Daniel Elías en el } \\
\text { mes de Junio de } 1976 . \\
\text { Ambos eran oriundos de La } \\
\text { Pampa y ejercían el periodis- } \\
\text { mo) }\end{array}$ & $\begin{array}{l}\text { Secretaráía de Derechos } \\
\text { Humanos de la Provincia de } \\
\text { La Pampa; Gobernador de La } \\
\text { Pampa; secretaria de DDHH } \\
\text { FP y CS (UNLP); decano de la } \\
\text { FP y CS UNLP; Dirección de } \\
\text { títulos UNLP; Familiares de } \\
\text { detenidos desaparecidos; } \\
\text { Madres de Plaza de Mayo; } \\
\text { familiares de Liliana Molteni }\end{array}$ & $\begin{array}{l}\text { Aportar a la construcción } \\
\text { de la memoria colectiva en } \\
\text { referencia a lo acontecido } \\
\text { en el Terrorismo de Estado } \\
\text { en la FP y CS. Vincularse } \\
\text { con les familiares de las } \\
\text { víctimas, con estudiantes de } \\
\text { la época, organismos de } \\
\text { DDHH a nivel Nacional y } \\
\text { también organizaciones } \\
\text { gubernamentales. }\end{array}$ & $\begin{array}{l}\text { Acto público y conferencia } \\
\text { de prensa en la ciudad de La } \\
\text { Pampa con autoridades del } \\
\text { gobierno provincial, de la } \\
\text { FP y CS, familiares de la } \\
\text { víctima y compañeres de } \\
\text { militancia. Anteriormente se } \\
\text { hicieron todas la gestiones } \\
\text { correspondientes con la } \\
\text { dirección de Títulos de la } \\
\text { UNLP. }\end{array}$ & $\begin{array}{l}\text { Finalmente y luego de } \\
\text { muchos trámites adminis- } \\
\text { trativos se logró conseguir } \\
\text { el titulo y hacer entrega del } \\
\text { mismo, en la ciudad de La } \\
\text { Pampa a los familiares de } \\
\text { Liliana Molteni, desapareci- } \\
\text { da por la dictadura cívico } \\
\text { militar y encontrada en una } \\
\text { tumba sin nombre en el } \\
\text { cementerio de Avellaneda } \\
\text { en el año } 2005\end{array}$ & $\begin{array}{l}\text { Los juicios de Lesa Humani- } \\
\text { dad se inician en el año } 2006 \\
\text { luego de la nulidad de las } \\
\text { leyes del perdón. Avanza a } \\
\text { paso firme el denominado } \\
\text { proceso de Memoria Verdad } \\
\text { y Justicia en nuestro país. }\end{array}$ & $\begin{array}{l}\text { Diarios de La Pampa, } \\
\text { informe de gestión. }\end{array}$ \\
\hline
\end{tabular}




\begin{tabular}{|c|c|c|c|c|c|c|c|}
\hline Fecha & Actividad & Participantes & Objetivos & Metodología & Resultado & Contexto & Fuentes \\
\hline 2007 & $\begin{array}{l}\text { Acto de colación a los } \\
\text { egresados de la clase } 1975 \\
\text { de la FP y CS, el mismo } \\
\text { había sido truncado por la } \\
\text { dictadura cívico militar. }\end{array}$ & $\begin{array}{l}\text { Centro de Graduados, FPy } \\
\text { CS; autoridades universita- } \\
\text { rias; comunidad académica } \\
\text { de la FP y CS; equipo de } \\
\text { gestión de la secretaría de } \\
\text { DDHH FP y CS; Madres } \\
\text { de Plaza de Mayo; entre } \\
\text { otros. }\end{array}$ & $\begin{array}{l}\text { Aportar a la construcción } \\
\text { de la memoria colectiva en } \\
\text { referencia a lo acontecido } \\
\text { en el Terrorismo de Estado. } \\
\text { Vincular a la FP y CS con } \\
\text { los familiares de las víctimas } \\
\text { y estudiantes de la época. } \\
\text { Realizar un acto de repara- } \\
\text { ción universitaria hacia la } \\
\text { generación de estudiantes } \\
\text { que fuerón víctimas de la } \\
\text { represión. }\end{array}$ & $\begin{array}{l}\text { Acto público en la FPyCS. } \\
\text { Estuvieron presentes y } \\
\text { entregaron diplomas Estela } \\
\text { Carlotto y Rosa Schonfeld } \\
\text { de Bru. }\end{array}$ & $\begin{array}{l}\text { Se concretó el acto y se } \\
\text { entregaron los títulos } \\
\text { simbólicos. Les egresades } \\
\text { fueron con familiares y } \\
\text { amiges, fue muy emotivo ya } \\
\text { que muchos, además de } \\
\text { recordar a les compañeres } \\
\text { que habían sido víctimas de } \\
\text { la dictadura, no habían } \\
\text { vuelto a pisar la ciudad de } \\
\text { La Plata desde el exilio. }\end{array}$ & $\begin{array}{l}\text { Gran consolidación del } \\
\text { proceso de Memoria Verdad } \\
\text { y Justicia en la Argentina. }\end{array}$ & $\begin{array}{l}\text { Informe de gestión, } \\
\text { página web de la FP y CS, } \\
\text { testimonios de los } \\
\text { egresades promoción } 75 .\end{array}$ \\
\hline 2007 & $\begin{array}{l}\text { Firma del convenio de } \\
\text { intercambio entre la } \\
\text { Universidad Nacional de } \\
\text { La Plata y la Universidad } \\
\text { Bolivariana de Venezuela. } \\
\text { Presentación de la muestra } \\
\text { de Rodolfo Walsh realizada } \\
\text { por la FP y CS de la UNLP } \\
\text { en la feria del libro que se } \\
\text { realiza anualmente en } \\
\text { Caracas, Venezuela. Esto } \\
\text { fue producto de la } \\
\text { invitación de la Secretaría } \\
\text { de Cultura de la Nación. }\end{array}$ & $\begin{array}{l}\text { FPyCS; rectorado UNLP; } \\
\text { Universidad Bolivariana } \\
\text { de Venezuela, Secretaría } \\
\text { de Cultura de la Nación. }\end{array}$ & $\begin{array}{l}\text { Fomentar el vínculo con la } \\
\text { patria grande de Latinoamé- } \\
\text { rica, en este caso con la } \\
\text { Universidad Bolivariana, } \\
\text { creada por el presidente } \\
\text { Chavez con el objetivo de } \\
\text { que los sectores populares } \\
\text { tengan acceso al estudio } \\
\text { universitario, cosa que } \\
\text { tenían vedada hasta } \\
\text { entonces. Poder hacer } \\
\text { intercambios de alumnes de } \\
\text { grado y posgrado, docentes } \\
\text { y planificar actividades } \\
\text { conjuntas. }\end{array}$ & $\begin{array}{l}\text { En el marco de la } \\
\text { invitación de la Secretaría } \\
\text { de Cultura de la Nación a } \\
\text { presentar la muestra de la } \\
\text { FP y CS sobre Rodolfo } \\
\text { Walsh, en la feria del libro } \\
\text { de Venezuela hicimos los } \\
\text { contacto previos con } \\
\text { autoridades de la Univer- } \\
\text { sidad Bolivariana, y con la } \\
\text { carrera de Comunicación } \\
\text { de la misma para firmar el } \\
\text { convenio marco que nos } \\
\text { autorizó y firmó el rector } \\
\text { de la UNLP. }\end{array}$ & $\begin{array}{l}\text { Firmamos el convenio con } \\
\text { la rectora de la UBV. } \\
\text { Presentamos la muestra } \\
\text { sobre Rodolfo Walsh en la } \\
\text { feria del Libro de Venezuela. }\end{array}$ & $\begin{array}{l}\text { La unidad Latinoamericana } \\
\text { entre gobiernos que } \\
\text { piensan ideológicamente en } \\
\text { forma similar y proyectan } \\
\text { políticas que benefician a } \\
\text { los sectores populares, } \\
\text { pensando en el proyecto de } \\
\text { patria grande de Simon } \\
\text { Bolívar. Lula en Brasil, } \\
\text { Morales en Bolivia, Correa } \\
\text { en Ecuador, Chavez en } \\
\text { Venezuela, Kirchner en } \\
\text { Argentina, etc. }\end{array}$ & $\begin{array}{l}\text { Convenio Marco; } \\
\text { informes de gestión. }\end{array}$ \\
\hline
\end{tabular}




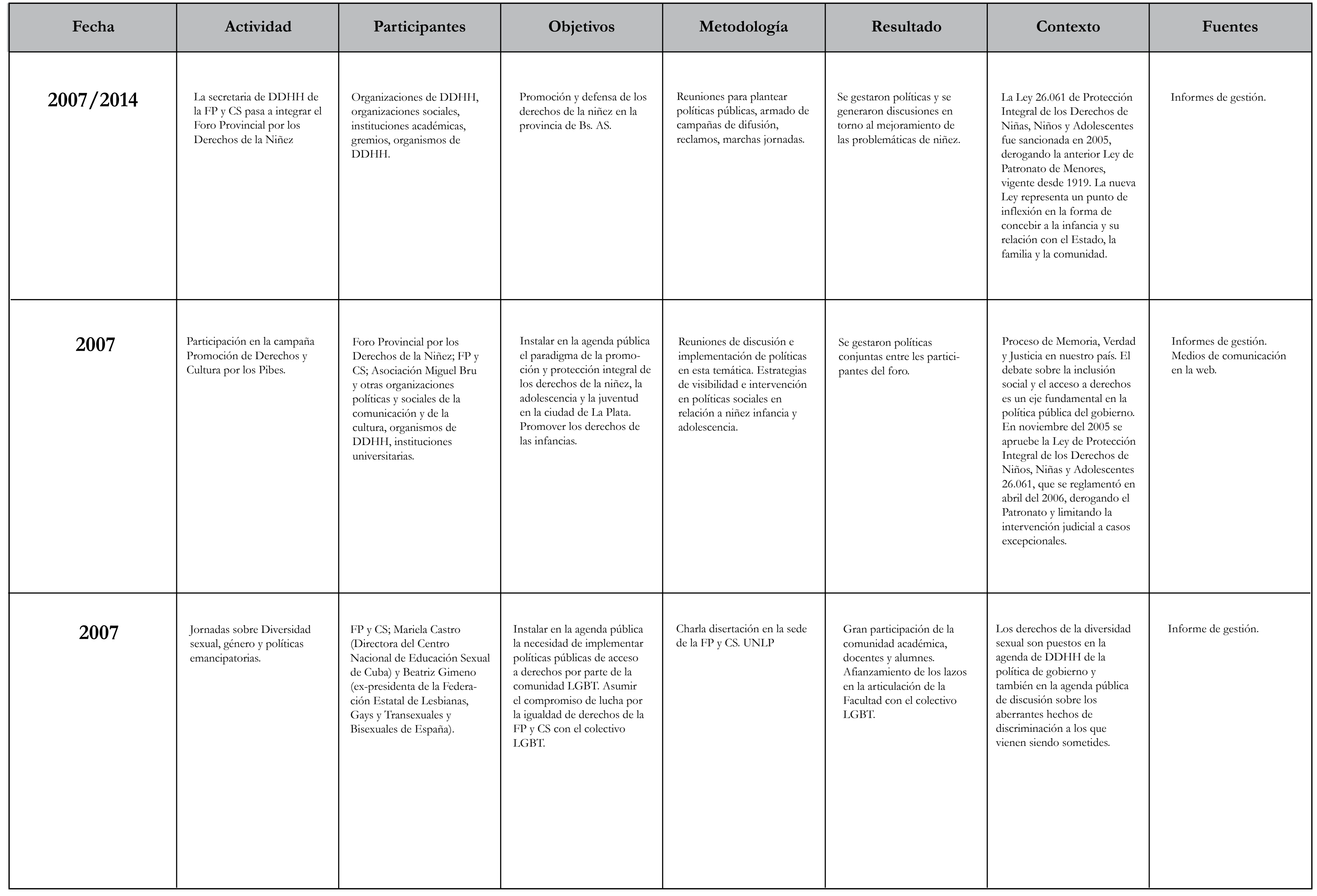




\begin{tabular}{|c|c|c|c|c|c|c|c|}
\hline Fecha & Actividad & Participantes & Objetivos & Metodología & Resultado & Contexto & Fuentes \\
\hline $2007 / 2014$ & $\begin{array}{l}\text { Seminario Interdisciplinario } \\
\text { Comunicación y Derechos } \\
\text { Humanos, en la ciudad de } \\
\text { La Plata y en la extensión } \\
\text { áulica de la ciudad de } \\
\text { Lincoln. }\end{array}$ & $\begin{array}{l}\text { Secretaría de DDHH FP y CS; } \\
\text { docentes del seminario de } \\
\text { Com y DDHH; un gran } \\
\text { número de alumnes cursaron } \\
\text { el seminario. }\end{array}$ & $\begin{array}{l}\text { Trabajar en la formación de } \\
\text { DDHH y la comunicación } \\
\text { con perspectiva en DDHH } \\
\text { con estudiantes de las } \\
\text { extensiones de la FPyCS. } \\
\text { Trabajar los DDHH desde } \\
\text { una perspectiva comunica- } \\
\text { cional. }\end{array}$ & $\begin{array}{l}\text { Seminario cuatrimestral de } 4 \\
\text { hs. semanales }\end{array}$ & $\begin{array}{l}\text { Formación en defensa y } \\
\text { promoción de derechos } \\
\text { humanos y comunicación. }\end{array}$ & $\begin{array}{l}\text { El debate sobre la relación } \\
\text { DDHH y comunicación se } \\
\text { transforma en tema de } \\
\text { agenda pública. Se empeizan } \\
\text { a sentar los ejes para la } \\
\text { creación de una nueva ley de } \\
\text { servicios en comunicación } \\
\text { audiovisual. Además el } \\
\text { seminario pretende dar } \\
\text { cuenta de hablar sobre la } \\
\text { historicidad sino fundamen- } \\
\text { talmente sobre feń́menos } \\
\text { actuales en relación a los } \\
\text { DDHH. }\end{array}$ & $\begin{array}{l}\text { Informe de gestión. } \\
\text { Plantel docente. Director } \\
\text { del seminario. }\end{array}$ \\
\hline 2007 & $\begin{array}{l}\text { Presentación de la muestra } \\
\text { fotográfica itinerante "La } \\
\text { Sublevación de la Palabra"; } \\
\text { sobre la vida y la obra de } \\
\text { Rodolfo Walsh en homenaje } \\
\text { al cumplirse } 30 \text { años de su } \\
\text { desaparición. }\end{array}$ & $\begin{array}{l}\text { Equipo de gestión de la FP } \\
\text { y CS. UNLP }\end{array}$ & $\begin{array}{l}\text { Fortalecer el proceso de } \\
\text { memoria por la detención, } \\
\text { desaparaición y muerte de } \\
\text { Rodolfo Walsh. Aportar a la } \\
\text { construcción de la memoria } \\
\text { colectiva en referencia a lo } \\
\text { acontecido durante el } \\
\text { Terrorismo de Estado de la } \\
\text { última dictadura cívica-mili- } \\
\text { tar-eclesiástica. }\end{array}$ & Debate durante la muestra. & $\begin{array}{l}\text { La muestra itinerante } \\
\text { recorrió varios lugares no } \\
\text { solo del ámbito nacional si } \\
\text { no también en la Feria del } \\
\text { libro de Venezuela. }\end{array}$ & $\begin{array}{l}\text { Proceso de memoria Verdad } \\
\text { y Justicia en nuestro país } \\
\text { como política del Gobierno. } \\
\text { Presidencia de Néstor } \\
\text { Kirchner. }\end{array}$ & Informe de gestión. \\
\hline 2007 & $\begin{array}{l}\text { Seminario de Periodismo y } \\
\text { Comunicación en la } \\
\text { Universidad Bolivariana de } \\
\text { Venezuela. }\end{array}$ & $\begin{array}{l}\text { FP y CS; Universidad } \\
\text { Bolivariana. }\end{array}$ & $\begin{array}{l}\text { Trabajar los ejes temáticos: } \\
\text { Rodolfo Walsh, el icono del } \\
\text { periodismo argentino, su } \\
\text { legado y su influencia en los } \\
\text { profesionales de hoy; La } \\
\text { formación del periodista en } \\
\text { las carreras de comunica- } \\
\text { ción de Argentina; Medios } \\
\text { de Comunicación y } \\
\text { derechos humanos. El rol } \\
\text { de los medios en la búsque- } \\
\text { da de justicia. El rol de los } \\
\text { medios en la formación de } \\
\text { opinión pública y La } \\
\text { comnnicación como forma } \\
\text { de expresión e identidad de } \\
\text { los excluidos sociales. } \\
\text { Fortalecer vínculos entre la } \\
\text { UBV y la FP y CS. }\end{array}$ & Disertación. & $\begin{array}{l}\text { Se fomentó un gran } \\
\text { conversatorio con alumnes } \\
\text { y docentes de la UBV y } \\
\text { decano, secretario de } \\
\text { DDHH y docentes de la FP } \\
\text { CS.UNLP }\end{array}$ & $\begin{array}{l}\text { La unidad política y de } \\
\text { acción entre Venezuela y } \\
\text { Argentina está cada vez mas } \\
\text { consolidada de la mano de } \\
\text { los presidentes Chavez y } \\
\text { Kirchner. }\end{array}$ & Informe de gestión. \\
\hline
\end{tabular}




\begin{tabular}{|c|c|c|c|c|c|c|c|}
\hline Fecha & Actividad & Participantes & Objetivos & Metodología & Resultado & Contexto & Fuentes \\
\hline 2008 & $\begin{array}{l}\text { Organización y coordina- } \\
\text { ción de la charla-presenta- } \\
\text { ción del libro "Crónicas de } \\
\text { la Resistencia Mapuche" de } \\
\text { Adrián Moyano sobre la } \\
\text { comunidad mapuche y la } \\
\text { lucha indígena. }\end{array}$ & $\begin{array}{l}\text { Adrián Moyano, comunidades } \\
\text { indígenas, Pascual Pichum } \\
\text { representante indígena de la } \\
\text { FP CS, secretario de DDHH. }\end{array}$ & $\begin{array}{l}\text { Visibilizar la lucha y } \\
\text { resistencia de la comunidad } \\
\text { mapuche. }\end{array}$ & $\begin{array}{l}\text { Presentación del libro y } \\
\text { disertación en el marco del } \\
\text { seminario de Comunicación } \\
\text { y DDHH en la FP y CS. }\end{array}$ & $\begin{array}{l}\text { Formación de nuestra } \\
\text { comunidad estudiantil con } \\
\text { respecto a la problemática } \\
\text { mapuche y fortalecimiento } \\
\text { del vínculo de la Facultad } \\
\text { con las comunidades } \\
\text { indígenas. }\end{array}$ & $\begin{array}{l}\text { La Ley nacional } 26160 \text { fue } \\
\text { sancionada a fines del año } \\
2006 \text { por un plazo de } \\
\text { vigencia de } 4 \text { años, a efectos } \\
\text { de dar respuesta a la situación } \\
\text { de emergencia territorial de } \\
\text { las Comunidades Indigenas } \\
\text { del país }\end{array}$ & Informe de gestión. \\
\hline 2008 & $\begin{array}{l}\text { Charla-debate con la } \\
\text { periodista Luisana Colomi- } \\
\text { ne, Directora de la carrera } \\
\text { Comunicación de la } \\
\text { Universidad Bolivariana de } \\
\text { Venezuela. }\end{array}$ & $\begin{array}{l}\text { Investigadores, secretarios y } \\
\text { docentes de la FP y CS. }\end{array}$ & $\begin{array}{l}\text { Compartir experiencias y } \\
\text { planificar proyectos de } \\
\text { intercambio entre la UBV y } \\
\text { la FP y CS. Intercambiar la } \\
\text { formación sobre la realidad } \\
\text { venezolana y Argentina. }\end{array}$ & Charla debate en la FP y CS. & $\begin{array}{l}\text { Fortalecimiento del vínculo } \\
\text { y el intercambio de ideas } \\
\text { entre la FP y CS y la UBV. }\end{array}$ & $\begin{array}{l}\text { Fortalecimiento de lazos y } \\
\text { acciones políticas entre } \\
\text { diversos gobiernos latinoa- } \\
\text { mericanos. }\end{array}$ & $\begin{array}{l}\text { Informe de gestión. } \\
\text { Secretario de DDHH. }\end{array}$ \\
\hline 2008 & $\begin{array}{l}\text { Charla-debate "Universidad, } \\
\text { comunicación y comunida- } \\
\text { des en el nuevo contexto } \\
\text { Latinoamericano" }\end{array}$ & $\begin{array}{l}\text { Secretaría de DDHH; Luisana } \\
\text { Colomine, directora de la } \\
\text { carrera de Comunicación de la } \\
\text { Universidad Bolivariana de } \\
\text { Venezuela y Decano de la } \\
\text { Facultad de Periodismo y } \\
\text { Comunicación Social de } \\
\text { Universidad de La Plata. }\end{array}$ & $\begin{array}{l}\text { Fomentar los vínculos } \\
\text { políticos y acciones en el } \\
\text { marco del convenio entre la } \\
\text { UBV y la FP y CS. }\end{array}$ & Charla/Debate. & $\begin{array}{l}\text { Intercambio de saberes y } \\
\text { experiencias. }\end{array}$ & $\begin{array}{l}\text { Fortalecimiento de lazos y } \\
\text { acciones políticas entre } \\
\text { diversos gobiernos latinoa- } \\
\text { mericanos. }\end{array}$ & Informe de gestión. \\
\hline 2008 & $\begin{array}{l}2^{\circ} \text { año de dictado de } \\
\text { Talleres de comunicación } \\
\text { gráfica y radiofónica en } \\
\text { Cárceles del SPB. }\end{array}$ & $\begin{array}{l}\text { Ministerio de Justicia de la } \\
\text { Provincia; SPV docentes y } \\
\text { secretaria de ddhh de la FP y } \\
\text { CS; UNLP; alumnxs detenidxs } \\
\text { en las unidades: No } 8 \text { de Los } \\
\text { Hornos, No.34 de Melchor } \\
\text { Romero; No } 36 \text { de Magdalena } \\
\text { y No } 42 \text { de Florencio Varela. }\end{array}$ & $\begin{array}{l}\text { Promover el Derecho a la } \\
\text { educación en las cárceles. } \\
\text { Garantizar el derecho a la } \\
\text { comunicación y educación } \\
\text { dentro del contexto de } \\
\text { encierro. }\end{array}$ & $\begin{array}{l}\text { Talleres de Producción } \\
\text { Gráfica, Radiofónica y } \\
\text { Planificación Comunicacional. }\end{array}$ & $\begin{array}{l}\text { Convenio con el Ministerio } \\
\text { de Justicia de la Provincia } \\
\text { de Buenos Aires. }\end{array}$ & $\begin{array}{l}\text { Daniel Scioli es gobernador } \\
\text { en la provincia de Buenos } \\
\text { Aires. }\end{array}$ & $\begin{array}{l}\text { Publicaciones gráficas y } \\
\text { radiales. Convenio entre la } \\
\text { FP y CS y el Ministerio de } \\
\text { justicia de la Provincia. } \\
\text { Informe de gestión. }\end{array}$ \\
\hline 2008 & $\begin{array}{l}\text { Congreso de Género } \\
\text { "Cuestiones de Género y } \\
\text { Comunicación y Narrativas } \\
\text { de la Diversidad Desigual": } \\
\text { "Lenguaje ofendido y } \\
\text { femicidio" }\end{array}$ & $\begin{array}{l}\text { FP y CS; Secretaría de } \\
\text { DDHH; comunidad } \\
\text { académica; equipo de gestión, } \\
\text { activistas y referentes. }\end{array}$ & $\begin{array}{l}\text { Fortalecer la defensa y } \\
\text { promoción de derechos } \\
\text { en cuestiones de género } \\
\text { y diversidad. Fortalecer la } \\
\text { formación en el área } \\
\text { específica de la comuni- } \\
\text { cación en cuestiones de } \\
\text { género. }\end{array}$ & $\begin{array}{l}\text { Disertaciones en diferentes } \\
\text { mesas y paneles. }\end{array}$ & $\begin{array}{l}\text { Formación de la comuni- } \\
\text { dad académica en cuestio- } \\
\text { nes de género y vínculo con } \\
\text { organizaciones y referentes } \\
\text { en la materia. }\end{array}$ & $\begin{array}{l}\text { Presidencia de Cristina } \\
\text { Fernandez de Kirchner, que } \\
\text { sigue llevando adelante y } \\
\text { profundizando las políitcas } \\
\text { de DDHH. En el marco de la } \\
\text { política de ddhh gran avance } \\
\text { en la agenda de derechos y en } \\
\text { materia de discusión sobre la } \\
\text { igualdad de género. La } \\
\text { desigualdad de género se } \\
\text { pone de manifiesto en la } \\
\text { agenda pública de discusión. }\end{array}$ & $\begin{array}{l}\text { Informe de gestión de la } \\
\text { Secretaría de DDHH de la } \\
\text { FP y CS. }\end{array}$ \\
\hline
\end{tabular}




\begin{tabular}{|c|c|c|c|c|c|c|c|}
\hline Fecha & Actividad & Participantes & Objetivos & Metodología & Resultado & Contexto & Fuentes \\
\hline 2008 & $\begin{array}{l}\text { Armado y presentación ante } \\
\text { el Consejo Académico por } \\
\text { reconocimiento a la } \\
\text { identidad de género de } \\
\text { Claudia Vasquez Haro, } \\
\text { alumna de la Facultad de } \\
\text { Periodismo y Comunicación } \\
\text { Social. }\end{array}$ & $\begin{array}{l}\text { Secretaría de DDHH y } \\
\text { Consejo académico de la FP y } \\
\text { CS; UNLP. Claudia Vásquez } \\
\text { Haro (alumna trans de la } \\
\text { Facultad) }\end{array}$ & $\begin{array}{l}\text { Reconocer la identidad de } \\
\text { género auto percibida de } \\
\text { Claudia Vásquez Haro y de } \\
\text { toda la comunidad estudian- } \\
\text { til de la FP y CS en nuestras } \\
\text { actas administrativas. Poder } \\
\text { llevar la propuesta al } \\
\text { Consejo Superior de la } \\
\text { UNLP. Contribuir desde la } \\
\text { universidad a la posibilidad } \\
\text { de tener la identidad de } \\
\text { género en el DNI. Poder } \\
\text { llevar adelante políticas } \\
\text { emancipatorias relacionadas } \\
\text { con los derechos humanos } \\
\text { en cuestiones de género y } \\
\text { diversidad sexual. }\end{array}$ & $\begin{array}{l}\text { Armado de la propuesta } \\
\text { entre el secretario de } \\
\text { DDHH, la alumna trans } \\
\text { Claudia Vasquez, el equipo } \\
\text { legal de la FP y CS. Presen- } \\
\text { tación en el Consejo } \\
\text { Directivo. }\end{array}$ & $\begin{array}{l}\text { La resolución } \mathrm{N}^{\circ} 25 / 20008 \\
\text { fue aprobada por unanimi- } \\
\text { dad y contempló además } \\
\text { hacer extensiva la medida a } \\
\text { todas las facultades de } \\
\text { UNLP. Una medida sin } \\
\text { precedentes en la historia } \\
\text { de las universidades } \\
\text { nacionales. }\end{array}$ & $\begin{array}{l}\text { Avance en la visibilidad de la } \\
\text { discriminación en nuestro } \\
\text { pá́s sobre la comunidad } \\
\text { LGBT }\end{array}$ & $\begin{array}{l}\text { Informe de gestión de la } \\
\text { Secretaría de DDHH FP } \\
\text { y CS. Testimonio de } \\
\text { Caludia Vasquez Haro. } \\
\text { Resolución del Consejo } \\
\text { Directivo. }\end{array}$ \\
\hline 2009 & $\begin{array}{l}\text { Firma del convenio con el } \\
\text { Ministerio de Justicia de la } \\
\text { Provincia de Buenos Aires } \\
\text { para la implementación de } \\
\text { una extensión áulica de las } \\
\text { carreras de de grado de la } \\
\text { FPyCS en la Unidad } \\
\text { Penitenciaria } \mathrm{N}^{\circ} 9 \text { de La } \\
\text { Plata dirigido a privades de } \\
\text { libertad de las cácreles del } \\
\text { SPB Servicio Penitenciario } \\
\text { Bonaerense. }\end{array}$ & $\begin{array}{l}\text { Ministerio de Justicia de la } \\
\text { provincia de Buenos Aires; } \\
\text { equipo de gestión de la } \\
\text { FPyCS; UNLP; Servicio } \\
\text { Penitenciario Bonaerense.) }\end{array}$ & $\begin{array}{l}\text { Garantizar el derecho a la } \\
\text { educación superior dentro } \\
\text { del contexto de encierro } \\
\text { carcelario. Llevar las } \\
\text { carreras de la Facultad de } \\
\text { Periodismo y Comunicación } \\
\text { Social de la UNLP a las } \\
\text { cárceles del SPB. Generar } \\
\text { condiciones para la circula- } \\
\text { ción de la palabra y el } \\
\text { ejercicio del derecho a la } \\
\text { universidad, educación y } \\
\text { comunicación. }\end{array}$ & $\begin{array}{l}\text { Tareas administrativas, } \\
\text { prácticas docentes, y } \\
\text { articulación con lxs } \\
\text { estudiantes. }\end{array}$ & $\begin{array}{l}\text { Firma del convenio para el } \\
\text { dictado del primer año de la } \\
\text { carrera de Licenciatura en } \\
\text { Comunicación Social de la } \\
\text { UNLP en la extensión } \\
\text { áulica ubicada en la Unidad } \\
\text { Penitenciaria } N^{\circ} \text { dirigida a } \\
\text { todes les privades de } \\
\text { libertad de cárceles del SPB. } \\
\text { Gran desarrollo y profundi- } \\
\text { zación de la inserción de la } \\
\text { Facultad en la cárcel y } \\
\text { viceversa. }\end{array}$ & $\begin{array}{l}\text { Siguen las prácticas discrimi- } \\
\text { natorias de la sociedad antes } \\
\text { lxs privadxs de libertad, } \\
\text { fogoneada muy especialmen- } \\
\text { te por los medios masivos de } \\
\text { comunicación que lxs define } \\
\text { solo como algo peligroso y } \\
\text { sin posibilidad de cambio o } \\
\text { reinserción. La Argentina } \\
\text { sigue siendo apercibida por } \\
\text { los organismos internaciona- } \\
\text { les debido a las pésimas } \\
\text { condiciones carcelarias. }\end{array}$ & $\begin{array}{l}\text { Convenio, coordinadores } \\
\text { de la secretaría de DDHH } \\
\text { de la FP y CS, informe de } \\
\text { gestión. }\end{array}$ \\
\hline 2009 & $\begin{array}{l}\text { Charla/Debate sobre } \\
\text { medios y dictadura con } \\
\text { motivo de cumplirse } 75 \\
\text { años del nacimiento de } \\
\text { nuestra casa de altos } \\
\text { estudios (FP y CS). }\end{array}$ & $\begin{array}{l}\text { Hebe de Bonafini; } \\
\text { FPyCS; Rosa Bru; } \\
\text { referentes periodísticos } \\
\text { de destacada trayecto- } \\
\text { ria en materia de } \\
\text { DDHH,comunidad } \\
\text { académica de la FP y } \\
\text { CS; autoridades de la } \\
\text { UNLP; equipo de } \\
\text { gestión de la FP y CS. }\end{array}$ & $\begin{array}{l}\text { Aportar a la construcción } \\
\text { de la memoria colectiva de } \\
\text { lo acontecido durante el } \\
\text { Terrorismo de Estado en la } \\
\text { última dictadura cívica- } \\
\text { militar - eclesística y } \\
\text { haciendo el foco especial- } \\
\text { mente en el rol de los } \\
\text { medios de comunicación. }\end{array}$ & Debate. & $\begin{array}{l}\text { Gran debate con referentes } \\
\text { en la temática en el interior } \\
\text { de nuestra Facultad. }\end{array}$ & $\begin{array}{l}\text { Presidencia de Cristina } \\
\text { Fernandez de Kirchner, que } \\
\text { sigue llevando adelante y } \\
\text { profundizando las políticas } \\
\text { de DDHH del gobierno } \\
\text { anterior. }\end{array}$ & $\begin{array}{l}\text { Informe de Gestión de la } \\
\text { Secretaria de DDHH de la } \\
\text { FP y CS. UNLP }\end{array}$ \\
\hline
\end{tabular}




\begin{tabular}{|c|c|c|c|c|c|c|c|}
\hline Fecha & Actividad & Participantes & Objetivos & Metodología & Resultado & Contexto & Fuentes \\
\hline 2009 & $\begin{array}{l}\text { Primer Encuentro Nacional } \\
\text { de Experiencias de Comuni- } \\
\text { cación y Cultura en } \\
\text { Cárceles, en la Universidad } \\
\text { Nacional de Córdoba. }\end{array}$ & $\begin{array}{l}\text { FP y CS (UNLP); Universidad } \\
\text { Nacional de Córdoba; } \\
\text { Universidades Nacionales de } \\
\text { la República Argentina y de la } \\
\text { región. }\end{array}$ & $\begin{array}{l}\text { Interactuar y compartir } \\
\text { recorridos y experiencias } \\
\text { educativas con otras } \\
\text { instituciones a nivel } \\
\text { nacional en referencia a la } \\
\text { educación universitaria } \\
\text { dentro de las cárceles de } \\
\text { Argentina desde una } \\
\text { perspectiva en DDHH. }\end{array}$ & $\begin{array}{l}\text { Disertaciones, charlas } \\
\text { debate, muestra de produc- } \\
\text { ciones comunicacionales. }\end{array}$ & $\begin{array}{l}\text { Fue muy enriquecedor el } \\
\text { intercambio de experiencias } \\
\text { y construir acuerdos } \\
\text { estratégicos de trabajo en } \\
\text { red desde las diversas } \\
\text { universidades nacionales. }\end{array}$ & $\begin{array}{l}\text { Avance en la preocupación } \\
\text { por llevar políticas públicas } \\
\text { de las universidades a las } \\
\text { cárceles, gran desarrollo en } \\
\text { este sentido. }\end{array}$ & $\begin{array}{l}\text { Informe de gestión de la } \\
\text { Secretaría de DDHH de la } \\
\text { FP y CS, certificados de } \\
\text { asistencia al encuentro, } \\
\text { protagonistas del encuentro. }\end{array}$ \\
\hline 2009 & $\begin{array}{l}\text { Participación en la jornada } \\
\text { de repudio a } 2 \text { años y medio } \\
\text { del femicidio de Sandra } \\
\text { Ayala Gamboa (joven } \\
\text { migrante peruana de } 23 \\
\text { años violada y asesinada) }\end{array}$ & $\begin{array}{l}\text { Nélida Gamboa Guillén; } \\
\text { FPyCS; agrupaciones feminis- } \\
\text { tas; agrupaciones de mujeres, } \\
\text { de los pueblos originarios; de } \\
\text { trabajadores; diversas organi- } \\
\text { zaciones políticas; asociacio- } \\
\text { nes de residentes peruanos en } \\
\text { Argentina y de otros países de } \\
\text { Latinoamérica. }\end{array}$ & $\begin{array}{l}\text { Visibilizar el femicidio de } \\
\text { Sandra Ayala Gamboa y } \\
\text { pedir justicia. Acompañar a } \\
\text { Nelly la mamá de Sandra en } \\
\text { la búsqueda de justicia. }\end{array}$ & $\begin{array}{l}\text { Movilización, acto y } \\
\text { disertaciones. }\end{array}$ & $\begin{array}{l}\text { Vinculación de la Secretaría } \\
\text { de DDHH de la FP y CS } \\
\text { con las luchas en las calles } \\
\text { de la ciudad y en las } \\
\text { problemáticas de DDHH } \\
\text { de La Plata que no tienen } \\
\text { que ver directamente con el } \\
\text { interior de los claustros } \\
\text { académicos de nuestra } \\
\text { universidad. }\end{array}$ & $\begin{array}{l}\text { Los femicidios y la violencia } \\
\text { hacia las mujeres ocupan un } \\
\text { lugar destacado en la agenda } \\
\text { social de discusión y } \\
\text { reclamos sobre las violacio- } \\
\text { nes a los DDHH }\end{array}$ & Informe de gestión. \\
\hline 2010 & $\begin{array}{l}\text { Implementación del 1er año } \\
\text { de la carrera de Licenciatura } \\
\text { en Comunicación Social en } \\
\text { la extensión áulica Unidad } \\
\text { No } 9 \text { de La Plata. }\end{array}$ & $\begin{array}{l}\text { Secretaría DDHH; FP y CS; } \\
\text { equipo de gestión; comunidad } \\
\text { educativa de la FP y CS; } \\
\text { UNLP; internos de la Unidad } \\
\text { Na9 de La Plata; Servicio } \\
\text { Penitenciario Bonaerense. }\end{array}$ & $\begin{array}{l}\text { Garantizar el derecho a la } \\
\text { educación superior dentro } \\
\text { del contexto de encierro } \\
\text { carcelario. Llevar las } \\
\text { carreras de la Facultad de } \\
\text { Periodismo y Comunicación } \\
\text { Social de la UNLP a las } \\
\text { cárceles del SPB. Generar } \\
\text { condiciones para la circula- } \\
\text { ción de la palabra y el } \\
\text { ejercicio del derecho a la } \\
\text { universidad, educación y } \\
\text { comunicación. }\end{array}$ & $\begin{array}{l}\text { Trámites de Inscripción a la } \\
\text { carrera de más de } 70 \\
\text { alumnes privade s de la } \\
\text { libertad. Acto de inicio. } \\
\text { Formación de docentes para } \\
\text { esta práctica. Dictado de } \\
\text { clases. }\end{array}$ & $\begin{array}{l}\text { Dictado del primer año de } \\
\text { la carrera de Licenciatura } \\
\text { en Comunicación Social de } \\
\text { la UNLP en la extensión } \\
\text { áulica ubicada en la Unidad } \\
\text { Penitenciaria } \mathrm{N}^{\circ} \text { dirigida a } \\
\text { todxs lxs privadxs de } \\
\text { libertad de cárceles del SPB. } \\
\text { Gran desarrollo y profundi- } \\
\text { zación de la inserción de la } \\
\text { Facultad en la cárcel y } \\
\text { viceversa. Armado de actos } \\
\text { y jornadas estudiantiles. }\end{array}$ & $\begin{array}{l}\text { Siguen las prácticas discrimi- } \\
\text { natorias de la sociedad sobre } \\
\text { les privades de libertad, } \\
\text { fogoneada muy especialmen- } \\
\text { te por los medios masivos de } \\
\text { comunicación que les define } \\
\text { como algo peligroso y sin } \\
\text { posibilidad de cambio o } \\
\text { reinserción. La Argentina } \\
\text { sigue siendo apercibida por } \\
\text { los organismos internaciona- } \\
\text { les debido a las pésimas } \\
\text { condiciones carcelarias. }\end{array}$ & $\begin{array}{l}\text { Convenio, coordinadorxs de la } \\
\text { secretaría de DDHH de la FP y CS, } \\
\text { informe de gestión. Docentes de la } \\
\text { FP y CS. UNLP. }\end{array}$ \\
\hline
\end{tabular}




\begin{tabular}{|c|c|c|c|c|c|c|c|}
\hline Fecha & Actividad & Participantes & Objetivos & Metodología & Resultado & Contexto & Fuentes \\
\hline 2010 & $\begin{array}{l}\text { Durante todo el año }(23 / 06 \text { - } \\
18 / 08 \text { - } 22 / 09 \text { - } 01 / 09) \\
\text { realizamos manifestaciones al } \\
\text { Consulado Chileno, en la } \\
\text { ciudad de Buenso Aires, por } \\
\text { la detención del alumno de la } \\
\text { FP y CS y miembro de la } \\
\text { Secretaría de DDHH, Pascual } \\
\text { Pichún Collonao y } 34 \text { presos } \\
\text { políticos mapuches en huelga } \\
\text { de hambre en Chile. } \\
\text { También se hicieron varias } \\
\text { notas desde la Secreataria de } \\
\text { DDHH a diversas autorida- } \\
\text { des Chilenas y se armaron } \\
\text { disertaciones en la Facultad } \\
\text { con el papá de Pascual, } \\
\text { dirigente mapuche muy } \\
\text { reconocido en Chile.. }\end{array}$ & $\begin{array}{l}\text { Secretaría de DDHH; FP y } \\
\text { CS, decana de la FP y CS, } \\
\text { abogados chilenos; activistas } \\
\text { de pueblos originarios de } \\
\text { Argentina y Chile, alumnes de } \\
\text { la Universiddad de La Plata, } \\
\text { familiares de Pascual Pichún } \\
\text { Collonao. }\end{array}$ & $\begin{array}{l}\text { Difundir la causa y lucha de } \\
\text { los pueblos originarios y } \\
\text { reclamar la pronta libera- } \\
\text { ción de alumno de la FP y } \\
\text { CS, Pascual Pichún Collo- } \\
\text { nao. Manifestarse por el no } \\
\text { a la aplicación de la ley } \\
\text { antiterrorista 18.314, } \\
\text { promulgada por Augusto } \\
\text { Pinochet, en causas contra } \\
\text { la comunidad mapuche. } \\
\text { Desmilitarización de todas } \\
\text { las comunidades. Libertad a } \\
\text { todos los presos politicos } \\
\text { mapuches. Basta de } \\
\text { persecución y maltrato a los } \\
\text { niños/as mapuches. }\end{array}$ & $\begin{array}{l}\text { Se realizan actividades para } \\
\text { el recclamo, enviamos } \\
\text { documentos institucionales a } \\
\text { las autoridades chilenas, } \\
\text { organización y participación } \\
\text { en marchas, radio abiertas, } \\
\text { movilizaciones en La Plata y } \\
\text { Ciudad de Buenos Aires, } \\
\text { charlas debate y disertacio- } \\
\text { nes en nuestra Facultad, } \\
\text { contacto y acompanamiento } \\
\text { con los familiares y aboga- } \\
\text { dos en Chile de Pascual } \\
\text { Pichún Collonao, joven } \\
\text { mapuche de } 2 \text { años, } \\
\text { estudiante y miembro de la } \\
\text { Secretaría de Derechos } \\
\text { Humanos de la FPyCS. } \\
\text { Promotor de los derechos de } \\
\text { los pueblos originarios en } \\
\text { Argentina, donde estuvo } \\
\text { refugiado de la justicia } \\
\text { chilena desde el } 2005 \text { hasta } \\
\text { el 2010, injustamente } \\
\text { acusado de incendiar un } \\
\text { camión forestal en Traiguén } \\
\text { (Chile) en el año } 2002 \text {, } \\
\text { condenado a } 5 \text { años de } \\
\text { prisión y al pago de } 12 \text { mil } \\
\text { dólares-, detenido, cuando } \\
\text { vuelve a su país y se entrega } \\
\text { en febrero de } 2010 \text {, en } \\
\text { Traiguén. }\end{array}$ & $\begin{array}{l}\text { Finalmente Pascual fue } \\
\text { juzgado con dos años de } \\
\text { prisión efectiva en Chile. }\end{array}$ & $\begin{array}{l}\text { Gobierno de Michele } \\
\text { Bachelet en Chile y Cristina } \\
\text { Kirchner en Argentina. } \\
\text { Persecución a las comunida- } \\
\text { des indígenas para expropia- } \\
\text { ción y explotación de las } \\
\text { tierras por parte de empresas } \\
\text { multinacionales. }\end{array}$ & $\begin{array}{l}\text { Informe de gestión. } \\
\text { Entrevista a Pascual } \\
\text { Pichún Collonao para la } \\
\text { realización de esta tesis. }\end{array}$ \\
\hline 2010 & $\begin{array}{l}\text { Organización, realización y } \\
\text { presentación de "Verdad y } \\
\text { Justicia. El diario del juicio } \\
\text { a los penitenciarios", } \\
\text { realizado por las secreta- } \\
\text { rías de Derechos Humanos } \\
\text { y de Producción de la FP } \\
\text { y CS conjuntamente con la } \\
\text { Asamblea Permanente por } \\
\text { los Derechos Humanos de } \\
\text { La Plata }\end{array}$ & $\begin{array}{l}\text { Estudiantes y graduados de la } \\
\text { FP y CS; equipo de gestión; } \\
\text { secretarias de Derechos } \\
\text { Humanos y de Producción de } \\
\text { la FP y CS; Asamblea } \\
\text { Permanente por los Derechos } \\
\text { Humanos de La Plata; ex } \\
\text { detenidos políticos sobrevi- } \\
\text { vientes de la áltima dictadura } \\
\text { civico-militar eclesiástica. }\end{array}$ & $\begin{array}{l}\text { Realizar una producción } \\
\text { gráfica que dé cuenta de la } \\
\text { importancia que reviste el } \\
\text { proceso de enjuiciamiento de } \\
\text { los acusados en los juicios } \\
\text { por delitos de lesa humanidad } \\
\text { acontecidos en la Unidad No } \\
9 \text { de La Plata durante la } \\
\text { última dictadura cívico-mili- } \\
\text { tar-eclesiástica en Argentina. } \\
\text { Aportar a los registros de la } \\
\text { memoria colectiva en } \\
\text { referencia a lo acontecido } \\
\text { durante el terrorismo de } \\
\text { estado. Brindar aportes de } \\
\text { registros históricos para la } \\
\text { memoria, verdad y justicia del } \\
\text { pueblo con descripciones de } \\
\text { la historia de la causa y su } \\
\text { importancia. }\end{array}$ & $\begin{array}{l}\text { Entrevistas y editoriales. } \\
\text { Producción gráfica en } \\
\text { soporte papel. }\end{array}$ & $\begin{array}{l}\text { Se presenta "Verdad y } \\
\text { Justicia. El diario del juicio } \\
\text { a los penitenciarios" en un } \\
\text { acto en la Facultad con } \\
\text { organismos de DDHH, } \\
\text { Madres y Abuelas de Plaza } \\
\text { de Mayo y ex detenidos de } \\
\text { la Unidad penitenciaria No9 } \\
\text { de La Plata en la dictadura } \\
\text { cívico- militar y eclesiástica. }\end{array}$ & $\begin{array}{l}\text { Se sigen desarrollando } \\
\text { numerosas políticas públicas } \\
\text { en materia de memoria y } \\
\text { dictadura en nuestro país. }\end{array}$ & $\begin{array}{l}\text { Diario"Verdad y Justicia. } \\
\text { El diario del juicio a los } \\
\text { penitenciarios". Informes } \\
\text { de gestión. }\end{array}$ \\
\hline
\end{tabular}




\begin{tabular}{|c|c|c|c|c|c|c|c|}
\hline Fecha & Actividad & Participantes & Objetivos & Metodología & Resultado & Contexto & Fuentes \\
\hline 2010 & $\begin{array}{l}\text { Jornadas sobre la temática } \\
\text { "Universidad y Dictadura" } \\
\text { en la Facultad de Trabajo } \\
\text { Social -UNLP. }\end{array}$ & $\begin{array}{l}\text { Facultad de Trabajo Social; } \\
\text { decana de la Facultad de } \\
\text { Trabajo Social Mg. Verónica } \\
\text { Cruz; comunidad educativa; } \\
\text { Lic. Jorge Jaunarena; FP y CS. }\end{array}$ & $\begin{array}{l}\text { Aportar a la construcción } \\
\text { de la memoria colectiva en } \\
\text { referencia a lo acontecido } \\
\text { durante el terrorismo de } \\
\text { estado. Fortalecer el vínculo } \\
\text { con otras Facultades y } \\
\text { Unidades Académicas. }\end{array}$ & $\begin{array}{l}\text { Disertación del Lic. Jorge } \\
\text { Jaunarena, Mg Verónica } \\
\text { Cruz, integrantes de la } \\
\text { agrupación H.IJ.J.S. } \\
\text { Madres y Abuelas de Plaza } \\
\text { de Mayo. Paneles, disertacio- } \\
\text { nes y charlas debate, } \\
\text { presentaciones de produc- } \\
\text { ciones comunicacionales e } \\
\text { investigaciones, durante en } \\
\text { varias jornadas. }\end{array}$ & $\begin{array}{l}\text { Realización de diversos } \\
\text { paneles, charlas debate, } \\
\text { presentaciones de produc- } \\
\text { ciones en el marco de las } \\
\text { jornadas. Gran participa- } \\
\text { ción de la comunidad } \\
\text { académica de la araultad de } \\
\text { Trabajo Social. }\end{array}$ & $\begin{array}{l}\text { La política de Memoria, } \\
\text { Verdad y Justicia ocupa un } \\
\text { lugar preponderante en la } \\
\text { agenda política del gobierno. } \\
\text { Se multiplican los juicios de } \\
\text { Lesa Humanidad. }\end{array}$ & Informe de gestión. \\
\hline 2010 & $\begin{array}{l}\text { Seminario de Comunicación, } \\
\text { Discriminación y Derechos } \\
\text { humanos: Charla-Debate } \\
\text { "Repensar el } 12 \text { de octubre. } \\
\text { Día del Respeto a la diversi- } \\
\text { dad Cultural". }\end{array}$ & $\begin{array}{l}\text { Direcciòn de Derechos } \\
\text { Humanos; FP y CS; } \\
\text { comunidad educativa; } \\
\text { equipo de gestión; referentes } \\
\text { de comunidades indígenas } \\
\text { de la ciudad de La Plata. }\end{array}$ & $\begin{array}{l}\text { Promover el derecho y } \\
\text { respeto a la diversidad } \\
\text { cultural y difundir la causa y } \\
\text { lucha de los pueblos } \\
\text { originarios de la región. }\end{array}$ & $\begin{array}{l}\text { Disertación. Charla debate } \\
\text { con alumnes, docentes y } \\
\text { comunidades indígenas. }\end{array}$ & $\begin{array}{l}\text { Se profundizan los temas y } \\
\text { debates sobre pueblos } \\
\text { originarios en nuestra } \\
\text { Facultad. Se fortalecen los } \\
\text { lazos institucionales con las } \\
\text { comunidades originarias. }\end{array}$ & $\begin{array}{l}\text { Gran desarrollo y consolida- } \\
\text { ción del eje pueblos indígenas } \\
\text { en la FP y CS. }\end{array}$ & $\begin{array}{l}\text { Dirección de Pueblos } \\
\text { Indígenas, informes de } \\
\text { gestión. }\end{array}$ \\
\hline 2010 & $\begin{array}{l}\text { Presentación del Documental } \\
\text { "Comunicación en Cárceles", } \\
\text { realizado por el programa de } \\
\text { educación superior en } \\
\text { cárceles de la FP y CS, en el } \\
\text { Congreso AMARC. }\end{array}$ & $\begin{array}{l}\text { FP y CS; Asociación Mundial } \\
\text { de Radios Comunitarias. }\end{array}$ & $\begin{array}{l}\text { Difundir la palabra de lxs } \\
\text { privadxs de libertad sobre } \\
\text { qué signififica para elles el } \\
\text { proceso de educación en } \\
\text { cárceles. Difundir, promo- } \\
\text { ver y garantizar el derecho a } \\
\text { la educación universitaria } \\
\text { dentro de las cárceles. }\end{array}$ & Exposición. Charla debate. & $\begin{array}{l}\text { Difusión sobre la dificultad } \\
\text { para acceder al derecho a la } \\
\text { educación en las cárceles. }\end{array}$ & $\begin{array}{l}\text { Se dicta la carrera de } \\
\text { Comunicación Social en la } \\
\text { Unidad } \mathrm{N}^{\circ} 9 \text { de La Plata. Mas } \\
\text { de } 20 \text { alumnxs privadxs de } \\
\text { libertad vienen a cursar a la } \\
\text { sede del bosque de la FP y } \\
\text { CS. Se multiplica la relación y } \\
\text { el intercambio de docentes y } \\
\text { estudiantes de la sede del } \\
\text { bosque con la Extensión en } \\
\text { la Unidad Penitenciaria No } 9\end{array}$ & $\begin{array}{l}\text { Informe de gestión. } \\
\text { Documentos administra- } \\
\text { tivos del Programa de } \\
\text { Educación Superior en } \\
\text { cárceles. }\end{array}$ \\
\hline 2010 & $\begin{array}{l}\text { Disertación de Jorge Jaunare- } \\
\text { na en el Seminario de } \\
\text { Cárceles y Derechos Huma- } \\
\text { nos, organizado por el } \\
\text { GESEC (Grupo de Estudios } \\
\text { de Educación en Cárceles) en } \\
\text { la Facultad de Trabajo Social } \\
\text { UNLP. }\end{array}$ & $\begin{array}{l}\text { Secretaría de DDHH FP y CS; } \\
\text { Facultad de Trabajo Sociala } \\
\text { Gastón Guglielmo, privado de } \\
\text { libertad; comunidad educativa; } \\
\text { Francisco Scarfó pte del } \\
\text { Grupo de Estudios de } \\
\text { Educación en Cárceles. }\end{array}$ & $\begin{array}{l}\text { Exponer la experiencia de } \\
\text { educación en cárceles de la } \\
\text { Facultad de Periodismo y } \\
\text { Comunicación Social } \\
\text {-UNLP como forma de } \\
\text { inclusión y garantía de } \\
\text { derechos en el contexto de } \\
\text { encierro. Articular activida- } \\
\text { des con la Facultad de } \\
\text { Trabajo Social. Articular } \\
\text { actividades con la Asocia- } \\
\text { ción Civil Grupo de } \\
\text { EStudios de Educación en } \\
\text { Cárceles (GESEC) }\end{array}$ & Disertación, charla-debate. & $\begin{array}{l}\text { Intercambio de experien- } \\
\text { cias y articulaciones } \\
\text { institucionales. }\end{array}$ & $\begin{array}{l}\text { La experiencia de la } \\
\text { facultad de Periodismo en } \\
\text { las cárceles se empiezza a } \\
\text { difundir y reconocer no } \\
\text { solo en unidades académi- } \\
\text { cas de la UNLP, también en } \\
\text { universidades nacionales de } \\
\text { todo el país. }\end{array}$ & $\begin{array}{l}\text { Informe de gestión. Integran- } \\
\text { tes del programa de Educa- } \\
\text { ción Superior en Cárceles de } \\
\text { la Fcultad de Periodismo y } \\
\text { Comunicación Social. }\end{array}$ \\
\hline
\end{tabular}




\begin{tabular}{|c|c|c|c|c|c|c|c|c|}
\hline Fecha & Actividad & Participantes & Objetivos & \multicolumn{2}{|c|}{ Metodología } & Resultado & Contexto & Fuentes \\
\hline 2010 & $\begin{array}{l}\text { "Congreso de Comunicación } \\
\text { Alternativa”, Mesa Movi- } \\
\text { mientos LGBT: debates } \\
\text { actuales. }\end{array}$ & $\begin{array}{l}\text { Secretaría de DDHH; } \\
\text { comunidad educativa; equipo } \\
\text { de gestión de la FP y CS.; } \\
\text { referentes del activismo y la } \\
\text { militancia LGBT. }\end{array}$ & $\begin{array}{l}\text { Visibilizar la lucha por la } \\
\text { dignidad, igualdad de } \\
\text { derechos y libertades } \\
\text { individuales y colectivas del } \\
\text { colectivo LGBT. Entendien- } \\
\text { do que las luchas se deben } \\
\text { dar de manera conjunta y } \\
\text { desde los diferentes } \\
\text { espacios, fundamental } \\
\text { mente desde la sociedad } \\
\text { civil y desde los diferentes } \\
\text { movimientos sociales. }\end{array}$ & $\begin{array}{l}\text { Disertaciones, } \\
\text { diversos ejes to } \\
\text { ponencias. }\end{array}$ & $\begin{array}{l}\text { paneles con } \\
\text { máticos, }\end{array}$ & $\begin{array}{l}\text { Articulación con referentes, } \\
\text { intercambio de ideas, } \\
\text { debate y formación en } \\
\text { cuestiones de género y } \\
\text { diversidad. }\end{array}$ & $\begin{array}{l}\text { Visibilidad de los } \\
\text { reclamos de los movi- } \\
\text { mientos LGBT en } \\
\text { nuestro país. }\end{array}$ & Informe de gestión. \\
\hline 2011 & $\begin{array}{l}\text { Presentación del Proyecto } \\
\text { "Madres y Abuelas de Plaza } \\
\text { de Mayo. Relatos del Futuro". }\end{array}$ & $\begin{array}{l}\text { Estela Barnes de Carlotto, } \\
\text { Abuela de Plaza de Mayo; } \\
\text { Adelina Dematti de Alaye, } \\
\text { Madre de Plaza de Mayo de La } \\
\text { Plata; el secretario de Dere- } \\
\text { chos Humanos de la Nación, } \\
\text { Eduardo Luis Duhalde; el } \\
\text { subsecretario de Derechos } \\
\text { Humanos de la Nación y } \\
\text { docente de la maestría, Martín } \\
\text { Gras; Alejandro Kaufman, } \\
\text { docente de la maestría; equipo } \\
\text { de gestión; comunidad } \\
\text { educativa y Florencia } \\
\text { Saintout, decana de la } \\
\text { FP y CS de la UNLP. }\end{array}$ & $\begin{array}{l}\text { Aportar a la construcción } \\
\text { de la memoria colectiva } \\
\text { mediante una serie de } \\
\text { producciones audiovisuales, } \\
\text { un registro público con } \\
\text { entrevistas realizadas a } 26 \\
\text { Madres y Abuelas de Plaza } \\
\text { de Mayo sobre sus historias } \\
\text { de vida y divididas por ejes } \\
\text { temáticos. Fortalecer el } \\
\text { vinculo de la FP y CS con } \\
\text { las Madres y Abuelas de } \\
\text { Plaza de Mayo. }\end{array}$ & $\begin{array}{l}\text { Investigación } \\
\text { armado de los } \\
\text { cos, preprodu } \\
\text { entrevistas, re } \\
\text { posproducción } \\
\text { ción del acto }\end{array}$ & $\begin{array}{l}\text { periodística, } \\
\text { ejes temáti- } \\
\text { ción de } \\
\text { lización, } \\
\text {, organiza- } \\
\text { resentación. }\end{array}$ & $\begin{array}{l}\text { Registro y armado del } \\
\text { packaging para distribuir a } \\
\text { Madres y Abuelas y } \\
\text { organizaciones e institucio- } \\
\text { nes. Gran reconocimiento } \\
\text { al proyecto por parte de } \\
\text { organismos y organizacio- } \\
\text { nes e instituciones. }\end{array}$ & $\begin{array}{l}\text { Gran avance del proceso de } \\
\text { memoria, verdad y justicia en } \\
\text { nuestro país, inclusive } \\
\text { reconocido a nivel mundial. }\end{array}$ & $\begin{array}{l}\text { Informe de gestión. } \\
\text { Entrevistas audiovisuales. } \\
\text { Packaging con entrevistas. }\end{array}$ \\
\hline $2011 / 2014$ & $\begin{array}{l}\text { Presentación ante el Consejo } \\
\text { Directivo de la solicitud para } \\
\text { la inclusión de idioma o } \\
\text { lengua indígena (en el marco } \\
\text { de la Reforma del Plan de } \\
\text { Estudios) como materia de la } \\
\text { currícula de la carrera y de } \\
\text { cursada cuatrimestral de las } \\
\text { carreras de la FP y CS. }\end{array}$ & $\begin{array}{l}\text { Secretaría de DDHH; Consejo } \\
\text { Directivo.Miembros de las } \\
\text { comunidades indígenas }\end{array}$ & $\begin{array}{l}\text { Reconocer nuestros } \\
\text { orígenes a través de las } \\
\text { lenguas originarias. Crear la } \\
\text { posibilidad de hacer real la } \\
\text { educación intercultural sin } \\
\text { dejar de lado el paradigma } \\
\text { bilingüe en la FP y CS. } \\
\text { Formar estudiantes desde la } \\
\text { cosmovisión indígena. La } \\
\text { inserción de comunidades } \\
\text { indígenas y los pueblos } \\
\text { ancestrales en nuestros } \\
\text { claustros académicos. }\end{array}$ & $\begin{array}{l}\text { Se desarrolló 1 } \\
\text { idioma origina } \\
\text { un idioma cad } \\
\text { Quechua, Man } \\
\text { fueron las len } \\
\text { dictaron en lo } \\
\text { mencionados. }\end{array}$ & $\begin{array}{l}\text { cátedra de } \\
\text { rio dictando } \\
\text { cuatrimestre. } \\
\text { uche, Guaraní } \\
\text { uas que se } \\
\text { años }\end{array}$ & $\begin{array}{l}\text { Gran participación del } \\
\text { alumnado. Reconocimiento } \\
\text { de comunidad educativa y } \\
\text { activistas en relación a la } \\
\text { pertenencia de idioma } \\
\text { originario a la currícula de } \\
\text { la carrera. }\end{array}$ & $\begin{array}{l}\text { Era de ampliación de } \\
\text { derechos. Consolidación en } \\
\text { nuestra unidad académica de } \\
\text { la inserción indígena en } \\
\text { nuestros claustros. }\end{array}$ & $\begin{array}{l}\text { Informes de gestión. } \\
\text { Dirección de Pueblos } \\
\text { indígenas. Secretario de } \\
\text { DDHH FP y CS. }\end{array}$ \\
\hline
\end{tabular}




\begin{tabular}{|c|c|c|c|c|c|c|c|}
\hline Fecha & Actividad & Participantes & Objetivos & Metodología & Resultado & Contexto & Fuentes \\
\hline 2011 & $\begin{array}{l}\text { Participación en charla "La } \\
\text { resistencia de la palabra: } \\
\text { escritura en la cárcel" } \\
\text { organizada por la Facultad } \\
\text { de Filosofia y Letras de la } \\
\text { UBA. }\end{array}$ & $\begin{array}{l}\text { Secretaría de DDHH FP y CS } \\
\text {-UNLP; Facultad de Filosofia } \\
\text { y Letras -UBA; Docentes del } \\
\text { Centro Universitario de } \\
\text { Devoto, estudiantes privados } \\
\text { de libertad y estudiantes } \\
\text { liberados, onganizaciones que } \\
\text { trabajajn en cárceles, unidades } \\
\text { académicas nacionales. }\end{array}$ & $\begin{array}{l}\text { Favorecer la circulación de } \\
\text { la palabra hablada y escrita y } \\
\text { el ejercicio al derecho de la } \\
\text { comunicación. Fortalecer el } \\
\text { vínculo con otras Universi- } \\
\text { dades. Fortalecer el } \\
\text { intercambio de experiencias } \\
\text { con organizaciones que } \\
\text { trabajan en cárceles. }\end{array}$ & $\begin{array}{l}\text { Conversatorio. Presentación } \\
\text { de publicaciones. } \\
\text { Disertaciones }\end{array}$ & $\begin{array}{l}\text { Conocimiento e intercam- } \\
\text { bio de experiencias y } \\
\text { producciones. Articulación } \\
\text { e intercambio de propues- } \\
\text { tas para desarrollar en } \\
\text { cárceles. }\end{array}$ & $\begin{array}{l}\text { Crece el compromiso } \\
\text { educativo en contextos de } \\
\text { encierro por parte de las } \\
\text { instituciones universitarias. Se } \\
\text { multiplican los trabajos } \\
\text { educativos en las cárceles. }\end{array}$ & $\begin{array}{l}\text { Informes de gestión. } \\
\text { Producciones comunica- } \\
\text { cionales. }\end{array}$ \\
\hline 2011 & $\begin{array}{l}\text { Disertación e intercambio } \\
\text { de experiencias en la } \\
\text { Universidad de Murcia, } \\
\text { España, sobre Educación en } \\
\text { Contextos de Encierro. } \\
\text { Organizado por la Universi- } \\
\text { dad de Murcia y la UNED } \\
\text { (Universidad Nacional de } \\
\text { Educación a Distancia de } \\
\text { España). Fiscalización del } \\
\text { proyecto realizado opor la } \\
\text { UNED sobre el sistema } \\
\text { carcelario español en } \\
\text { relación con el eje educa- } \\
\text { ción en cárceles. }\end{array}$ & $\begin{array}{l}\text { Secretario de DDHH } \\
\text { FP y CS - UNLP; Universidad } \\
\text { de Murcia, España; UNED; } \\
\text { Referntes académicos en } \\
\text { relación a las cárceles de } \\
\text { México, Francia, Italia, } \\
\text { España, Gran Bretaña. }\end{array}$ & $\begin{array}{l}\text { Compartir experiencias con } \\
\text { trabajos de investigación } \\
\text { sobre privados y privadas de } \\
\text { libertad en diversos países } \\
\text { del mundo. Fiscalizar el } \\
\text { proyecto de educación en } \\
\text { cárceles españolas de la } \\
\text { Universidad Nacional de } \\
\text { Educación a Distancia, } \\
\text { UNED. }\end{array}$ & $\begin{array}{l}\text { Disertación y muestra del } \\
\text { video realizado por alumnes } \\
\text { de la FP y CS de la UNLP. } \\
\text { Disertación del Lic. Jorge } \\
\text { Jaunarena con representan- } \\
\text { tes de experiencias e } \\
\text { investigaciones en países } \\
\text { antes mencionados. En las } \\
\text { ciudades de Murcia y Madrid } \\
\text { en España. }\end{array}$ & $\begin{array}{l}\text { Conocimiento de experien- } \\
\text { cias y otrxs actores con } \\
\text { diversas realidades sobre el } \\
\text { trabajo en cárceles de } \\
\text { distintos lugares del mundo }\end{array}$ & $\begin{array}{l}\text { La experiencia que realiza la } \\
\text { Facultad en las cárceles se } \\
\text { convierte en referencia en } \\
\text { universidades de argentina y } \\
\text { también del mundo. }\end{array}$ & $\begin{array}{l}\text { Informes de gestión. } \\
\text { Producciones comunica- } \\
\text { cionales. }\end{array}$ \\
\hline $2010 / 20141$ & $\begin{array}{l}\text { Organización del V } \\
\text { Encuentro Nacional de } \\
\text { Periodistas argentinos en } \\
\text { red (Red Par). }\end{array}$ & $\begin{array}{l}\text { Observatorio de Género } \\
\text { comunicación y Derechos } \\
\text { Humanos; Secretaría de } \\
\text { DDHH; equipo de gestión; } \\
\text { comunidad educativa. }\end{array}$ & $\begin{array}{l}\text { Destacar promover la } \\
\text { importancia en la produc- } \\
\text { ción de notas periodísticas } \\
\text { no sexistas. Concientizar } \\
\text { que la falta de formación } \\
\text { en perspectiva de género } \\
\text { reproduce notas con } \\
\text { discurso dominante } \\
\text { hegemónico y desigual. }\end{array}$ & $\begin{array}{l}\text { Disertaciones. Intercambios } \\
\text { de experiencias. Formación. }\end{array}$ & $\begin{array}{l}\text { Formación en la produc- } \\
\text { ción de noticias informati- } \\
\text { vas no sexistas. }\end{array}$ & $\begin{array}{l}\text { Las políticas de género son } \\
\text { un tema central en la agenda } \\
\text { de discusión de la Universi- } \\
\text { dad de La Plata. Hay un } \\
\text { avance importante de la } \\
\text { demandas y avances en } \\
\text { políticas de género. }\end{array}$ & Informes de gestión. \\
\hline 2011 & $\begin{array}{l}\text { Participación en la organiza- } \\
\text { ción del COMCIS (Congreso } \\
\text { de Comunicación y Ciencias } \\
\text { Sociales). Grupo de Trabajo: } \\
\text { "Abordajes de las Ciencias } \\
\text { Sociales en relación a los } \\
\text { DDHH: Diferencias cultura- } \\
\text { les, memorias, minorías y } \\
\text { disputas hegemónicas en } \\
\text { Latinoamérica". }\end{array}$ & $\begin{array}{l}\text { Dr. Raúl Eugenio Zaffaroni, } \\
\text { Ministro de la Corte suprema } \\
\text { de Justicia de la Nación. } \\
\text { Abogado y Escribano, y } \\
\text { exposición/presentación a } \\
\text { cargo del Dr. Martín Gras, } \\
\text { Secretario Ejecutivo del Plan } \\
\text { Nacional de Derechos Huma- } \\
\text { nos, Secretaría de Derechos } \\
\text { Humanos, Presidencia de la } \\
\text { Nación. Especialista en } \\
\text { políticas públicas y derechos } \\
\text { humanos; Secretaría de DDHH } \\
\text { de la FP y CS; equipo de } \\
\text { gestión FP y CS. }\end{array}$ & $\begin{array}{l}\text { Problematizar sobre los } \\
\text { debates actuales en materia } \\
\text { de DDHH. }\end{array}$ & Exposición y organización. & $\begin{array}{l}\text { Masiva participación en la } \\
\text { charla debate. Formación. }\end{array}$ & $\begin{array}{l}\text { Eduardo Luis Duhalde es } \\
\text { Secretario de DDHH de la } \\
\text { Nación, abogado de peresxs } \\
\text { políticss en la dictadura } \\
\text { cívico militar eclesística, } \\
\text { preso político y exiliado } \\
\text { durante la última dictadura. } \\
\text { Es Secretario de DDHH de } \\
\text { la Nación desde el } 2003 \text { con } \\
\text { la asunción de Nestor } \\
\text { Kirchner. }\end{array}$ & Informes de gestión. \\
\hline
\end{tabular}




\begin{tabular}{|c|c|c|c|c|c|c|c|}
\hline Fecha & Actividad & Participantes & Objetivos & Metodología & Resultado & Contexto & Fuentes \\
\hline 2011 & $\begin{array}{l}\text { Realización, coordinación y } \\
\text { presentación de la Maestría } \\
\text { en Comunicación y } \\
\text { Derechos Humanos de la } \\
\text { FP y CS, aprobada por } \\
\text { CONEAU que se pondría } \\
\text { en práctica en 2012. }\end{array}$ & $\begin{array}{l}\text { Estela Barnes de Carlotto, } \\
\text { abuela de Plaza de Mayo; } \\
\text { Adelina Dematti de Alaye, } \\
\text { madre de Plaza de Mayo; el } \\
\text { Secretario de Derechos } \\
\text { Humanos, Dr. Eduardo Luis } \\
\text { Duhalde; el Prof. Alberto } \\
\text { Sileoni, Ministro de Educa- } \\
\text { ción de la Nación; el Dr. } \\
\text { Alejandro Kauffman, docente } \\
\text { de la maestría; Rosa Schonfeld } \\
\text { de Bru; Director de la } \\
\text { maestría y Secretario de } \\
\text { DDHH: Lic. Jorge A. } \\
\text { Jaunarena; Dra.Florencia } \\
\text { Saintout, decana de nuestra } \\
\text { casa de estudios. }\end{array}$ & $\begin{array}{l}\text { Brindar un panorama } \\
\text { definido sobre teorías y } \\
\text { prácticas en DDHH, } \\
\text { relacionadas con las Ciencias } \\
\text { Sociales en general y las } \\
\text { experiencias profesionales y } \\
\text { concretas, desde una } \\
\text { perspectiva comunicacional. } \\
\text { Desarrollar una carrera de } \\
\text { posgrado de la FP y CS para } \\
\text { debatit, investigar y producir } \\
\text { en relación a los derechos } \\
\text { humanos y las ciencias } \\
\text { sociales desde una perspecti- } \\
\text { va comunicacional. }\end{array}$ & $\begin{array}{l}\text { Armado de la propuesta del } \\
\text { plan de estudios, presenta- } \\
\text { ción a la Comisión Nacional } \\
\text { de Evaluación y Acredita- } \\
\text { ción Universitaria, } \\
\text { CONEAU, para su aproba- } \\
\text { ción, designación de planta } \\
\text { docente, apertura de } \\
\text { inscripciones para puesta en } \\
\text { práctica de la maestría de } \\
\text { Comunicación y DDHH.s }\end{array}$ & $\begin{array}{l}\text { Armado y presentaciones } \\
\text { administrativas para } \\
\text { implementación y dictado } \\
\text { de la Maestría en Com y } \\
\text { DDHH a partir de Agosto } \\
\text { de } 2012 \text {. }\end{array}$ & $\begin{array}{l}\text { Gran desarrollo de políticas } \\
\text { públicas en ampliación de } \\
\text { derechos en nuestro país. }\end{array}$ & $\begin{array}{l}\text { Propuesta. Resolución } \\
\text { Coneau es la N } \mathrm{N}^{\circ} \\
11.072 / 11 \text {. Res. Ministe- } \\
\text { rial } \mathrm{N}^{\circ} 1374 / 15 \text { y La } \\
\text { Disp. } \mathrm{N}^{\circ} 252 / 11 \text { de la } \\
\text { Universidad Ncional de } \\
\text { La Plata sobre la aproba- } \\
\text { ción de la carrera. }\end{array}$ \\
\hline 2012 & $\begin{array}{l}\text { Co-organización conjunta- } \\
\text { mente con la Mesa por Más } \\
\text { juicio y Castigo - la cual } \\
\text { integra la Sec. de DDHH de } \\
\text { esta unidadacadémica-, de } \\
\text { la Charla debate "Papel } \\
\text { prensa Complicidad Civil en } \\
\text { la Dictadura". }\end{array}$ & $\begin{array}{l}\text { Lidia Papaleo, Osvaldo } \\
\text { Papaleo, Florencia Saintout, } \\
\text { Andrea Holgado y Diego } \\
\text { Perdoni de la Agrupación } \\
\text { H.I.J.O.S. regional La Plata } \\
\text { Berisso y Ensenada. FP y CS. } \\
\text { UNLP. }\end{array}$ & $\begin{array}{l}\text { Fortalecer el proceso de } \\
\text { construcción de la memoria } \\
\text { colectiva en referencia al rol } \\
\text { de los medios hegemónicos y } \\
\text { su complicidad durante la } \\
\text { última dictadura cívico-mili- } \\
\text { tar eclesiástica. Dufundir el } \\
\text { robo de empresas y bienes en } \\
\text { los cuales la dictaduara y } \\
\text { empresarios se asociaron en } \\
\text { la apropiación ilegal. }\end{array}$ & Disertación. & $\begin{array}{l}\text { Charla informativa y panel } \\
\text { de preguntas en aula repleta } \\
\text { de comunidad académica, } \\
\text { referentes de DDHH y } \\
\text { militantes polítices. }\end{array}$ & $\begin{array}{l}\text { El escrito presentado por la } \\
\text { Secretaría de Derechos } \\
\text { Humanos de la Nación en } \\
\text { 2010, ante el Juzgado } \\
\text { Criminal y Correccional } \\
\text { federal No } 3 \text { de La Plata, fue } \\
\text { la punta del ovillo para que la } \\
\text { transferencia del paquete } \\
\text { accionario de la empresa } \\
\text { comenzara a investigarse } \\
\text { como delito de lesa humani- } \\
\text { dad. Además de las amenazas } \\
\text { a la familia Graiver, el escrito } \\
\text { plantea que se llevó a cabo } \\
\text { "una cuidadosa preparación } \\
\text { mediática" para la apropia- } \\
\text { ción ilegítima de Papel Prensa } \\
\text { por parte de Clarín, La } \\
\text { Nación y La Razón. }\end{array}$ & $\begin{array}{l}\text { Informe de gestión. } \\
\text { Secretario de DDHH. }\end{array}$ \\
\hline 2012 & $\begin{array}{l}\text { Coordinación del convenio } \\
\text { con el Ministerio de Justicia } \\
\text { de la Provincia de Buenos } \\
\text { Aires en la implementación } \\
\text { del ler y 3er año de la } \\
\text { carrera de Comunicación } \\
\text { Social en la Extensión } \\
\text { Aulica Unidad No } 9 \text { de La } \\
\text { Plata y de los asuntos } \\
\text { estudiantiles de estudiantes } \\
\text { privados de libertad. }\end{array}$ & $\begin{array}{l}\text { Ministerio de Justicia de la } \\
\text { Provincia de Buenos Aires; } \\
\text { Servicio Penitenciario } \\
\text { Bonaerense; FP y CS; } \\
\text { Secretaría de Derechos } \\
\text { Humanos; equipo de gestión. }\end{array}$ & $\begin{array}{l}\text { Garantizar el derecho a la } \\
\text { educación universitaria } \\
\text { dentro del contexto de } \\
\text { encierro. }\end{array}$ & $\begin{array}{l}\text { Dictado de clases intra } \\
\text { muros en la Unidad Número } \\
9 \text { de La Plata para privados y } \\
\text { privadas de libertad del } \\
\text { Servicio penitenciario } \\
\text { bonaerense. }\end{array}$ & $\begin{array}{l}\text { Se incrementa la matrícula } \\
\text { de alumnes. La Facultad } \\
\text { está absolutamente } \\
\text { atravesada por el proyecto } \\
\text { de educación universitaria } \\
\text { en cárceles. }\end{array}$ & $\begin{array}{l}\text { Avance y desarrollo en la } \\
\text { inserción e eiteracción de la } \\
\text { FP y CS en las unidades } \\
\text { penitenciarias y de privades } \\
\text { de libertad que cursan en la } \\
\text { sede del bosque en el marco } \\
\text { del convenio con el Ministe- } \\
\text { rio de Justicia de la Provincia } \\
\text { de Buenos Aires. }\end{array}$ & $\begin{array}{l}\text { Informe de gestión. } \\
\text { Convenio entre el } \\
\text { Ministerio de Justicia de la } \\
\text { provincia de Buenos Aires } \\
\text { y la FP y CS de la UNLP. }\end{array}$ \\
\hline
\end{tabular}




\begin{tabular}{|c|c|c|c|c|c|c|c|}
\hline Fecha & Actividad & Participantes & Objetivos & Metodología & Resultado & Contexto & Fuentes \\
\hline $2010 / 2014$ & $\begin{array}{l}\text { Organización y participa- } \\
\text { ción de las vigilias cada } 17 \\
\text { de Agosto, en la comisaría } \\
\text { 9na. de La Plata (calle } 59 \\
\text { esquina 5), para exigir } \\
\text { justicia por la desaparición } \\
\text { del estudiante de la FP y CS, } \\
\text { Miguel Bru. }\end{array}$ & $\begin{array}{l}\text { Rosa Bru; integrantes de la } \\
\text { Asoc. Miguel Bru; Secretaría } \\
\text { de DDHH la de FP y CS; } \\
\text { centro de estudiantes de la FP } \\
\text { y CS Agrupación Rodolfo } \\
\text { Walsh; comunidad académica } \\
\text { de la Universidad de La Plata, } \\
\text { comunidad universitaria en } \\
\text { general; militantes; represen- } \\
\text { tantes de organismos de } \\
\text { DDHH y organizaciones } \\
\text { políticas y sociales; gremios } \\
\text { universitarios; referentes y } \\
\text { familiares de víctimas de la } \\
\text { Violencia Institucional en } \\
\text { democracia. }\end{array}$ & $\begin{array}{l}\text { Reforzar institucionalmente } \\
\text { la memoria y la historia de } \\
\text { lucha en la búsqueda de } \\
\text { justicia por nuestro estudian- } \\
\text { te Miguel Bru (torturado, } \\
\text { asesinado y desaparecido por } \\
\text { la polić́a bonaerense el } \\
17 / 8 / 1993) \text {. Fortalecer el } \\
\text { vínculo de la FP y CS con } \\
\text { Rosa Bru, la Asociaciòn } \\
\text { Miguel Bru y los familiares } \\
\text { de víctimas de violencia } \\
\text { policial e institucional. }\end{array}$ & $\begin{array}{l}\text { Vigilia, actos, radio abierta, } \\
\text { muestras artísticas. }\end{array}$ & $\begin{array}{l}\text { Masiva vigilia en la Comisa- } \\
\text { ría Novena de La Plata. }\end{array}$ & $\begin{array}{l}\text { La vigilia por el reclamo de } \\
\text { justicia por la aparición del } \\
\text { cuerpo de Miguel Bru, está } \\
\text { instalada en la agenda de } \\
\text { DDHH de la ciudad de La } \\
\text { Plata y como movilización de } \\
\text { referencia contra el gatillo } \\
\text { fácil en la Argentina. }\end{array}$ & $\begin{array}{l}\text { Informe de gestión. } \\
\text { Participación en la misma. }\end{array}$ \\
\hline 2013 & $\begin{array}{l}\text { Reorganización de datos de } \\
\text { les detenides desaparecides } \\
\text { de la Escuela Superior de } \\
\text { Periodismo para mantener } \\
\text { viva la memoria de lo que } \\
\text { pasó durante el terrorismo } \\
\text { de Estado con la comunidad } \\
\text { académica de la FP y CS de } \\
\text { la UNLP en el marco del } \\
\text { Proyecto de Investigación } \\
\text { "Textos de la Memoria". }\end{array}$ & $\begin{array}{l}\text { FP y CS; Secretaría de } \\
\text { Derechos Humanos FP y CS; } \\
\text { UNLP; docentes y alumnes, } \\
\text { compañeres de la agrupación } \\
\text { HIJES que cursan en la } \\
\text { Facultad.. }\end{array}$ & $\begin{array}{l}\text { Aportar a la construcción de } \\
\text { la memoria colectiva en } \\
\text { referencia a lo acontecido } \\
\text { con los estudiantes de la } \\
\text { Escuela Superior de Periodis- } \\
\text { mo detenides y desapareci- } \\
\text { dxs durante el Terrorismo de } \\
\text { Estado. }\end{array}$ & $\begin{array}{l}\text { Sistematización, registro } \\
\text { final y producción gráfica. }\end{array}$ & $\begin{array}{l}\text { Fascículo con historias de la } \\
\text { dictadura y les desapareci- } \\
\text { dxs de la FP y CS. }\end{array}$ & $\begin{array}{l}\text { Se multiplican los juicios de } \\
\text { lesa humanidad en la } \\
\text { Argentina. Gran avance del } \\
\text { proceso de Memoria Verdad } \\
\text { y Justicia en nuestro país. }\end{array}$ & $\begin{array}{l}\text { Fascículos, testimonios de } \\
\text { integrantes del proyecto, } \\
\text { informe de gestión. }\end{array}$ \\
\hline $2013 / 2014$ & $\begin{array}{l}\text { Realización del programa de } \\
\text { radio La Punta del Ovillo. }\end{array}$ & $\begin{array}{l}\text { Dirección de Derechos } \\
\text { Humanos; FP y CS; Radio } \\
\text { Perio; estudiantes privades de } \\
\text { la libertad y estudiantes no } \\
\text { privades de la libertad. }\end{array}$ & $\begin{array}{l}\text { Garantizar y promover y } \\
\text { difundir el derecho a la } \\
\text { comunicación y la circulación } \\
\text { de la palabra desde el ámbito } \\
\text { carcelario. Fortalecer el } \\
\text { vínculo de la FP y CS con } \\
\text { alumnes privades de la } \\
\text { libertad. }\end{array}$ & $\begin{array}{l}\text { Producción Radiofónica que } \\
\text { se transmite por Radio } \\
\text { Perio, todos los miércoles a } \\
\text { las } 13 \text { hs. Programa hecho } \\
\text { por les compañerxs privadxs } \\
\text { de la libertad que estudian } \\
\text { en la FP y CS. Los progra- } \\
\text { mas se pueden esucuchar en } \\
\text { el sitio de Facebook con el } \\
\text { nombre La Punta del Ovillo. } \\
\text { Se produce en el estudio de } \\
\text { radio de la FP y CS y } \\
\text { contiene relatos producidos } \\
\text { en contextos de encierro. }\end{array}$ & $\begin{array}{l}\text { Puesta en el aire, en Radio } \\
\text { Perio, del programa } \\
\text { semanal de una hora, } \\
\text { producido por privades de } \\
\text { libertad y miembros de ls } \\
\text { Secretaría de DDHH de la } \\
\text { FP y CS. }\end{array}$ & $\begin{array}{l}\text { Se siguen dictando las } \\
\text { carreras de Profesorado y } \\
\text { Licenciatura en Comunica- } \\
\text { ción Social en la sede de la } \\
\text { Unidad Penitenciaria N }{ }^{\circ} 9 \text { y } \\
\text { tb vienen privades de libertad } \\
\text { a cursar a la sede del bosque. }\end{array}$ & $\begin{array}{l}\text { Informe de gestión. Sitio } \\
\text { de Facebook "La Punta } \\
\text { del Ovillo". }\end{array}$ \\
\hline
\end{tabular}




\begin{tabular}{|c|c|c|c|c|c|c|c|}
\hline Fecha & Actividad & Participantes & Objetivos & Metodología & Resultado & Contexto & Fuentes \\
\hline 2013 & $\begin{array}{l}\text { Jornada de formación de } \\
\text { promotores barriales bajo la } \\
\text { consigna "Ni un pibe } \\
\text { Menos", en el marco de la } \\
\text { Campaña Nacional contra la } \\
\text { Violencia Institucional. La } \\
\text { actividad tuvo lugar en el } \\
\text { edificio "Néstor Kirchner" } \\
\text { de la Facultad de Periodis- } \\
\text { mo y Comunicación Social } \\
\text { de la UNLP. }\end{array}$ & $\begin{array}{l}\text { Rosa Bru, Alejandro } \\
\text { Mosquera; el defensor de } \\
\text { Cámara Casación Mario } \\
\text { Coriolano; Secretaría de } \\
\text { Derechos Humanos de la } \\
\text { FP y CS; miembros de la } \\
\text { comunidad de diversos barrios } \\
\text { de la ciudad de La Plata; } \\
\text { equipo de gestión; alumnes. }\end{array}$ & $\begin{array}{l}\text { Debatir sobre seguridad } \\
\text { democrática, abusos policia- } \\
\text { les, criminología mediática y } \\
\text { derechos humanos. }\end{array}$ & Talleres; charlas/debates. & $\begin{array}{l}\text { Elaboración de un } \\
\text { documento con aportes } \\
\text { para abordar la problemáti- } \\
\text { ca de la Violencia Institu- } \\
\text { cional. Debate, intercambio } \\
\text { e información sobre la } \\
\text { problemática. }\end{array}$ & $\begin{array}{l}\text { En Noviembre de } 2012 \text { se } \\
\text { vota la propuesta de declarar } \\
\text { el } 8 \text { de Mayo como Día } \\
\text { nacional contra la Violencia } \\
\text { Institucional, en ese mismo } \\
\text { año se lanza la Campaña } \\
\text { Nacional contra la Violencia } \\
\text { Institucional. El viernes } 3 \text { de } \\
\text { mayo se lanzó la Campaña } \\
\text { Nacional contra la Violencia } \\
\text { Institucional. La misma estáa } \\
\text { destinada a víctimas, familia- } \\
\text { res, militantes, referentes } \\
\text { políticos, sindicales, profesio- } \\
\text { nales, trabajadores e integran- } \\
\text { tes de los tres poderes del } \\
\text { Estado. }\end{array}$ & $\begin{array}{l}\text { Informe de gestión. } \\
\text { Participación en la } \\
\text { Campaña nacional Contra } \\
\text { la Violencia Institucional. }\end{array}$ \\
\hline 2013 & $\begin{array}{l}\text { Jornadas por los } 20 \text { años } \\
\text { de la desaparición de } \\
\text { Miguel Bru. }\end{array}$ & $\begin{array}{l}\text { Sectores de la cultura de la } \\
\text { ciudad de La Plata. León } \\
\text { Gieco. Rosa Bru, Victoria } \\
\text { Montenegro; Cristian Alarcón, } \\
\text { Hugo Cañón, Leonardo } \\
\text { Grosso, Baltasar Garzón, } \\
\text { Martín Fresneda, Estela de } \\
\text { Carlotto y Florencia asintout. } \\
\text { Comunidad académica de la } \\
\text { UNLP, organismos de } \\
\text { DDHH, organizaciones } \\
\text { políticas y sociales. }\end{array}$ & $\begin{array}{l}\text { Fortalecer el proceso de } \\
\text { memoria y justicia por la } \\
\text { desaparición del estudiante } \\
\text { Miguel Bru. }\end{array}$ & $\begin{array}{l}\text { Jornada cultural por los } 20 \\
\text { años de la desaparición de } \\
\text { Miguel Bru en el Galpón de } \\
\text { La Grieta y entrega del } \\
\text { Premio Rodolfo Walsh por } \\
\text { la Comunicación Popular a } \\
\text { León Gieco. Jornadu contra } \\
\text { la violencia institucional y la } \\
\text { complicidad policial en la FP } \\
\text { y CS. Invitados como: Rosa } \\
\text { Bru, Victoria Montenegro; } \\
\text { Cristian Alarcón, Hugo } \\
\text { Cañón, Leonardo Grosso, } \\
\text { Baltasar Garzón, Martín } \\
\text { Fresneda, Estela de Carlotto } \\
\text { y Florencia Saintout. } \\
\text { Presentación del documental } \\
\text { "Rosa Bru: } 20 \text { años de } \\
\text { lucha", realizado por la } \\
\text { AMB y la FP y CS. }\end{array}$ & $\begin{array}{l}\text { Realización y proyección } \\
\text { del documental " Rosa Bru, } \\
20 \text { años de lucha". Armado } \\
\text { y realización de jornadas } \\
\text { culturales en el galpón La } \\
\text { Grieta. Organización de } \\
\text { acto en la FP y CS. }\end{array}$ & $\begin{array}{l}\text { La violencia institucional está } \\
\text { en la agenda parlamentaria y } \\
\text { social. Se avanza en proyectos } \\
\text { para aportar al mejoramiento } \\
\text { de esta problemática. }\end{array}$ & $\begin{array}{l}\text { Informe de gestión. } \\
\text { Documental "Rosa Bru } \\
20 \text { años de Lucha". }\end{array}$ \\
\hline 2013 & $\begin{array}{l}\text { Participación en el 1er } \\
\text { Congreso del Mercosur de } \\
\text { Educación en Contexto de } \\
\text { Encierro organizado por la } \\
\text { Universidad Nacional de } \\
\text { Córdoba (UNC). }\end{array}$ & $\begin{array}{l}\text { Universidad Nacional de } \\
\text { Córdoba (UNC); Secretaría de } \\
\text { DDHH de la FP y CS de al } \\
\text { UNLP. Universidades } \\
\text { nacionales de todo el pás. }\end{array}$ & $\begin{array}{l}\text { Crear una red interuniversita- } \\
\text { ria de Derechos Humanos } \\
\text { para visibilizar y garantizar el } \\
\text { derecho a la educación } \\
\text { universitaria las cárceles de la } \\
\text { región. }\end{array}$ & $\begin{array}{l}\text { Mesas debate, intercambio } \\
\text { de propuestas, elaboración } \\
\text { de documentos, presenta- } \\
\text { ción de producciones } \\
\text { comunicacionales, en la } \\
\text { ciudad universitaria de } \\
\text { Córdoba }\end{array}$ & $\begin{array}{l}\text { Se conformó la Red } \\
\text { Interuniversitaria de } \\
\text { Educación Superior en } \\
\text { Cárceles, de la cual la } \\
\text { FP y CS de al UNLP } \\
\text { participa como miembro } \\
\text { asociado. }\end{array}$ & $\begin{array}{l}\text { Gran avance en las universi- } \\
\text { dades nacionales sobre la } \\
\text { necesidad de profundizar la } \\
\text { educación universitaria en } \\
\text { cárceles. Se promueven } \\
\text { actividades de investigación, } \\
\text { producción y extensión entre } \\
\text { las universidades y las } \\
\text { cárceles. }\end{array}$ & $\begin{array}{l}\text { Documentos. Informes de } \\
\text { gestión. }\end{array}$ \\
\hline
\end{tabular}




\begin{tabular}{|c|c|c|c|c|c|c|c|}
\hline Fecha & Actividad & Participantes & Objetivos & Metodología & Resultado & Contexto & Fuentes \\
\hline 2014 & $\begin{array}{l}\text { Implementación del idioma } \\
\text { originario en la currícula de } \\
\text { la carrera }\end{array}$ & $\begin{array}{l}\text { FP y CS; Academia de } \\
\text { Lengua Quechua de } \\
\text { Cuzco; profesor Mario } \\
\text { Auca. }\end{array}$ & $\begin{array}{l}\text { Reconocer nuestros orígenes } \\
\text { a través de las lenguas } \\
\text { originarias. Crear la posibili- } \\
\text { dad de hacer real la educa- } \\
\text { ción intercultural. }\end{array}$ & $\begin{array}{l}\text { Gestión para la consolida- } \\
\text { ción de la propuesta } \\
\text { aprobada por el consejo } \\
\text { directivo de la FP y CS, por } \\
\text { unanimidad, para el dictado } \\
\text { de idioma originario } \\
\text { Quetchua a cargo de Mario } \\
\text { Auca profesor de lengua } \\
\text { Quechua de la Academia } \\
\text { Mayor de Lengua Quechua } \\
\text { de Cuzco, filial La Plata en el } \\
\text { primer cuatrimestre del año } \\
\text { 2014. }\end{array}$ & $\begin{array}{l}\text { Cursada cuatrimestral con } \\
\text { gran concurrencia de } \\
\text { estudiantes en la misma. }\end{array}$ & $\begin{array}{l}\text { Es la primer materia de } \\
\text { idioma originario en la } \\
\text { currícula de la carrera en la } \\
\text { UNLP. }\end{array}$ & $\begin{array}{l}\text { Informe de gestión. } \\
\text { Integrantes de la Secreta- } \\
\text { ría de DDHH FP y CS. }\end{array}$ \\
\hline 2012-2013 & $\begin{array}{l}\text { Primera Muestra de Cine } \\
\text { Indígena dependiente del I } \\
\text { Festival de Cine Indígena } \\
\text { BAIn, Buenos Aires } \\
\text { Indígena. }\end{array}$ & $\begin{array}{l}\text { Comunidad Qom de barrio } \\
\text { Malvinas y de la Comunidad } \\
\text { Quechua de La Plata; Grupo } \\
\text { Universitarios de Investiga- } \\
\text { ción en Antropología Social } \\
\text { de La Plata; FP y CS; Cristian } \\
\text { Jure; comunidad educativa; } \\
\text { equipo de gestión; represen- } \\
\text { tantes de diversas comunida- } \\
\text { des indígenas. }\end{array}$ & $\begin{array}{l}\text { Promover institucionalmen- } \\
\text { te y también en la ciudad de } \\
\text { La Plata las problemáticas } \\
\text { indígenas y su visualización. } \\
\text { Comprender la cosmovisión } \\
\text { indígena. }\end{array}$ & $\begin{array}{l}\text { Muestra, talleres, presenta- } \\
\text { ción audiovisual. Conversa- } \\
\text { torios. Con la presentación } \\
\text { de la película Diez veces } \\
\text { venceremos de Cristian Jure, } \\
\text { sobre la vida de Pascual } \\
\text { Pichun Collonao; contó } \\
\text { también con la realización } \\
\text { de talleres de capacitación } \\
\text { audiovisual con docentes de } \\
\text { la Catedra Audiovisual I y } \\
\text { realizadores qom adolescen- } \\
\text { tes de la Comunidad Qom } \\
\text { de barrio Malvinas y de la } \\
\text { Comunidad Quechua de La } \\
\text { Plata y la presentación de la } \\
\text { Muestra fotográfica Prisio- } \\
\text { neros de guerra a cargo del } \\
\text { colectivo GUIAS, Grupo } \\
\text { Universitarios de Investiga- } \\
\text { ción en Antropología Social } \\
\text { de La Plata. Relatos sobre las } \\
\text { prisiones de la ciencia en el } \\
\text { Museo de Ciencias Naturales } \\
\text { de La Plata. }\end{array}$ & $\begin{array}{l}\text { Gran participación de la } \\
\text { comunidad académica y la } \\
\text { presencia de realizadores y } \\
\text { comunidades indígenas en } \\
\text { la jornada. Intercambio de } \\
\text { saberes y cosmovisiones } \\
\text { sobre la cuestión indígena. }\end{array}$ & $\begin{array}{l}\text { Se profundiza la temática } \\
\text { indígena como eje de trabajo } \\
\text { de la Secretaría de DDHH de } \\
\text { la FP y CS. UNLP. }\end{array}$ & $\begin{array}{l}\text { Informe de gestión de la } \\
\text { Secretaría de DDHH de la } \\
\text { FP y CS, certificados de } \\
\text { asistencia al encuentro, } \\
\text { protagonistas del encuentro. }\end{array}$ \\
\hline
\end{tabular}




\begin{tabular}{|c|c|c|c|c|c|c|c|}
\hline Fecha & Actividad & Participantes & Objetivos & Metodología & Resultado & Contexto & Fuentes \\
\hline $2010 / 2014$ & $\begin{array}{l}\text { Tres jornadas de Trabajo en } \\
\text { conjunto con la Universidad } \\
\text { Nacional de Educación a } \\
\text { Distancia, UNED en } \\
\text { relación a la educación } \\
\text { universitaria en cárceles. }\end{array}$ & $\begin{array}{l}\text { Docente Antonio Viedma } \\
\text { Rojas de UNED, Integrantes } \\
\text { del Programade Educación } \\
\text { Superior en Contextos de } \\
\text { Encierro de la FP y CS. } \\
\text { Estudiantes privados/as de } \\
\text { libertad alojados en la } \\
\text { Extensión Aulica Unidad No9; } \\
\text { Marta Laferrière (Docente } \\
\text { fundadora del Programa UBA } \\
\text { XXII- Universidad de Buenos } \\
\text { Aires); Jorge Jaunarena } \\
\text { (Secretario de Derechos } \\
\text { Humanos - Coordinador de la } \\
\text { Extensión Unidad No9 - } \\
\text { Universidad Nacional de La } \\
\text { Plata); docentes, tesistas e } \\
\text { integrantes de los Observato- } \\
\text { rio de Comunicación, Género } \\
\text { y Diversidad con perspectiva } \\
\text { en Derechos Humanos FP y } \\
\text { CS; Observatorio de Medios } \\
\text { con perspectiva de Género FP } \\
\text { y CS.; sestudiantes universita- } \\
\text { rios de las carreras de Comu- } \\
\text { nicación Social, Ciencias } \\
\text { Jurídicas y Humanidades. }\end{array}$ & $\begin{array}{l}\text { Intercambio de experien- } \\
\text { cias, establecer vínculos } \\
\text { entre las universidades y lxs } \\
\text { privadxs de libertad. }\end{array}$ & $\begin{array}{l}\text { 18; } 19 \text { y } 20 \text { de Diciembre - } \\
\text { Trabajo en conjunto con el } \\
\text { docente Antonio Viedma } \\
\text { Rojas (UNED), en el marco } \\
\text { del Programa de Educación } \\
\text { Superior en Contextos de } \\
\text { Encierro. Para la visita del } \\
\text { Licenciado se han pautado } \\
\text { las siguientes actividades. }\end{array}$ & $\begin{array}{l}\text { Se desarrollaron con éxito } \\
\text { las jornadas, enriquecimien- } \\
\text { to con los intercambios de } \\
\text { experiencias. }\end{array}$ & $\begin{array}{l}\text { Se multiplica el trabajo, la } \\
\text { difusión de la experiencia y la } \\
\text { red de articulaciones del } \\
\text { Programa de Educación en } \\
\text { Contextos de Encierro de la } \\
\text { FP y CS. }\end{array}$ & $\begin{array}{l}\text { Informe de gestión. Partici- } \\
\text { pación en las jornadas. }\end{array}$ \\
\hline
\end{tabular}




\section{4 / 2007}

\section{El inicio de la nueva política}

En este periodo, se instaló una nueva política de derechos humanos en la Facultad. El contexto político nacional de 2004 ofrecía las condiciones ideales para gestionar lo que primero fue la Dirección y, algunos años más tarde, la Secretaría de Derechos Humanos. La lectura de la Matriz de Sistematización evidencia cómo en este primer período se consolidó la gran mayoría de los ejes temáticos sobre los cuales se desarrollarían las futuras líneas de acción de la Secretaría

En 2003, había asumido la presidencia del país Néstor Kirchner, acontecimiento que iba a cambiar el rumbo de nuestra historia. Entre otros hechos simbólicos y fácticos muy fuertes, el nuevo Presidente tomó la decisión política de anular las «Leyes del Perdón» y de incorporar a los organismos, referentes y organizaciones de derechos humanos a la política pública; pidió perdón en nombre del Estado por las atrocidades cometidas durante el terrorismo de Estado y le hizo descolgar al jefe del Ejército los cuadros de los presidentes de la Dictadura que se encontraban en la Escuela de Mecánica de la Armada (ESMA). Como Secretario de Derechos Humanos de la Nación, había sido nombrado Eduardo Luis Duhalde, ex abogado de presos políticos durante la última Dictadura, que en 1976 debió exiliarse en España, desde donde se dedicó a denunciar el accionar de la junta cívico militar eclesiástica.

En su mayoría, el gobierno de la denominada «era de ampliación de derechos» estaba integrado por compañeres que se habían tenido que exiliar debido a su militancia política en los años setenta, la cual se fundaba en un proyecto de país con igualdad de condiciones en el acceso a derechos para todes. La nueva política de Estado constituyó un envión esencia para lo que vendría en la gestión de la Facultad y generó un contexto que permitió abrir innumerables puertas y llevar a cabo acciones que requerían de estar a la altura de los avances que se avecinaban en el país en materia de derechos.

En el proyecto presentado, se planteaban las bases de la gestión:

Desde la Dirección de Derechos Humanos, el objetivo básico de una primera etapa de trabajo estará dirigido a la capacitación académica de estudiantes, docentes e investigadores/as, en un sentido amplio del término, no solo en cuestiones históricas, sino también en el abordaje de fenómenos actuales como el denominado gatillo fácil, la tortura y otras formas de represión en el marco de la democracia.

También creemos necesario incursionar en otros modos de violación de derechos humanos como ser las prácticas discriminatorias en términos de género, etnia, edad, raza, identidad de género, orientación sexual, minorías culturales, entre otras cuestiones.
La Universidad, como espacio educativo dedicado a la enseñanza, la investigación y la extensión, posee, por su propia naturaleza, una conexión directa con los derechos humanos (civiles, políticos, económicos, sociales y culturales), que debe recrearse en abordajes sustancialmente más integrales que los hasta ahora intentados, estableciendo una línea académica sobre la educación y la articulación cívica, como política de la institución (Carta de intención, 2004). ${ }^{29}$

Finalmente, el 20 de agosto de 2004, por unanimidad de las autoridades del entonces Consejo Académico se creó la Dirección de Derechos Humanos de la Facultad de la cual fui nombrado Director (FPYCS, Resolución 88).

Es importante señalar que esta Dirección fue la primera área de gestión con esa especificidad en una unidad académica de la UNLP. En el ámbito del Rectorado, la Dirección de Derechos Humanos había sido creada en 1998, por lo que desde un principio buscamos interactuar con sus referentes. Con el resto de las unidades académicas, por el contrario, la ausencia de áreas específicas de representación institucional dificultaba el contacto y la comunicación. Sin embargo, con el correr de los años, esto se iría revirtiendo, especialmente, a partir de 2014.

\section{Pedagogía en comunicación y derechos humanos}

Una de las primeras acciones de la por entonces Dirección de Derechos Humanos fue el desarrollo del curso extracurricular «Periodismo y Derechos Humanos», dirigido a estudiantes avanzades de la carrera. Como muestra clara de la búsqueda de articulación que caracterizaba a la gestión, el seminario fue organizado de manera conjunta con la Asamblea Permanente por los Derechos Humanos (APDH) La Plata, uno de los organismos de derechos humanos más antiguos y con mayor prestigio de nuestro país. ${ }^{30}$

La política de gestión se construyó en el marco del diálogo de saberes. En este caso, además de la articulación con la APDH, las personas invitadas eran especialistas o referentes en los ejes de debate propuestos: historia de los organismos de derechos humanos, dictado por Edna Ricceti, Madre de Plaza de Mayo, y por Jaime Glüzmann, Presidente de la APDH La Plata; violencia institucional-policial, por Ricardo Rajendorfer, periodista y escritor; criminalización de la pobreza, por Enrique Symms, periodista y escritor; conflictos laborales en el ejercicio de la profesión, por Néstor Maldonado, periodista y miembro del Sindicato de Prensa de Buenos Aires (SiPreBA); cobertura de noticias de derechos humanos, por Victoria Guinsberg, periodista de Página/12; caso Von Wernich, por Hernán Brienza, periodista y escritor; caso Bru, por Rosa Bru y por Alberto Mendoza, integrantes de la Asociación Miguel Bru (AMB); discriminación y diversidades culturales, por Flavio Rapisardi, politólogo y profesor en 29 Se ofrece en el Anexo la Carta de intención del proyecto de la Dirección de Derechos Humanos de la Facultad de Periodismo y Comunicación Social de la UNLP (2004).

30 La Asociación Civil apdh fue creada en 1975 
Filosofía de la Universidad de Buenos Aires (UBA); género y medios de comunicación, por Liliana Daunes, periodista y escritora; comunicación alternativa y derechos humanos, por Cecilia Ceraso, Secretaria de Planificación y Gestión para la Comunidad de la Facultad.

Entendíamos que la formación de periodistas con perspectiva en derechos humanos era fundamental, pues les otorgaba a les futures egresades herramientas para aplicar desde la práctica profesional concreta. Además, temas como memoria y dictadura, violencia institucional, género, comunicación alternativa y derechos humanos, discriminación y diversidad, se iban transformando en el centro del debate de nuestra institución.

Entre los resultados de este curso, se destacan las incorporaciones al equipo docente de Lucas Miguel, secretario de Prensa de la APDH y egresado de nuestra Facultad, y de Luciana Burgos, estudiante avanzada de la carrera de Licenciatura en Comunicación Social, que se convirtió en la primera estudiante becada que tuvo la Dirección. De ese modo, y mediante el diálogo de saberes, se iba armando la estructura de nuestro espacio.

En el marco de esta primera propuesta pedagógica de grado que realizó la gestión, el estudio de las prácticas comunicacionales en relación con los derechos humanos ocupó un lugar trascendental. El seminario estaba dividido en cuatro módulos. El referido a «Periodismo y Derechos Humanos» atravesaba la currícula de toda la materia y abordaba las conceptualizaciones sobre derechos humanos, memoria y dictadura, violencia instituciona en democracia, géneros, diferencias culturales y disputas por el sentido. Lo comunicacional era un eje central en relación con la temática de cada módulo. Cuando nos referíamos a la comunicación también analizábamos los procesos o los modos de organización colectiva para los reclamos de justicia.

El diálogo de saberes se acentuaba, también, por la presencia de docentes como Antonia Portaneri, egresada de la Facultad que trabajaba en Cancillería como representante en cuestiones de género de la Argentina para el mundo, cuya participación en la vanguardia de los debates sobre políticas de género le agregaba una impronta extra; Flavio Rapisardi, uno de los máximos referentes del colectivo TLGBI a nivel nacional; Lucas Miguel, que trabajaba en los Juicios de Lesa Humanidad en La Plata, anteriormente en los Juicios por la Verdad, y también en la APDH La Plata; Leonardo Godoy, periodista con perspectiva en derechos humanos; y Lelio Sánchez, compañero no vidente (aunque él dice que prefiere autodefinirse como «ciego») de la Comisión de Discapacidad de la Facultad. Más adelante, se incorporaron la estudiante trans, y actualmente docente, Claudia Vásquez Haro, a dictar el eje sobre diversidad sexual, y el estudiante mapuche y activista indígena Pascual Pichun Collonao, quien desarrollaba en aquel entonces las cuestiones indígenas.

En el marco de la cursada, Rosa Bru, compañeres de la AMB y referentes de víctimas de la Violencia Institucional brindaban charlas-debate. Asimismo, Adelina Dematti de Alaye Madre de Plaza de Mayo de La Plata, y Estela Carlotto, Presidenta de Abuelas de Plaza de Mayo, eran dos referentes que no faltaban al seminario, junto con una gran diversidad de actores que, además de compartir sus saberes y sus experiencias, participaban en la construcción de la política de la institución.

Pronto comenzamos a llevar el seminario Comunicación y Derechos Humanos a las extensiones de la Facultad que funcionaban en las localidades de Bolívar, Lincoln, Moreno, Monte Caseros y Santa Teresita del Partido de La Costa, donde instalábamos temas como género y diversidad sexual, violencia institucional, periodismo con perspectiva en derechos humanos, y llevábamos a diferentes referentes en la materia. Era muy movilizador poder discutir en esos lugares sobre temas tan actuales y generar debates que en comunidades más conservadoras se convertían en una oportunidad única para el estudiantado.

\section{Memoria y Dictadura}

Desde el inicio de la gestión, el armado de los listados de nuestras víctimas institucionales del terrorismo de Estado fue un hecho fundamental para el proceso de Memoria, Verdad y Justicia de la Facultad, una de las unidades académicas más castigadas (la por entonces Escuela, fue cerrada, intervenida y más de la mitad de su población académica fue asesinada desaparecida o exiliada) en el marco de una de las instituciones públicas con más víctimas como fue la Universidad Nacional de La Plata.

Como en todos los aspectos de la gestión, convocamos a Madres y a Abuelas de Plaza de Mayo, a familiares de detenides desaparecides, a hijes de desaparecides, a estudiantes y a la militancia de la época. Así, con les protagonistas de los hechos y con la información sobre nuestras víctimas aportada por la Dirección de Derechos Humanos de la UNLP, fuimos reconstruyendo nombres e historias. Lo cierto es que los listados encontrados eran muy precarios y con numerosos datos erróneos, lo que evidenciaba que el proceso de reparación de las víctimas en nuestra universidad -como en todas las instituciones de nuestra democracia- había sido demasiado lento para lo que se pretendía desde muchos sectore sociales, al igual que el proceso de Memoria Verdad y Justicia; situación que cambió para siempre con el gobierno que asumió en 2003.

Desde la Dirección, presentamos en el Consejo Académico de la Facultad el proyecto "Textos de la Memoria. Historias de los desaparecidos de Periodismo», lo que permitió que a iniciativa se fortaleciera institucionalmente. Posteriormente, también fue aprobado como proyecto de investigación y desarrollo en la UNLP. Cito su resumen:

El proyecto propone relevar y compilar historias de vida de las víctimas del Terrorismo de Estado en la Argentina entre 1976-1983 que fueron estudiantes, profesores y miembros de la Escuela Superior de Periodismo y Comunicación Social de la Universidad Nacional de la Plata, y además, ponerlas en contexto para obtener datos de la época. Hasta el momento, la información incluye cuarenta desaparecidos/as y asesinados/as, entre estudiantes, docentes y graduados de la Escuela. El proyecto plantea un 
trabajo de historización, de compilación testimonial y de registro público de sus historias de vida en el marco de la investigación y el activismo por la memoria, la verdad y la justicia. El proyecto se inscribe dentro del campo de estudios de la comunicación-cultura que define a la comunicación como disputa por la producción social de sentido, entendiendo que la recuperación de los relatos memoriales es clave para fortalecer la identidad nacional y el permanente proceso de construcción de la memoria colectiva.

La investigación periodística estuvo a cargo de docentes, alumnes, graduades, familiares y compañeres de víctimas. Se realizaron numerosas entrevistas, inclusive a personas que se exiliaron y que aún viven en el exterior. Para hacerla pública e institucionalizarla, la información obtenida era subida al sitio oficial de la Facultad.

En este sentido, también se fortaleció el vínculo con ex estudiantes de la carrera que militaban y que cursaban en la Escuela durante los años setenta. Comenzó a ser frecuente encontrarlos por los pasillos de la Facultad, recorriendo las aulas, sosteniendo entrevistas con les estudiantes, disertando en actos alusivos o participando de actividades académicas e institucionales. Organismos de derechos humanos, familiares de víctimas, Madres y Abuelas de Plaza de Mayo e H.I.J.O.S. eran invitados permanentemente a nuestras aulas.

En el trabajo de articulación con la Dirección de Derechos Humanos del Rectorado, también fuimos convocades a participar en el armado de los listados de las víctimas del Terrorismo de Estado de la UNLP, cuyos nombres están inscriptos en las placas que se encuentran en la actualidad en el ingreso a la sede del Rectorado y cuyas semblanzas se ofrecen en el sitio institucional.

En todas estas jornadas, intentábamos que Madres y Abuelas de Plaza de Mayo interactuaran con madres de víctimas de la Violencia Institucional. Entendíamos, a partir de la experiencia de Rosa, y de lo que significó para su formación y su desarrollo político el gran acompañamiento de Madres y Abuelas, que eran puentes muy necesarios para esta democracia y para nuestra vida institucional. Uno de los actos más significativos fue cuando Adelina Dematti de Alaye le regaló a Rosa el pañuelo de las Madres de Plaza de Mayo con un bordado hecho por ella misma que decía Miguel Bru y la fecha de su desaparición.

En el marco del diálogo de saberes que constituye la política central de la gestión, también se destaca la organización de la mesa "Memoria y Justicia. Madres de ayer y de hoy», realizada en el marco de los Congresos Ibercom, Alaic y Redcom (2004). Allí se abordó «El rol de los medios de comunicación en la lucha por el cumplimiento de los $\mathrm{DDHH}$, en un panel integrado por Adelina Dematti de Alaye (Madres de Plaza de Mayo), Edna Richetti (Madres Línea Fundadora) y madres de las víctimas de Violencia Institucional en democracia: Rosa Bru (madre de Miguel), Raquel Wittis (madre de Mariano) y Dolores Demonty (madre de Ezequiel). La mesa fue presentada y coordinada por María Eugenia Ludueña, periodista de la revista TXT y del diario La Nación, compañera de la AMB y especialista en periodismo con perspectiva de derechos.

Desde aquellos primeros años y hasta la actualidad, fuimos convocados a formar parte de la organización de las «Jornadas por la Memoria Fértil», donde se rinden diversos homenajes a militantes del justicialismo y a referentes del proceso de las «bases para una nueva universidad», que se desarrolló en la UNLP durante los años setenta, y que siempre se conmemora en el aniversario por los asesinatos de Rodolfo Achem, Carlos Miguel, Luis Macor y Carlos Pierini. Es siempre muy emotivo, y significa un proceso enriquecedor y de aprendizaje, poder articular con compañeres de esa generación tan importante para la historia de la universidad y la vida política platense de los años de plomo.

Por una cuestión generacional y de militancia, también compartíamos jornadas con hijes de desaparecides, que siempre apoyaron e impulsaron la causa de Miguel Bru. Con elles, no solo compartíamos la militancia sino también mucha amistad y encuentros que disfrutamos. El afecto que sentimos es absolutamente compartido y siempre nos ha emocionado el amor que le demuestran a Rosa.

Con la UNLP, fundamentalmente a partir de 2006, cuando asumió como Directora de Derechos Humanos la abogada Verónica Piccone (ella también militaba el proyecto kirchnerista de derechos humanos) comenzamos a organizar jornadas en común, y a compartir proyectos y actividades. Entre ellas, la presentación del III Informe Interamericano de Educación en Derechos Humanos, realizada en el Día Internacional de los Derechos Humanos. Un año antes, en 2005, habíamos participado de la organización de la conferencia «Compromisos de la Argentina, compromisos con las mujeres» y de la presentación de la Campaña Nacional «Conocé tus derechos para poder ejercerlos».

De a poco, íbamos instalando una línea política de trabajo que tomaba mucha visibilidad. Desde la Secretaría de Derechos Humanos de Corrientes, nos invitaron a dictar un curso de periodismo con perspectiva de derechos humanos para periodistas de toda la provincia.

\section{Violencia Institucional en democracia}

Un eje de trabajo fundamental, teniendo en cuenta nuestra memoria colectiva institucional, fue el relacionado con Miguel Bru y la Violencia Institucional. El primer año de gestión hicimos un acto institucional en su memoria, el primero desde su desaparición. Si bien históricamente la Facultad y sus autoridades acompañaron la causa de manera incondicional, quienes integrábamos el núcleo duro de la «Comisión de familiares, amigos y compañeros de Miguel» no éramos todes militantes del oficialismo de la Facultad, de hecho, algunes compañeres eran de otras agrupaciones políticas, por lo que mi incorporación a la Dirección contribuyó a que se fortaleciera la relación entre la institución, la AMB y Rosa, que pronto se convirtió en un actor central de nuestra cotidianidad académica.

En 2005, al cumplirse los doce años de la desaparición de Miguel, inauguramos dos murales alusivos, uno con su imagen y otro con la de Rosa, realizados por la artista plástica 
Cristina Terzaghi en la fachada de nuestra sede de calle 44, a la cual también le pusimos el nombre «Miguel Bru, Memoria y Justicia» por ser el edificio donde nuestro compañero estudiaba Periodismo antes de ser desaparecido. Del acto participaron Estela Barnes de Carlotto, presidenta de Abuelas de Plaza de Mayo; Adelina Dematti de Alaye, de Madres de Plaza de Mayo; familiares de víctimas de violencia institucional; autoridades académicas; estudiantes; y organizaciones sociales.

En ese marco también se inauguró una muestra de textos y fotos realizada por jóvenes de Isla Maciel que participan de los talleres de Periodismo y Fotografía que coordinaba la AMB como parte de un trabajo comunitario. El acto se realizó sobre la Avenida 44; casi dos cuadras de esa doble mano fueron cortadas por una gran cantidad de personas emocionadas que asistieron a la inauguración. Desde entonces, el fortalecimiento del vínculo entre la AMB y la Facultad dio lugar a numerosas actividades y proyectos.

Un acto simbólicamente muy fuerte fue la propuesta que presentamos en el Consejo Superior de la UNLP para otorgarle el premio Doctora Honoris Causa, el título honorífico más importante de la universidad, a Rosa Bru. Por su procedencia humilde y su imposibilidad de terminar los estudios primarios, este hecho constituyó un hito sin precedentes, además de la importancia que tuvo realizar la entrega en la Facultad, a la que asistieron las máximas autoridades de la UNLP, organismos de derechos humanos, organizaciones sociales, gremios, estudiantes, docentes y no docentes, numerosas agrupaciones políticas, y referentes del gobierno provincial y nacional.

El acto tuvo lugar un año después, el 17 de agosto de 2006, al cumplirse trece años de la desaparición de Miguel, y la pluralidad de actores que estuvieron presentes marcó una línea central de la gestión: la diversidad de sectores populares habitando la academia. El entonces presidente de la UNLP, Gustavo Azpiazu, fue quien le entregó el título Docto Honoris Causa a Rosa, quien estuvo acompañada por Estela Carlotto y por Raúl Zaffaroni. La UNLP fundamentó la distinción en la «acción ejemplar» de Rosa y en su trayectoria, que la convirtieron en un «símbolo de lucha por la defensa y la promoción de los Derechos Humanos para la sociedad argentina». En la laudatio, ${ }^{31}$ el por entonces ministro de la Suprema Corte de Justicia de la Nación, expresó: «No sé cuántas, sería imposible determinarlo, pero la lucha de Rosa Schonfeld ha salvado muchas vidas [...]. Desde el dolor, hay quien puede reaccionar con el suficiente grado de salud para hacer de eso un canto a la vida».

Rosa agradeció a todes y, sobre todo, a sus «hermanas del dolor», en referencia a las madres de víctimas de la policía que junto con los familiares llenaban la sala con sus fotos y carteles. Denunció que en la Provincia de Buenos Aires la fuerza policial acusada de matar jóvenes gozaba de una gran impunidad. «En la época de la desaparición de Miguel, el Estado era nuestro enemigo. En este momento, no sé si tenemos el aval, pero sí una decisión del Estado de cambiar. Es hora, para que no haya nunca más un Miguel Bru, un Mariano Witis, un Frente Víctor Vital», pidió la homenajeada.

31 Discurso en la antigua ceremonia de entrega de esta "máxima distinción académica», que las universidades hacen desde la Edad Media a figuras de una relevancia extraordinaria.
Previamente, tuvo lugar una mesa redonda sobre periodismo y derechos humanos en la que participaron periodistas como Cristian Alarcón, Ricardo Ragendorfer y Miriam Lewin, junto con Luis Hipólito Alén, Jefe de Gabinete de la Secretaría de Derechos Humanos de la Nación, y la abogada Analía Elíades, Profesora Titular de la Cátedra de Derecho de la Comunicación de la Facultad. Entre les asistentes, hubo referentes del poder judicial familiares de víctimas de la violencia institucional, periodistas con perspectiva de derechos humanos, representantes de la gestión ministerial y numeroses militantes, actores que era cada vez más común verles compartiendo y apropiándose de los claustros universitarios.

Sin duda, un antes y un después en la historia de los derechos humanos de nuestro país lo marcó la desaparición de Jorge Julio López, ocurrida en La Plata el 18 de septiembre de 2006. Durante la última Dictadura cívico militar eclesiástica, López había sido víctima de desaparición forzada y había pasado por varios centros clandestinos de detención (CCD) por lo que su testimonio fue clave para condenar a prisión perpetua a Miguel Etchecolatz. Sin embargo, un día antes de la sentencia López fue desaparecido y hasta hoy seguimos reclamando por su aparición y por el castigo a los culpables. ${ }^{32}$

En relación con este eje, es importante mencionar uno de los primeros proyectos de extensión que desarrollamos: el «Observatorio - Contralor de noticias informativas sobre jóvenes en situación de delito», una investigación interdisciplinaria que relevó durante seis meses las noticias publicadas por los diarios Hoy y El Día de La Plata, Clarín, La Nación y Crónica donde les jóvenes aparecían como víctimas o como victimarios. El proyecto, desarrollado por la AMB, la Dirección de Derechos Humanos de la Facultad, el Área Quee de la Facultad de Filosofía y Letras de la UBA y la Federación Argentina TLGBI, buscó dar cuenta de la producción de noticias informativas sobre jóvenes en situación de delito desde una perspectiva de defensa y de promoción de derechos humanos, y de políticas contra la represión y la discriminación, en articulación con un trabajo en red de activistas de organizaciones de la sociedad civil.

En un contexto nacional donde se fortalecía y se visibilizaba el rol de los monopolios informativos y la necesidad de democratizar la información, asistimos en los medios de comunicación a un debate sobre la proliferación y la acentuación de la denominada «delincuencia juvenil», la baja de la edad de imputabilidad, la pena de muerte y la inseguridad en articulación con el problema de la juventud como sector estigmatizado en tanto responsable del crecimiento de los índices delictivos. Frente a la producción de noticias que en la mayoría de los medios de comunicación no articulaba sus consideraciones con los condicionamientos sociales y culturales, nos propusimos elaborar un informe sobre la estigmatización de jóvenes a partir de la difusión de prácticas culturales de construcción

32 Durante los primeros dieciocho meses la causa fue caratulada como desaparición simple y la investigación quedó a cargo de la Policía Bonaerense, la misma fuerza de la que Etchecolatz había sido un alto funcionario. Al momento de la desaparición de López, el gobernador era Felipe Solá. Las principales sospechas recaen en el represor Etchecolatz y en miembros activos de las fuerzas de seguridad. La desaparición hizo arreciar las críticas sobre el régimen de protección de testigos y sobre la falta de recaudos para frustrar amenazas contra su vida y su libertad. Además, la investigación judicial fue duramente criticada por su inoperancia y su inacción. 
de «perfiles de peligrosidad» que se difunden como «marcos de lectura» de un fenómeno complejo como la delincuencia. La disputa por el sentido y la necesidad de comunicar con una perspectiva de derechos eran centrales para la gestión, y la interdisciplinariedad y la construcción de miradas colectivas nos parecía un aporte esencial en este sentido.

La discusión sobre la influencia de los medios de comunicación en tanto formadores de opinión cobraba cada vez mayor relevancia. El rol del periodismo en relación con la inseguridad (principal hecho de temor en la agenda social) también era un tema central para nuestra facultad, y no es casual que esto se diera en el marco en que comenzaba a tomar cuerpo la posibilidad de contar con una nueva ley de servicios en comunicación plural y democrática, que permitiera visibilizar otras voces que no tenían lugar. Nuevamente, articulamos la universidad con organizaciones de la sociedad civil y del sector público, con activistas y con referentes académicos, y debatimos sobre la relación comunicaciónderechos humanos y sobre el lugar de los medios, desde una visión multidisciplinaria. Finalmente, en 2006 publicamos un libro con el informe final de la investigación.

Dolores Demnty, Miriam Medina, Raquel Witis, Marcelo Melmann, Mirna Gómez, Eugenia Vásquez, Pedro Domínguez, Sabina Sotelo, Linda Vasquez, son madres y padres de víctimas de las fuerzas de seguridad en democracia y grandes referentes de la lucha contra la Violencia Institucional, que pasaron a formar parte de las actividades realizadas por la Facultad. Colaboraron en la definición de los contenidos del eje VI seminario en Comunicación y Derechos Humanos, donde brindaban charlas y eran fuente de consulta permanente para las prácticas de les estudiantes, además de estar siempre presentes en los actos alusivos sobre el tema. Desde la Facultad, acompañamos siempre sus reclamos de justicia, lo que entendíamos como fundamental para que nos sientan como compañeres que transitábamos a la par sus pedidos de justicia y para que se convirtieran en parte constitutiva de nuestra política.

Nos invitaban a compartir disertaciones y experiencias en otras localidades, como la charla sobre «Derechos Humanos, Memoria y Participación Solidaria» que se realizó en el Centro Cultural de Verónica, en 2006 y 2007, como parte de las actividades por el mes de la juventud, y en otras instituciones como la Facultad de Ciencias Sociales de la UBA, la Comisión Provincial de la Memoria, escuelas secundarias de Avellaneda, etcétera.

También nos invitaron a disertar sobre derechos humanos y universidad en el intercambio cultural «Buenos Aires y Medellín se miran y se encuentran», un encuentro realizado en Medellín, Colombia, donde compartimos charlas y experiencias con madres de víctimas de la Violencia Institucional y activistas de ese país. Como miembro invitado, compartí la mesa sobre «Memoria y Verdad», junto con Raquel Robles, fundadora y miembro de la agrupación H.I.J.O.S.; María Teresa Uribe, socióloga colombiana, filósofa, historiadora y escritora; y Juan Luis Mejía, rector de la Universidad Eafit. En ese marco, generamos un convenio que abrió las puertas para numerosos intercambios estudiantiles de grado y de posgrado con la Universidad de Antioquia.

\section{Educación superior en cárceles}

En 2006, iniciamos un proceso de inclusión educativa que se iba a convertir en referencia universitaria tanto a nivel nacional como internacional: el Programa de Educación Superior en cárceles. En ese entonces, Eduardo Di Rocco era el ministro de Justicia de la Provincia de Buenos Aires y Juan Carlos Sallenave, el jefe de prensa -graduado de la Facultad que siempre participaba en las marchas de búsqueda de justicia por Miguel Bru-, cumplió un papel clave, pues fue quien nos trajo la propuesta de trabajar en las cárceles.

Durante el periodo 2006-2008, se realizaron, de común acuerdo entre ambas instituciones y como experiencia piloto, talleres de comunicación y de producción periodística radiofónica y gráfica. A partir de estas experiencias, las personas privadas de libertad no solo conocieron las herramientas que brinda la comunicación social, para potenciar las capacidades expresivas y de contacto con otres, sino que también reconocieron que es un espacio que requiere de estudio y que se abre como posibilidad de acceder a la educación superior, entendiendo a la educación como transformadora de la propia realidad, como herramienta liberadora y, fundamentalmente, como derecho humano.

La organización de este proceso, sin precedentes en la UNLP, fue sumamente compleja Personalmente, venía de una experiencia no muy buena desde la AMB, cuando colapsamos por no tener la capacidad estructural para dar respuesta a las demandas de la población carcelaria que, a mi entender, era y es el colectivo más vulnerado de derechos humanos en nuestro país. Les hice saber que no se trataba solo de buena voluntad, sino que había que tener capacidad estructural y política, y precisamente por eso insistieron en que lo coordinara. Tampoco me agradaban mucho las negociaciones que iba a tener que llevar adelante con el Servicio Penitenciario Bonaerense (SPB) y con el Ministerio de Justicia de la Provincia, porque toda mi vida esa relación había estado marcada por el enfrentamiento político. No obstante, como parte de un colectivo político sentí que debía aceptar el desafío

Para esta primera instancia, se convocó a docentes con trabajo y militancia en territorios barriales, a organizaciones que se dedicaban al tema y a docentes con experiencia en trabajo en cárceles. Nos asesoramos permanentemente con compañeres del programa UBA XXII, de la Facultad de Filosofía y Letras de la UBA, del Centro Universitario de Devoto (CUD), que tenían un amplia trayectoria en la materia por ser los primeros que llevaron la educación universitaria a las cárceles, en 1985. En tanto, con la Comisión Provincial por la Memoria se articulaba todo lo relacionado con denuncias sobre hechos de violencia o sobre traslados irregulares.

Con el Ministerio de Justicia y, en especial, con el SPB la situación era siempre muy tensa. Resultaba sumamente difícil que instituciones con lógica punitiva incorporaran una lógica educativa, lo que generaba constantes conflictos y un desgaste permanente. También era importante que les privades de libertad -siempre y cuando contaran con autorización judicial-, pudieran asistir a la Facultad para cursar o para rendir materias. Esto implicaba un gran despliegue de seguridad, casi siempre innecesario, ostentoso y violento, que 
provocaba tensiones con docentes y estudiantes. Estaba claro, además, que la institución universitaria (en lo referido a la burocracia administrativa, por ejemplo) no estaba adaptada a las necesidades particulares que tenían les privades de libertad para poder acceder al derecho a la educación.

El poder judicial era otro actor protagónico, ya que cada juez/a decidía qué persona privada de la libertad podía ejercer efectivamente el derecho a la educación y las autorizaciones debían darse en cada caso particular. Muchas eran las dificultades para cobrar los honorarios de docentes y de coordinadores que se estipulaban en el convenio y que debía pagar el Ministerio de Justicia. La gestión de estos trámites insumía demasiado tiempo y era un desgaste muy grande, a lo que se sumaba la propia realidad docente que ocasionaba que los reclamos salariales recayeran sobre la gestión.

Incontables eran las piedras que ponían en el camino las autoridades del SPB para impedir el desarrollo del proceso. Por ejemplo, en la primera huelga de hambre iniciada -principal método de les privades de libertad para hacer escuchar sus reclamos- cerraron un pabellón universitario que nunca volvieron a abrir y hubo numerosos traslados, lo que generó que nos quedáramos con la mitad de la población estudiantil. Requisas ilegales, rotura de elementos pedagógicos, falta de conectividad y de dispositivos, traslados, inconvenientes para sacar de sus celdas a les estudiantes que asistían a clases, largas esperas para que les docentes pudieran ingresar, son solo algunos ejemplos de las dificultades del proceso.

En este marco, en 2006 se firmó el primer convenio y se iniciaron los talleres en diferentes unidades penitenciarias de La Plata (Unidad 9); Los Hornos (Unidades 8 y 33) Magdalena (Unidades 28, 35 y 51); San Nicolás (Unidad 3); Olmos (Unidades 1 y 26); Florencio Varela (Unidades 23 y 24); Gorina (Unidad 18); y Melchor Romero (Unidad 34). Se dictaron talleres de producción gráfica y radiofónica, dirigidos a privades de libertad, y talleres de comunicación institucional, dirigidos a agentes del SPB. En estos últimos, se sumaron la Asociación La Cantora, el Colectivo de Investigación y Acceso a la Justicia (CIAJ) y la AMB. En el marco de este primer convenio bianual (2006/2008), se dictaron talleres en 16 unidades penitenciarias del SPB. La cárcel entró realmente en nuestra facultad y viceversa. Se multiplicaron las producciones del estudiantado sobre privades de libertad y cárceles, así como las producciones periodísticas de privades de libertad que dieron cuenta de la compleja trama carcelaria.

En relación con el contexto, es importante señalar que a instancias de Adriana Puiggrós, por entonces directora General de Cultura y Educación de la Provincia de Buenos Aires, se incorporó a la Ley 26206 de Educación Nacional el capítulo «Educación en ámbitos de privación de libertad» (cap. XII), lo que significó un gran impulso y un importante avance en el tema. Con estas acciones, se empezaban a cumplir los primeros objetivos que perseguía la política de inclusión educativa de nuestra Facultad para reforzar el acceso a derechos; en este caso, potenciar el derecho a la educación, las capacidades expresivas y el derecho a la comunicación para privades de libertad, y posibilitar el dictado de la carrera en las cárceles

\section{y el acceso a nuestra sede.}

El convenio establecía que a tras su finalización se implementaría la carrera de Licenciatura en Comunicación Social con modalidad de cursada dentro de las unidades carcelarias, hecho que finalmente se produjo en 2009 y que continúa, de manera ininterrumpida, hasta la actualidad.

\section{Pueblos indígenas}

En 2005, se presentó en la Dirección de Derechos Humanos Pascual Pichún Collonao, ciudadano mapuche, de nacionalidad chilena, que vivió exiliado siete años en la Argentina luego de que en 2003 le dictaran, junto con su hermano, una condena de cinco años de prisión, tras ser falsamente acusado de un atentado («incendio agravado»), a una máquina propaladora de bandera suiza.

La «Ley Antiterrorista», que en ese momento se utilizaba para criminalizar a las comunidades indígenas en Chile, negaba el derecho a la defensa y no se sabía quiénes eran los testigos que acusaban, entre otras irregularidades. Para las autoridades chilenas, el caso tenía un «agravante»: Pascual era hijo de un Lonko Mapuche y su familia participaba muy activamente en las movilizaciones y en los reclamos por los derechos indígenas. En Chile gobernaba Michelle Bachelett y era complejo que un gobierno que se autoproclamaba de centro izquierda pidiera una extradición al gobierno kirchnerista con la buena sintonía que existía entre ambos.

En ese contexto, a fines de 2006 el kirchnerismo promovió la aprobación y la puesta en marcha de la Ley Nacional 26160 de relevamiento territorial de comunidades indígenas, para dar respuesta a la situación de emergencia territorial de las comunidades indígenas del país y como primer paso para el reconocimiento del derecho a la tierra que habitaban.

Mientras vivió en la Argentina, Pascual estudió en la Facultad y trabajó en la Dirección. La comunidad universitaria, encabezada por la Secretaría, lo acompañó en su reclamo. Aunque sabía que podía ir preso, en 2010 decidió volver a Chile para estar cerca de su familia. Y así fue. Pascual pasó más de un año en la cárcel hasta que la Justicia dictó su libertad. Según nos cuenta, gracias sus estudios en la Facultad y a su trabajo en la Secretaría le redujeron tres años de condena.

Recuerdo su andar callado y, al principio, bastante desconfiado. No obstante, hablamos claro y le aseguramos que haríamos todo lo posible para ayudarlo en su situación. Teníamos una amiga en común, Zulema Enríquez, hoy directora de Pueblos Indígenas de la Facultad, y eso sumado al acompañamiento permanente, ayudó mucho a que confiara. Enseguida, como nos pidió, armamos una conferencia de prensa en la Facultad para difundir su situación, conjuntamente con las comunidades indígenas y con les abogades de la Liga por los Derechos Humanos que llevaban su causa de pedido de refugio político. Con la abogada de la Facultad, Analía Elíades, diseñamos una estrategia para que pudiera convertirse en 
estudiante regular de la carrera -lo que supuso una verdadera ingeniería administrativa- y pronto comenzó a cursar.

A partir del inicio de su trabajo en la Dirección, se visibilizó tanto su caso como la persecución de la que eran víctimas las comunidades mapuches, lo que permitió fortalecer el vínculo y la relación con diversas organizaciones indígenas. Cuando Pascual se sumó a dar clases en el seminario, armamos los ejes del módulo «Pueblos indígenas» y comenzamos a trabajar sobre políticas indígenas. Sin duda, este accionar fue clave para vincularnos desde otro lugar con las comunidades y con las organizaciones indígenas.

\section{Diversidad sexual}

Otro eje temático que sería fundamental para la gestión es el de diversidad sexual. En marzo de 2006, en el inicio del ciclo lectivo y en el marco del seminario Comunicación y Derechos Humanos, se sentó en la primera fila del aula la estudiante trans Claudia Vásquez Haro. Consciente de que al pasar lista iba a decir un nombre que no era el de ella, empecé a nombrar a los estudiantes solo por el apellido, pero me sentía muy incómodo porque no quería que se sintiera mal, tanto que no recuerdo cuando dijo «presente». Al finalizar la clase, se acercó y me dijo: "Sé que sos el secretario de Derechos Humanos» y en ese mismo momento le propuse: «Tenemos que escribir el proyecto de derecho a la identidad de género en nuestras actas administrativas, para que se apruebe en nuestro Consejo Directivo, primero, $y$, luego, en el Consejo Superior de la UNLP». Y así lo hicimos, siempre pensando que esa propuesta debía servir de cara al objetivo más importante: tener la identidad de género en el Documento Nacional de Identidad (DNI)

Desde ese momento, Claudia se sumó a participar de la diagramación de la política de la Secretaría. Empezamos a planificar y a articular políticas de diversidad sexual, revisamos jurisprudencia de casos similares en otros ámbitos y desarrollamos el proyecto formal para la nueva normativa sobre la ley de identidad de género autopercibida, que luego presentamos en el Consejo Directivo de la Facultad. ${ }^{33}$ Paralelamente, íbamos dialogando con las autoridades de la Facultad para obtener apoyo y para darle volumen político a la propuesta.

Al año siguiente, la convocamos para trabajar el módulo sobre diversidad sexual en e seminario de Comunicación y Derechos Humanos, que desde 2004 incluía esta temática en su programa: «Armado de un glosario sobre género, etnia, orientación sexual, identidad de géneros y diferencias etarias. Mecanismos institucionales: ordenamiento jurídico nacional e internacional».

33 Fuente fundamental de dicho escrito fue la Ley Nacional 25864, de 2003, conocida como «Ley Filmus», que abrió en esos años el camino a la dignidad y al respeto de las personas trans. El 7 de febrero de 2003, siend recomienda a todos los establecimientos educativos de la Ciudad Autónoma de Buenos Aires, sean estos de gestión pública o privada, así como a todas las instancias administrativas dependientes de esa Secretaría, que en el ámbito de sus competencias se garantice el respeto por la identidad de género, dignidad e integración de las personas pertenecientes a minorías sexuales».
En este punto, no puedo dejar de mencionar mis inicios en la militancia sobre diversidad sexual, mediante la participación en las marchas del orgullo realizadas en la Ciudad Autónoma de Buenos Aires (CABA), casi desde sus comienzos (la primera se realizó en 1992), donde tuve la oportunidad de conocer y de compartir muchas charlas y entrevistas periodísticas con Lohana Berkins y Marlene Wayar, dos referentes fundamentales, con quienes articulábamos trabajo pero también espacios de café y charlas que redundaron en una formación muy importante. Y también a mis compañeres docentes Flavio Rapisardi y Silvia Delfino, dos eminencias en la militancia TLGBI y actores fundamentales en el desarrollo de la gestión de derechos humanos en la Facultad.

En 2006, tuve el placer de presentar el libro La gesta del nombre propio. Informe sobre la situación de la comunidad travesti en la Argentina, y compartir panel con sus coordinadoras, Lohana Berkins y Josefina Fernández, y con Marlene Wayar, también referente y activista de la comunidad TLGBI. La presentación del libro, que ofrece un análisis impecable sobre la realidad del colectivo travesti en la Argentina, se realizó con un aula colmada de estudiantes y de docentes. En el marco de un contexto político nacional de reparación de derechos, producto de la política de gobierno de Néstor Kirchner, los reclamos de la diversidad sexual tenían mucha visibilidad. Las referencias del propio Presidente a la identidad de género y al matrimonio igualitario, instalaron el tema en la agenda de debate y permitieron dar cuenta de la discriminación, la violencia y la vulneración de derechos que padecía este colectivo.

En la actualidad, todo por lo que luchamos en este período sucedió, y Claudia no solo es docente de la Facultad sino que conduce la Dirección de Diversidad Sexual dependiente de la actual Secretaría.

Cabe agregar que todos los temas descriptos eran desarrollados en el programa de radio "De igual a igual», coproducido por la Dirección de Derechos Humanos y la AMB, y transmitido por FM y AM radio Universidad de La Plata a partir de 2004. El programa, que pronto se convirtió en una referencia en materia de derechos humanos dentro de la radio, nos permitió incorporar una herramienta comunicacional con la comunidad y contar con un espacio donde estudiantes, graduades, docentes, periodistas, militantes y referentes teníamos la posibilidad de expresarnos. En un contexto donde los derechos humanos comenzaban a ocupar un lugar central en la agenda política, contar con un canal de difusión propio hacia y con la comunidad resultó fundamental.

Algunos de los entrevistados fueron: Horacio Vertbisky (periodista y escritor), Lilia Ferreyra (periodista y compañera de Rodolfo Walsh), Osvaldo Bayer (periodista y escritor), Raúl Zaffaroni (ex Juez de la Corte Suprema de Justicia de la Nación), Rubén López (hijo de Jorge Julio López), Dora Bravo (alumna de Carlos Fuentealba), Alba Martino (Madre de Plaza de Mayo), Estela Carlotto (Presidenta de Abuelas de Plaza de Mayo), Verónica Piccone (Directora de Derechos Humanos de la UNLP), Antonio Fenoy (Marcha Pibes del Pueblo) Walter Oviedo (Presidente del Centro de estudiantes Unidad 9), Julio Ferrer (autor del libro 
Osvaldo Bayer íntimo. Conversaciones con el eterno libertario), ${ }^{34}$ Nilda Eloy (ex detenida desaparecida), Norberto Liwsky (Director del Programa de Asistencia a Testigos avalado por la ONU), Guadalupe Godoy (abogada de la querella en juicios de Lesa Humanidad), Lohana Berkins (activista TLGBI), Félix Croux (fiscal en juicios de Lesa Humanidad), Roberto Cipriano (integrante del Comité Contra la Tortura), Rosa Bru, entre otres.

$\sim$

Como se desprende de lo detallado hasta aquí, en este primer período, la articulación con referentes sobre la temática y con protagonistas de los hechos, en el marco de un proceso de búsqueda de esas "otras voces, otras ideas, otros sentidos» (Arrúa, 2006), fueron fundamentales en la construcción de la estrategia política para la acción. Dialogamos diferentes saberes y perspectivas para alcanzar síntesis novedosas y creativas entre sujetes de conocimiento que fueron clave en la política de gestión. Instituciones gubernamentales y no gubernamentales, organizaciones sociales y políticas, referentes, colectivos sociales, víctimas, militantes, especialistas, voluntaries, estudiantes, docentes, no docentes, gremios, fueron y son quienes nos iluminan el camino para aportar a la construcción de un mundo mejor y más justo desde la política pública universitaria.

El tema presupuestario era un problema en la gestión, en realidad en la universidad pública en general, pero lo cierto es que la cantidad de actividades que se llevaban adelante eran demasiadas para la cantidad de personas que componían el equipo de la Dirección, además de que las becas de trabajo ofrecían una escasa remuneración. Otra dificultad era que no resultaba común que la conducción de un espacio de esta naturaleza estuviera a cargo de alguien que no venía de los organismos históricos o que no tuviera familiares desaparecides. También era mucha la responsabilidad en este primer período de gestión, ante el desconocimiento general, lo novedoso de la propuesta y la diversidad de actores con que se articulaba. No obstante, como nos enseñó siempre Rosa Bru, poniendo mucho el cuerpo en el trabajo pudimos salir adelante.

El balance que hacía la Facultad sobre esta experiencia era muy positivo. Esto nos ayudó a crecer interna y externamente, a tener más espalda y espacio. Sin duda, el primer ciclo había tenido una repercusión política importante y comenzaba a adquirir reconocimiento. El desafío era seguir desarrollándolo y consolidarlo.

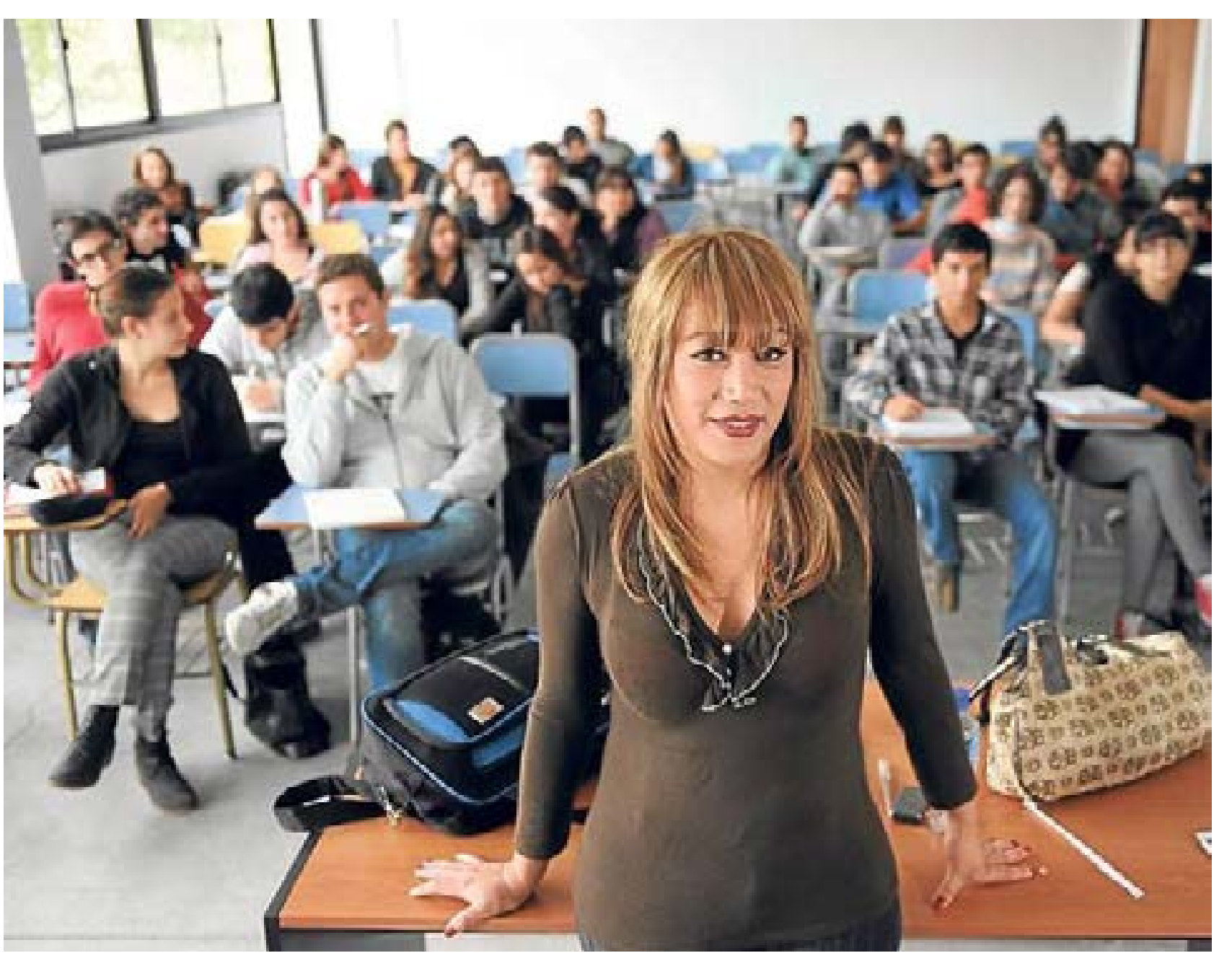

155

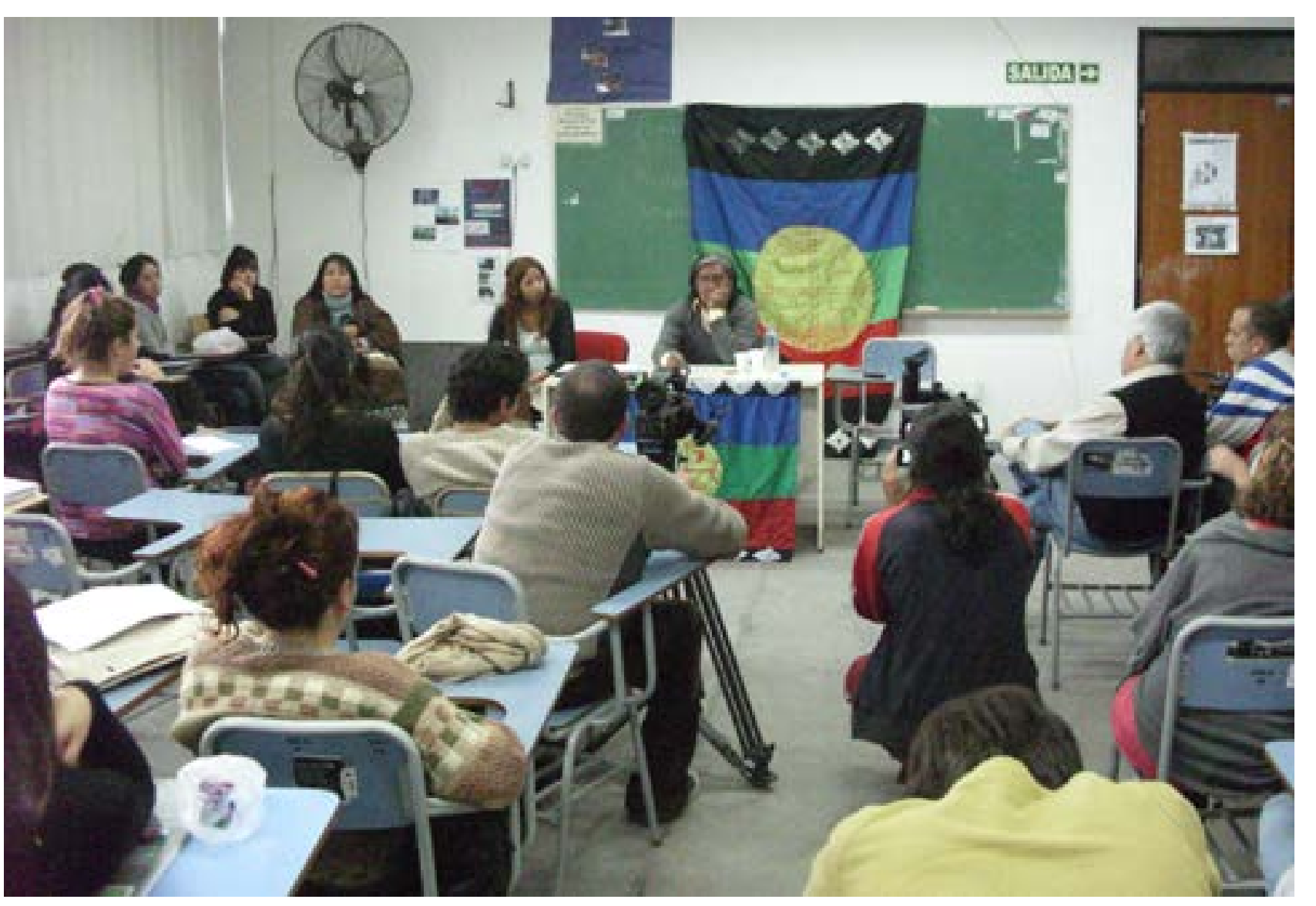



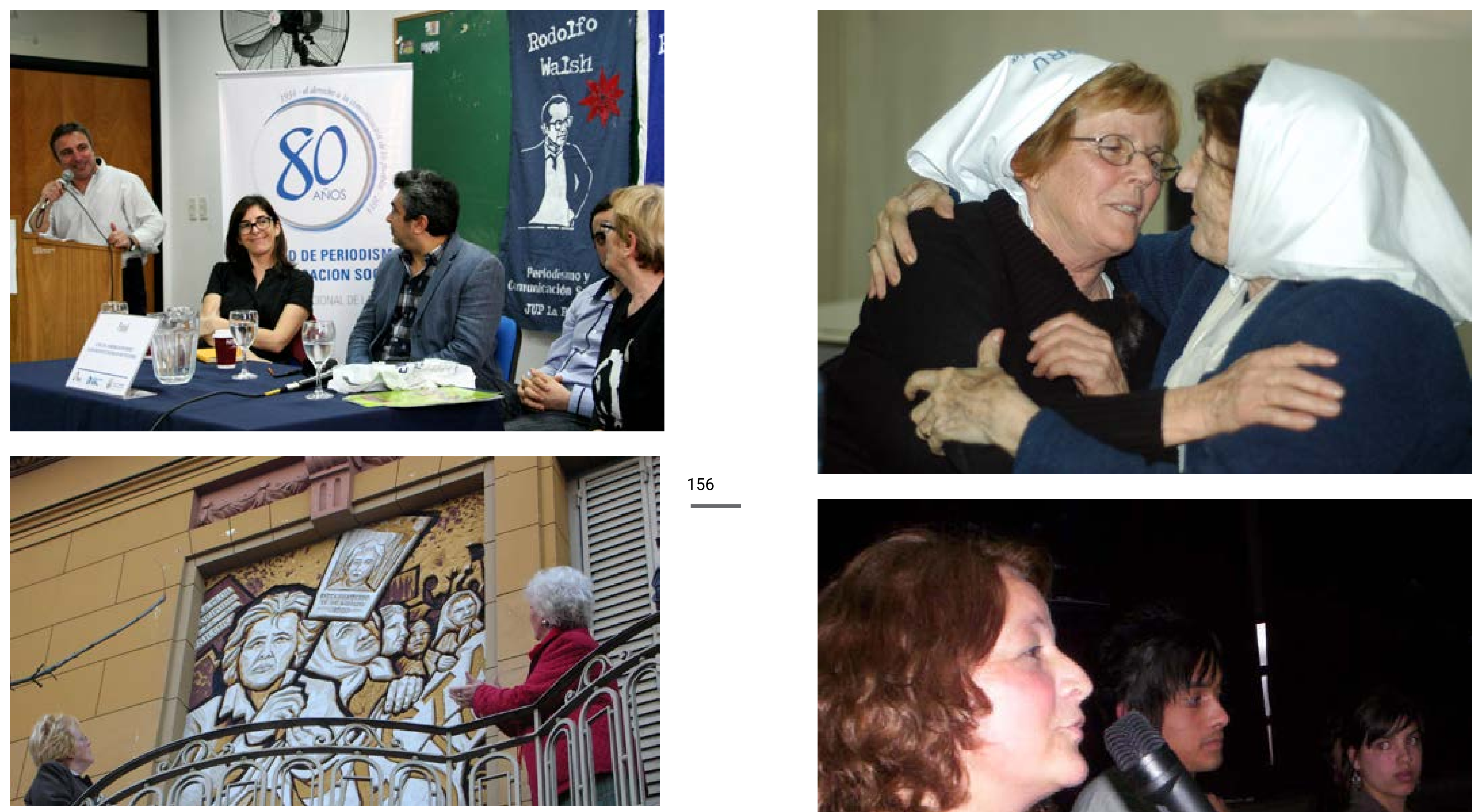

Claudia Vasquez Haro, Directora de Diversidad de la facultad, dando clases en la cátedra de Comunicación y DDHH.2. Zulema Enriquez, Directora de Pueblos Indígenas de la FP y CS, dando una charla en la facultad con Pascual Pichún, papá de nuestro estudiante Pascual, en reclamo por su liberación.3. María Eugenia Ludueña y Cristian Alarcón, ambos periodistas y de la AMB, con el diputado Leonardo Grosso (que presentó el proyecto de ley aprobado por la instauración del día nacional Contra la Violencia Institucional) y Rosa Bru, disertando sobre "El rol del comunicador frente a la Violencia Institucional".4. Estela Cartina Terzaghi en la sede de calle 44 de la FP y CS.
Cristion

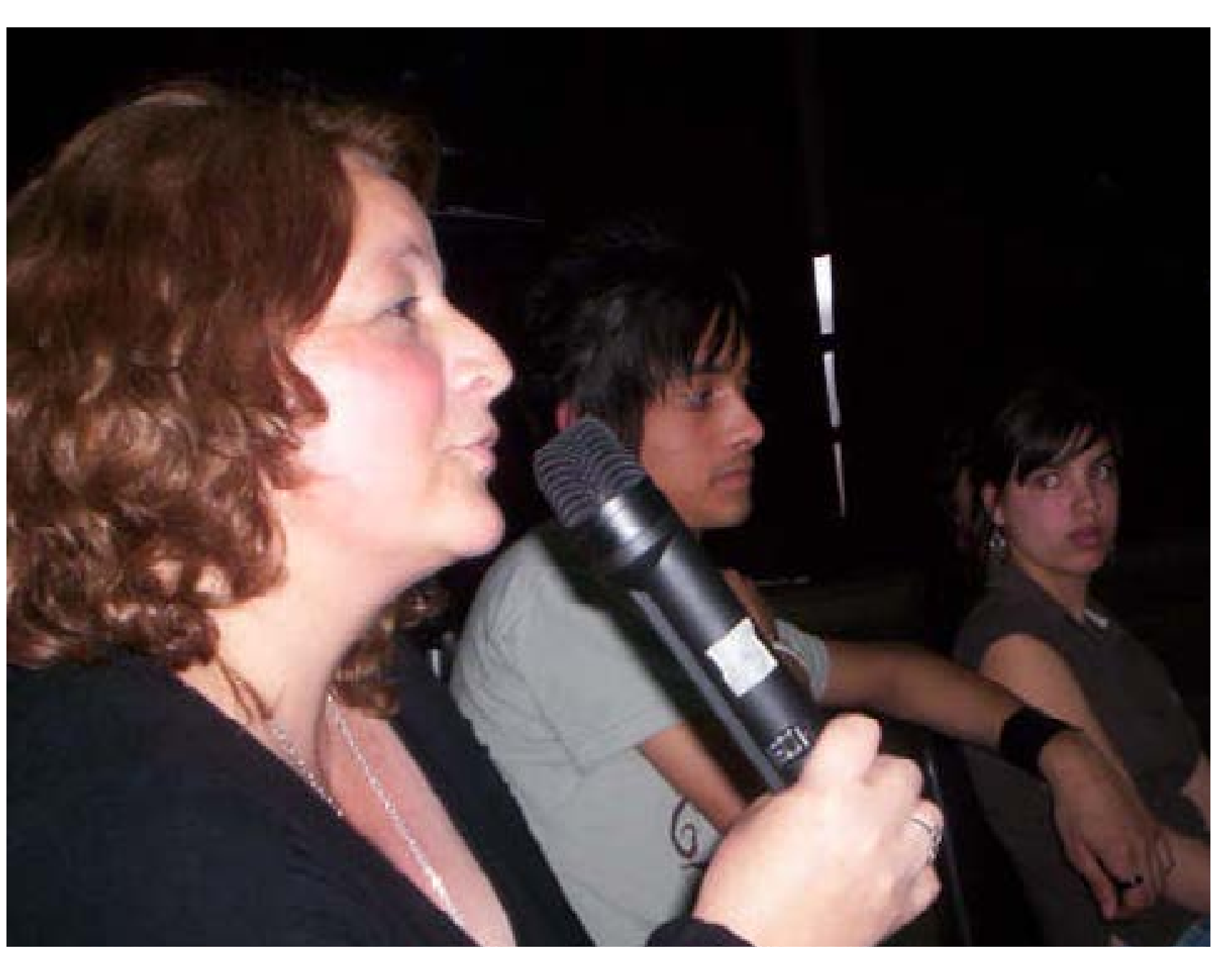



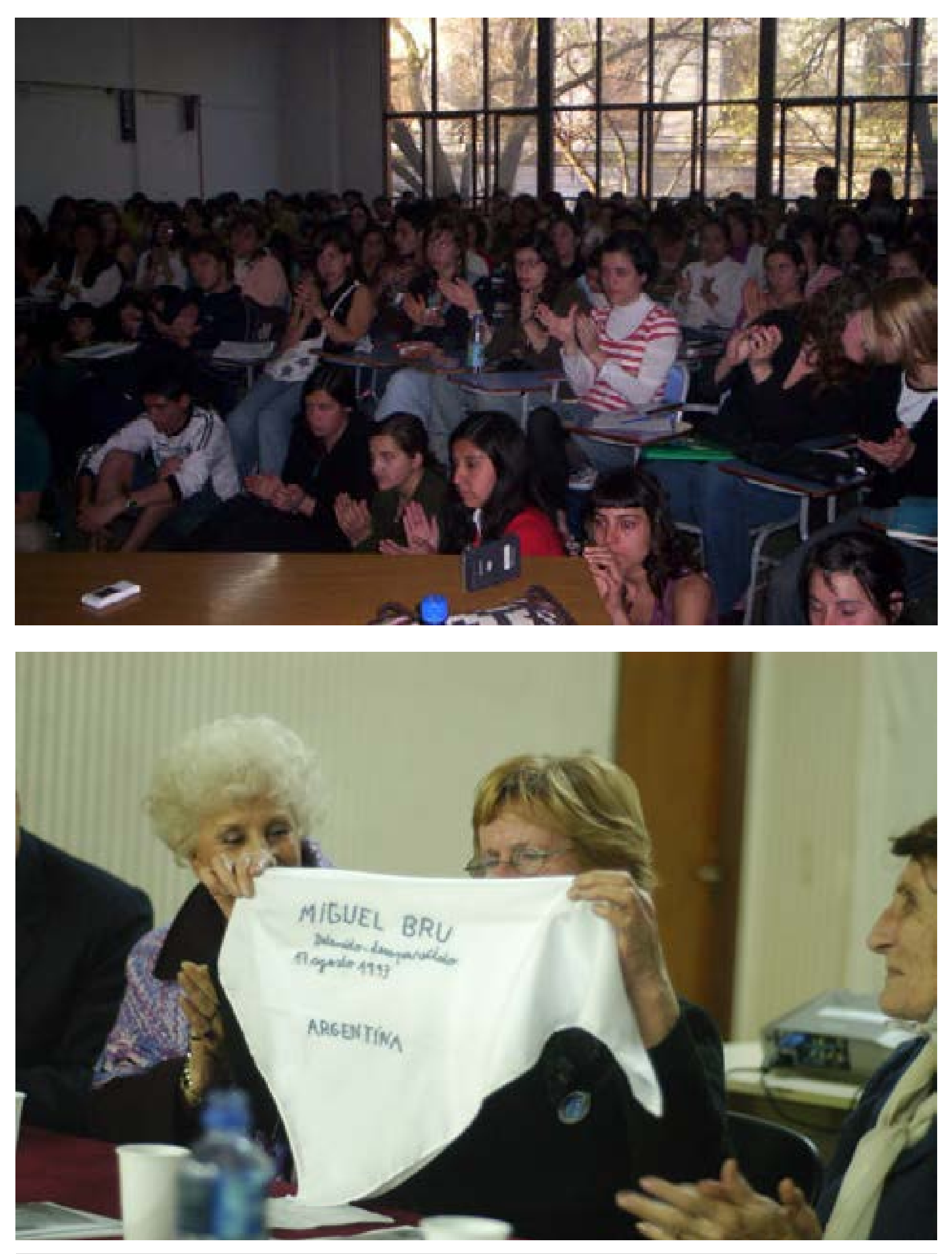

1 y 4.Rosa Bru recibiendo el pañuelo de las Madres de Plaza de Mayo de La Plata a manos de Adelina Alaye, para el acto aniversario de la desaparición de Miguel Bru en la FP y CS de la UNLP en el año 2007.2 y 3.Nora Ungaro, ex detenida desaparecida y hermana de Horacio Ungaro, victima de la denominada Noche de los Lápices disertando en un aula repleta en la FP y CS.

\section{DÓNDE ESTÁ MIGUEL}

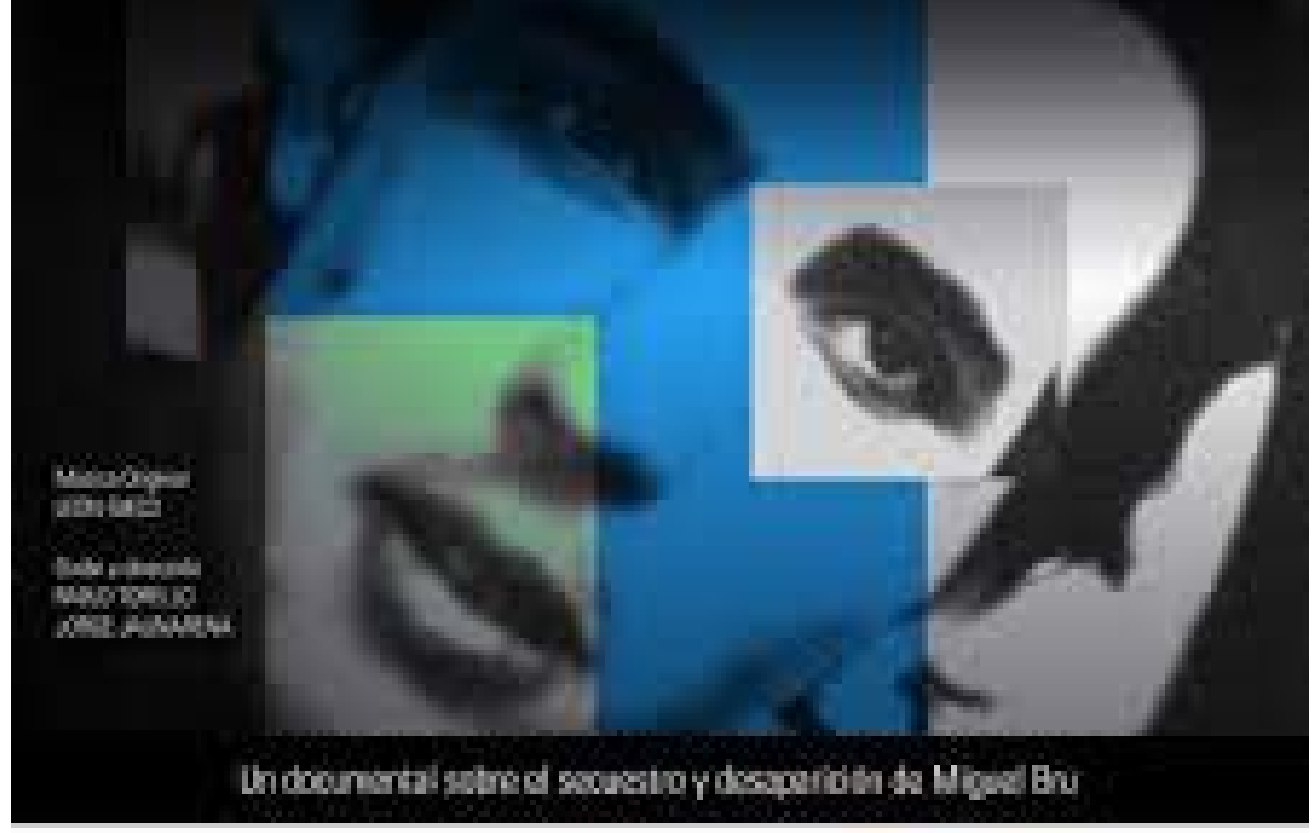

웅 (ㄷ) $8=$

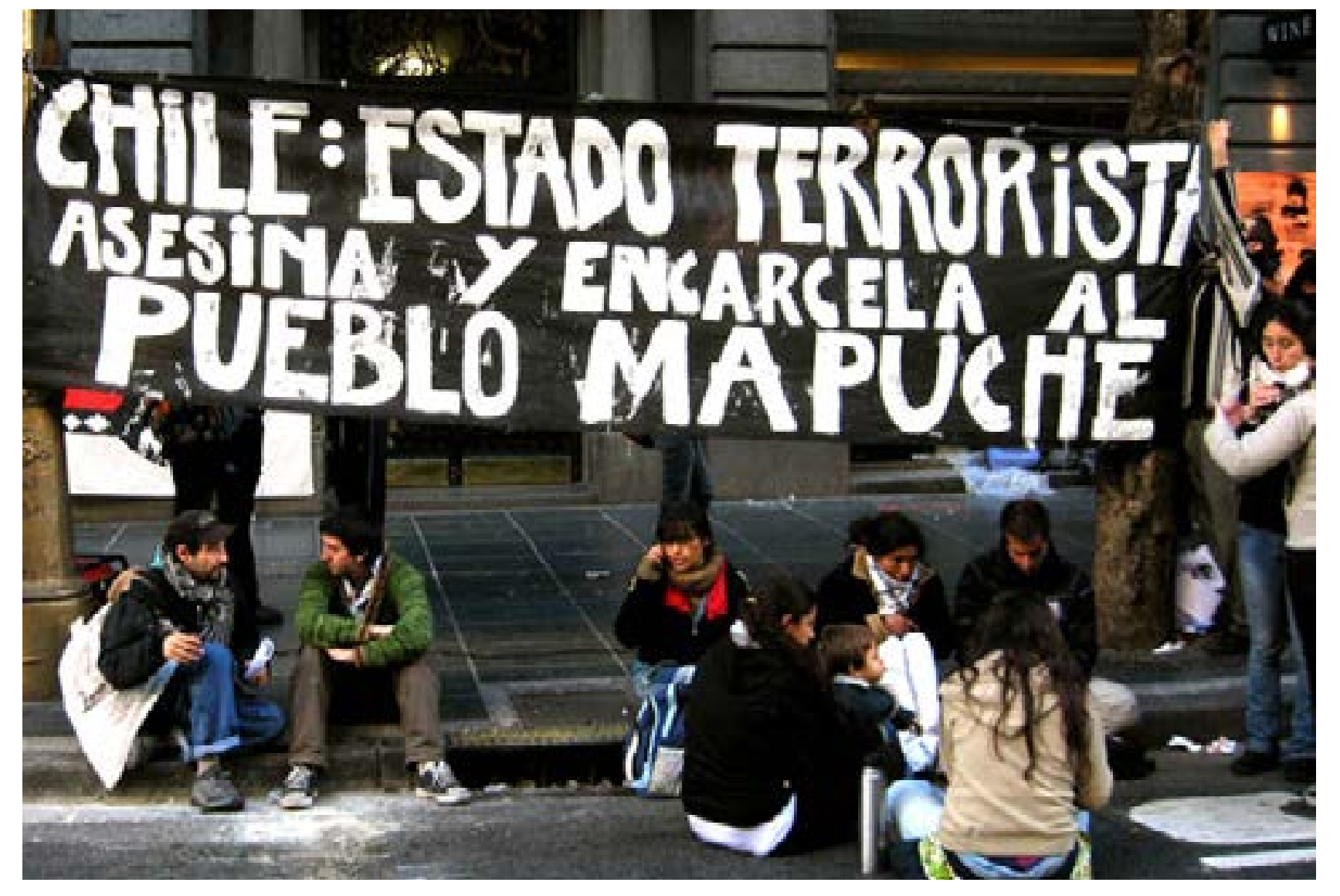



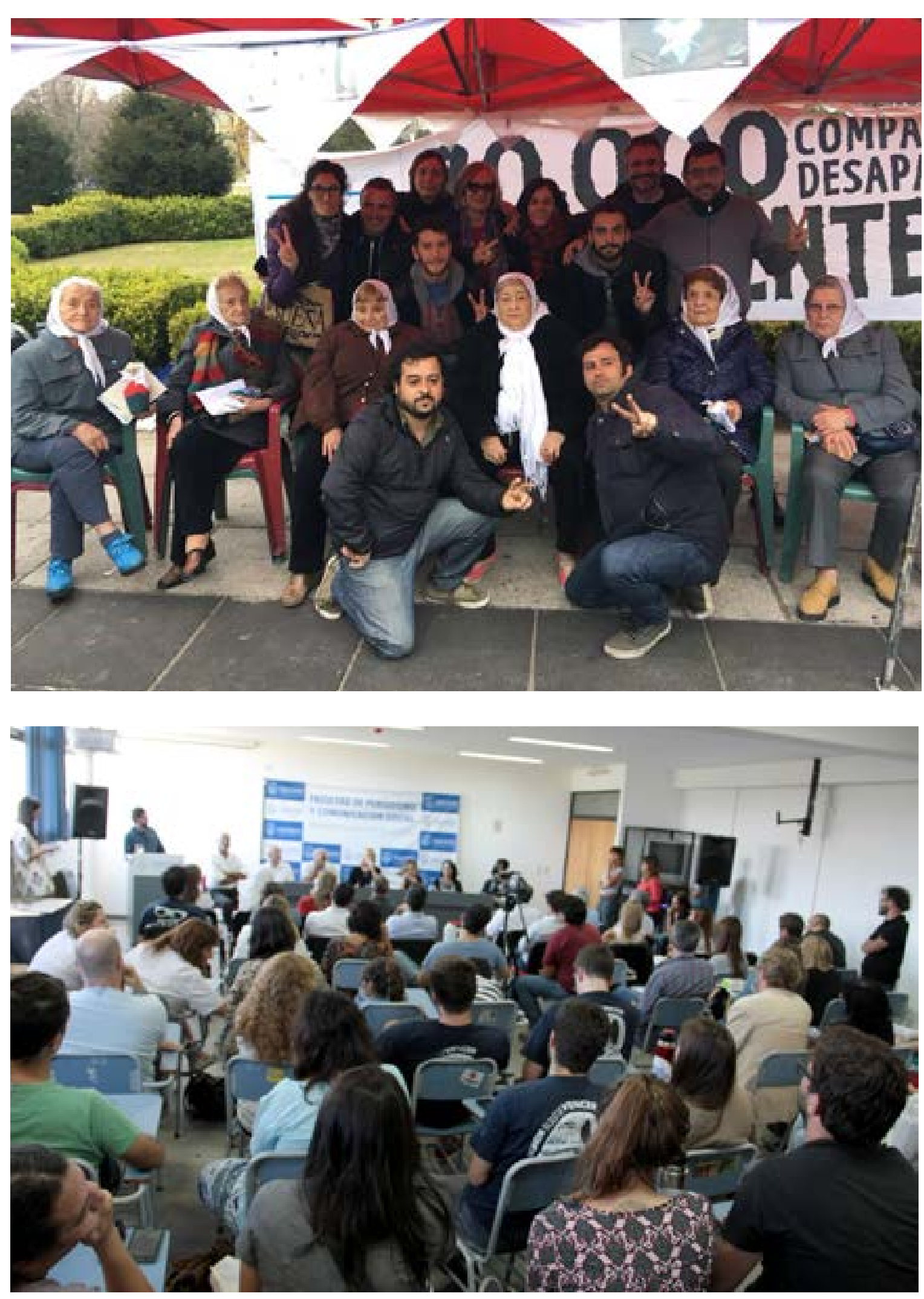

Afiche del documental sobre el asesinato y desaparición de Miguel Bru realizado en el año 2000.2.Marcha por la desaparición de Miguel Bru en la ciudad de La Plata.3.Acto de pintada de pañuelos de las Madres que realizamos en la Plaza Moreno de La Plata, junto a H.I.J.O.S. La Plata, Hebe de Bonafini y las Madres.4. Aula repleta en la FP y CS en disertación de ex alumnes de la facultad durante la dictadura civico-militar-eclesiástica.

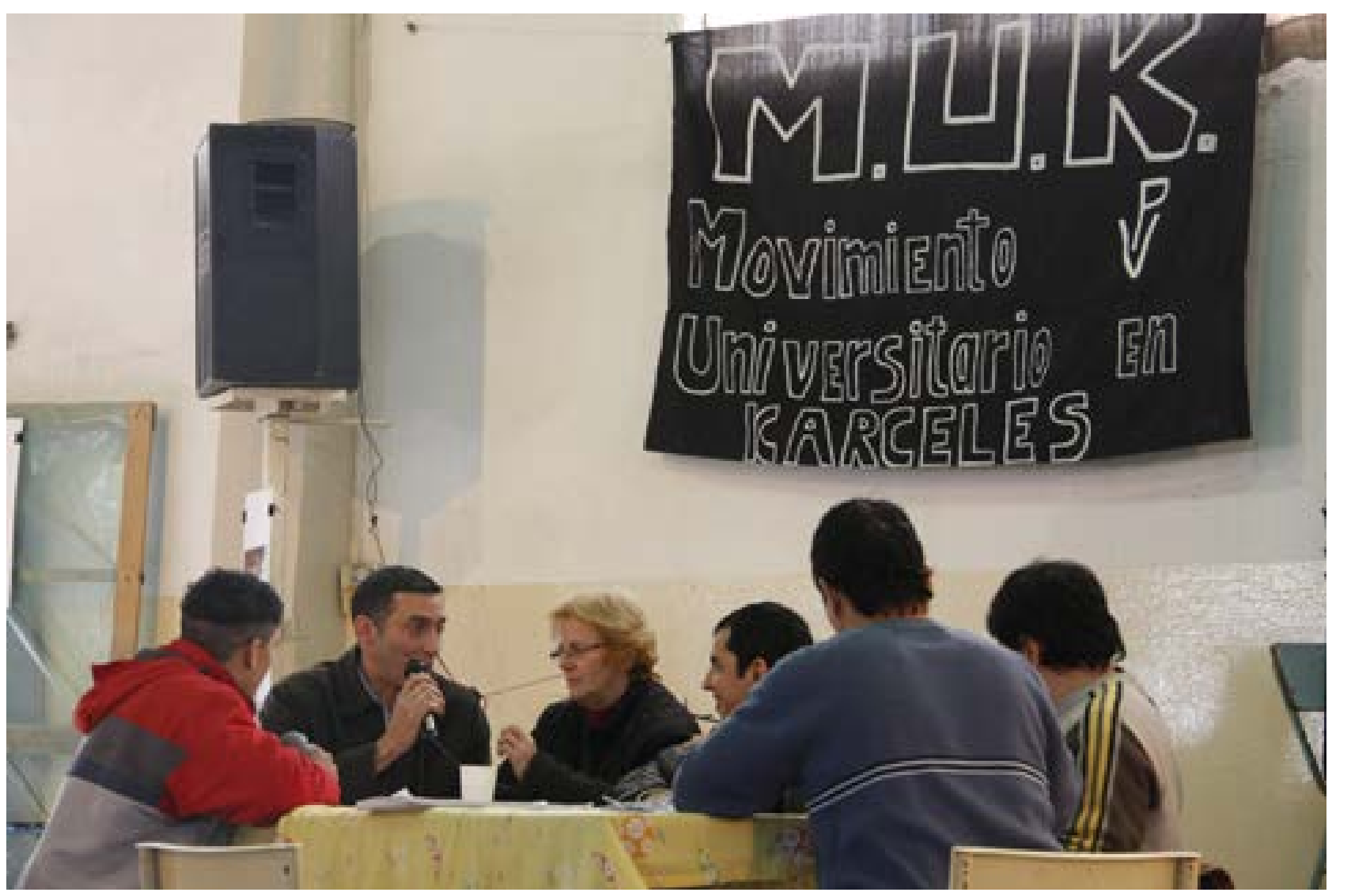

Comunicación en Cárceles

Uni heramentis para cambio

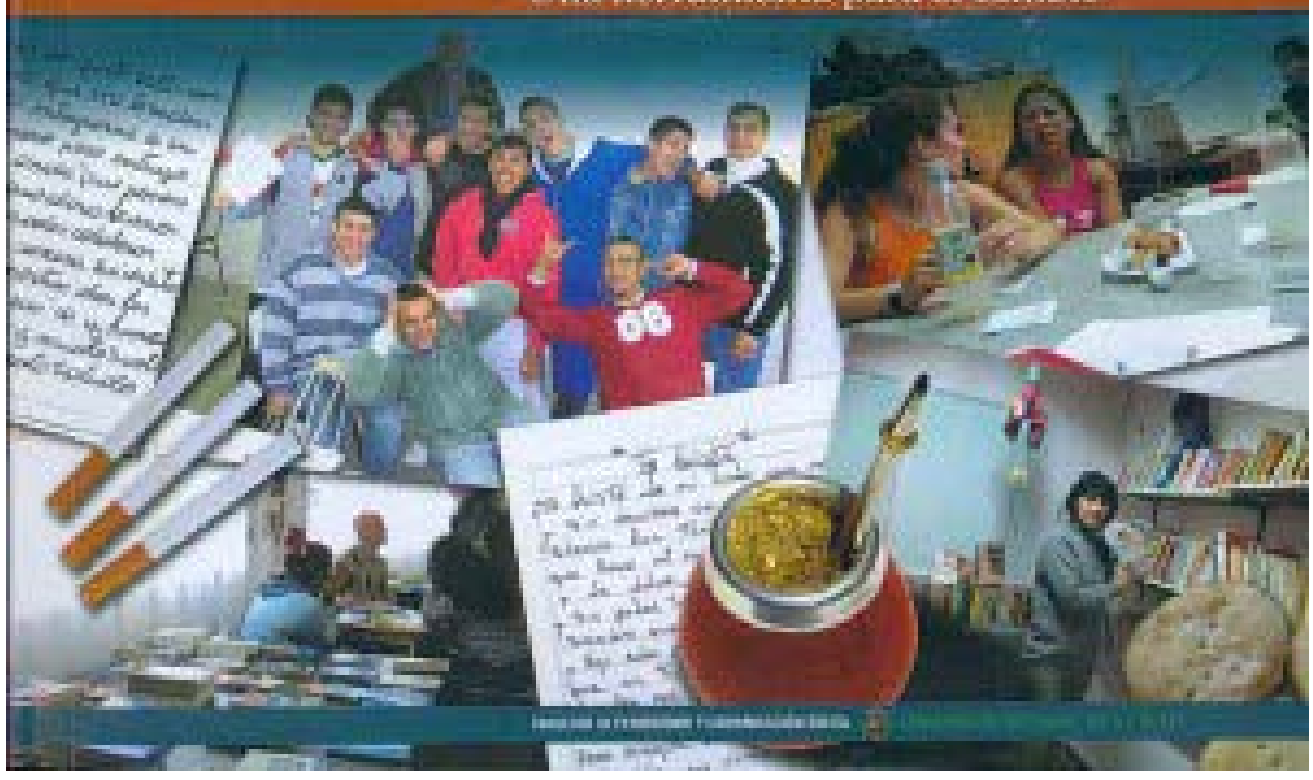



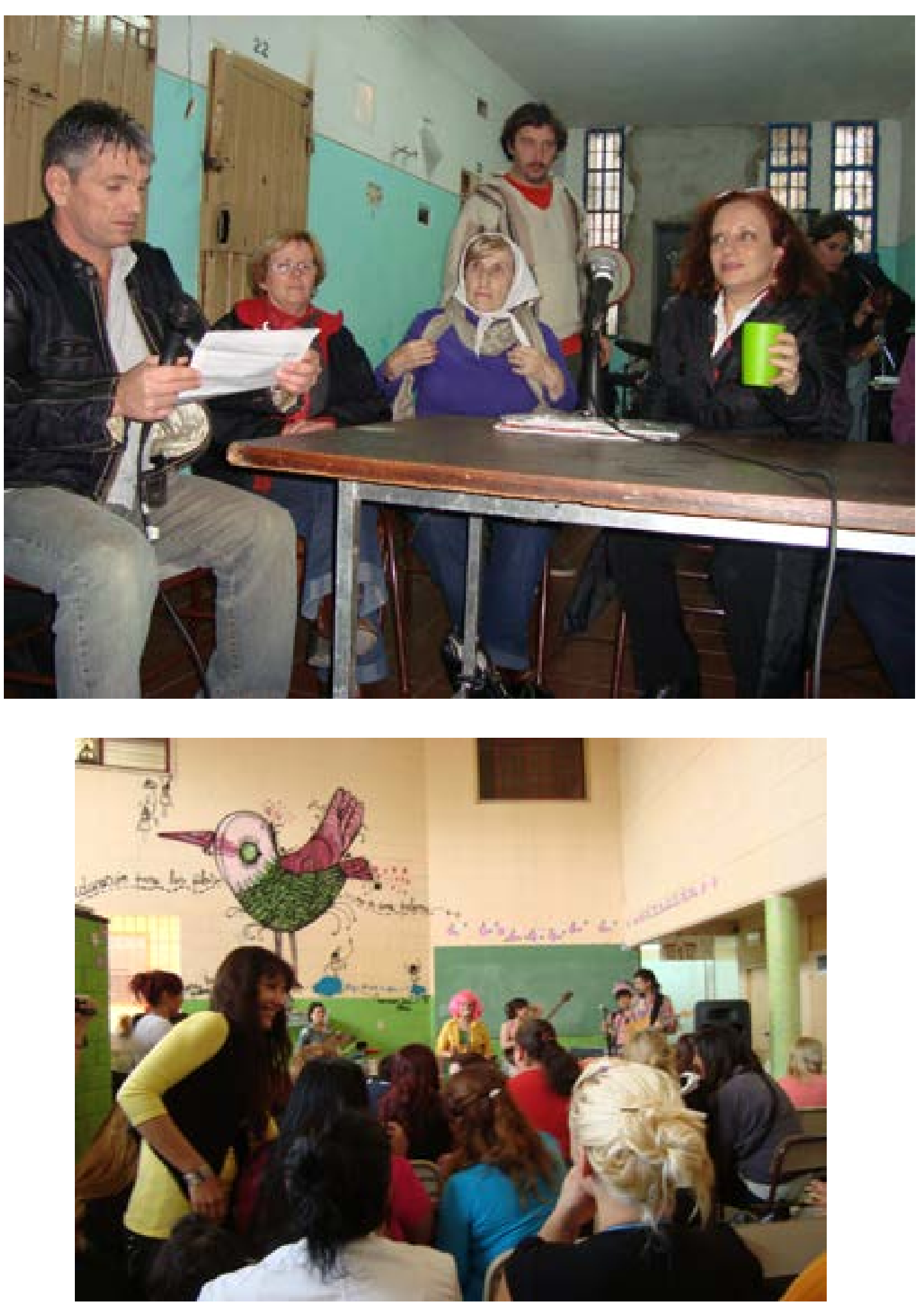

Tapa del libro resultante del proyecto de Extensión "Comunicación en cárceles, una herramienta para el cambio", realizado en el año 2008.2. Rosa Bru en radio abierta con alumnos de la FP y CS privados de la libertad en la extensión de Unidad $\mathrm{N}^{\circ} 9$ de La Plata conmemorando el día del periodista en el año 2010.3.Rosa Bru, Adelina Alaye y Miriam Lewin en radio abierta en el pabellón estudiantil (ex pabellón de detenidos de Lesa Humanidad en la dictadura) de la Unidad $N^{\circ} 9$ de la Plata.4. Recital del grupo de cumbia Les Minon en la Unidad penitenciaria $N^{\circ} 33$ de Mujeres, organizado por la FP y CS en el día de la madre.
2007 / 2010

La consolidación del proyecto

La Facultad contaba con una Dirección de Derechos Humanos que instalaba claramente su línea política, con ejes temáticos bien definidos que sintetizaban lo que en este ámbito pretendía la institución. Se trataba, además, de un proceso sin precedentes en la UNLP, por las temáticas abordadas, por quienes participaban desde el diálogo de saberes, por la diversidad de las propuestas y por la visibilidad que adquirían las actividades que se llevaban adelante. Personalidades de la política, de los territorios platenses, referentes, víctimas y familiares de víctimas, colectivos de la diversidad cultural, entre muchos otros actores, no solo transitaban frecuentemente la Facultad sino que se apropiaban de los espacios y de la generación de la política.

El desafío de esta segunda etapa de gestión, que comprende de 2007 a 2010, era la consolidación del proyecto y la posibilidad de continuar desarrollando políticas innovadoras que se iban instalando en el contexto político nacional de la mano del gobierno «de los derechos humanos», como se calificaba popularmente al kirchnerismo.

Un factor clave a tener en cuenta es el lugar que ocupa la UNLP en la trama urbana y en el desarrollo social de la ciudad de La Plata. Las intervenciones en la vida de la ciudad eran permanentes y de todo tipo: movilizaciones, clases públicas, campañas de salud, proyectos de extensión en diversos barrios, expresiones artísticas, etcétera.

En 2007 comenzó el segundo período de gestión. Los hechos descriptos hasta el momento fueron determinantes para que las autoridades de la Facultad decidieran jerarquizar el proceso de gestión llevado a cabo y apostaran a su crecimiento: por decisión unánime del Consejo Académico, el 2 de julio de 2007 la Dirección pasó a ser una Secretaría. ${ }^{35}$

Por último, en este período ya había empezado a pensar en la posibilidad de un posgrado en Comunicación y Derechos Humanos y, de cara a ese objetivo, había iniciado los diálogos con referentes y con especialistas. La consigna era clara: tenía que tener una fuerte impronta militante y generar las posibilidades para que la militancia en derechos humanos pudiera cursar y apropiarse de la futura carrera.

\section{Pedagogía en comunicación y derechos humanos}

Durante este período, seguía ocupando un lugar estratégico y fundamental para la gestión el desarrollo del seminario interdisciplinario «Comunicación, derechos humanos y discriminación: teorías, prácticas y herramientas» dictado junto con el Instituto Nacional Contra la Discriminación, la Xenofobia y el Racismo (INADI) y el Consejo Nacional de la Mujer, dos espacios de una referencia muy importante para la Facultad. En La Plata, las

35 La propuesta fue aprobada por Resolución 87/2007 
comisiones no bajaban de 200 estudiantes, y seguíamos llevando la materia a diversas extensiones (Lincoln, Santa Teresita, Moreno, Monte Caseros, Junín); incluso, la dictamos como cursada de verano. Era un lugar de encuentro en donde teníamos la posibilidad de abordar y de desarrollar una diversidad de temáticas, así como de invitar a organizaciones y a referentes de la lucha por justicia que se relacionaban directamente con les estudiantes. En el marco del seminario, también se incorporaban estudiantes para que se desempeñaran en la Secretaría.

En el eje Violencia Institucional del seminario, pasó a ocupar un lugar central un hecho que también marcó un punto de inflexión en nuestra historia, el asesinato del docente Carlos Fuentealba, ocurrido el 4 de abril de 2006, durante una movilización en Arroyito, provincia de Neuquén. Desde lo personal, fue una experiencia muy impactante ya que estando con familiares en Neuquén por motivo del feriado de Semana Santa, fui a acompañar a amigues en ese reclamo docente y quedé envuelto en el medio de la represión. Nunca viví algo similar dada la ferocidad represiva con que actuaban las fuerzas de seguridad y la violencia e intransigencia que presentaban ante el reclamo docente por condiciones dignas de trabajo. Con Sandra Rodríguez, la compañera de Fuentealba, y con referentes del sindicato docente neuquino ATEN (Asociación Trabajadores de la Educación de Neuquén), empezamos a abordar el tema en la facultad.

Asimismo, éramos una referencia muy importante para la gestión política de la Facultad. Era muy importante la presencia que habían alcanzado las jornadas sobre Derechos Humanos en el Curso de Ingreso. Entre las temáticas abordadas se destacan: discapacidad, caso Miguel Bru, Dictadura cívico militar eclesiástica, género y diversidad, pueblos indígenas, periodismo y derechos humanos, y educación universitaria en cárceles. Referentes y especialistas en esos ejes tenían contacto directo y permanente con estudiantes de nuestra carrera, y significaban un vínculo fundamental para la vida institucional.

\section{Memoria y Dictadura}

El 25 de marzo de 2007 se cumplió un aniversario muy importante para la Facultad y para toda la sociedad: Rodolfo Walsh, icono de nuestra profesión, era asesinado 30 años antes, en el momento que estaba entregando y difundiendo una de las piezas más significativas de la historia del periodismo argentino: la «Carta abierta de un escritor a la Junta Militar».

De hecho, la agrupación estudiantil que se mantiene desde que ingresamos, y que siempre nos acompañó, es la Agrupación Rodolfo Walsh (RW), por la que han pasado compañeres y amigues e, inclusive, Miguel Bru en algún momento. El apoyo de la RW a la gestión de la Dirección y, después, Secretaría de Derechos Humanos fue siempre incondicional. Nos apoyó a lo largo de la historia del proceso de justicia por Miguel y nunca dejó de mantener viva la memoria de nuestro compañero -y de tantos otres que hemos acompañado hasta la fecha-, junto con el amor y el lugar que en todos estos años le han dado a nuestra referente,
Rosa Bru, un amor absolutamente mutuo que ella también comparte.

Respecto del acto, debe destacarse, nuevamente, la variedad de actores que participaron y el diálogo de saberes. Mientras que al frente de la Secretaría de Derechos Humanos de la Nación seguía Eduardo Luis Duhalde, en la provincia de Buenos Aires el Secretario de Derechos Humanos era Edgardo Binstock, militante en la Juventud Universitaria Peronista (JUP) de los años setenta y en la Organización Montoneros. Hermano de Guillermo Daniel Binstock, militante de la Unión de Estudiantes Secundarios (UES), secuestrado en su domicilio en 1976 y que fue visto por última vez en el Centro Clandestino de Detención (CCD) «Automotores Orletti». Su primera esposa, Mónica Pinus, fue secuestrada el 12 de marzo de 1980 junto con Horacio Campiglia, miembro de la conducción de la organización Montoneros, en el Aeropuerto de Río de Janeiro. Este secuestro formó parte del Plan Cóndor. Trasladada a la Argentina por miembros del Batallón 601, estuvo detenida en el CCD que funcionaba en Campo de Mayo y hasta la fecha permanece desaparecida. A fines de 1982, Binstok se trasladó a San Pablo, Brasil. Allí denunció la desaparición de Mónica y de Horacio. Su madre, Mina Feuer, fue una de las fundadoras de Madres de Plaza de Mayo; su padre, Julio Binstock, integró el Centro de Estudios Legales y Sociales (CELS). Edgardo declaró y es querellante en las causas de lesa humanidad Plan Cóndor y Automotores Orletti I y II.

Les compañeres de la Facultad que trabajaban en esa Secretaría, que siempre habían acompañado el proceso de justicia por Miguel Bru, nos propusieron realizar una actividad en conjunto para el aniversario por los treinta años del asesinato y la desaparición de Walsh. Tras decidir que se haría una escultura en alusión al escritor y periodista, nos contactamos con la muralista Cristina Terzaghi, quien nos recomendó el equipo de escultores de la ONG «Hombre-Barro-Fuego». La obra consiste en una silla en la que se ve la cara de Rodolfo Walsh y una máquina de escribir con los lentes arriba. Fue instalada en la esquina de calles 6 y 53, sobre la plaza San Martín de La Plata, un lugar de mucha circulación ubicado frente al club de Ajedrez que Walsh frecuentaba. Para la inauguración del monolito, realizamos un acto público multitudinario que contó con una diversidad de actores que era difícil que compartieran un acto; de hecho, hubo algunas tensiones, debido a que integrantes de la agrupación H.I.J.O.S. y grupos militantes reclamaban al Gobernador por la aparición de Jorge Julio López.

Organizado por la Secretaría de Derechos Humanos de la Provincia de Buenos Aires y por la Dirección de Derechos Humanos de la Facultad, el acto contó con la participación del gobernador Felipe Solá; la presidenta de la Comisión de Derechos Humanos de la Municipalidad de La Plata, Lorena Riesgo; una enorme cantidad de Madres y Abuelas de Plaza de Mayo; H.I.J.O.S. La Plata, autoridades de la UNLP y de la Facultad; comunidad académica; Rosa Bru; referentes y organismos de derechos humanos; y muchísima militancia barrial. Fue una sensación muy fuerte esas presencias tan diversas y la universidad interviniendo en el espacio público, en el centro neurálgico de la ciudad.

En relación con este eje, en este período se siguió completando y ampliando la información 
sobre las víctimas del terrorismo de Estado en la Facultad, y fortaleciendo los vínculos con familiares de víctimas y con referentes de la militancia de la época. Realizamos numerosos actos, editamos publicaciones y organizamos entrevistas que llevaban a cabo les estudiantes. Cotidianamente, veíamos en nuestra facultad a Adelina Dematti de Alaye, Estela Carlotto, Beba Dillon, Alba Martino, Herenia Sánchez Viamonte, Coqui Pereyra, referentes de Madres y Abuelas La Plata. Circulaban por las aulas e interactuaban con el estudiantado; a veces, incluso, participaban en actos que ni siquiera eran específicos en esas temáticas. Estela Carlotto siempre dice públicamente: «Esta es mi Facultad», y el pecho nos estalla de orgullo cada vez que la escuchamos. También les compañeres de H.I.J.O.S. habían encontrado en la Facultad un lugar de debate y de difusión de sus actividades. En tanto, el proyecto «Textos de la Memoria. Historias de los desaparecidos de Periodismo», había sido avalado por la Secretaría de Cultura de la Nación (Expediente S.C. 1721/06).

En especial, hubo dos actividades muy fuertes en este período. En 2007, se comunicaron desde la Secretaría de Derechos Humanos de La Pampa para consultar sobre la posibilidad de entregarles el título de grado post mortem a los padres y a la hermana de Liliana Molteni, graduada de la Facultad, desaparecida junto con su pareja, Daniel Elías, en junio de 1976. Luego de innumerables trámites ante la Dirección de títulos de la UNLP, lo conseguimos y partimos hacia La Pampa. La familia estaba muy emocionada. Se hizo un hermoso acto en el que estuvieron presentes el gobernador de La Pampa, Oscar Jorge, autoridades de la FPYCS, familiares de detenides desaparecides y Madres de Plaza de Mayo. Liliana era la única estudiante que tenía en el analítico todas las notas completas, pero no había podido tramitar el título porque tuvo que pasar a la clandestinidad. Como nos confirmaron las autoridades de la UNLP, y como reflejaron medios locales y nacionales, la entrega del título post morten era una situación inédita en la universidad.

Ese mismo año, tuvo lugar un hecho institucional muy emotivo y de gran reparación: el acto de colación para les egresades de la clase 1975, que había sido truncado por el accionar de la Dictadura cívico militar eclesiástica. ${ }^{36}$ La emoción y la alegría de les egresades, que estaban acompañades de sus familias, era indescriptible. Se abrazaban, como si fueran estudiantes jóvenes, y nos decían: «Después de mi hija, esto es lo más fuerte que me pasó en la vida», «Soy paciente oncológico, esto es muy importante para mí en este momento», «Es la primera vez que piso La Plata desde mi exilio». Entre anécdotas y carcajadas, parecía que el tiempo no había pasado. Y, por supuesto, fue incontenible la emoción al recordar a las víctimas que faltaban.

\section{Violencia institucional en democracia}

Seguimos profundizando el debate sobre la disputa por el sentido y el rol de la comunicación en la construcción de perfiles discriminatorios. En el marco de la batalla cultural en relación con los medios de comunicación, pasamos a formar parte de la Red Nacional de

\footnotetext{
$36 \quad$ Ver el documental audiovisual Un grito sagrado (Vitola, 2008).
}

Investigadoras/es sobre Discriminación del INADI, donde especialistas de este organismo, referentes de universidades nacionales, y representantes de observatorios de comunicación y discriminación de la Argentina, trabajamos temas relacionados con la discriminación y los medios de comunicación. Desde este espacio, se investigaba, se producían informes y se trabajaba en la difusión de la problemática.

\section{Educación superior en cárceles}

Luego de la firma del convenio entre la Facultad y el Ministerio de Justicia de la Provincia de Buenos Aires, y de sortear las numerosas dificultades que se nos presentaban, continuamos ampliando y desarrollando el proyecto de educación en cárceles. La lógica punitiva era un problema central, y si bien nos encontramos con algunas excepciones en la Dirección de Cultura y Educación del SPB, estaba claro que no pensábamos lo mismo, fundamentalmente, que la educación es un derecho humano y no un sistema de premios y de castigos que supone un privilegio o una forma de ocupar parte del tiempo de ocio.

Si bien el Ministerio de Justicia de la Provincia impulsaba y apoyaba el proceso, una vez que se cerraban las rejas era evidente que se trataba de otro planeta: el penitenciario, con reglas y códigos propios, donde los derechos no son una prioridad, sino todo lo contrario. Era una política de desgaste permanente y la sensación era que dábamos un paso para adelante y tres para atrás. Rotura de elementos de estudio, ausencia de equipamiento para estudiar, demoras o falta de traslado de estudiantes a las aulas, comentarios desubicados a docentes, largas esperas para permitir el acceso a los salones de clase, requisas y traslados ilegales, malos tratos, son solo algunos de los hechos que caracterizaron la experiencia educativa más difícil que he vivenciado.

De todos modos, frente a lo complejo de la situación, teníamos la sensación de que nuestra institución estaba cada vez más atravesada por esta experiencia; eso era irreversible. Finalmente, en lo que constituyó un hecho inédito en la UNLP, en octubre de 2009, se puso en marcha la Extensión Áulica Unidad 9 de La Plata, ${ }^{37}$ a la que asistían privades de libertad de diversas unidades penitenciarias de la provincia de Buenos Aires. Con esta experiencia de formación superior de manera presencia, la facultad se convirtió en la primera unidad académica en dictar una carrera con modalidad de cursada intramuros.

Este proceso nos convirtió en referentes tanto en universidades nacionales como de exterior. Ese mismo año, fuimos convocades al «Primer Encuentro Nacional de Experiencias de Comunicación y Cultura en Cárceles», realizado en la Universidad Nacional de Córdoba; a la Universidad de Cuyo; a la Biblioteca Nacional -junto con el Centro Universitario de Devoto y la UBA- e invitades por la Universidad Nacional de Educación a Distancia (UNED) a exponer sobre nuestra experiencia en universidades de España, con referentes de Italia, Francia, México e Inglaterra.

$37 \quad$ Este lugar fue elegido por su estructura áulica, pero podían cursar privades de libertad de todas las unidades penitenciarias. 


\section{Pueblos indígenas}

En estos años, un hecho relevante fue la invitación que recibimos en 2007 para llevar a la Feria del libro de Caracas, Venezuela, «La sublevación de la Palabra», la muestra realizada por la Facultad sobre Rodolfo Walsh, y para dar conferencias sobre periodismo y derechos humanos en la Universidad Bolivariana. En el marco de un convenio firmado con esta Universidad, disertamos con estudiantes y con docentes de la carrera de Comunicación una experiencia impactante y movilizadora que nos permitió conocer el país y la universidad creada por el presidente Chávez, realmente. Un hecho que me marcó a futuro la gestión fue conocer la Dirección de Pueblos Indígenas que articulaba con la comunidad y que, inmediatamente, me llevó a pensar en la necesidad de contar con una dirección de esa naturaleza en nuestra facultad que permitiera jerarquizar y profundizar el trabajo que se venía realizando en ese eje.

En el marco de la política de ampliación de las relaciones y los vínculos con las comunidades indígenas, en 2007 presentamos el libro Mujeres dirigentes indígenas. Relatos e historias de vida, publicado por la Secretaría de Cultura de la Nación. Contamos con el acompañamiento de Carmelo Sardinas, presidente de la comunidad Mink'akuy Tawantinsuyupaq, y profesor de Quechua en la UBA y en la Universidad de La Matanza, y de Patricia González, representante de la Comunidad Mocovi de Berisso e integrante de la primera familia que llegó desde Chaco. El objetivo era acompañar y visibilizar la lucha y la resistencia de las comunidades originarias del territorio argentino desde una perspectiva de género. En 2008, y como forma de contribuir a la visibilización de la resistencia de la comunidad mapuche, organizamos la presentación del libro Crónicas de la resistencia Mapuche, que contó con la participación de su autor, Adrián Moyano, y de nuestro referente Pascual Pichún.

\section{Diversidad sexual}

En 2007, presentamos el libro Medios de Comunicación y Discriminación. Desigualdad de clase, diferencias de identidades, expresiones de género y orientaciones sexuales, junto con el Área Queer de la Facultad de Filosofía y Letras de la UBA, el Proyecto Antirrepresivo de la Secretaría de Extensión de la Facultad de Ciencias de la Educación de la Universidad Nacional de Entre Ríos (UNER), el Observatorio de Medios de la Unión de Trabajadores de Prensa de Buenos Aires (UTPBA), la Federación Argentina de Lesbianas Gays Bisexuales y Trans (FALGBT) y la Liga Argentina por los Derechos del Hombre (LADH).

La obra proponía un debate de vanguardia: analizar la cobertura periodística y los problemas relacionados con la desigualdad de clase y las diferencias por edad, etnias, géneros, identidades de géneros, orientaciones y prácticas sexuales no normativas, y problematizar sobre discursos discriminatorios que ayudan a legitimar ideologías represivas vinculadas con xenofobia, racismo, sexismo, homofobia, lesbofobia, travestofobia y transfobia. Y así lo demostró el aula rebalsada de personas del mundo académico, de activistas, de numerosas organizaciones y de mucha militancia.

Muy activa fue nuestra participación en el congreso «Cuestiones de género y comunicación Narrativas de la diversidad desigual: lenguaje ofendido y femicidio», realizado en 2008. También fueron muy importantes en aquellos años las jornadas sobre «Diversidad sexual, género y políticas emancipatorias», que realizamos con Mariela Castro, directora del Centro Nacional de Educación Sexual de Cuba, y con Beatriz Gimeno, ex presidenta de la Federación Estatal de Lesbianas, Gays y Transexuales y Bisexuales de España.

Todo se producía en el contexto de una conducción política nacional -la presidenta Cristina Fernández de Kirchner había asumido a fines de 2007-, que continuaba priorizando y profundizando las políticas de inclusión en derechos: se debatía sobre una ley que castigue el femicidio y la violencia de género, el matrimonio igualitario estaba cada vez más cerca y la identidad de género en el DNI era una realidad casi palpable.

En la Facultad seguíamos desarrollando este tema y en 2008, antes del inicio del ciclo lectivo, presentamos ante el Consejo Académico el reconocimiento de la identidad de género de Claudia Vásquez Haro, con el objetivo de reconocer su identidad autopercibida en las actas administrativas y, a partir de entonces, de toda la comunidad estudiantil de la Facultad. Con el claro objetivo, además, de poder llevar la propuesta al Consejo Superior de la UNLP y contribuir desde la universidad a la posibilidad de tener la identidad de género en el DNI. La Resolución 25 fue aprobada por unanimidad y contempló hacer extensiva la medida a todas las facultades de UNLP, lo que supuso una medida sin precedentes en la historia de las universidades nacionales, de Latinoamérica y el Caribe. La repercusión mediática del hecho hizo que la Facultad se convirtiera en una referencia sobre la materia y que desde diversas universidades nacionales nos pidieran el proyecto para poder replicarlo.

Es importante destacar, por último, algunas actividades que dan cuenta de la política llevada adelante por la Secretaría.

En este período, las demandas de publicaciones académicas crecían al ritmo de la política de derechos humanos. Al respecto, destaca la coordinación de la edición 53 de la revista científica electrónica Tram(p)as de la Comunicación y la Cultura, titulado: "Comunicación y Derechos Humanos. La búsqueda de justicia, historias de ayer y de hoy», que contó con los aportes de Eugenio Zaffaroni, Eduardo Luis Duhalde, Lilia Ferreira, Horacio Verbitsky, Adelina Alayes, Estela Carlotto, Rosa Bru y Silvia Delfino. Con este número, publicado en junio de 2007, buscamos promover y difundir los debates de mayor actualidad en aquel entonces, dar cuenta de los ejes temáticos que trabajábamos desde la Secretaría, interactuar con les máximes referentes de la política nacional en materia de derechos humanos y difundir las principales políticas de derechos humanos de ese momento en la Argentina. Simultáneamente, se multiplicaban las columnas periodísticas que se publicaban en los medios de comunicación locales y las contribuciones que realizábamos en distintas producciones académicas de la Facultad. 
Integramos la comisión de Derechos Humanos del Foro Provincial por los Derechos de la Niñez junto con organizaciones sociales y de derechos humanos, instituciones académicas y gremios, para plantear políticas públicas, campañas de difusión, documentos, marchas jornadas. La Ley Nacional 26061 de Protección Integral de los Derechos de Niñas, Niños y Adolescentes, sancionada en 2005, había derogado la anterior Ley de Patronato de Menores, vigente desde 1919. La nueva Ley representaba un punto de inflexión, de gran avance en la forma de concebir la infancia y su relación con el Estado, la familia y la comunidad.

En tanto, estudiantes y compañeres de la Secretaría continuaban realizando prácticas profesionales en el programa «De Igual a Igual», emitido por Radio Universidad. Era un lugar de difusión que nos permitía comunicarnos con la comunidad pero, fundamentalmente con la militancia en derechos humanos de la ciudad de La Plata. Entre las fieles oyentes estaba Chicha Mariani, que siempre mandaba mensajes afectuosos. También era un espacio que permitía desarrollar investigaciones y producir informes específicos sobre la materia, así como realizar prácticas concretas en periodismo con perspectiva en derechos humanos. Claudia Vásquez, Pascual Pichún, Lelio Sánchez (compañero de la Comisión de Discapacidad de la Facultad), Rosa Bru, Madres y Abuelas de Plaza de Mayo, Hijes de desaparecides, familiares de víctimas de violencia institucional en democracia y periodistas especializades encontraban en el programa un espacio de difusión que les identificaba. Para ese entonces, contábamos con un horario central en la AM 1390, que nos daba más audiencia que la FM 107.5, donde nos iniciamos.

$\sim$

Eje central de la política también era estar en las calles acompañando las demandas y los procesos colectivos de búsqueda de justicia, donde a partir del caso de Miguel Bru nos tenían como referentes. Entendíamos que las luchas fundamentales del pueblo se dan en las calles movilizando, acompañando y poniendo el cuerpo. Nunca dejamos de participar en las movilizaciones por Miguel, en los reclamos de justicia por Jorge Julio López ni de acompañar la lucha de Nelly en la búsqueda de justicia por el femicidio de su hija, Sandra Ayala Gamboa. ${ }^{38}$

Marchábamos con las compañeras trans y travestis hacia la comisaría 9. de La Plata para que cesen la persecución y los malos tratos hacia el colectivo de la diversidad, ya que esta seccional tenía la jurisdicción de la denominada «zona roja». Participábamos de las marchas y de los escraches en repudio a los genocidas y a la Dictadura. El acompañamiento era mutuo, y esa diversidad de actores encontraba en nuestra institución una forma de contención y de acompañamiento incondicional.

Estaba claro que la consolidación de la Secretaría se seguía dando, que las diversas áreas de trabajo se continuaban fortaleciendo y que la visibilidad de las acciones llevadas a cabo iba en aumento. Al cierre de este segundo período, ya no era lo novedoso sino la profundización y el desarrollo de los ejes lo que marcaba el ritmo de gestión, además del muy importante luga político que el espacio ocupaba en la institución, en la UNLP y en la trama urbana de la ciudad.

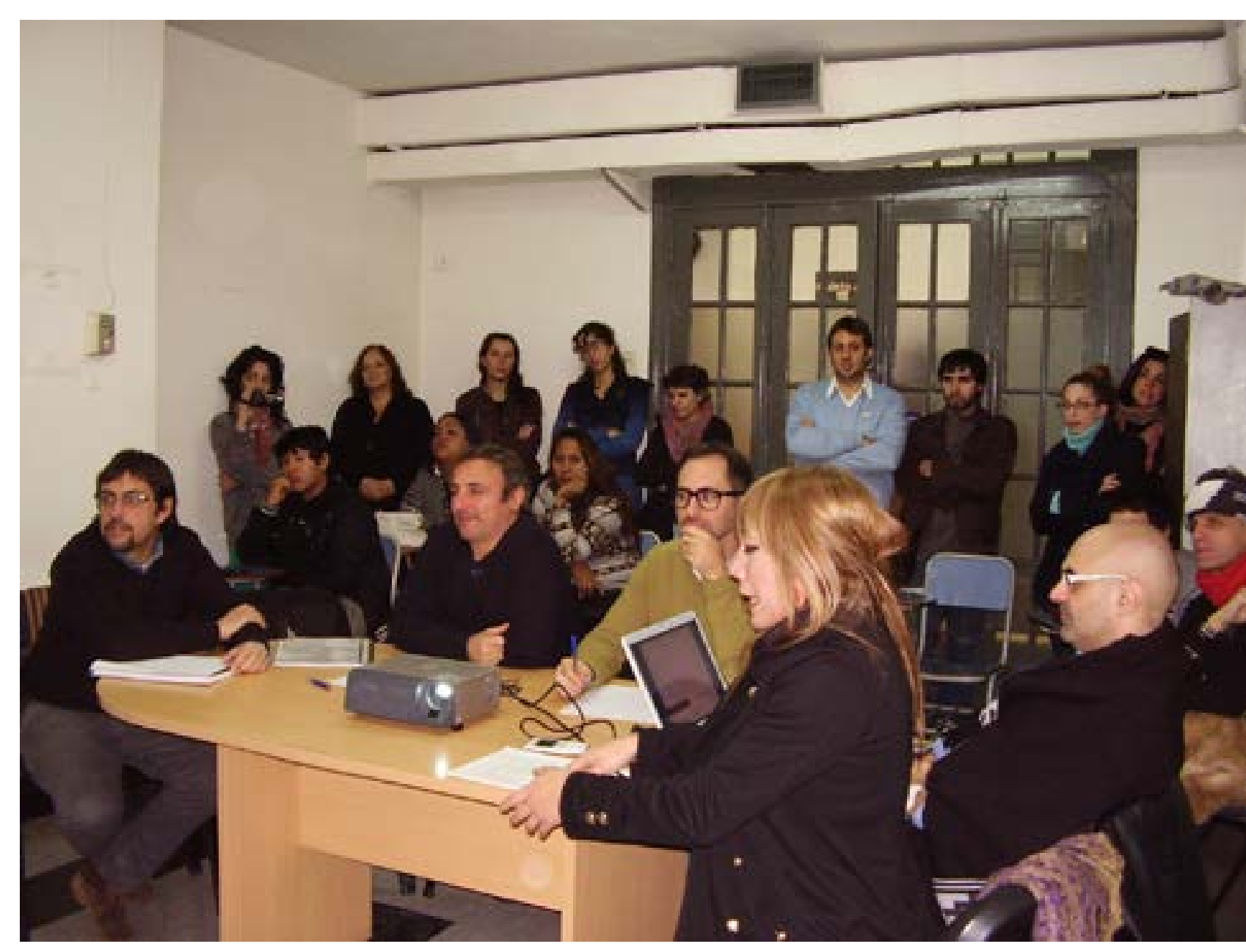

171

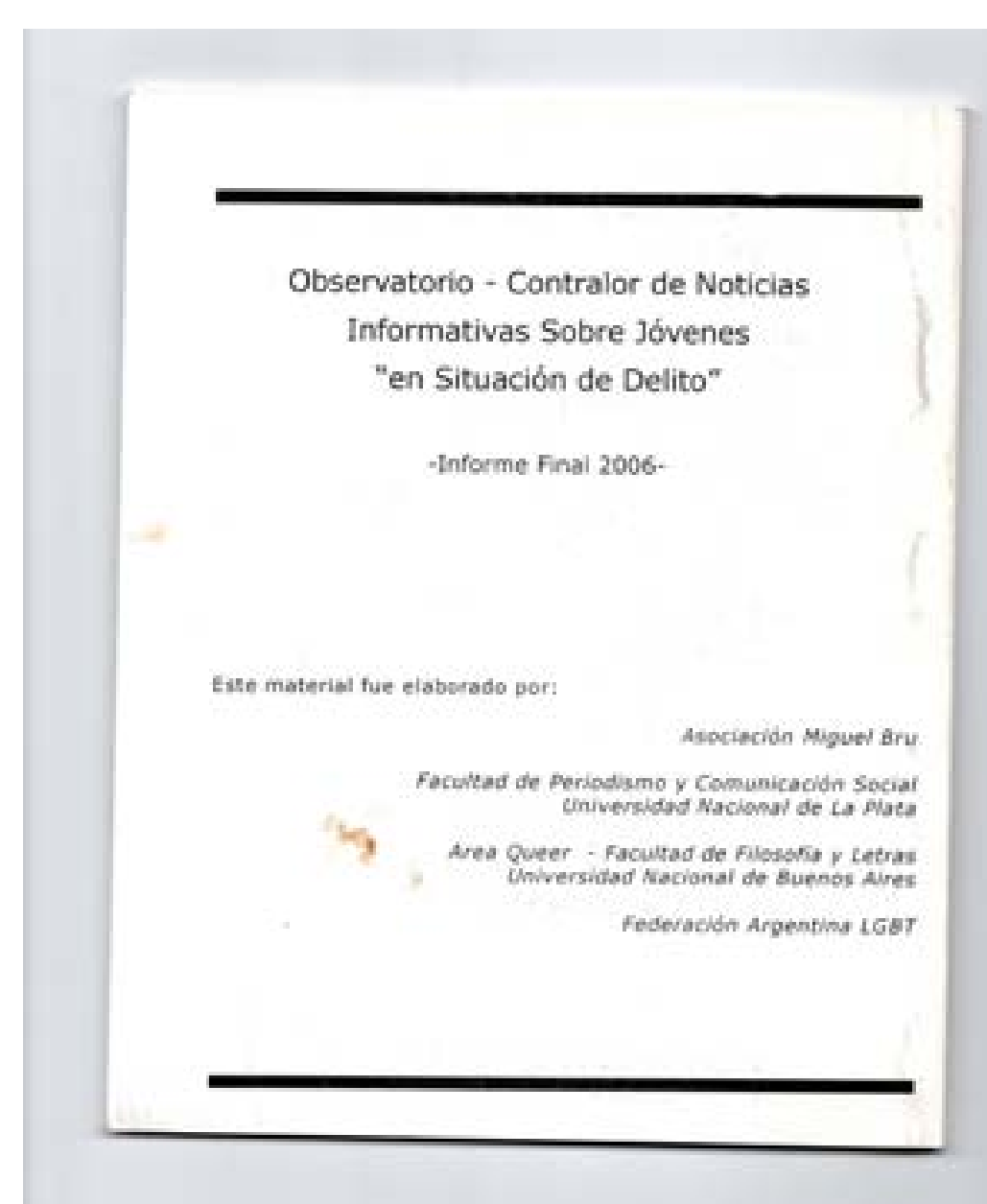

Defensa de tesis de la Licenciatura en Comunicación Social de Claudia Vásquez Haro.2 y 3. tapa y contratapa del informe final del proyecto de Extensión "Observatorio-Contralor de Noticias Informativas sobre Jóvenes en Situación de Delito". Informe fina 2006.4. En la marcha del Orgullo Gay en el año 2007 en CABA. 


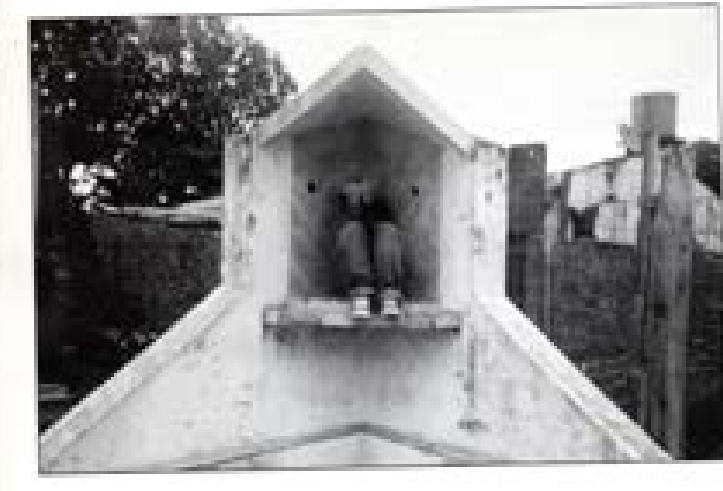

Observatorio - Contralor

de Noticias Informativas

sobre Jóvenes

"en Situación de Delito"

-Informe Final 2006.

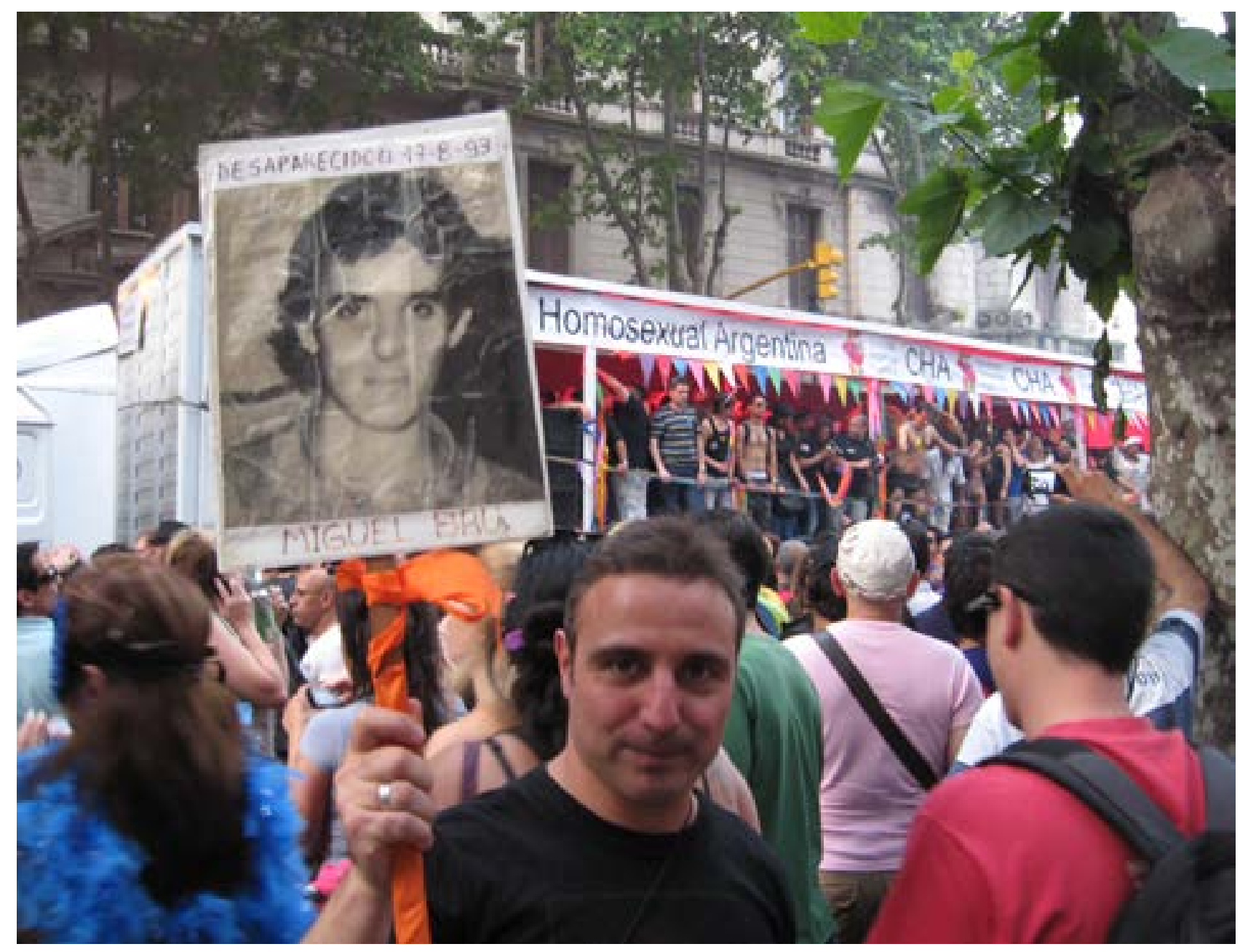

172
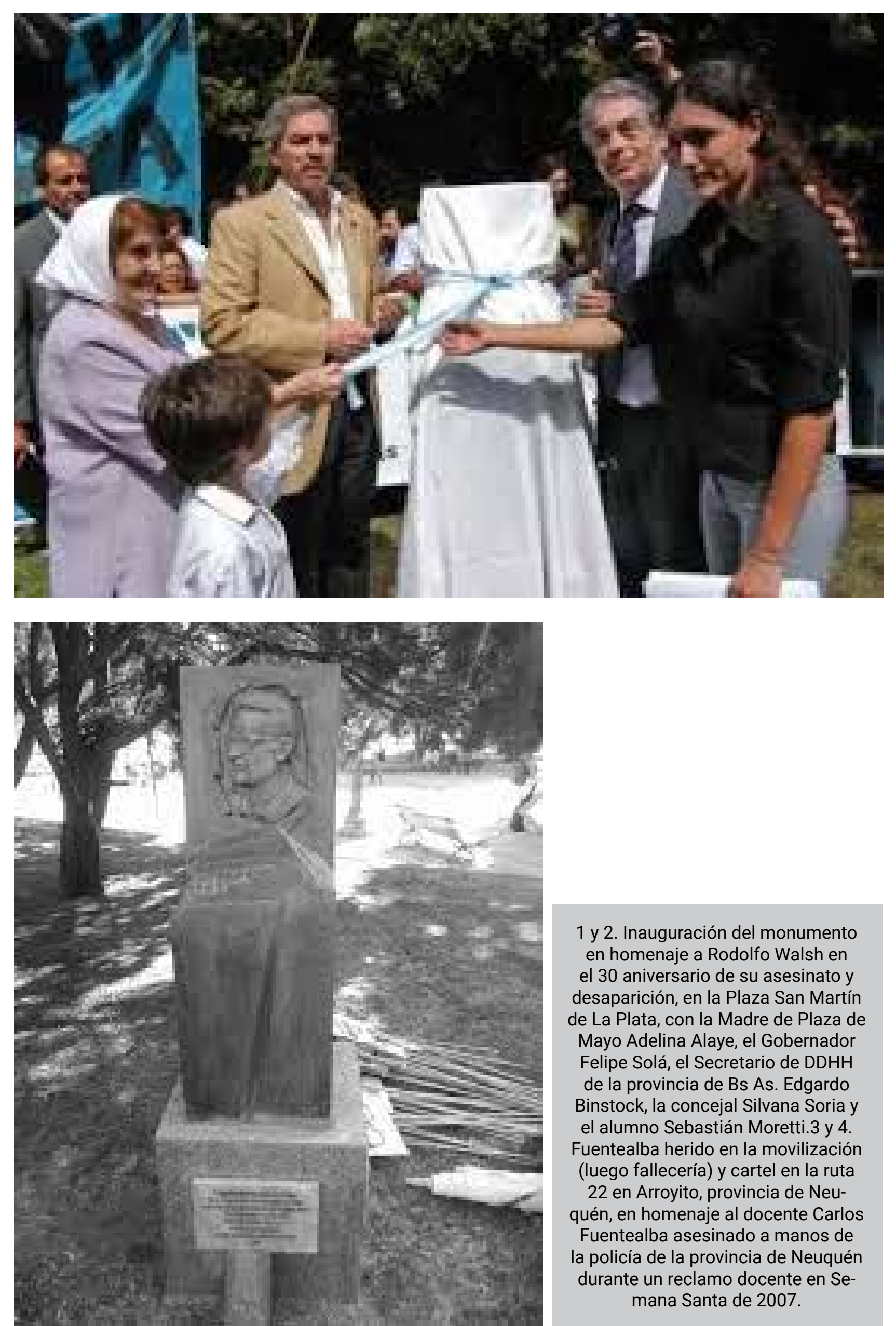
1 y 2. Inauguración del monumento el 30 aniversario de su asesinato y desaparición, en la Plaza San Martín de La Plata con la Madre de Plaza de Mayo Adelina Alaye el Gobernador Felipe Solá el Secretario de DDHH de la provincia de Bs As. Edgardo Binstock, la concejal Silvana Soria y el alumno Sebastián Moretti 3 y 4. Fuentealba herido en la movilización (luego fallecería) y cartel en la ruta 22 en Arroyito, provincia de Neuquén, en homenaje al docente Carlos Fuentealba asesinado a manos de la policía de la provincia de Neuquén durante un reclamo docente en Semana Santa de 2007. 


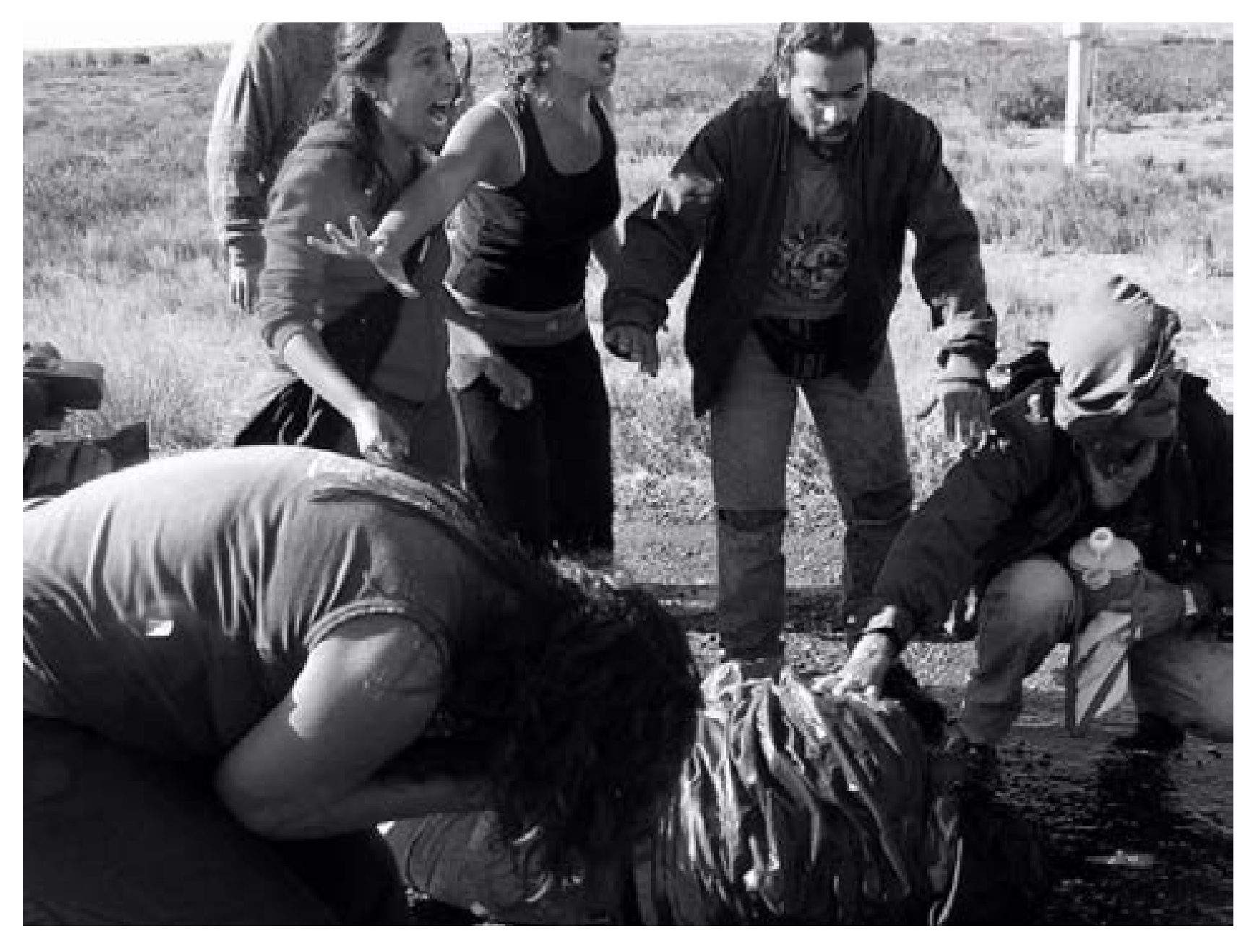

174
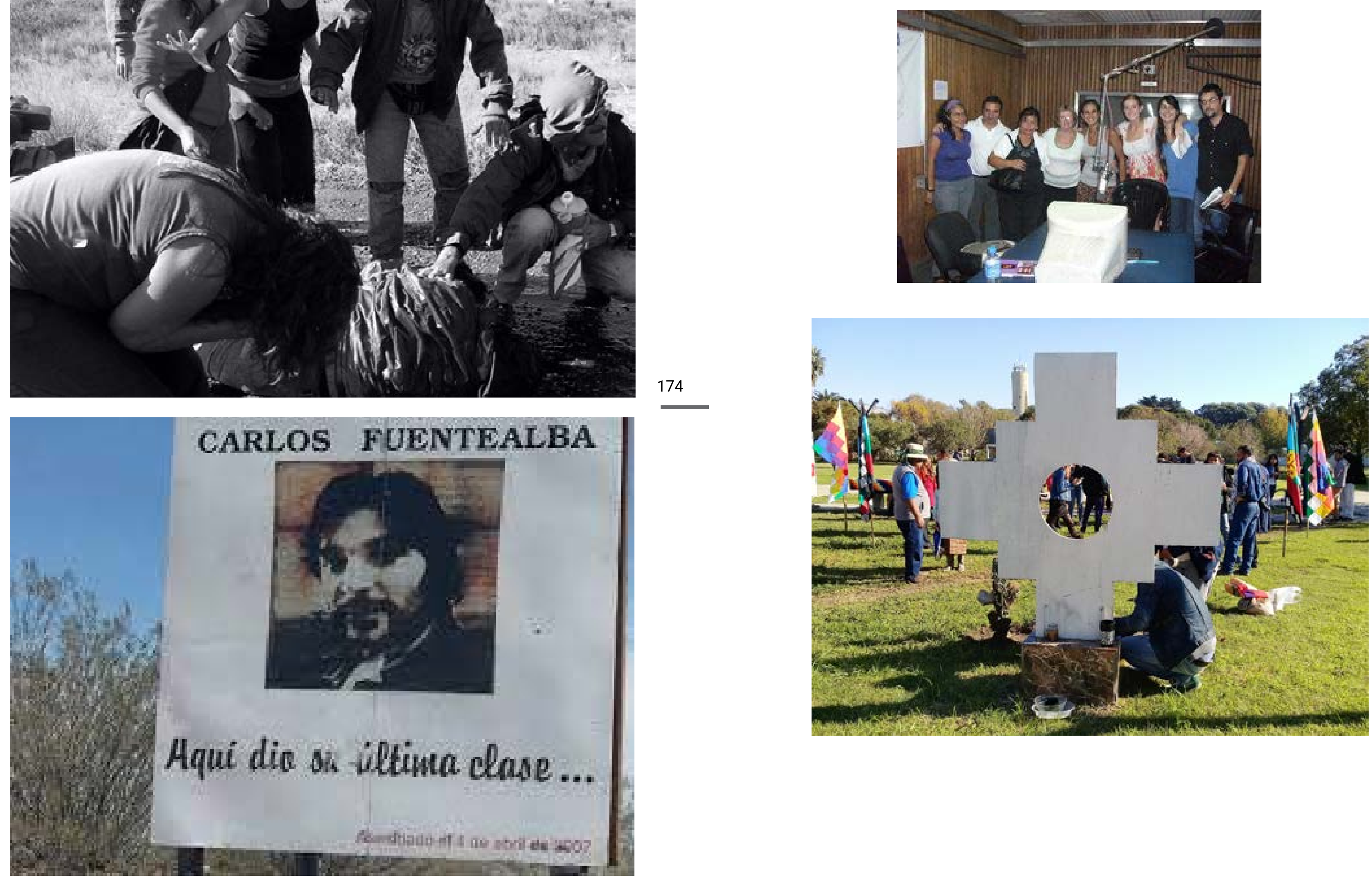

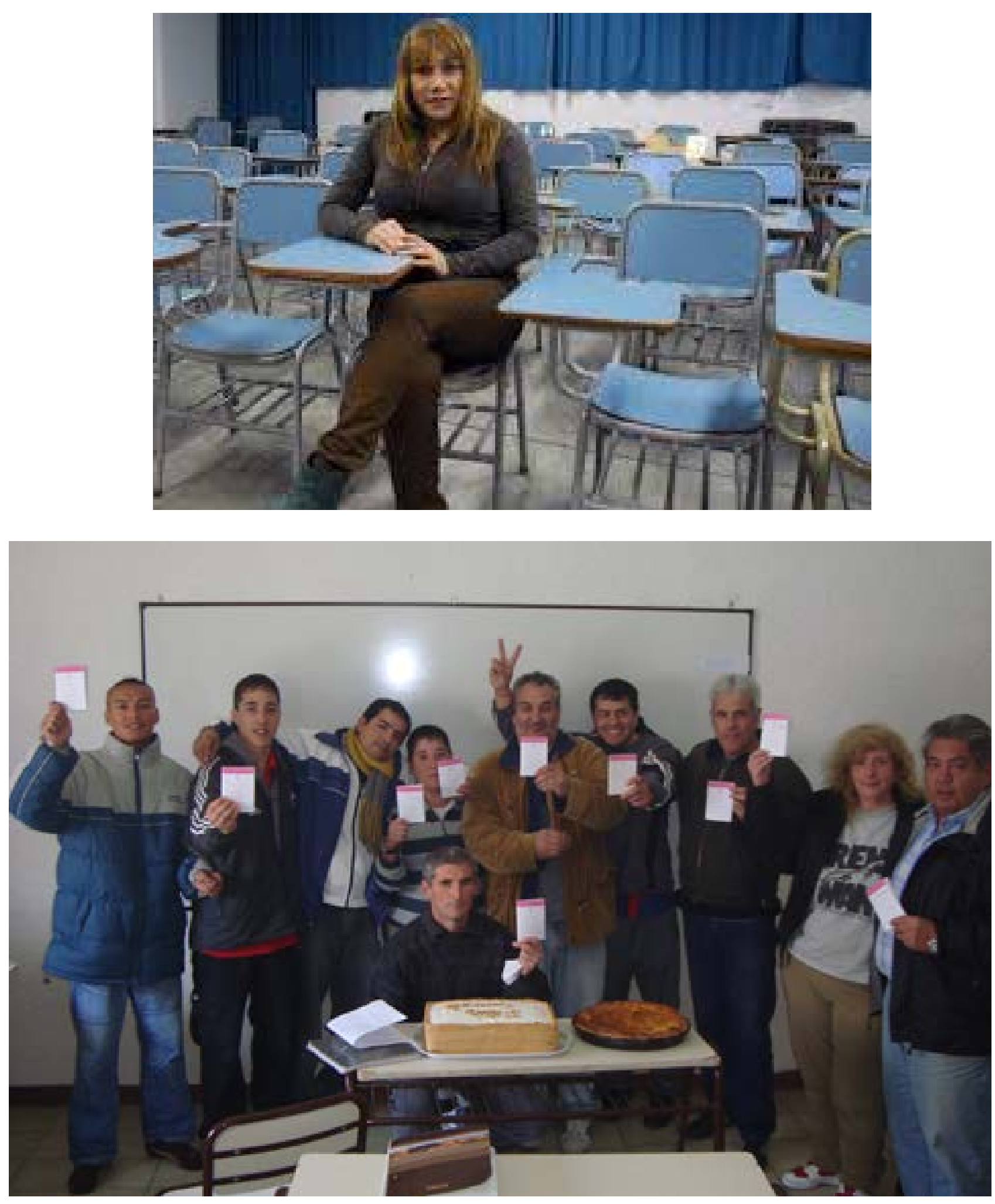

Equipo del programa de radio "de Igual a Igual", con Isabel Burgos, experta en cuestiones de género, Nelly Ayala Gamboa, mamá de Sandra víctima de femicidio y Rosa Bru.2. Ceremonia indígena en la Chakana (cruz Andina) en el patio de la facultad en la sede del bosque.3. la docente trans Claudia Vasquez Haro en el aula de la Facultad de Periodismo.4. Alumnes privades de libertad, con libreta estudiantil en mano, en la sede de la Extensión de la Unidad Penitenciaria $n^{\circ} 9$ de La Plata.
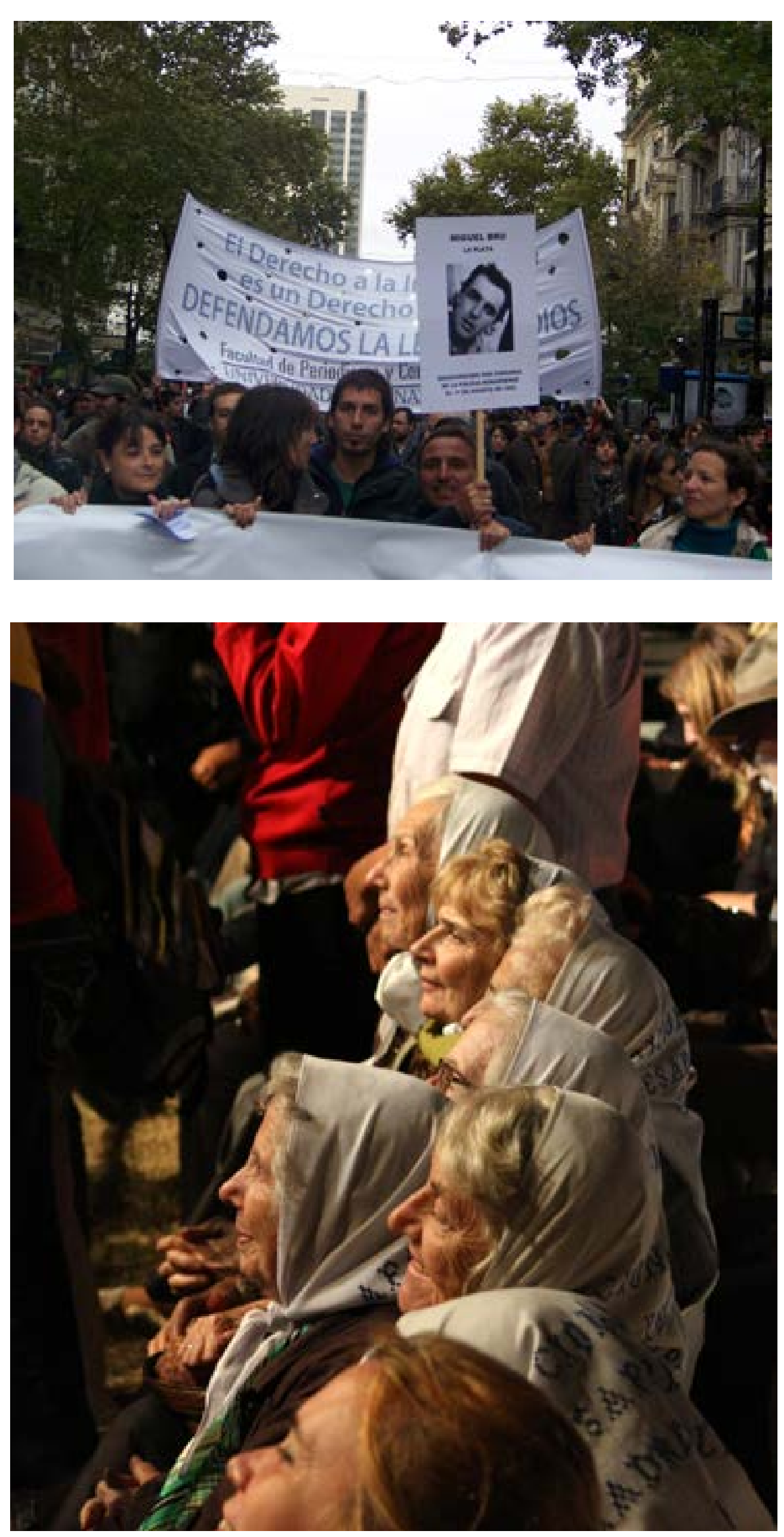


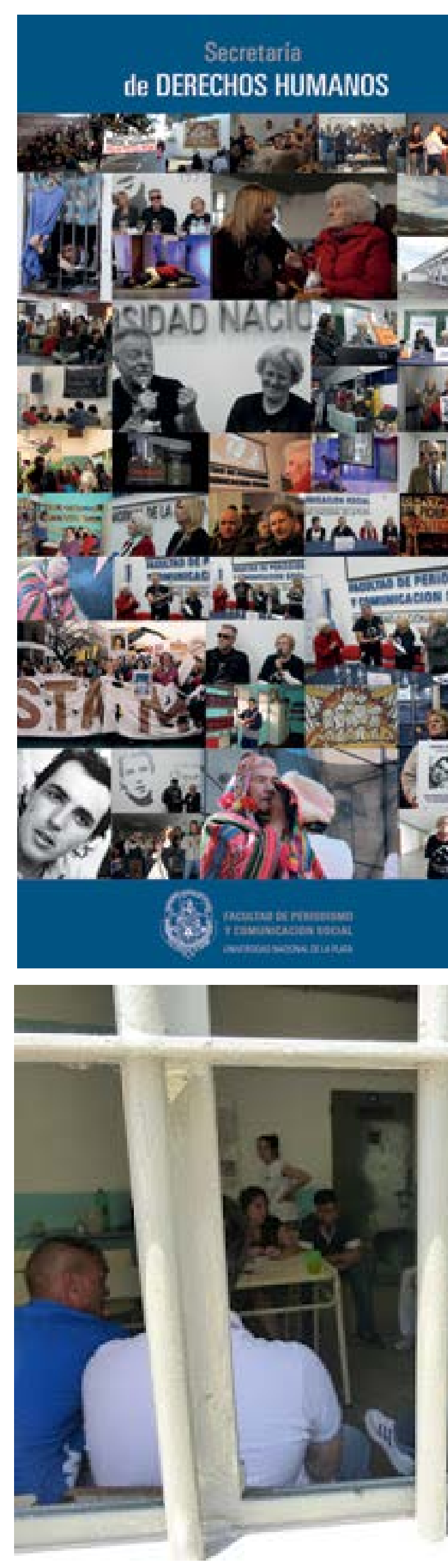

Marcha en CABA con la FP y CS en reclamo por una nueva ley de Servicios en Comunicacion Audiovisual en el año 2007.2. Madres de Plaza de Mayo, en la entrega de premio Rodolfo Walsh al presidente de Venezuela Hugo Chavez, acto realizado en la Facultad en la sede del bosque en el año 2014.3. Banner de la Secretaría de DDHH. 4. Charla de Antonio Vied-

ma Rojas, de la Universidad Naciona

de Educación a Distancia de España,

con estudiantes privados de libertad en la Unidad Penitenciaria N ${ }^{4} 5$ de Melchor Romero.

Inauguración del Salón Auditorio "ABUELAS de Plaza de Mayo"

on la presencia de Estela Barnes de Carlotto
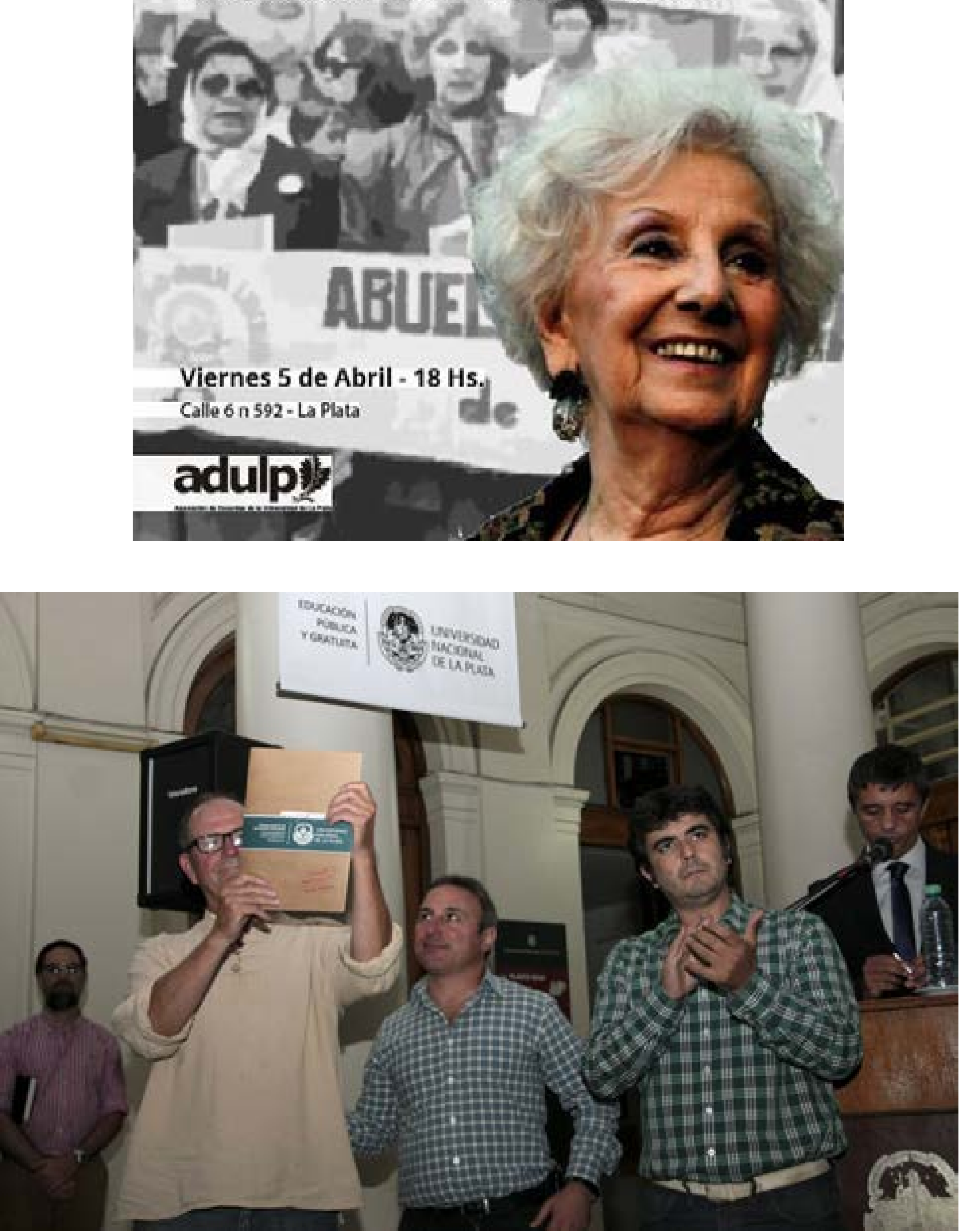

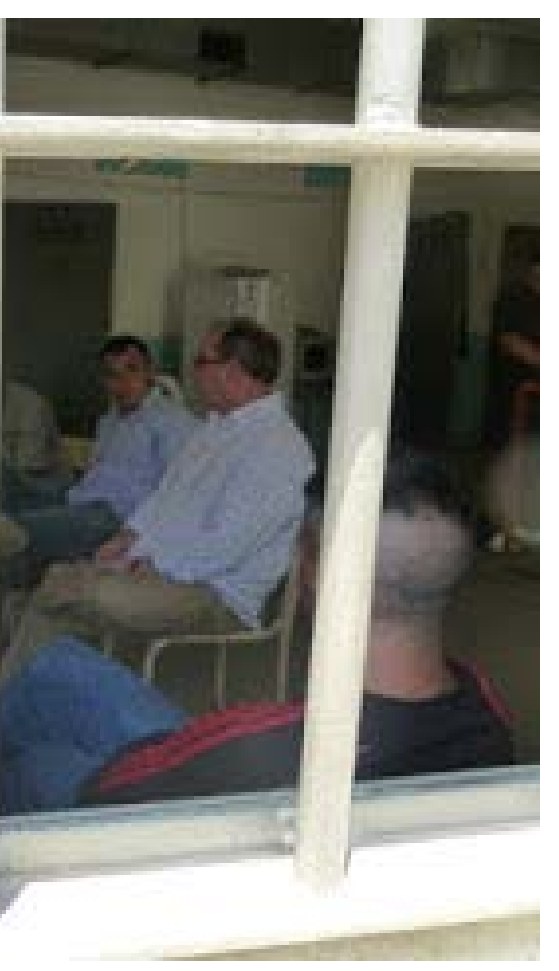


"...Siempre he estado en territorio mapuche..."

Pascual Pichún Collonao

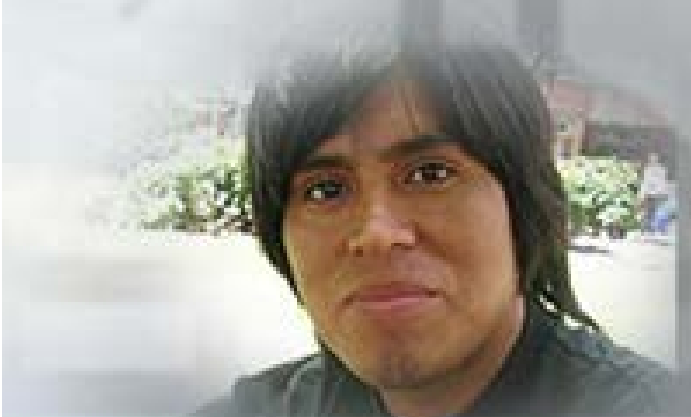

Audiencia

Viernes 14

de mayo

11:00hrs.

Tribunal Oral de Temuko

Pichún Collonao se encuentra prisionero desde el 27 de feb., por el Escado racista chileno en la

Carcél Pública de Traiguén

Coronel Urrutia $N^{*} 129$.

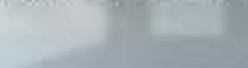

Libertad a los Presos Politicos Mapuche!!!

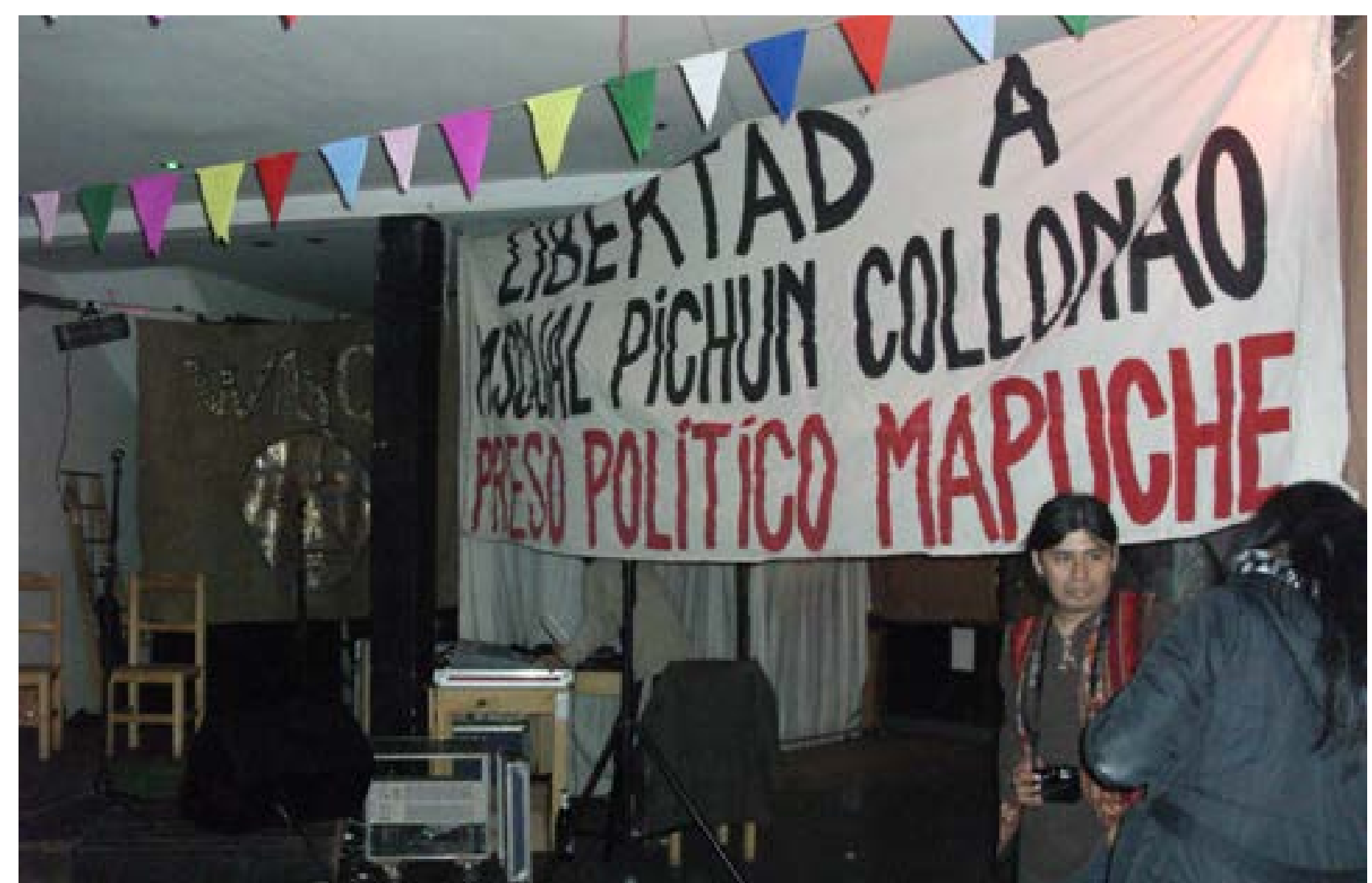

Estela Carlotto en el bautismo del salón auditorio del sindicato ADULP con el nombre de "Abuelas de Plaza de Mayo".2. Con Octavio Miloni, Secretario General de ADULP, entregando legajos reparados de docentes victimas del terrorismo de Estado en el Rectorado de IO UNLP. 3 Y 4. ROSA BRU, ADA SANCHEZ VIAMONTE NAA SANCHEZ VIAMENTE POR HIJ OS REGIONAL LA PLATA.
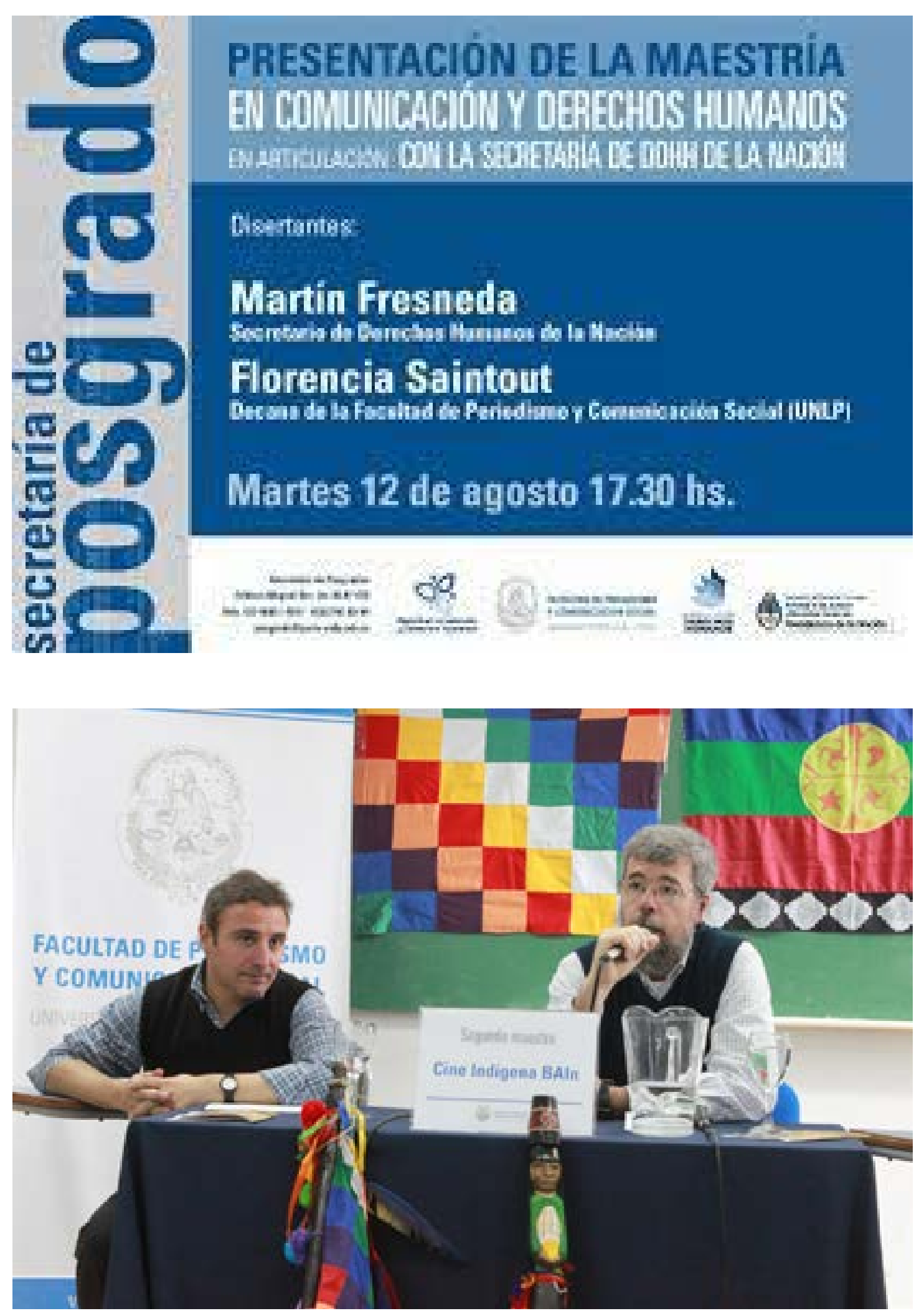

Afiche de la presentación de la Maestría en Comunicación y Derechos Humanos de la FP y CS.2. Con el profesor Carlos Ciappina en la presentación de la segunda Muestra de Cine Indigena Bain en la FP y CS.3. Zulema Enriquez con Pascual Pichún, papá de nuestro alumno Pascual, reclamando por la libertad del mismo en la FP y CS.4. Con Florencia Saintout, la decana, en la inauguración del monolito en homenaje a las víctimas del terrorismo de Estado de la FP y CS. 

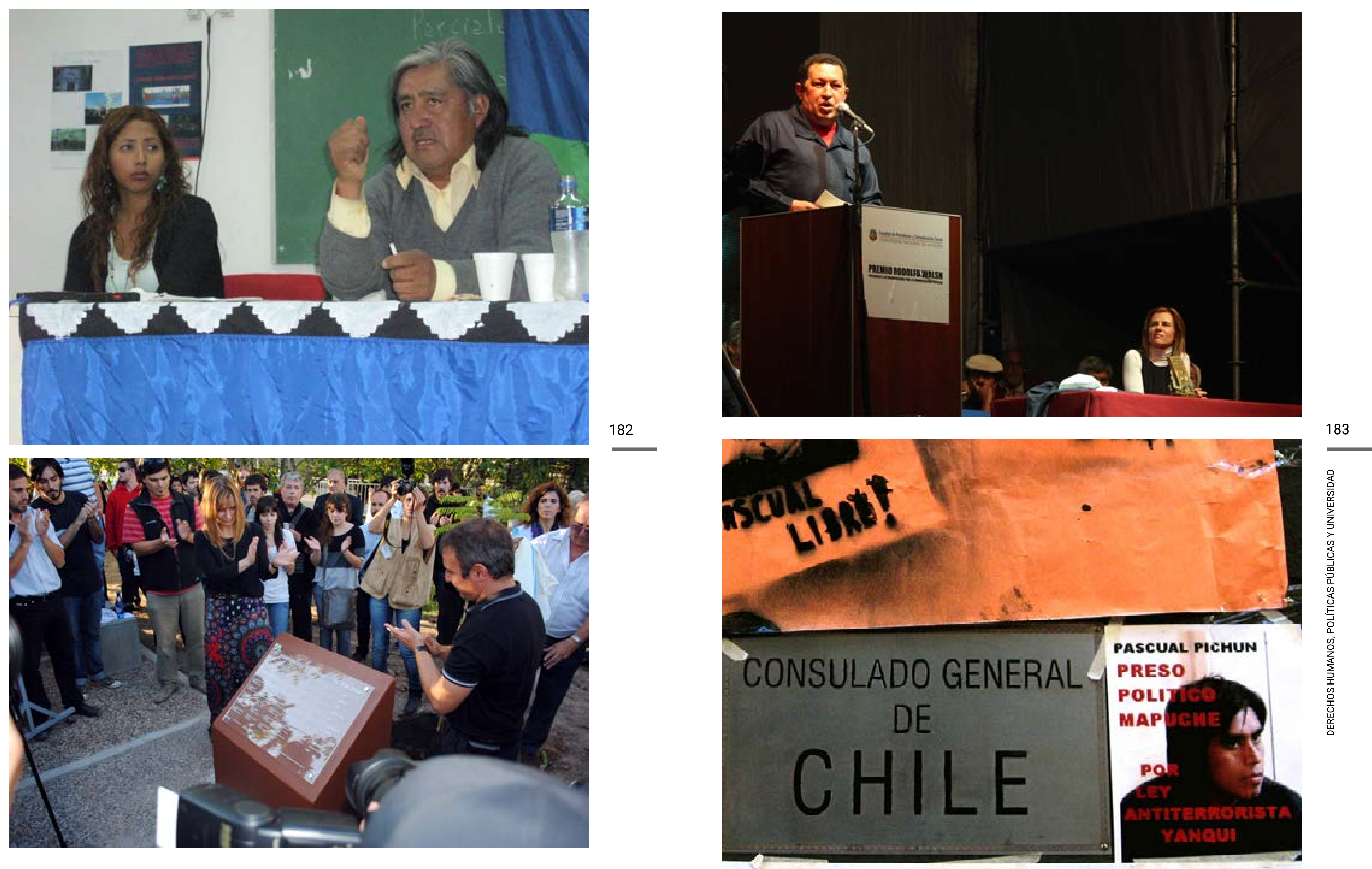

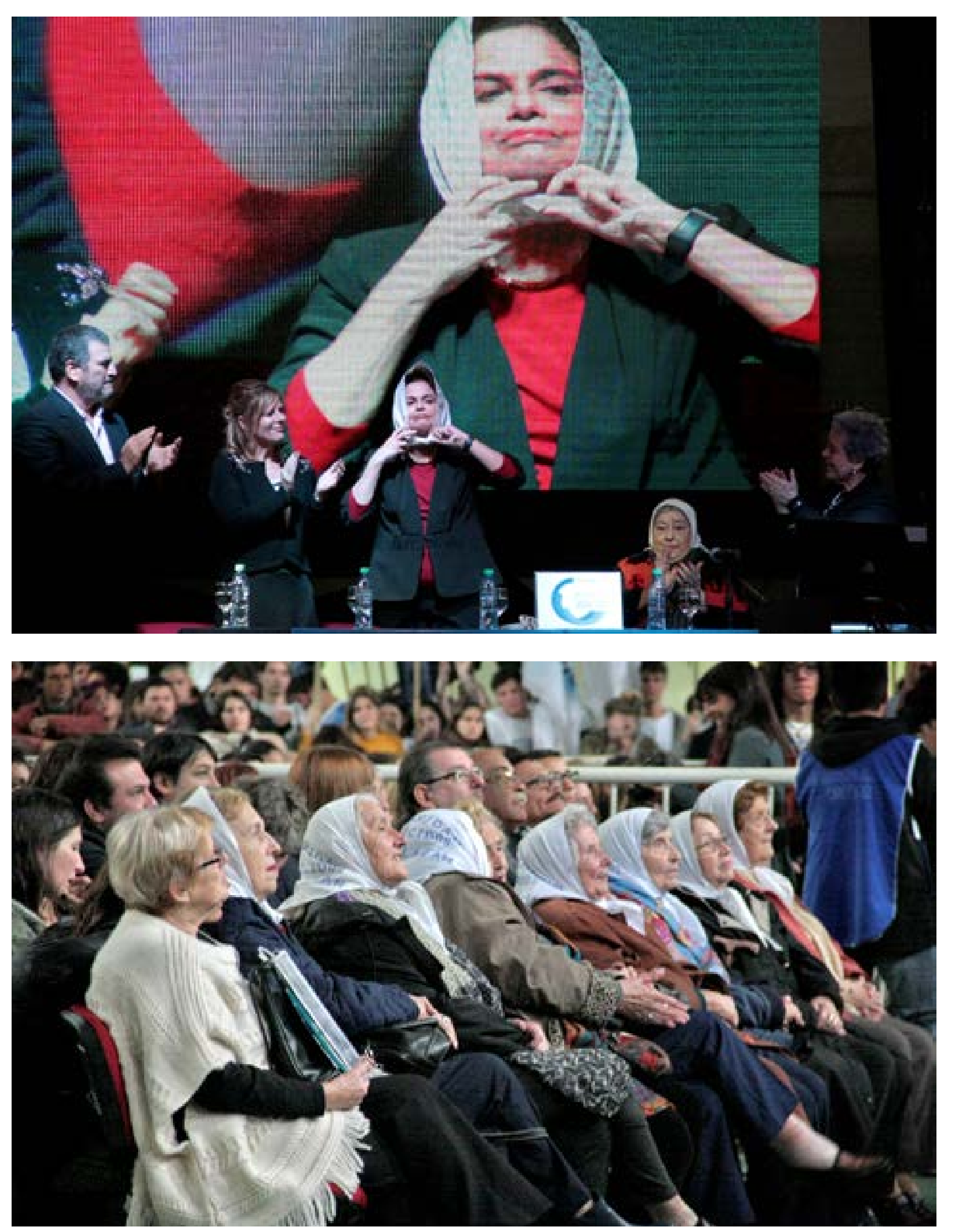

Hugo Chavez Frías, presidente de Venezuela y Florencia Saintout, decana de la Facultad de Periodismo, en la entrega del premio Rodolfo Walsh en el año 2011.2. Afiche de Pascual Pichún Collonao en el Consulado de Chile en el año 2010.3 y 4. Entrega del premio Rodolfo Walsh a Dilpañuelo de las Madres. Rosa Bru junto a las Madres de Plaza de Mayo en el mismo acto.
$2010 / 2014$

Los nuevos desafíos

En este tercer período de gestión, que va de 2010 a 2014, hubo una renovación total de las autoridades que encabezaban la gestión de la Facultad. Si bien eran de la misma organización política surgida de la Agrupación Rodolfo Walsh, generacionalmente se trataba de otro grupo político dentro del mismo espacio. Para ese entonces, la gestión de derechos humanos de la Facultad gozaba de prestigio y de reconocimiento político; inclusive, desde la Asociación de Docentes de la Universidad de La Plata (ADULP) me propusieron que encabezara la Secretaría de Derechos Humanos. Si bien sentía que no sabía mucho del mundo de los sindicatos, me plantearon que trabajara en la misma línea política que teníamos en la Facultad. En tanto, las autoridades de la Facultad me dijeron que no podía negarme, que mi participación en el sindicato era una forma de afianzar lazos con nuestra unidad académica. Desde entonces, formo parte de la comisión directiva y me desempeño como Secretario de Derechos Humanos del gremio que, en cantidad de afiliades, es el más grande de la Confederación Nacional de Docentes Universitarios (CONADU).

Las nuevas autoridades de la Facultad valoraban mucho la política de derechos humanos que se venía desarrollando, así como el lugar que ocupaba en la ciudad y en la UNLP, por lo que me propusieron que continuara en el cargo y que incorporara como prosecretario a Alberto Mendoza, con quien éramos compañeros de la AMB, amigos del grupo de Miguel Bru $y$, a esta altura de nuestras vidas, como si fuéramos parte de la misma familia.

Se habría un capítulo nuevo y muy fuerte en la Facultad: había que revalidar los pergaminos e ir mucho más allá. La nueva gestión proponía una exigencia política muy importante, más formación, más protagonismo político en la ciudad y en la UNLP, más relación con la política territorial, más militancia comprometida con el proyecto político nacional, más juventud con ideas nuevas y espíritu de profundizar los cambios de época y la política de derechos humanos en todo sentido.

No fue fácil, tardé un tiempo en asimilar y en acoplarme a la nueva gestión, al nuevo equipo y al crecimiento que había experimentado la Facultad. Sin embargo, lo que nos favorecía en esta nueva propuesta era la necesidad de fomentar la presencia en los diversos territorios y viceversa, de los diversos territorios en la facultad. La vinculación con la comunidad se había desarrollado muchísimo en todos los espacios, pero esa era, precisamente, la esencia de la política en derechos humanos de la Facultad. La epistemología del barro y el contagio.

Nos disponíamos a enfrentar estos desafíos cuando muere Néstor Kirchner. El golpe fue tremendo y muy doloroso. Sentíamos que a través de la política, él nos había devuelto la dignidad, había puesto al país de pie y había convertido a la política de derechos humanos en un modelo para el mundo entero. Con gran esfuerzo, nosotres debíamos estar a la altura de las circunstancias. La presidenta Cristina iba a estar a la altura de la historia. 


\section{Pedagogía en comunicación y derechos humanos}

La formación seguía siendo un tema trascendental para la gestión y más para esta nueva conducción. Una de las primeras cosas que me dijo Florencia Saintout, la decana entrante, fue: «Tenemos que poner en marcha la Maestría en Comunicación y Derechos Humanos». Desde hacía varios años venía manteniendo encuentros con diversos referentes para llevarla adelante, por lo que empezamos a trabajar en los contenidos, y en el perfil de estudiantes y de docentes que queríamos y que necesitábamos. Fueron casi seis años de trabajo.

En la primera evaluación, realizada por la Comisión Nacional de Evaluación y Acreditación Universitaria (CONEAU), nos rechazaron la presentación aduciendo que los derechos humanos no se enmarcaban en la disciplina de la comunicación, sino del derecho y la filosofía del derecho. Luego de apelar con sólidos fundamentos, en 2011 se logró su aprobación. ${ }^{39}$

La línea política de la Maestría era la que marcaba la gestión de la Facultad y, aunque con otra complejidad y profundidad en su desarrollo, similar a la del seminario. Entendíamos que era fundamental que la pudieran cursar aquelles que acreditaran trabajo y trayectoria en derechos humanos, y no necesariamente quienes tuvieran una carrera universitaria aprobada; queríamos una maestría en la que se pudiera insertar la militancia en derechos humanos.

Muy emocionante fue el acto inaugural, en donde estuvieron presentes Estela Barnes de Carlotto, Adelina Dematti de Alaye, Martín Gras, Eduardo Luis Duhalde, Alberto Sileoni, Ministro de Educación de la Nación, Alejandro Kaufman, Rosa Bru y Florencia Saintout. Se me propuso y fui nombrado director.

La carrera propone brindar un panorama definido sobre teorías y prácticas en derechos humanos, relacionadas con las ciencias sociales en general y con experiencias profesionales concretas, para debatir, investigar y producir desde una perspectiva comunicacional anclada, fundamentalmente, en la posibilidad de pensar y de establecer vínculos sociales y comunitarios donde la construcción de sentidos con otres desplace el monopolio de la enunciación y de la palabra como estatuto de verdad que legitima la opresión.

Bajo la premisa de que la perspectiva de comunicación y derechos humanos es una perspectiva para la emancipación, la Maestría no pretende establecer un campo profesional específico sino promover un modo particular de acción profesional capaz de ser puesto en juego en cualquier campo en el que intervengan les comunicadores. No es prioridad establecer los dónde del profesional sino los cómo, siendo imprescindible un modo particular de ver, de diagnosticar, de pensar y de actuar.

La Maestría, primera en nuestro país y en Latinoamérica, comenzó a dictarse en agosto de 2012 con una fuerte impronta latinoamericana, en tiempos políticos donde los procesos que tenían lugar en Venezuela, en Paraguay, en Bolivia, en Ecuador y en Brasil comenzaban a

\footnotetext{
$39 \quad$ Resolución CONEAU 11072, Resolución Ministerial 1374 y Disposición 252/ de la UNLP.
}

cumplir el sueño de la patria grande ${ }^{40}$ al que aspiraban Simón Bolívar y José de San Martín. Pasaron por las aulas estudiantes de Chile, México, Costa Rica, Brasil, Colombia, Guatemala Uruguay, República Dominicana, Venezuela, Paraguay y Ecuador. ${ }^{41}$

Fundamentalmente los ejes temáticos que aborda son las conceptualizaciones históricas y su relación con las prácticas en materia de derechos humanos. Configuraciones de sentidos en las sociedades del presente: organizaciones y debates en América Latina. Derechos Humanos: memoria y actualidad en las agendas. Acción cívica en las democracias actuales: políticas públicas y organizaciones sociales. Políticas de la diversidad en los debates actuales. El debate sobre hegemonía y producciones material-simbólicas. ${ }^{42}$

Respecto del seminario Comunicación y Derechos Humanos, en 2012 se llamó a concursos y en 2014 se convirtió en una asignatura obligatoria para las diversas carreras de comunicación de la Facultad. A partir de los concursos, y bajo la conducción de Alberto Mendoza, la materia logró instalarse en la currícula del ciclo básico del nuevo Plan de estudios 2014. Siempre multitudinaria en cuanto a la cantidad de estudiantes, siguió contando con docentes compañeres de la agrupación H.I.J.O.S. y de la AMB, con las Madres de Plaza de Mayo, con la docente trans Claudia Vásquez Haro, con la docente Quetchua Zulema Enríquez y con compañeres de la Comisión Provincial por la Memoria, entre otres.

En relación conestemismo eje,y en el marco dela organización del Congreso de Comunicación y Ciencias Sociales (ComcIs), en 2011 armamos el grupo de trabajo «Abordajes de las ciencias sociales en relación con los DDHH: diferencias culturales, memorias, minorías y disputas hegemónicas en Latinoamérica», del que participaron Eugenio Zaffaroni y Martín Gras, quienes problematizaron sobre los debates más actuales en materia de derechos humanos, lo que resultó muy importante para nuestra formación.

\section{Memoria y Dictadura}

En el marco de este eje, se siguió desarrollando el proyecto "Textos de la Memoria. Historias de los desaparecidos de Periodismo». Publicamos notas e informes en la página institucional y editamos fascículos impresos sobre Daniel Elías y Liliana Molteni, víctimas del terrorismo de Estado de nuestra institución. También se continuó aportando información en las causas de lesa humanidad y trabajando con estudiantes que realizaban trabajos prácticos o tesis sobre estas temáticas.

A sala llena, se presentó Verdad y Justicia. El diario del juicio a los penitenciarios, un periódico realizado por las secretarías de Derechos Humanos y de Producción de la Facultad,

$40 \quad$ El concepto «Patria grande» alude a la unidad política de las naciones latinoamericanas y su origen corresponde a los libertadores Bolívar y San Martín.

41 A través de un convenio con la Secretaría de Derechos Humanos de la Nación, se dictó en el sitio de memoria Ex ESMA (2014-2016) y, mediante un convenio con la Asociación Madres de Plaza de Mayo, en la sede de la casa de la Madres en la Ciudad Autónoma de Buenos Aires (2018-2020).

42 Ver, al respecto, los contenidos de las diferentes asignaturas, disponibles en https://perio.unlp.edu.ar/ posgrado/maestrias/derechos-humanos/contenidos-minimos/ 
conjuntamente con la APDH La Plata, que dio cuenta de la importancia que reviste el proceso de enjuiciamiento de los acusados en los juicios por delitos de lesa humanidad acontecidos en la Unidad 9 de La Plata. La publicación contó con la participación de sobrevivientes de la dictadura y de ex detenidos en el pabellón de lesa humanidad de la Unidad 9 de La Plata, Madres y Abuelas e Hijes de desaparecides, personalidades de diversas unidades académicas y funcionarios de la gestión del Rectorado de la UNLP. Asimismo, desde otras unidades académicas (Trabajo Social, Psicología, Ciencias Veterinarias, Ciencias Naturales, Humanidades), nos invitaban a disertar sobre estas actividades y experiencias que cobraron gran notoriedad y difusión. Junto con otros organismos e instituciones, en 2012 pasamos a integrar «La mesa por más Juicio y Castigo», con la intención de visibilizar y de apoyar los juicios de lesa humanidad.

El 10 de abril de 2011, se inauguró el nuevo edificio de la Facultad, al que se lo nombró «Presidente Néstor Kirchner». Unas horas antes, se había inaugurado el «Monumento a los desaparecidos», en la plaza del mismo nombre que ocupa el lugar central del patio. La estructura, construida por Néstor Bru, cuenta con un acrílico que lleva los nombres y la fecha de desaparición/asesinato de las víctimas del terrorismo de Estado de la Facultad, y a los que se agregó el de Miguel Bru. Participaron del acto ex alumnes, familiares, Estela Carlotto, Adelina Dematti de Alaye y numerosa cantidad de Madres y Abuelas de Plaza de Mayo, Hijes, Rosa Bru y mucha militancia.

En relación con este eje, un trabajo que marcó otro punto de inflexión, tanto personal como institucional, fue la realización del proyecto de investigación y de extensión «Madres y Abuelas de Plaza de Mayo. Relatos del futuro», una serie de producciones audiovisuales que ofrece un registro de acceso público a las entrevistas realizadas a 26 Madres y Abuelas de Plaza de Mayo sobre sus historias de vida. Especialmente pensado para las nuevas generaciones, el objetivo fundamental del proyecto era aportar a la construcción de la memoria colectiva mediante la posibilidad de que le hablen a la juventud del futuro. En el acto de presentación, estuvieron presentes: Estela Barnes de Carlotto, Adelina Dematti de Alaye, Eduardo Luis Duhalde, Martín Gras, Alejandro Kaufman, Florencia Saintout, Madres y Abuelas de Plaza de Mayo, H.I.J.O.S., referentes y organismos de derechos humanos, la infaltable Rosa Bru, compañeres de los sindicatos ADULP y ATULP, y, por supuesto, nuestra comunidad educativa.

Como preveíamos, dada la franja etaria, este trabajo se convirtió en un aporte trascendental para toda la sociedad, y en especial para las futuras generaciones, ante la desaparición física de muchas de las entrevistadas. El equipo de trabajo quedó marcado por esta maravillosa experiencia. Los encuentros personales fueron experiencias muy movilizantes que permitieron compartir momentos únicos, no solo por los testimonios sino por la calidez y la humildad con las que las Madres y Abuelas relataban su lucha, el amor y la reivindicación de los derechos humanos constituyendo un ejemplo de vida.

\section{Violencia Institucional en democracia}

En el marco de la Campaña Nacional contra la Violencia Institucional, en 2013 se desarrollaron en la Facultad las Jornadas de Formación de Promotores Barriales bajo la consigna «Ni un pibe menos», que contó con referentes locales y nacionales en la materia y con la participación de muches pibes de los barrios en talleres donde se debatió sobre seguridad democrática, abusos policiales, criminología mediática y derechos humanos. La actividad finalizó con la elaboración de un documento con aportes para abordar la problemática de la Violencia Institucional, una prueba de que nuestra institución se había convertido en una referencia sobre esta problemática, tanto en la ciudad de La Plata como a nivel nacional.

Durante todos estos años, seguimos participando y organizando jornadas y charlas relacionadas con las políticas de memoria y de justicia, y orientadas a visibilizar la problemática de la Violencia Institucional en democracia. La política nacional también se hacía eco de esta problemática. El 11 de noviembre de 2012 el Congreso de la Nación había firmado el dictamen de la Ley 26811 , un proyecto presentado por el Frente para la Victoria, que declaró el 8 de mayo como el Día Nacional contra la Violencia Institucional. La fecha elegida se relaciona con la denominada masacre de Ingeniero Budge, ocurrida en 1987, cuando tres pibes fueron fusilados a manos de la Policía Bonaerense, lo que se convirtió en el primer proceso colectivo de reclamo de justicia por gatillo fácil en democracia.

En este período se cumplió una fecha muy especial, los 20 años de la tortura y posterior desaparición de Miguel Bru. En la Facultad se realizó un acto muy emotivo, en el que participaron Baltazar Garzón, Estela Carlotto, Adelina Dematti de Alaye, Herenia Sánchez Viamonte, Rosa Bru, Cristian Alarcón, Hugo Cañón, les diputades Victoria Montenegro y Leonardo Grosso, ${ }^{43}$ y el Secretario de Derechos Humanos de la Nación, Martín Fresneda. Le entregamos a León Gieco, padrino de la AMB, el premio Rodolfo Walsh a la Comunicación Popular; se proyectó el documental «Rosa Bru, 20 años de lucha», que realizamos con docentes de la facultad e integrantes de la AMB y con la colaboración de mucha gente; se llevó a cabo la vigilia en la comisaría $9 .^{\circ}$ y varios referentes de la cultura platense rindieron homenaje en el galpón cultural «La Grieta», del club Meridiano V.

Miguel era parte de la Facultad, pero, sin ninguna duda, también estará por mucho tiempo en la memoria misma de la ciudad de La Plata. Siempre decimos con Rosa lo impactante que es ver tanta gente joven acompañando -muches que cuando sucedieron los hechos aún no habían nacido-, y su perseverancia por mantener viva la memoria. Mientras tanto, quienes en un principio conformamos la «Comisión de familiares, amigos y compañeros de Miguel» seguimos, en la actualidad desde la AMB, militando el proceso de memoria, verdad y justicia, fundamentalmente, en lo referido a la Violencia Institucional, pero el trabajo se ha multiplicado y se ha diversificado en varios sentidos. Al igual que con la política de la Secretaría, enseguida comprendimos que los procesos de articulación con familiares, organizaciones, referentes e instituciones del Estado, entre otros actores, son centrales en los procesos colectivos de búsqueda de justicia y de mejoramiento de las condiciones de 43 Grosso fue quien presentó en el Congreso el proyecto por el Día Nacional contra la Violencia Institucional. 
vida de las personas.

En este período, continuamos participando en marchas y reclamando en las calles por procesos colectivos de justicia, por las situaciones violentas a las que son sometidas las compañeras trans, por Jorge Julio López, y pidiendo cárcel común y efectiva para los genocidas, a los que también escrachamos junto con les compañeres de H.I.J.O.S. La Plata y con diversas organizaciones de derechos humanos. Nunca se dejó de acompañar a los familiares de las víctimas de violencia, lo que se convirtió en un sello fundamental de nuestra política de gestión.

\section{Educación superior en cárceles}

En este período, acompañado por el inicio del ciclo lectivo en las cárceles, el desarrollo de este eje de trabajo fue grandísimo. Privades de libertad venían a cursar, a nuestra sede del Bosque y en la sede de la Unidad 9, alumnas de las unidades de mujeres de Los Hornos, alumnos del complejo penitenciario de Varela, de Gorina y de Olmos. Las cárceles ya habían penetrado nuestros muros, y viceversa; cada vez eran más las producciones de les estudiantes que reflejaban la realidad carcelaria en trabajos prácticos, tesis, etcétera.

Pero esto también implicaba numerosas dificultades, agentes del Servicio Penitenciario Bonaerense ostentando uniformes y armas en nuestra facultad, violaciones a los derechos humanos que nos denunciaban les alumnes que estaban en la cárcel y en las que también nos involucramos denunciando, tensiones institucionales internas ante un proceso absolutamente novedoso y que administrativamente era difícil de asimilar (inscripciones por sistema informático, documentos administrativos, traslados carcelarios, motines, etc.) Un conjunto de situaciones que muchas veces se convertían en una carga muy grande para el equipo, ante la imposibilidad de dar respuestas a complejidades que nos excedían.

En el marco de la cátedra Taller de Producción Audiovisual I, de la cual era profesor titular, realizamos con estudiantes privades de libertad una producción audiovisual sobre qué significaba la posibilidad de ejercer el derecho humano a la educación. La producción, titulada «Comunicación en cárceles», se presentó en el Congreso de la Asociación Mundial de Radios Comunitarias (AMARC), realizado en 2010 en la ciudad de La Plata. Se articularon actividades en relación con la educación universitaria en cárceles con la Facultad de Trabajo Social, invitados por la Asociación Civil Grupo de Estudios de Educación en Cárceles (GESEC). También en la Biblioteca Pública Nacional en CABA, conjuntamente con la Facultad de Filosofía y Letras de la UBA, docentes del CUD, estudiantes privades de libertad y estudiantes liberades, organizaciones que trabajan en cárceles y diferentes unidades académicas nacionales, compartimos e intercambiamos conocimientos, experiencias, producciones y propuestas para desarrollar en cárceles.

En noviembre de 2011, junto con referentes académicos de México, Francia, Italia, España y Gran Bretaña, participé en el intercambio de experiencias sobre «Educación en contextos de encierro», organizado por la Universidad de Murcia y la Universidad Nacional de Educación a Distancia de España (UNED). ${ }^{44}$ Además de disertar sobre nuestra experiencia, pudimos llevar la voz y la imagen de nuestres estudiantes a través de la producción audiovisual antes mencionada. Al año siguiente, integrantes de la UNED visitaron la Facultad y los invitamos a las unidades penitenciarias de Melchor Romero, de Florencio Varela y de La Plata para que compartieran la situación de educación en contextos de encierro en otras partes del mundo.

En 2013, nos invitaron a participar en el Primer Congreso del Mercosur de Educación en Contexto de Encierro, organizado por la Universidad Nacional de Córdoba (UNC), del que participaron universidades nacionales de todo el país para crear una Red Interuniversitaria de Derechos Humanos tendiente a visibilizar y a garantizar el derecho a la educación universitaria en las cárceles. La necesidad de las universidades nacionales de profundizar la educación superior en cárceles, favoreció la promoción de actividades de investigación, de producción y de extensión en articulación con las cárceles. Cuando llegamos al congreso, fue muy impactante descubrir la centralidad de nuestra política: todas las universidades conocían la experiencia que llevábamos a cabo en las cárceles y nuestra Facultad era tomada como referencia.

Cada año, se conmemoró en la extensión áulica de la Unidad Penitenciaria Número 9 el Día del Periodista, con la presencia de Rosa Bru, Adelina Dematti de Alaye, Miriam Lewin y Juan Scatolini, ex detenido en el pabellón de Lesa Humanidad, entre otres. En las jornadas se hacían recitales, radios abiertas, se entregaban diplomas, se organizaban campeonatos de truco, y se compartían pizzas y empanadas. Este proceso educativo era una ventana hacia la libertad, tal como nos afirmaban les estudiantes: «Estudiar nos hace sentir personas normales».

\section{Pueblos indígenas}

Este período se inició con la noticia de que Pascual Pichún Collonao, por decisión propia se volvía a Chile. Estaba cansado de no poder salir de su semi clandestinidad, extrañaba a su familia y a su comunidad, y entendía que de esa manera sería muy complicado seguir desarrollando su vida. Estuvo refugiado de la justicia chilena desde 2005, Pascual se entregó en febrero de 2010, en Traiguén. Le propuse a Zulema Enríquez, docente Quetchua de la Facultad -a quien conocí porque era compañera de cátedra del Taller de Producción Audiovisual, y muy amiga y compañera de lucha de Pascual-, que retomara la tarea sobre pueblos indígenas que se llevaba a cabo en la Facultad y que comenzara a trabajar en la difusión de la causa de Pascual, en particular, y de la lucha de los pueblos originarios, en general.

Inmediatamente, nos comunicamos con su familia y nos pusimos a disposición para reclamar por su pronta liberación y, en línea con su estrategia política, manifestarnos en contra de la aplicación de la «Ley Antiterrorista», promulgada por Augusto Pinochet, en

$44 \quad$ Como parte de mis actividades, fiscalicé el proyecto «La situación de las mujeres encarceladas en España. Sistema de indicadores de discriminación penitenciaria», realizado por la UNED. 
causas contra la comunidad mapuche y contra todas las comunidades indígenas, pedir la liberación de todes les preses polítiques mapuches, y el cese de la persecución y el maltrato a les niñes mapuches.

En el marco de las jornadas por la liberación de Pascual, proyectamos en la Facultad el documental "La guerra por otros medios», dirigido por el docente y realizador Cristian Jure. La producción aborda el modo en que los pueblos indígenas utilizan sus propios medios de comunicación para resistir y para denunciar el avasallamiento de sus derechos. Del mismo director, presentamos, también, «10 veces venceremos», producción sobre la historia de Pascual en la que también aparece, en un relato en primera persona, Zulema Enríquez. La vinculación con las comunidades indígenas se multiplicaba y se profundizaba.

Durante todo 2012, realizamos manifestaciones en el Consulado chileno en la Argentina por su detención y por la de 34 presos políticos mapuches que se encontraban en huelga de hambre en Chile. También se presentaron varias notas desde la Secretaría a diversas autoridades chilenas y se armaron disertaciones en la Facultad con el papá de Pascual, un dirigente mapuche muy reconocido en Chile. Florencia Saintout, la nueva decana, se involucró inmediatamente con la causa. Fue al consulado y también le escribió una carta al presidente chileno, Sebastián Piñera, para pedir por su libertad. Finalmente, Pascual fue juzgado y condenado a dos años de prisión efectiva en Chile. Según el mismo nos dijo, la documentación aportada por la Facultad, que acreditaba su condición de estudiante y de trabajador en la Secretaría de Derechos Humanos, favoreció la reducción de la condena de cuatro a dos años.

La política indígena se seguía desarrollando en nuestra facultad y continuábamos involucrándonos con las diversas comunidades, que se iban apropiando de nuestro espacio académico para denunciar y para promover derechos originarios. Puede mencionarse, por caso, la denuncia institucional que realizamos ante la salvaje represión sufrida por la comunidad toba Qom «La Primavera», de Formosa.

En el marco de la reforma del Plan de Estudios, un hecho trascendental fue la presentación de una solicitud para la inclusión de un idioma o lengua indígena como opción dentro de la elección de "la capacitación en idioma extranjero», materia obligatoria y de cursada cuatrimestral para las carreras de Facultad. No obstante, se solicitó reconsiderar el carácter de «extranjero» que se exige a este idioma -ya que nuestras lenguas originarias no son extranjeras - y con mayor convicción se pidió este reconocimiento a nuestros orígenes, para hacer realidad la educación intercultural, sin dejar de lado el paradigma bilingüe. Finalmente, en el primer cuatrimestre de 2014, ante un aula repleta, implementamos el dictado de idioma originario, a cargo del profesor Mario Auca, de la Academia de Lengua Quechua de Cuzco. Fue la primera materia de idioma originario en la currícula de una carrera en la UNLP, a la que luego siguieron lengua mapuche, guaraní, etc. Se intentaba formar estudiantes desde la cosmovisión indígena y pluricultural, y abrir las puertas para la inserción de las comunidades y los pueblos ancestrales en nuestros claustros académicos.
También se realizaron las muestras de Cine Indígena en el marco del «Festival de Cine Indígena BAIn». Con la participación de la comunidad Qom de barrio Malvinas y de la comunidad Quechua de La Plata, el grupo GUíAs (Universitarios de Investigación en Antropología Social de La Plata), representantes de diversas comunidades indígenas y realizadores audiovisuales de las comunidades indígenas, se buscó promover la visualización de las problemáticas indígenas, para comprender la cosmovisión indígena y difundir producciones culturales en relación con los pueblos indígenas.

Realizamos muestras, talleres, presentaciones audiovisuales, conversatorios, talleres de capacitación con docentes de la cátedra Audiovisual I y realizadores adolescentes de la Comunidad Qom y de la Comunidad Quechua de La Plata. En 2013, también presentamos la muestra fotográfica «Prisioneros de guerra», a cargo del colectivo GUíAs, días durante los cuales la Facultad era literalmente tomada por las comunidades.

\section{Diversidad sexual}

En 2010, la Facultad aprobó la creación del Observatorio de Comunicación, Género y Diversidad con perspectiva en Derechos Humanos, bajo la órbita de la Secretaría y con Claudia Vásquez Haro como directora. El objetivo fundamental era observar las cuestiones relacionadas con el género desde las producciones mediáticas como forma de cotejar las distintas posturas que en ellas se exponen y de promover, a través del análisis de diarios locales y nacionales, el respeto por la diversidad sexual a fin de garantizar un lenguaje periodístico no discriminatorio.

En 2012, el Observatorio formó parte de la organización del V Encuentro Nacional de Periodistas Argentinos en Red (Red Par) que se desarrolló en nuestra Facultad con el objetivo de destacar y de promover la producción de notas periodísticas no sexistas y de concientizar sobre cómo la falta de formación en perspectiva de género reproduce notas con discursos dominantes hegemónicos y desiguales.

Las políticas de género son un tema central en la agenda de discusión de la UNLP y, muy especialmente, en la Facultad de Periodismo y Comunicación Social. En este sentido, podemos mencionar una política impulsada en 2012 por nuestra decana, Florencia Saintout, para implementar los baños mixtos, que acompañó la entrada en vigencia de la Ley Nacional 26743 de Identidad de Género. Este eje estaba absolutamente consolidado de la mano de Claudia Vásquez Haro, que ya era una referente que excedía nuestra institución, secundada por otres compañeres que militaban la diversidad en la Facultad, con gran incidencia y acompañamiento en la comunidad trans de nuestra ciudad y el país.

Nuevamente, es fundamental mencionar el contexto de una política nacional que bajo la presidencia de Cristina Fernández aprobó, en 2010, la Ley Nacional 26618 de Matrimonio igualitario, que permite el casamiento entre personas del mismo sexo y, en 2012, la mencionada Ley Nacional 26743 de Identidad de Género, que permite el nombre de género 
autopercibido en el DNI, lo que nos permitía, además, ser uno de los países más avanzados en este tipo de reconocimiento.

Ese mismo año, Claudia me invitó a la entrega de diplomas del taller literario que había dictado, denominado «En el papel todas somos tinta», con el objetivo de propiciar un espacio donde se brinden herramientas comunicacionales para escribir textos tanto ficcionales como periodísticos que potencien la posibilidad de constituir las propias identidades desde el espacio de la escritura y de la academia, toda una síntesis de la política que se llevaba adelante. En un aula repleta, fue impactante ver la emoción que tenían las compañeras de la comunidad trans al mostrar su diploma en una universidad pública.

En 2013 tuvo lugar un hecho clave en la historia de la Facultad y de su inserción en la comunidad de La Plata. En abril, luego de intensas lluvias y gran ausencia de infraestructura municipal, se produjo la inundación más grave de la historia de la ciudad, que dejó un saldo de 51 víctimas mortales y cientos de miles de damnificados. La Facultad se convirtió en un centro de evacuados, de recepción y de entrega de donaciones, por lo que el inicio de las clases, previsto para el 15 de abril, debió postergarse, así como las mesas de examen, las inscripciones y las actividades administrativas. Inclusive, nos visitó la presidenta de la Nación, quien se admiró del trabajo y destacó la organización de les jóvenes frente al hecho. La solidaridad y la disposición de la Facultad en aquella catástrofe marcaron un antes y un después en la trama urbana de la ciudad de La Plata.

También para entender el lugar y el posicionamiento político de la Facultad dentro de la ciudad y de la universidad hay que mencionar las visitas de tres presidentes latinoamericanos fundamentales en el desarrollo del proceso político de la región en aquellos tiempos. La Facultad entregó los premios Rodolfo Walsh a Evo Morales, presidente de Bolivia, en 2009 (nos visitó también en 2013); a Hugo Chávez, presidente de Venezuela, en 2011; y a Rafael Correa, presidente de Ecuador, en 2012. Esto también era un desafío para la política de derechos humanos de la Facultad, ahora absolutamente vinculada a la militancia por un proyecto político de ciudad, de país y de «Patria grande», liderado por Cristina Fernández de Kirchner en el país y por Florencia Saintout en la ciudad de La Plata.

Entiendo que el resultado de la gestión seguía siendo satisfactorio, prueba de ello es el ofrecimiento de las autoridades de la Facultad para que continuara a cargo de este espacio en el siguiente período. La intensidad y la profundización de la política se habían logrado con un gran compromiso y con mucho trabajo por parte de la Secretaría. Simultáneamente, era muy visible la madurez de sus diferentes áreas, cuyos responsables conducían política y estratégicamente.

Debe destacarse que, para este entonces, la política de derechos humanos había crecido en todos los ámbitos institucionales de la Facultad, por lo que la Secretaría no tenía la centralidad en el desarrollo de todos estos procesos. El presupuesto continuaba representando un obstáculo, pero con mucha militancia salimos adelante.
Seguíamos siendo un espacio de referencia cada vez más importante, tanto para la UNLP como para los organismos, las organizaciones, los sindicatos y la militancia. En este contexto, el proyecto político nacional en materia de derechos humanos era un plafón y significaba un empuje muy importante... Lo que no imaginábamos era que se acercaba el fin de un ciclo. 


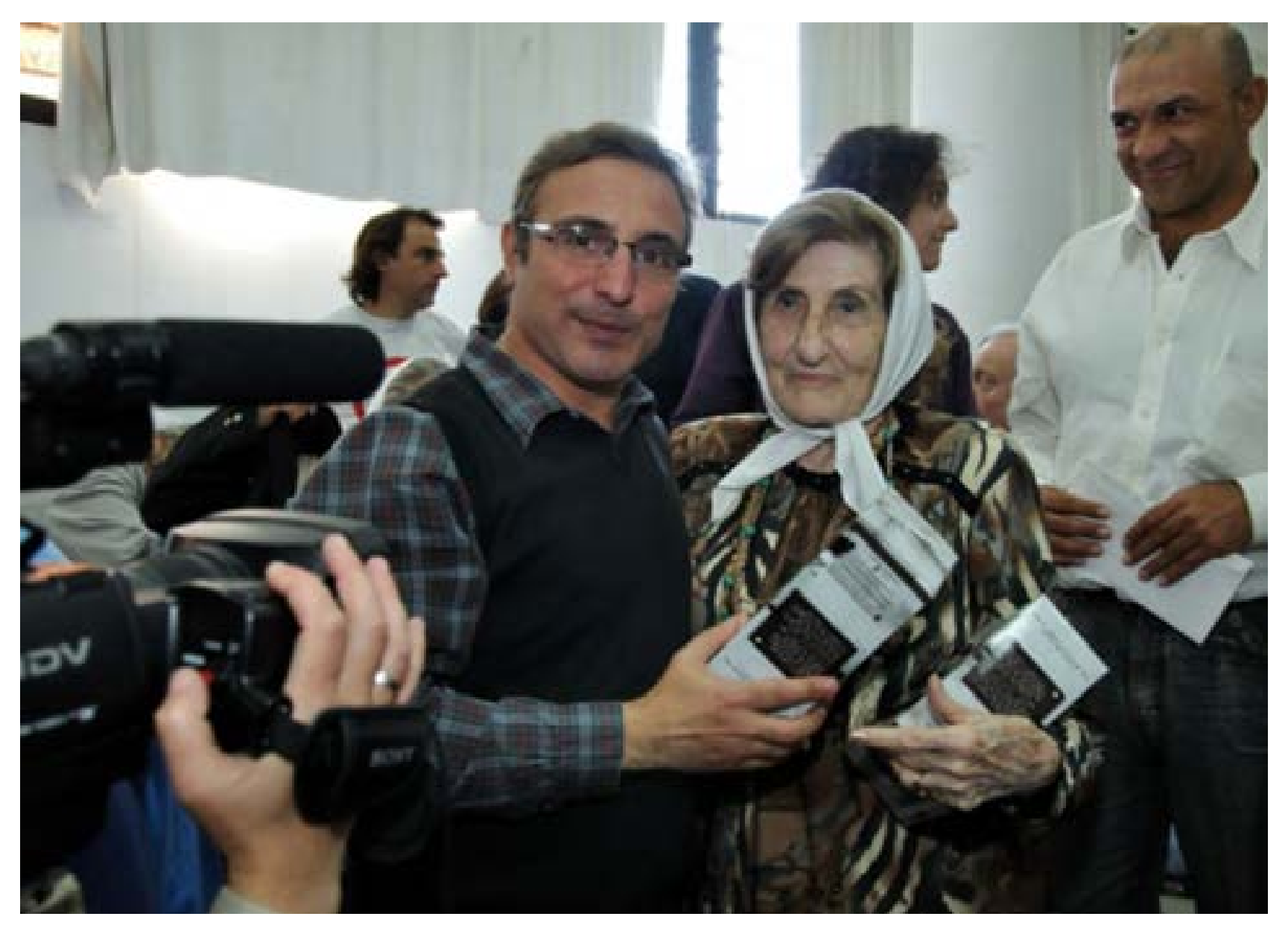

196

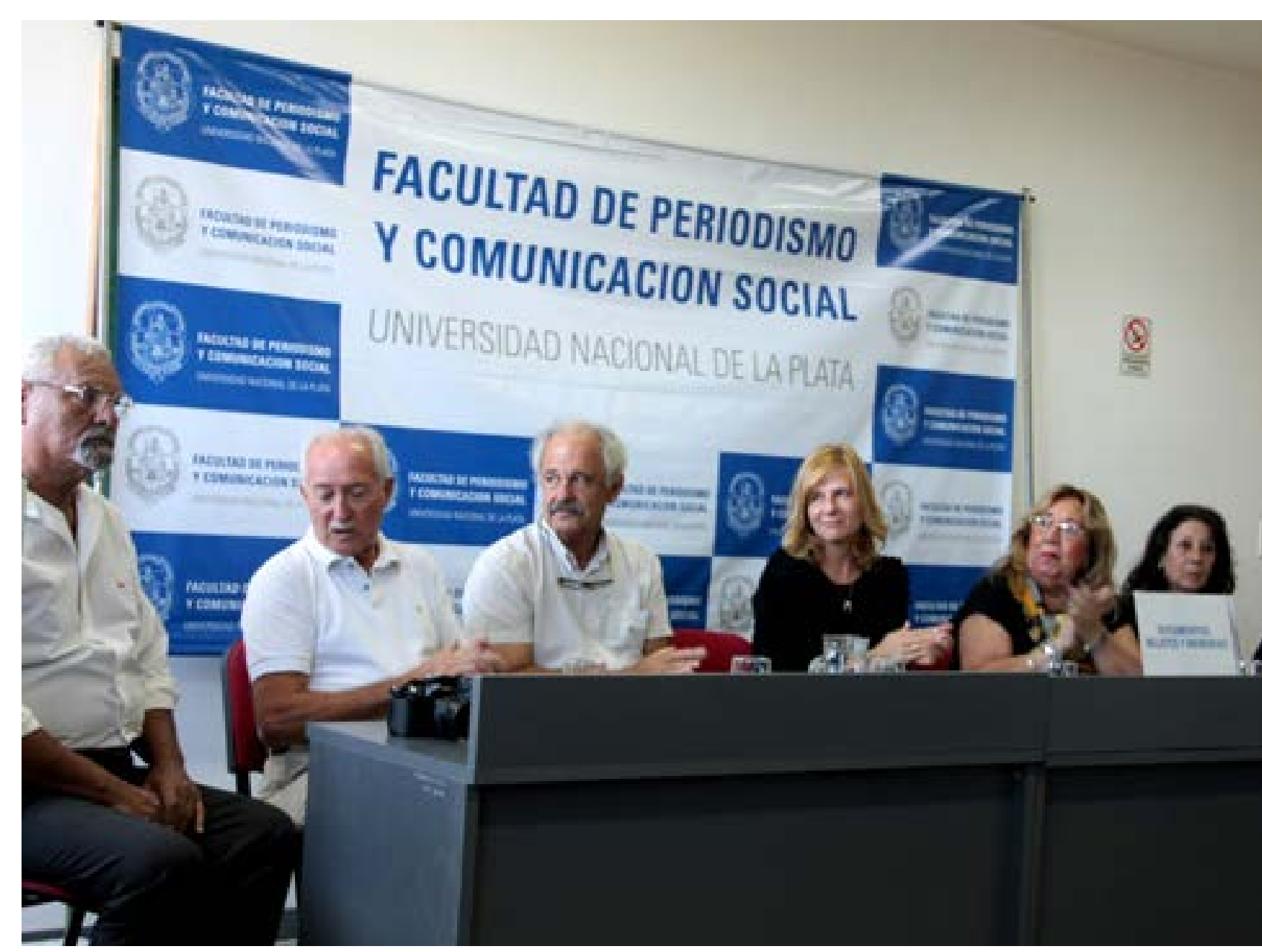

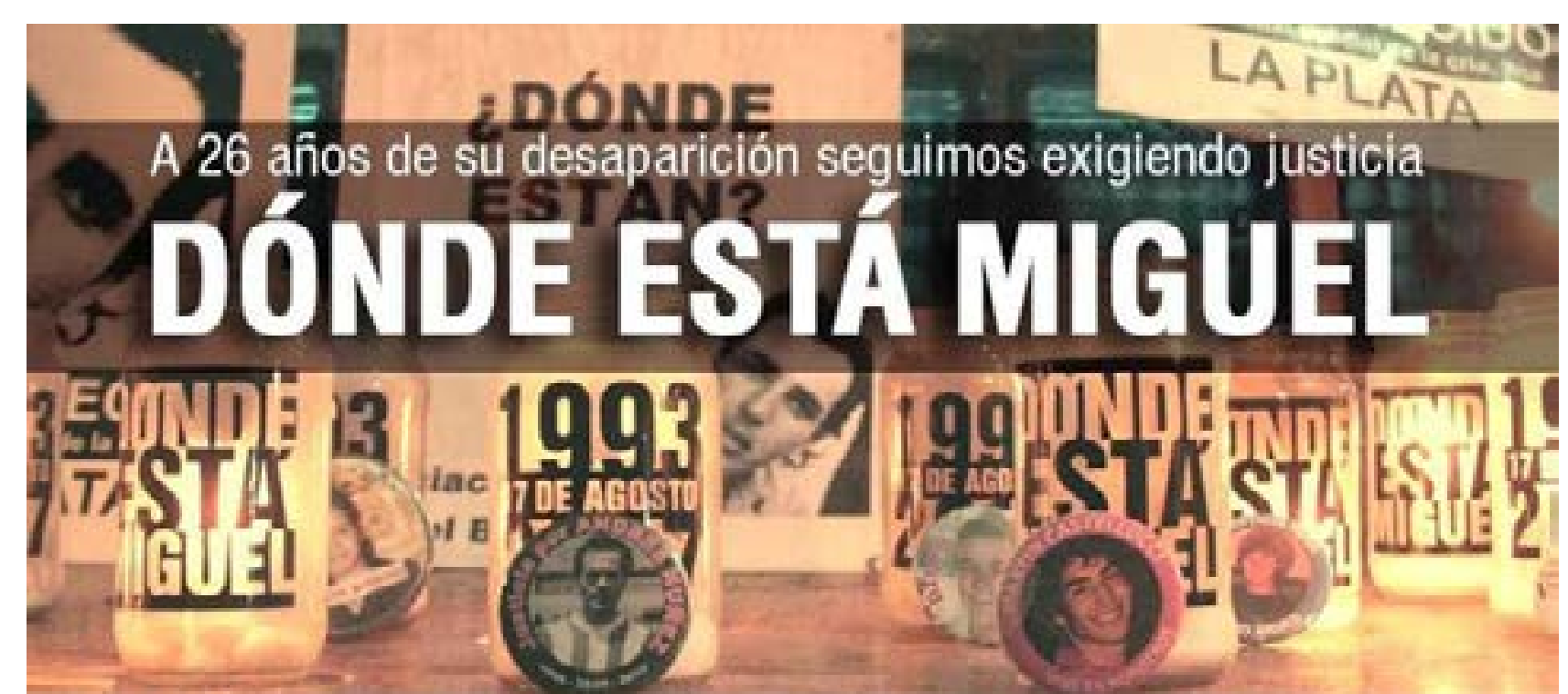

Vigilia 17/8. Comisaria Novena (5 y 59). 19hs a 2 am Radio abierta. Proyecciones. Muestras. Bandas en Vivo

\section{BASTA DE VIOLENCIA INSTITUCIONAL}
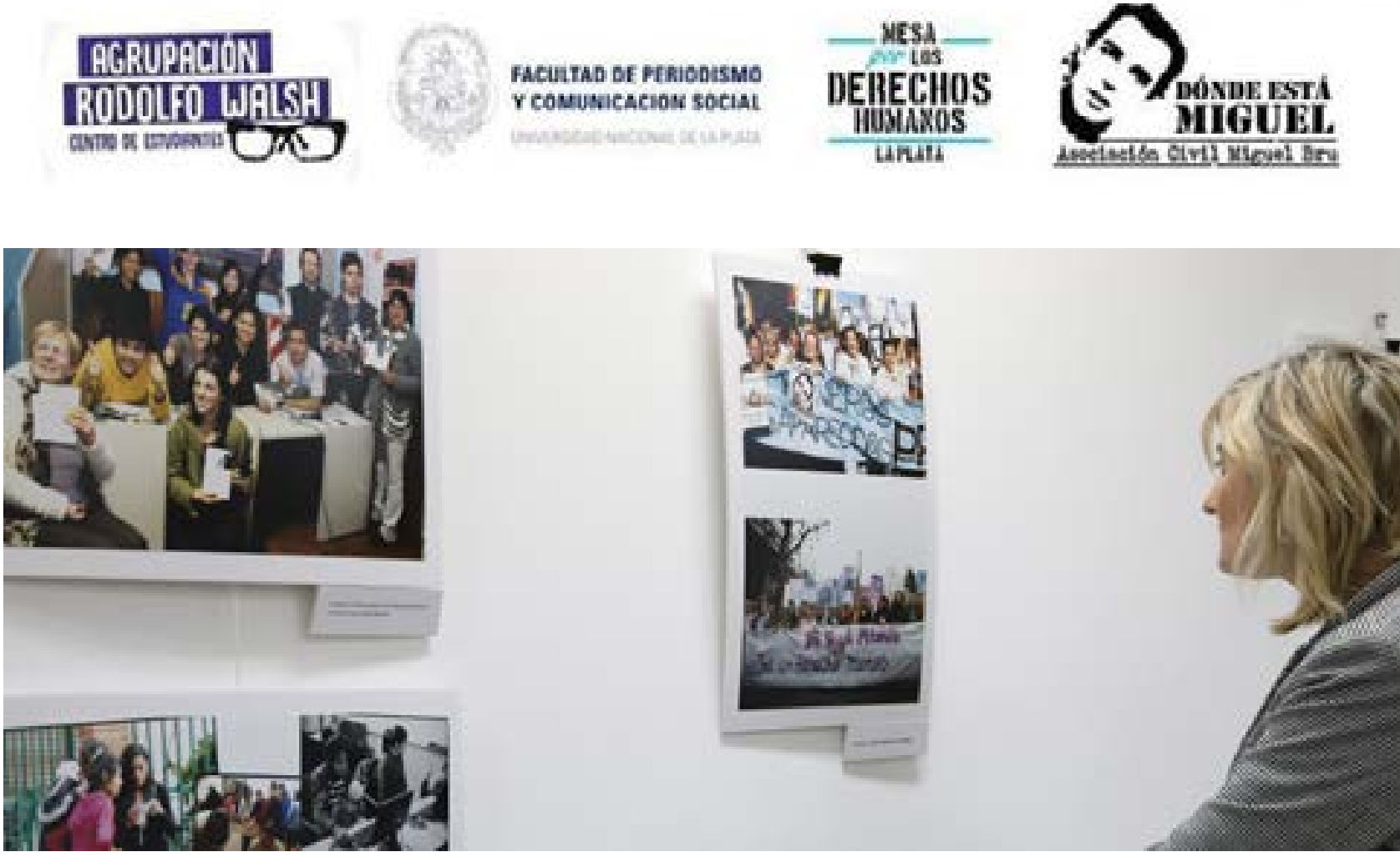

Con Adelina Alaye, Madre de Plaza de Mayo de La Plata, en la presentación del proyecto "Madres y Abuelas de Plaza de Mayo, Relatos del Futuro".2.Disertación en la FP y CS con Roberto Soria, Hugo Biasotti y Beatriz Blanco ex alumnes que sobrevivieron a la dictadura y Manuel Pedreira, hermano de Rafael Pedreira alumno de periodismo desaparecido por la dictadura cívico militar eclesiástica.3.Afiche de la vigilia por Miguel Bru en la Comisaría 9a de La Plata.4.Andrea Varela, decana de la Facultad de Periodismo, mirando la muestra fotográfica "¿Dónde está Miguel? 25 años", sobre Miguel Bru, realizada por la AMB, la Secretaría de Extensión de la UNLP y la FP y CS, a 25 años de su desaparición y expuesta en la facultad. 

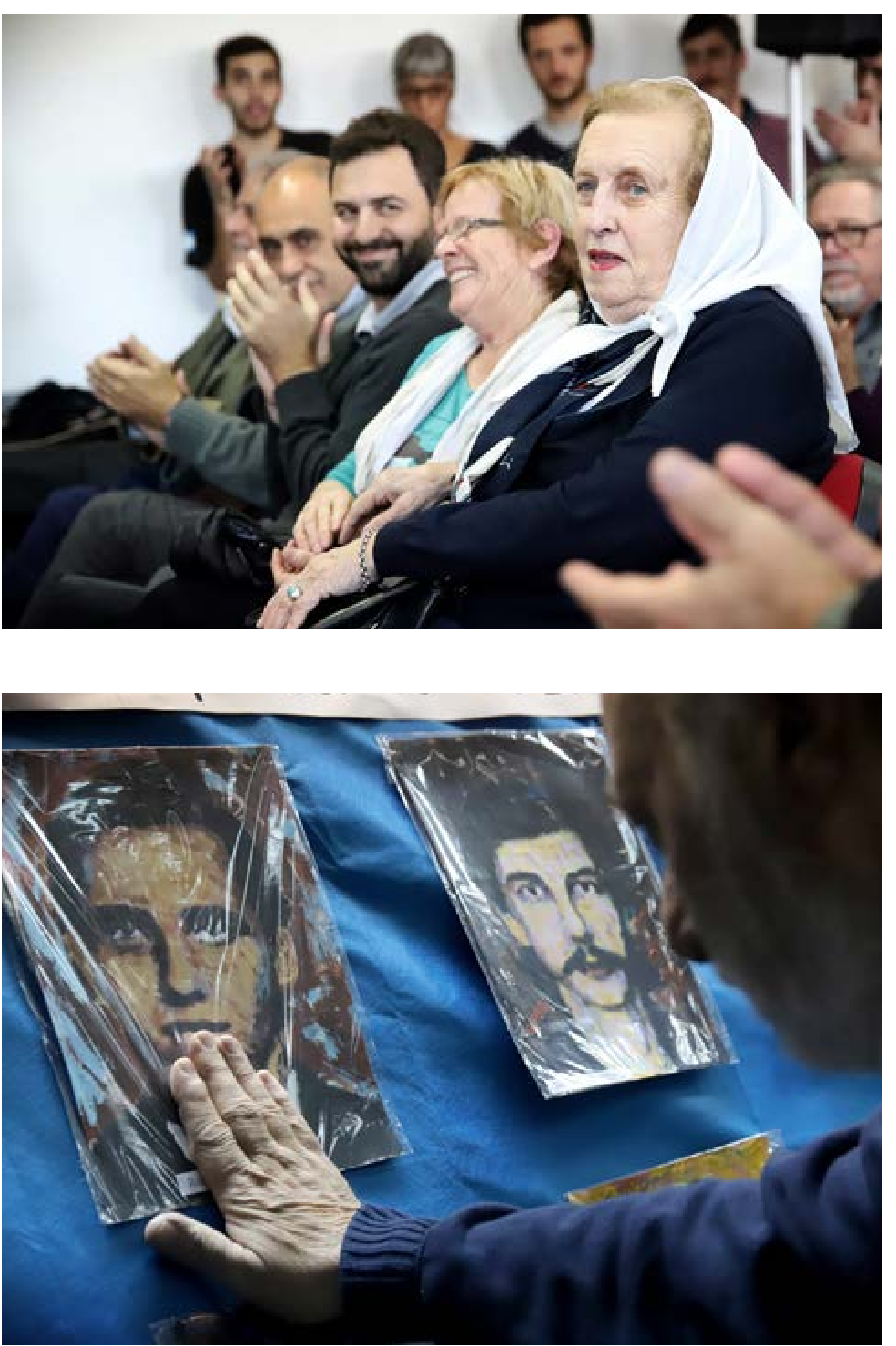

HEBE NOS ENTREGA

EL PAÑUELO DE LAS MADRES
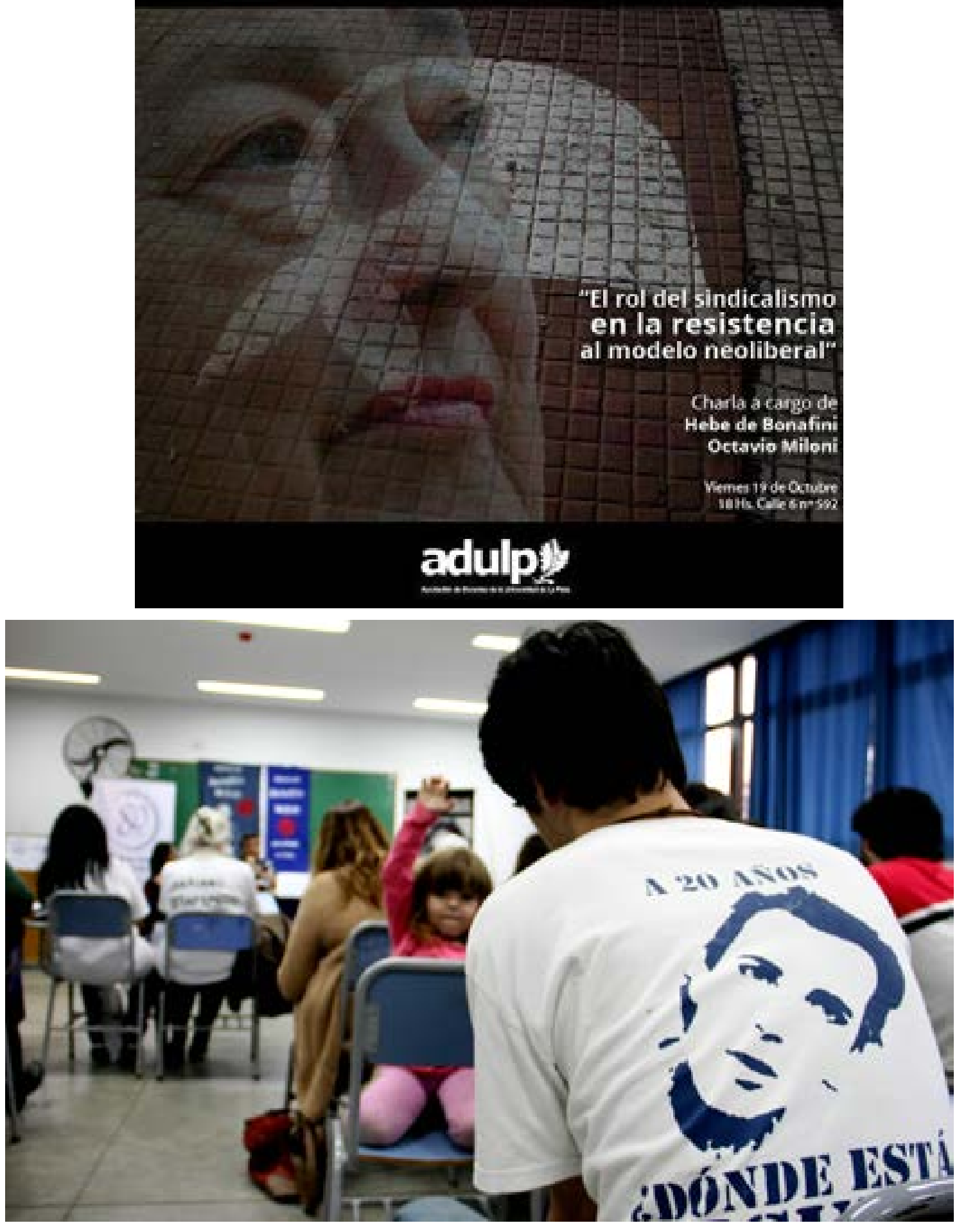

5.Leonardo Fossati, nieto de identidad restituida y miembro de Abuelas de Plaza de Mayo, Rosa Bru y . 6 familiar de demorecido de la FP y CS acariciando el dibujo de la foto, hecho por el pertis Brismo.6. familar de desaparcicio de lá Carlson, con motivo de la reparación de legajos en la $\mathrm{FP}$ y CS.7.Acto con Hebe Bonafni en el sindicato aDUL, cuando nos regaló las baldosas con el pañuelo pintado orighnarias de la Plaza de Mayo en la ciu(a de Bu ese año (a 20 años de su desaparición) de la conducción del Centro de Estudiantes de la FP y CS. 

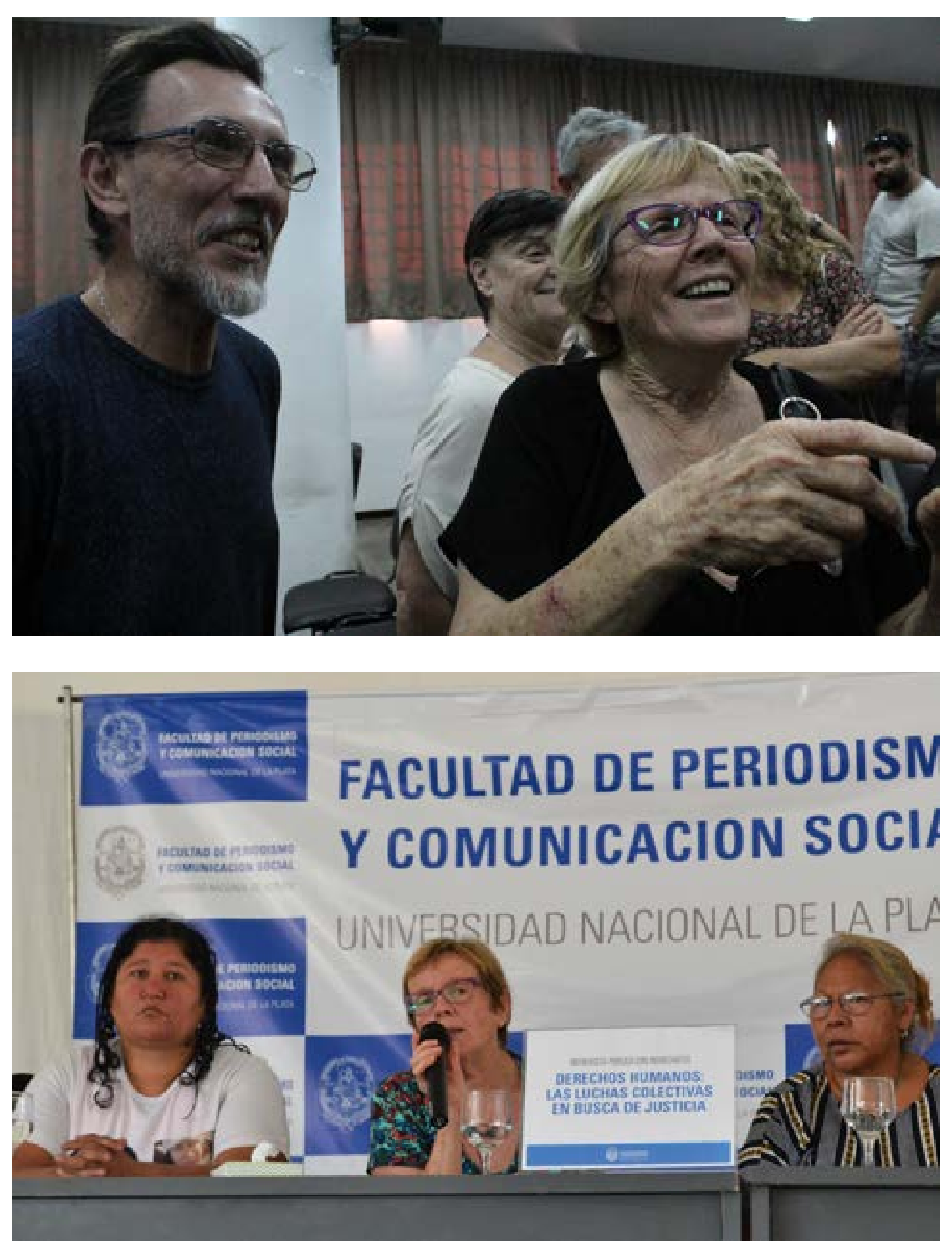

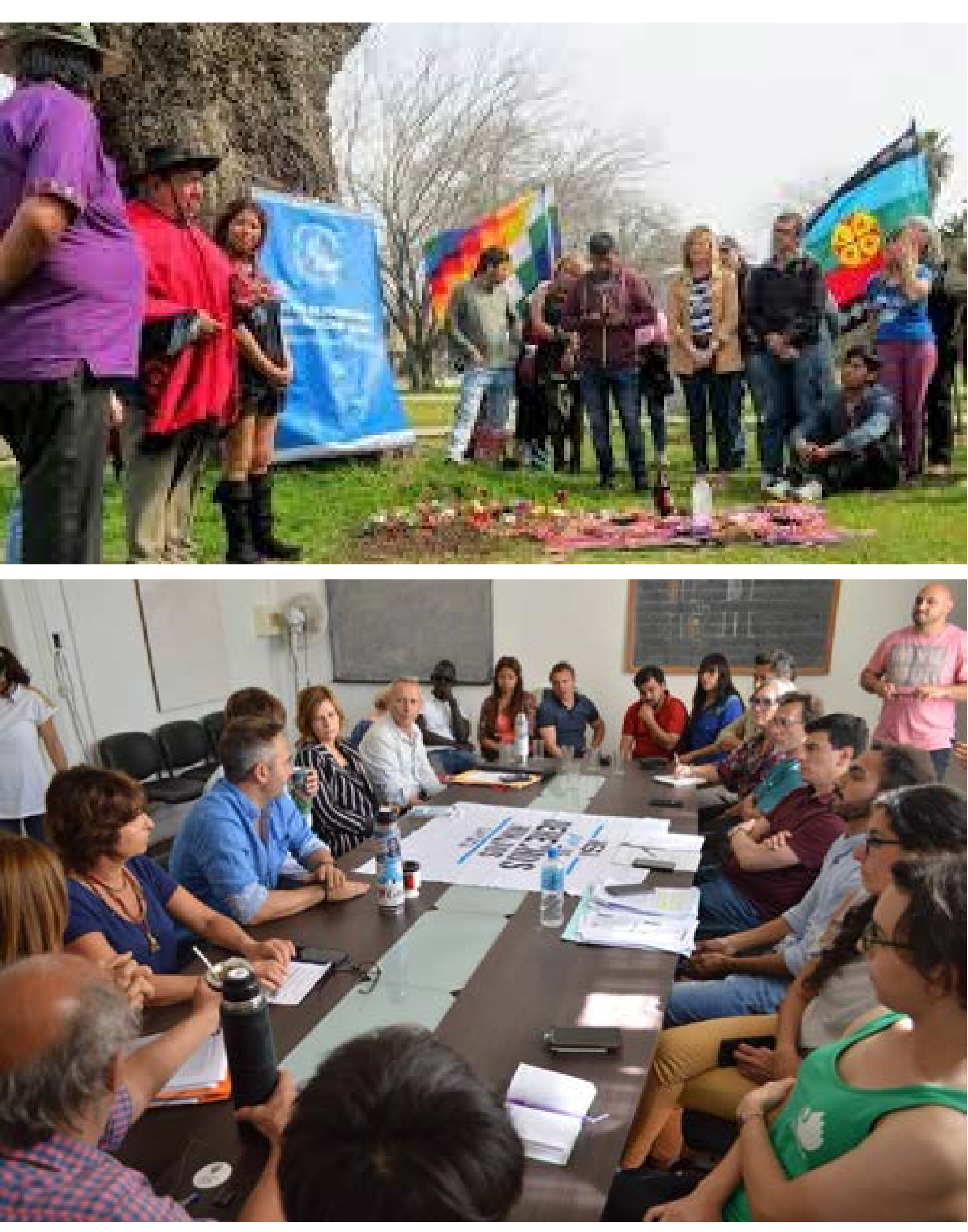

Rubén López, hijo del desaparecido Jorge Julio López, junto a Rosa Bru en una charla en la FP y CS.2. Marta Ramallo, mamá de Johana, asesinada víctima de trata de la ciudad de La Plata, Rosa Bru y Eugenia Uscamayta, mamá de Emilia, víctima de un hecho de negligencia en una fiesta clandestina en donde está involucrada la Municipalidad de la Plata de la gestión de Cambiemos y empresarios de la noche platense.3.Ceremonia en la Chakana (cruz Andina) en el patio de la sede Néstor Kirchner de la
FP y CS.4.Charla con concejales de la Municipalidad de La Plata, de la Mesa de DDHH de la ciudad de La Plata, Berisso, Ensenada (de la cual forma parte la FP y CS) oponiéndonos al código de convivencia que pretendía impulsar el bloque oficialista de la Alianza Cambiemos. 

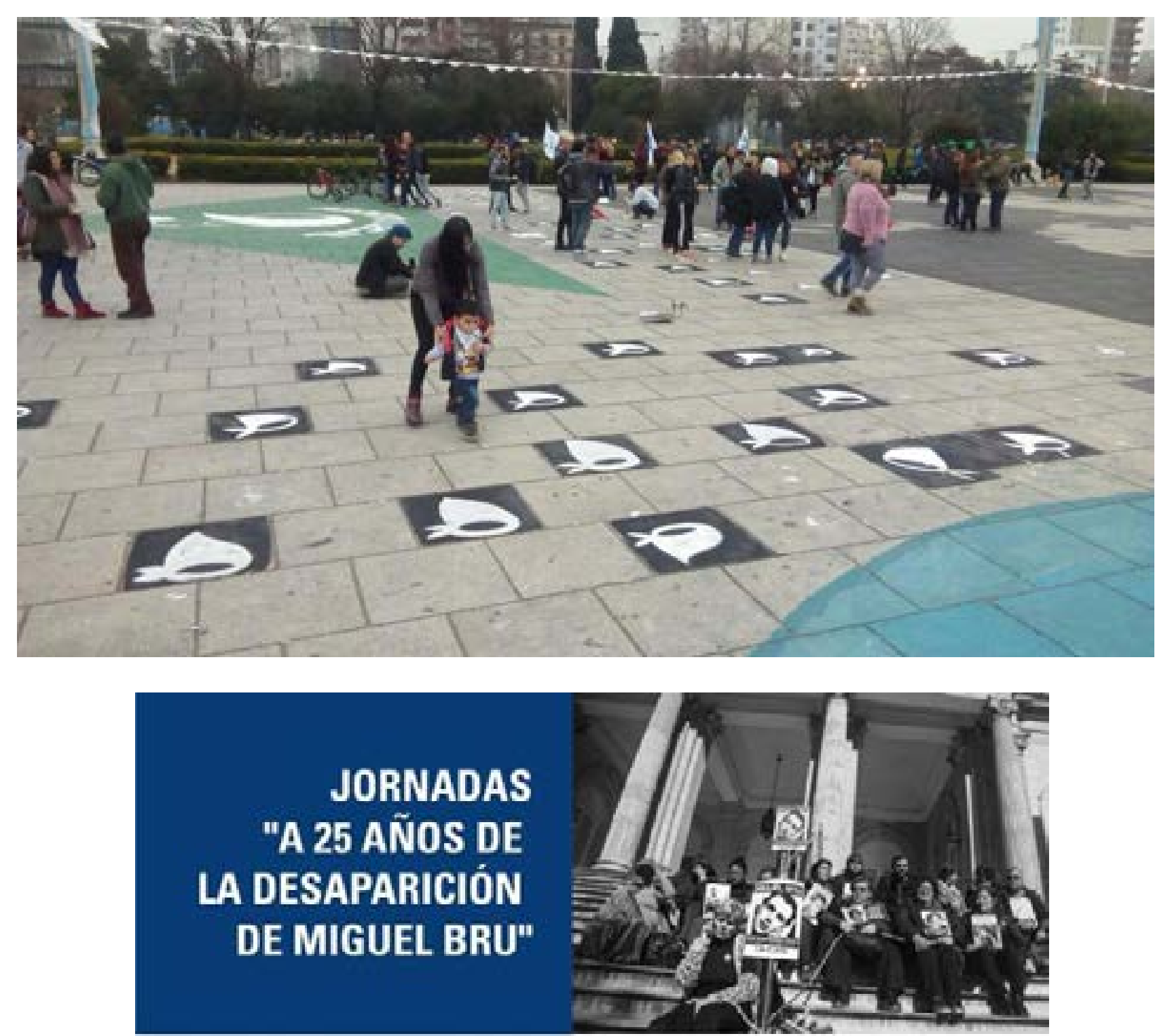

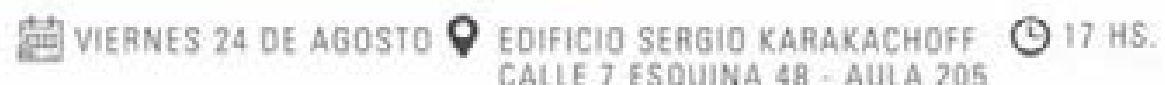

PANEL: "A 25 AÑOS DE

LA DESAPARICION

DE MIGUEL BRU.

LA VIOLENCIA INSTITUCIONAL

EN TIEMPOS DE AVANZADA

NEOLIBERAL

MUESTRA DE

MOTOS DONDE

ESTA MIGUEL.

25 ANOS

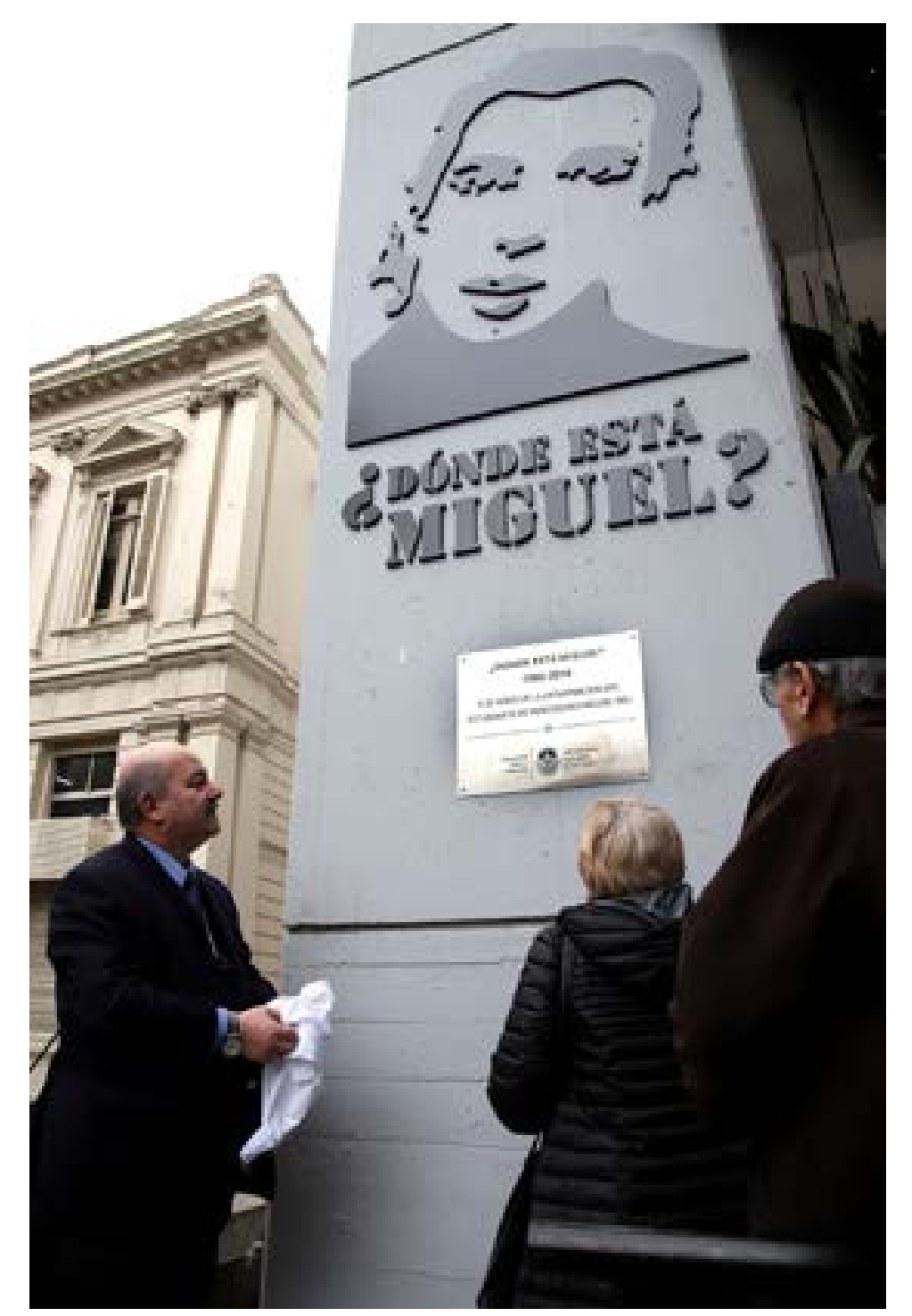

1.Pintando los pañuelos de las Madres de Plaza de Mayo, en Plaza Moreno, con la FP y CS y la Mesa por los DDHH de La Plata, reclamando contra las politicas negacionistas de la Alianza gobernante Cambiemos.2.Afiche de las jornadas or los 25 años de la desaparición de Miguel Bru.3. El rector de la UNLP Fernando Tauber augurando con Rosa y Nestor Bru la imagen de Miguel en la fachada del edificio Karakachof en el rectorado a los 25 años de su desaparición.4. Inauguración en la Facultad de la muestra de Fotos ¿Dónde está Miguel? 25 años, con Andrea Varela la decana, Rosa Bru y su nieta Abril y Gabriela Hernández, fotógrafa y miembro de la AMB.

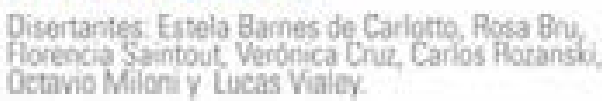

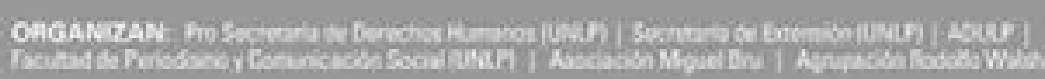

P.

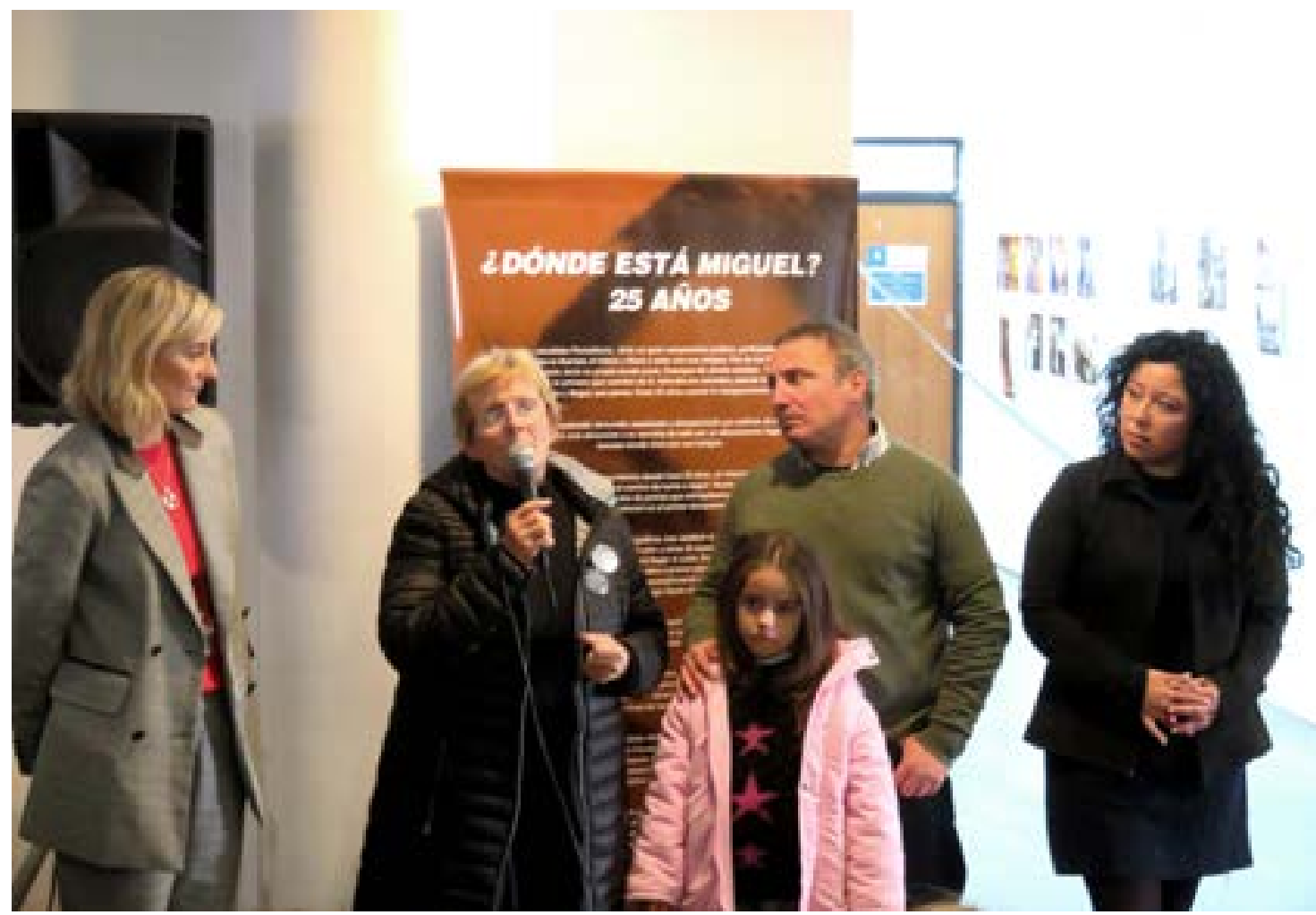



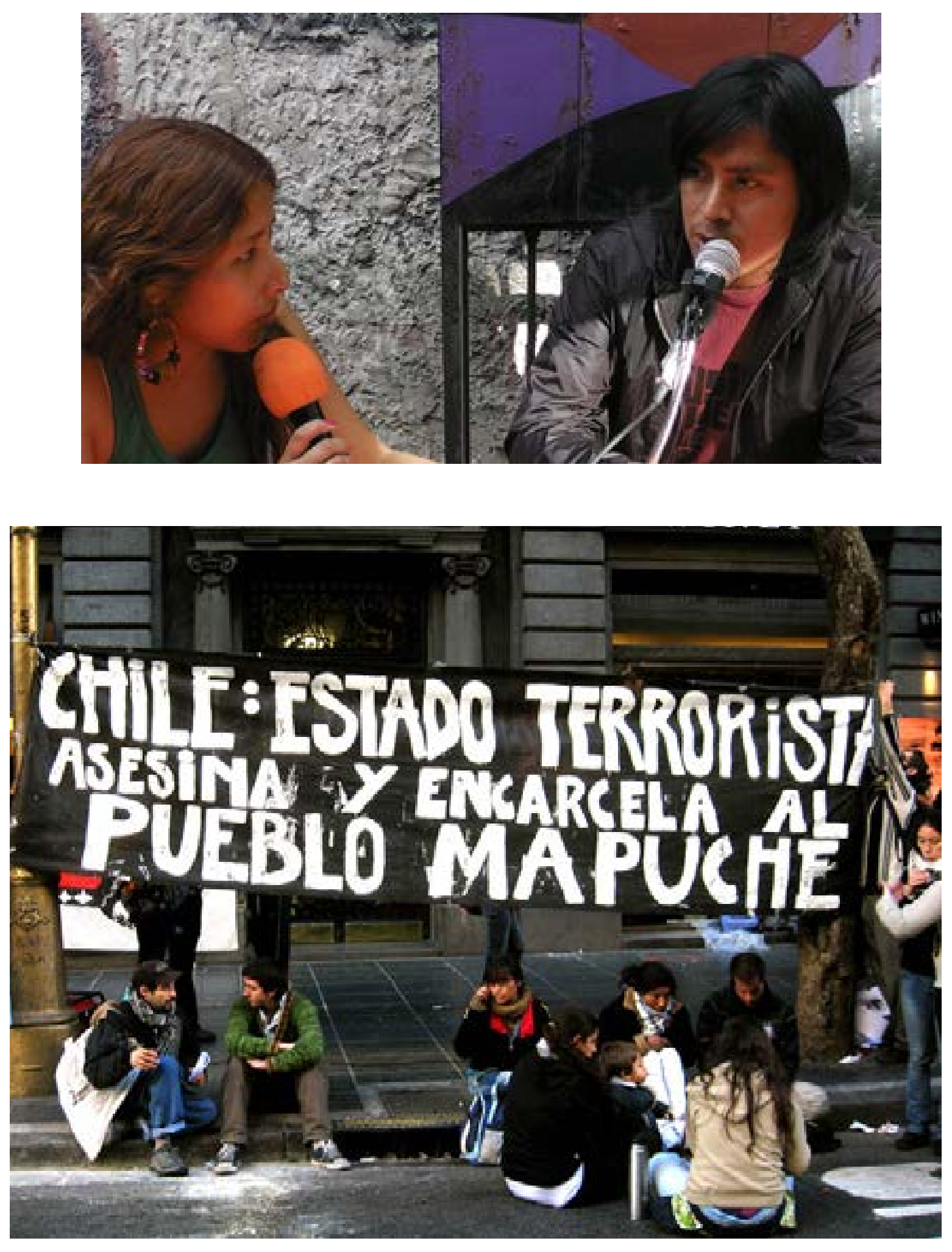
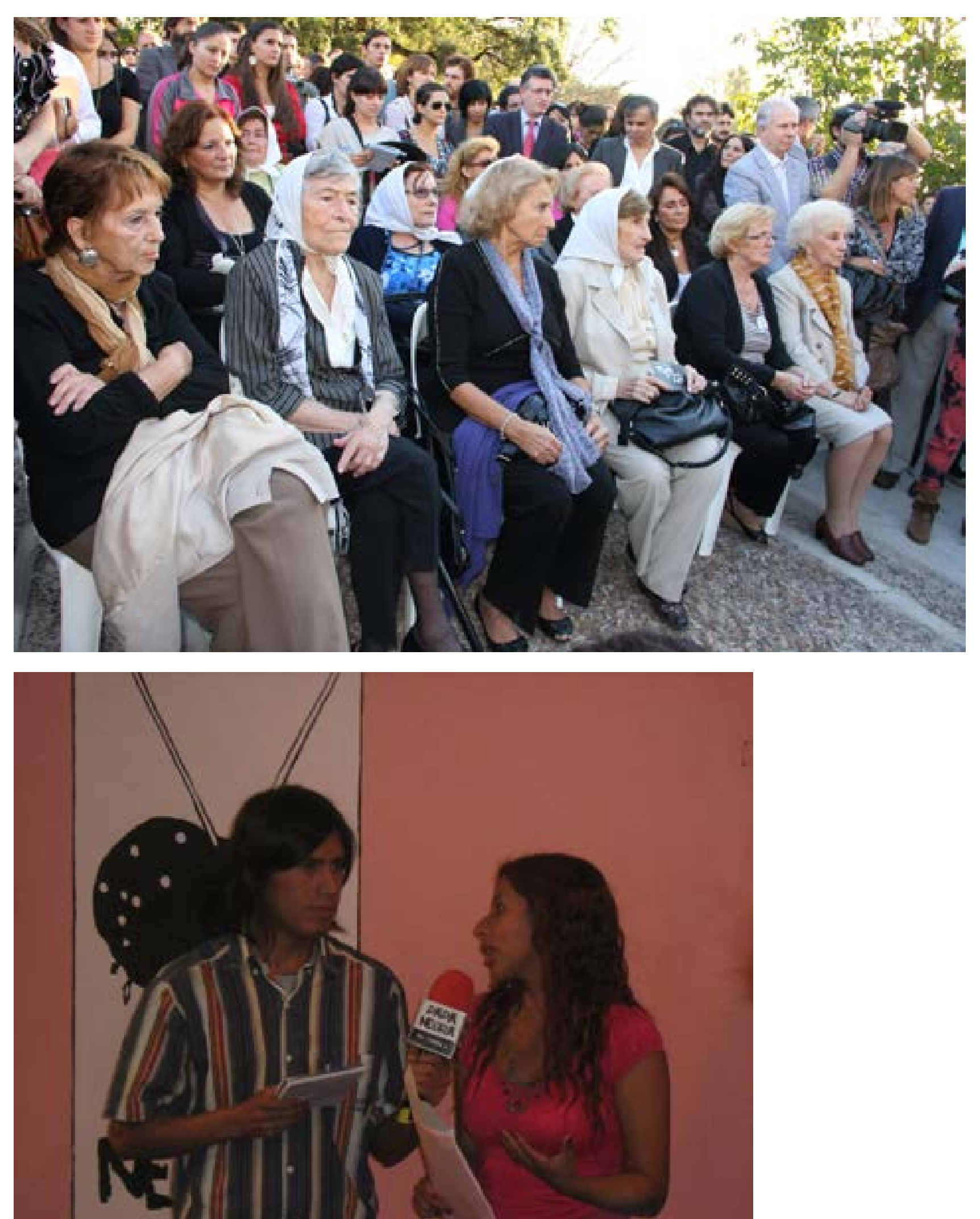

1 y 4. Pascual Pichún Collonao, compañero Mapuche y Zulema Enriquez, compañera Quechua, referentes de Pueblos Indígenas que condujeron esa temática en la facultad.2. Movilización al consulado chileno en Buenos Aires pidiendo la liberación de nuestro alumno Pascual y los presos mapuches en Chile 3 Inauguración del monolito (construido por Néstor papá de Miguel Bru) a les desaparecidos por el Terrorismo de Estado, con (consencia de Madres y Abuelas de Plaza de Mayo, familiares de víctimas, Rosa Bru, referentes de DDHH y comunidad académica. 


\section{REFLEXIONES FINALES}

\section{EL ROL DE LA UNIVERSIDAD PÚBLICA EN MATERIA}

\section{DE POLÍTICAS PÚBLICAS EN DERECHOS HUMANOS}

Este capítulo se propone articular lo desarrollado en los apartados precedentes con el objetivo de poner en común algunas líneas de reflexión que emergen de este proceso investigativo, el cual, como señalamos, se pregunta acerca de las relaciones entre los derechos humanos, la comunicación, las políticas públicas y la universidad.

Esta tesis se produjo a partir de analizar un caso concreto, es decir, no es meramente teórica sino que la teoría nos habilitó a relatar una práctica de gestión. Por ello, no pretendemos que las conclusiones sean verdades absolutas, sino pistas que puedan orientarnos hacia un futuro mejor, con nuevos aprendizajes, que permitan lograr mejores gestiones que redunden en mejores políticas públicas en derechos humanos. Asimismo, buscamos promover inquietudes a verificar en otros casos y que inspiren nuevas prácticas.

Cuando hablamos de políticas públicas, nos referimos a las que ejecuta el Estado, una ejecución que desde nuestro proyecto político académico se produce a través del diálogo de saberes con la heterogeneidad de sectores sociales. Es necesario poder ejercer el derecho a la universidad a través de una política inclusiva, mediante la cual los diversos colectivos tengan acceso a los claustros académicos y puedan ejercer el derecho a la educación. La misión esencial es generar políticas públicas que contribuyan a mejorar la calidad de vida de los diversos sectores de la sociedad, apuntando, fundamentalmente, a aquellos que históricamente no han accedido a esas posibilidades.

A partir de la lectura de la tesis, podemos afirmar que para las políticas públicas en derechos humanos ejecutadas desde la universidad el diálogo de saberes es una estrategia clave. Al mismo tiempo, siguiendo los lineamientos de la Maestría PLANGESCO, también estos procesos de diálogo son centrales para la producción de conocimientos acerca de procesos de planificación y de gestión, en donde todas las personas son reconocidas como sujetos de conocimiento. Los saberes producidos por elles en torno a sus diferentes realidades, experiencias y biografías, son valorados como fundamentales para la producción de nuevos saberes. Esta puesta en valor se genera a partir de procesos de diálogo que permiten el intercambio de percepciones y de sentidos, así como la producción y la puesta en común de nuevas síntesis que construyen nuevas perspectivas y que dinamizan la relación universidad / políticas públicas / derechos humanos.

Una cuestión que quiero destacar al inicio de estas reflexiones, se relaciona con el uso operativo de la sistematización de experiencias propuesta por Oscar Jara Holliday. Esta metodología intenta distinguir aspectos reflexivos y estratégicos de una práctica vivenciada concretamente por un grupo de personas que aportaron al proceso investigativo. Asimismo, fue valioso el uso práctico de la matriz de sistematización, compuesta a partir de la reconstrucción de datos provenientes de las prácticas más significativas distinguidas a lo largo de la tesis. En su construcción, la intención siempre fue potenciar aprendizajes útiles, relevantes, sobre la base de procesos de comunicación que intentan dar cuenta de las experiencias para ponerlas en común, para llevar a cabo intercambios con otras experiencias y para propiciar el diálogo entre los conceptos y las estrategias que promueven las prácticas. Esto permite, en palabras de Germán Retola (2018), «conocer las prácticas situadas en territorios y en territorialidades concretas para transformarlas, ponerlas en común con otras prácticas e impactar en la construcción del espacio público» (p. 202).

Para llevar adelante una política pública real y efectiva de construcción de derechos, que se materialice y que favorezca el proceso, es fundamental la construcción de nuevas políticas y la obligación de los Estados de llevarlas adelante. Como bien lo plantean Martín Grass, Víctor Abramovich y Eduardo Luis Duhalde, se trata de «una creación conjunta en la que debe participar el Estado y la totalidad de los miembros de la sociedad en una política de protección y de reparación, pero, además y muy fundamentalmente, en una política activa de construcción de derechos» (Duhalde, 2007, p. 32).

En esta línea de pensamiento, este proyecto político académico de gestión consolidó aprendizajes que son rescatados en la sistematización y retomados en estas conclusiones. Producto de este proceso, podemos decir que en la construcción de políticas públicas de derechos humanos desde la universidad, se deben considerar los siguientes lineamientos:

- Trabajar en nuevas narrativas con perspectiva en derechos humanos.

- Desarrollar procesos de memoria y de búsqueda de justicia en relación con la última Dictadura cívico militar eclesiástica.

- Abordar nuevas temáticas en materia de derechos humanos que se dan en el territorio.

- Trabajar las diversidades y las disidencias.

- Incorporar la perspectiva feminista.

- Garantizar políticas de inclusión educativa en el acceso a la universidad como un derecho.

- Incorporar otras cosmovisiones y lenguajes al mundo académico.

\section{Trabajar en nuevas narrativas}

\section{con perspectiva en derechos humanos}

En materia de nuestra disciplina específica, el periodismo y la comunicación, es relevante que formemos profesionales capaces de construir relatos periodísticos con una perspectiva inclusiva, con alternativas diferentes en cuanto a la búsqueda de fuentes, de contextos, de asesoramiento con especialistas y de inclusión de protagonistas, para la producción 
de noticias informativas que aporten nuevos marcos de lectura y no repliquen los perfiles estigmatizantes que solemos encontrar en los medios de comunicación masiva.

Asimismo, es fundamental aportar al mejoramiento de las prácticas comunicacionales en la organización colectiva de reclamos de justicias, así como promover la difusión sobre denuncias de violaciones a los derechos humanos. En otras disciplinas, en tanto, y según las territorialidades que cada unidad académica construye, se debe formar en los mismos sentidos, lo que significaría un importante aporte para la articulación y la formación interdisciplinaria

\section{Desarrollar procesos de memoria y de búsqueda de justicia}

\section{en relación con la última Dictadura cívico militar eclesiástica}

Es relevante que todas las áreas de gestión de derechos humanos y la currícula académica de las distintas universidades estén atravesadas y trabajen sobre el pasado reciente en materia de derechos humanos, abordando lo acontecido con el terrorismo de Estado como un eje institucional de formación. Para ello, es necesario recopilar datos, historias de vida, y hacer circular narraciones de compañeres de militancia, de facultad, de familiares; generar actividades con organismos de derechos humanos, instituciones del Estado, organizaciones sociales y militancia; construir obras artísticas, murales, monumentos; realizar actos, publicaciones, trabajos prácticos y tesis, talleres de capacitación; construir áreas de gestión y generar proyectos de investigación y de extensión; participar en las diversas formas de reclamos de justicia y de intervenciones en el espacio urbano; desarrollar ejes temáticos en programas de cátedra de grado y de posgrado.

En la medida en que se pueda articular de manera interdisciplinaria con otras unidades académicas, estos espacios se verán muy fortalecidos.

\section{Abordar nuevas temáticas en materia}

\section{de derechos humanos que se dan en el territorio}

Es relevante que las áreas de gestión de derechos humanos en ámbitos universitarios sean sensibles a las nuevas problemáticas que tienen lugar en los territorios. Por ejemplo, en nuestra sistematización, la temática referida a la violencia institucional fue considerada como uno de los flagelos más importantes que sufre la sociedad en materia de derechos humanos desde la apertura democrática, especialmente, en los territorios más excluidos de la distribución de la riqueza.

Para esto, es clave producir nuevas narrativas comunicacionales sobre los contextos de las situaciones delictivas; abordar la problemática de la seguridad / inseguridad con una perspectiva de derechos y no estigmatizante; consultar fuentes informativas que no sean solo el poder judicial / policial o la víctima directa de un delito; valorar los testimonios de familiares de víctimas de la violencia institucional; y dar cuenta de las nuevas formas organizativas de los procesos de búsqueda de justicia en estas situaciones. Los claustros académicos, por su parte, deben incluir a las víctimas y a les referentes en debates, en jornadas y en procesos de memoria.

\section{Trabajar las diversidades y las disidencias}

Como se desprende del proceso sistematizado, en la construcción de la política universitaria es necesario incorporar como un eje fundamental de trabajo la diversidad sexual y crear áreas concretas de gestión en este sentido. La multiplicación de los espacios institucionales vinculados a esta temática, deber ser acompañada de la adecuación de las normativas en sentido de igualdad de derechos en las actas administrativas (por ejemplo, mediante la declaración de la identidad de género), del establecimiento de políticas concretas (como fue, en nuestra Facultad, la creación de baños mixtos) y el acompañamiento en los reclamos de justicia, como modos de disputar sentidos contra la heteronormatividad, el patriarcado y la concepción binaria de género.

Un proceso que requiere ser acompañado de la edición de publicaciones, de la participación en eventos académicos y del trabajo sobre narrativas y lenguajes con perspectiva de género y diversidad, como estrategias y formas de lucha que disputen los sentidos sociales.

\section{Incorporar la perspectiva feminista}

En línea con lo anterior, este eje debe contemplar la creación de áreas específicas de trabajo, el fomento de la paridad de género en cargos docentes, no docentes y de gestión la elaboración de normativas institucionales y la generación de debates que promuevan las deconstrucciones de sentido patriarcal. Asimismo, la incorporación de la perspectiva feminista (que, como muestra la sistematización, en el período analizado recién comenzaba a instalarse en la agenda universitaria, en nuestro caso, bajo la denominación de derechos de las mujeres), requiere de la creación y la promoción de protocolos institucionales que sancionen la violencia de género.

\section{Garantizar políticas de inclusión educativa} en el acceso a la universidad como un derecho

Es preciso ampliar el acceso a la universidad a diversos sectores que históricamente tuvieron vedada esa posibilidad: privades de libertad, trans y travestis, comunidades indígenas, población rural que vive lejos de los centros urbanos, entre otros sectores excluidos de la distribución de la riqueza. Se considera necesario, para esto, dictar talleres de comunicación, multiplicar la matrícula de estudiantes, crear programas de extensión educativa, promover convenios institucionales, ampliar los sistemas de becas, albergues, difundir producciones comunicacionales.

En tanto, se asume como fundamental señalar la importancia de invertir el tradicional 
concepto de extensión: no se trata solo de que la universidad vaya a los territorios, sino también de que los territorios accedan a la universidad, frente a lo cual es central generar políticas inclusivas que atraviesen la totalidad de los estamentos universitarios.

\section{Incorporar otras cosmovisiones y lenguajes al mundo académico}

Es necesario asumir a la universidad como una institución plurinacional y pluricultural en pos de nutrir de diversidad epistémica las aulas. Para esto, se debe incorporar y profundizar el trabajo con y sobre los pueblos indígenas, a partir del establecimiento de áreas de gestión específicas y de la articulación con diversas actividades. Asimismo, consideramos que resulta central contribuir y participar en las luchas por las reivindicaciones de derechos, y entendemos que es un elemento clave la institucionalización del idioma indígena en la currícula de las diferentes carreras.

En este punto, no podemos dejar de señalar que el tema presupuestario es una lucha histórica de la universidad pública. La inversión en ciencia y tecnología que tuvo lugar en el período analizado - sin dudas, la más importante de la historia- ${ }^{45}$ nos lleva a afirmar que para gestionar una política pública de esta naturaleza es fundamental que haya un acompañamiento presupuestario. De allí que resulte clave señalar, aunque no sea materia de análisis en esta sistematización, la profundidad del daño que lo vivenciado durante el periodo 2015-2019 ocasionó en el marco contextual de la gestión, llevándola a otros planos y escenarios de resistencia.

Quiero insistir en que cualquier área de gestión en derechos humanos de la universidad debe entender al concepto de comunicación como acción política. Es central, como se desprende del proceso de gestión analizado, considerar a la comunicación como un modo de vincularse, de poner en común, de compartir y de intercambiar; esto es, la comunicación construida desde el diálogo de saberes. Como se desprende de la Matriz de Sistematización la articulación con referentes, con protagonistas de los hechos, con sus historias y con las «otras voces, ideas, sentidos» (Arrúa, 2006), estuvieron presentes y fueron centrales en la construcción de la estrategia para la acción política.

Los diálogos de saberes y de perspectivas diversas para alcanzar síntesis novedosas y creativas entre sujetes de conocimiento que históricamente no tenían inserción en la construcción de la política universitaria fueron clave para este proceso de gestión. Así instituciones gubernamentales y no gubernamentales, organizaciones sociales y políticas, referentes en derechos humanos, diversos colectivos sociales, víctimas, militantes, especialistas, voluntaries, estudiantes, docentes, no docentes, gremios, diversas culturas y voces, fueron y son quienes nos iluminan el camino para aportar a la construcción de un mundo mejor y más justo desde la política pública universitaria. En este escenario, la comunicación, entendida como disputa por el sentido y como hecho cultural, como espacio

$45 \quad$ Una política que incluyó la construcción de 17 universidades, la repatriación de científicos y más de 1\% del PBI destinado a educación universitaria, entre otras medidas. de interacción entre sujetes, y como práctica social y epistémica, representa el espacio donde cada quien pone en juego sus posibilidades de construirse con otres.

Asimismo, cuando nos referimos a comunicación como acción política, también tenemos que hacer hincapié en la disputa por el sentido, no solo porque las políticas concretas mencionadas aportan a los espacios de disputa de los sentidos sociales, sino porque es necesario producir nuevas narrativas que aporten a la batalla cultural. ${ }^{46}$ La fuerza simbólica de la política de gestión está en los ejes cotidianos de trabajo, en les actores que intervienen, en la producción de narrativas, en las obras artísticas, en lo discursivo, en las producciones, en lo pedagógico. En palabras de Reguillo (1998):

El mejor antídoto contra la violación sistemática a los derechos humanos desde la comunicación, estriba en la posibilidad de intervenir directamente en la ruptura de las representaciones asumidas como «orden natural» y develar así el disfrazamiento simbólico que construye a ciertos actores y ciertos espacios para representar acciones que se rechazan (Bartra, 1996), convirtiendo la desigualdad estructural en un problema de diferenciación cultural.

En este sentido, una dificultad inicial concreta fue que no era común que la conducción de un espacio como el analizado estuviera a cargo de alguien que no venía de los organismos históricos o no tenía familiares desaparecides o víctimas de violaciones a los derechos humanos. Era mucha la responsabilidad ante esta situación, tanto por lo novedoso de la propuesta como por la diversidad de actores con que se articulaba, pero poniendo mucho el cuerpo en el trabajo cotidiano pudimos salir adelante y, por sobre todas las cosas, desde una perspectiva de solidaridad y de acompañamiento con las distintas causas de defensa y de promoción de derechos. Esto, además, nos ayudó a crecer interna y externamente, a tener más espalda política y espacio.

El concepto «matriz de pensamiento» es fundamental para identificar los parámetros que determinan cómo se construye el conocimiento sobre la realidad y, en función de ello, cómo se gestiona para transformarla. Desde la gestión, lo popular en el acceso y en la construcción de las políticas se relaciona con la memoria individual y colectiva, con la combinación de las historias sociales, cuestión que también incluye las vivencias producidas por las políticas públicas. Como nos enseña Alcira Argumedo (1996), en el marco de la matriz latinoamericana de pensamiento popular, encabezada por líderes populares, «planteamos un concepto de totalidad que, sin caer en totalizaciones reduccionistas, sea capaz de develar los silencios de las corrientes hegemónicas en la ciencias sociales y de hacer emerger las voces de otros protagonistas de la historia» (p. 77).

En síntesis, debemos señalar que una política de gestión institucional debe partir de $46 \quad$ Por ejemplo, una forma de visibilizar lo que estaba invisible es la construcción de este documento de tesis mediante la utilización de lenguaje inclusivo. 
reconocer la propia historia de lucha y de organización en materia de derechos humanos. De esta forma, se garantiza que el área haga síntesis, que represente identitariamente a todas las voces que participan del proyecto político académico y que incluya, al mismo tiempo, a les otres. Partir de la propia experiencia es clave para garantizar las representaciones por fuera de las tradiciones, siempre ampliando las voces.

En esta sistematización, aprendimos lo relevante que fue para el desarrollo de la Secretaría que una de las primeras políticas de gestión tuvo por objetivo, precisamente, incluir voces excluidas de los claustros universitarios, para lo cual el gobierno nacional creaba el contexto apropiado. Ejemplos cabales son haber otorgado a Rosa Schonfeld de Bru el título Doctora Honoris Causa (un hecho impensable en épocas anteriores, en las que tal nombramiento se destinaba a eruditos del establishment académico), las políticas indígenas pluriculturales llevadas adelante, los avances concretos en la inclusión de derechos universitarios a les privades de libertad, la incorporación de la diversidad sexual, entre otros. Hechos que marcaron la línea política de la Facultad basada en la epistemología del barro.

Esas voces que emergen abren lugares de visibilidad y de inclusión que, especialmente en el campo académico, habían sido vedados. Tal fue el objetivo de la gestión de la Secretaría de Derechos Humanos: introducir, entrelazar esas voces, en y con los claustros académicos, pensando una universidad al servicio del pueblo, perspectiva absolutamente ligada salvando las distancias, por supuesto- con la que habían proyectado les compañeres de los setenta en la universidad antes de los años de plomo del terrorismo de Estado (19761983).

Los hechos históricos que atraviesan la experiencia política, más la formación teórica en una Facultad marcada por su compromiso y su formación con las causas sociales, instalaron y aún instalan en la gestión de la Secretaría prácticas concretas de valoración de los derechos humanos. Las matrices de pensamiento, en efecto, nos permiten encontrar rupturas y continuidades históricas en el debate político de nuestro tiempo. Son formas de reelaboración y de sistematización conceptual de determinados modos de percibir el mundo que se desarrollan en procesos históricos y en experiencias políticas determinadas como sucede con este proceso de gestión, que además de la inclusión de los diversos actores en las tramas políticas también incorpora una diversidad de historias propias de lucha, de identidad, etcétera.

De esta manera, queremos resaltar que en nuestra sistematización emerge el concepto de memoria como articulador esencial de las líneas de gestión. Entendimos, y entendemos, a la «Memoria» y a su significado como claves, teniendo en cuenta la visión dinámica con que la ponemos en práctica, íntimamente ligada con las matrices de pensamiento que la motorizan y con la disputa simbólica por el sentido que la define. Pilar Calveiro (2004) lo dice muy claramente: la memoria «llama», «despierta», «reorganiza lo vivido», es una marca hecha en el cuerpo social e individual. La memoria es una fuerza importante para la transformación de las sociedades y para el cambio de rumbo de la historia, consigna huellas, impresiones, marcas y fracturas en las vidas de los pueblos y de los individuos.

En nuestra trayectoria, la memoria es un recurso político, una necesidad histórica, un imperativo ético. Una muestra de esto es la fuerza simbólica que produce el mural de Miguel Bru y la lucha de Rosa en la fachada de nuestra sede histórica, el monumento con los nombres de las víctimas del terrorismo de Estado en el medio del patio de la Facultad, las producciones comunicacionales sobre narrativas indígenas, los relatos audiovisuales del proyecto Madres y Abuelas de Plaza de Mayo, las producciones comunicacionales sobre y de privades de libertad, el desarrollo del programa institucional sobre cárceles, el reconocimiento de la identidad de género, la creación de la Dirección y el Observatorio de diversidad, y la presencia de una heterogeneidad de colectivos que proponen y que comparten historias, narrativas, iniciativas pedagógicas, etcétera.

La Facultad de Periodismo y Comunicación Social quedará absolutamente atravesada por esas huellas, eso es irreversible, y esas marcas convivirán en todas las propuestas académicas de nuestra universidad por muchos años. Pero ese debe ser el piso, solo pueden permitirse instancias superadoras e innovadoras a partir de acá. Los trabajos sobre memoria son centrales en las políticas de derechos humanos de la universidad pública, porque la memoria implica conocer la verdad de la historia de los pueblos, traerla al presente evocarla, no solo para saber lo que pasó sino, en muchos casos, para reclamar justicia y para que no vuelva a suceder.

«Las marcas institucionales, territoriales y simbólicas explícitamente ancladas en el pasado reciente de violencia y de represión han proliferado en el mundo contemporáneo», sostiene Elizabeth Jelin (2013, p. 129) y agrega: «El énfasis está puesto en la preocupación por los legados y por la transmisión a las nuevas generaciones, lo que podríamos llamar la dimensión "pedagógica" de la memoria» (p. 130). Esta dimensión pedagógica y políticas públicas con fuerte acento en el proceso de Memoria como las que vivió el país en el período seleccionado, son claves que aportan a la explicación de este proceso de disputa y de lucha permanente por el sentido. La única forma de garantizarla está en quienes componemos la comunidad académica, en connivencia con les protagonistas de las historias, y una acción fundamental es demarcando esas huellas. Esta disputa simbólica fue la denominada «batalla cultural» que entendimos todes debíamos militar, desde y con la universidad, más que nunca a partir de un gobierno que sentíamos nos representaba y la encabezaba, como fue el proyecto político de Néstor Kirchner, primero, y de Cristina Fernández, luego. E compromiso como motor de la recuperación de la memoria se hace necesario en toda la comunidad universitaria.

Tanto en la batalla cultural como en la propia dinámica de los derechos humanos, en general, la mayoría de las personas son objetos discursivos antes que sujetos de derechos. Tal vez no se sepa con certeza, advierte de Sousa Santos (2006), si los derechos humanos actuales «son un legado de las revoluciones modernas o las ruinas de esas revoluciones, si tras ellos hay una fuerza revolucionaria de emancipación o una fuerza contrarrevolucionaria» 
(p. 30). Es condición sine qua non que la política pública de derechos humanos desde la universidad sea funcional a las luchas por los derechos de los sectores excluidos. En este sentido, la gestión de la Secretaría -casi de manera contrahegemónica- ha podido ampliar derechos hacia lo colectivo y lo comunitario.

No podemos dejar de pensar, entonces, que cada momento puede ser un eslabón central en un proceso histórico determinado. Desde las políticas públicas universitarias en derechos humanos es necesario afirmar, y asumir como fundamental, una epistemología de la esperanza. Como afirman Florencia Saintout y Andrea Varela (2014): «Un punto de vista que no solo vea lo que se ha destruido y lo que falta, sino lo que está naciendo en un sentido emancipador [...] o que aparece como nuevo, como creación y como excepción. Como tiempo emergente» (p. 113).

Cuando Oscar Jara Holliday me recomendó que estableciera un recorte más acotado, entendí que la selección del período de gestión a sistematizar estaba absolutamente emparentado con el hecho de que a partir de 2014, cuando inicia el siguiente proceso de gestión, el gobierno neoliberal gana las elecciones a nivel nacional, en la provincia de Buenos Aires y también en la ciudad de La Plata, lo que cambió el paradigma de las políticas públicas de corte nacional y popular que se venían desarrollando desde la asunción de Néstor Kirchner. La idea, entonces, es continuar con ese nuevo período en un futuro proyecto de investigación o como tesis doctoral, tal como es el plan luego de terminada esta Maestría.

Esta tesis no es un punto final sino aportes para el futuro sobre la base de una experiencia específica. En esta línea, fue fundamental sistematizar las experiencias según la metodología propuesta por Oscar Jara Holliday (2018). En este sentido, quiero destacar que de todos los dispositivos investigativos puestos en acción la construcción de la matriz de sistematización fue lo que me permitió objetivar las prácticas, ordenarlas cronológicamente y elaborar un registro para su posterior análisis. Por ello, decidí incluirla en el documento de tesis, porque, como afirma Jara Holliday (2018): «Posibilita que los sujetos de las experiencias podamos, gracias a la sistematización, apropiarnos críticamente de su sentido» (p. 62)

Fundamental es señalar la capacidad, la posibilidad y la necesidad de construir derechos desde las políticas públicas universitarias, cuyo beneficio redunda, concretamente, en el desarrollo de la sociedad. La universidad pública tiene un rol clave en el campo científico y en la posibilidad de obtener beneficios sociales como la inclusión de los diversos sectores en la ejecución de políticas públicas que aporten al mejoramiento de la vida de las comunidades, a la construcción de ciudadanía, a la promoción y al desarrollo de los derechos humanos de las personas y los pueblos, al derecho a la educación, entre otros. La universidad, en este sentido, tiene que ser un motor de cambio fundamental al servicio de la sociedad, incluso transformándose a sí misma, con las propias tensiones y contradicciones que esto conlleva.
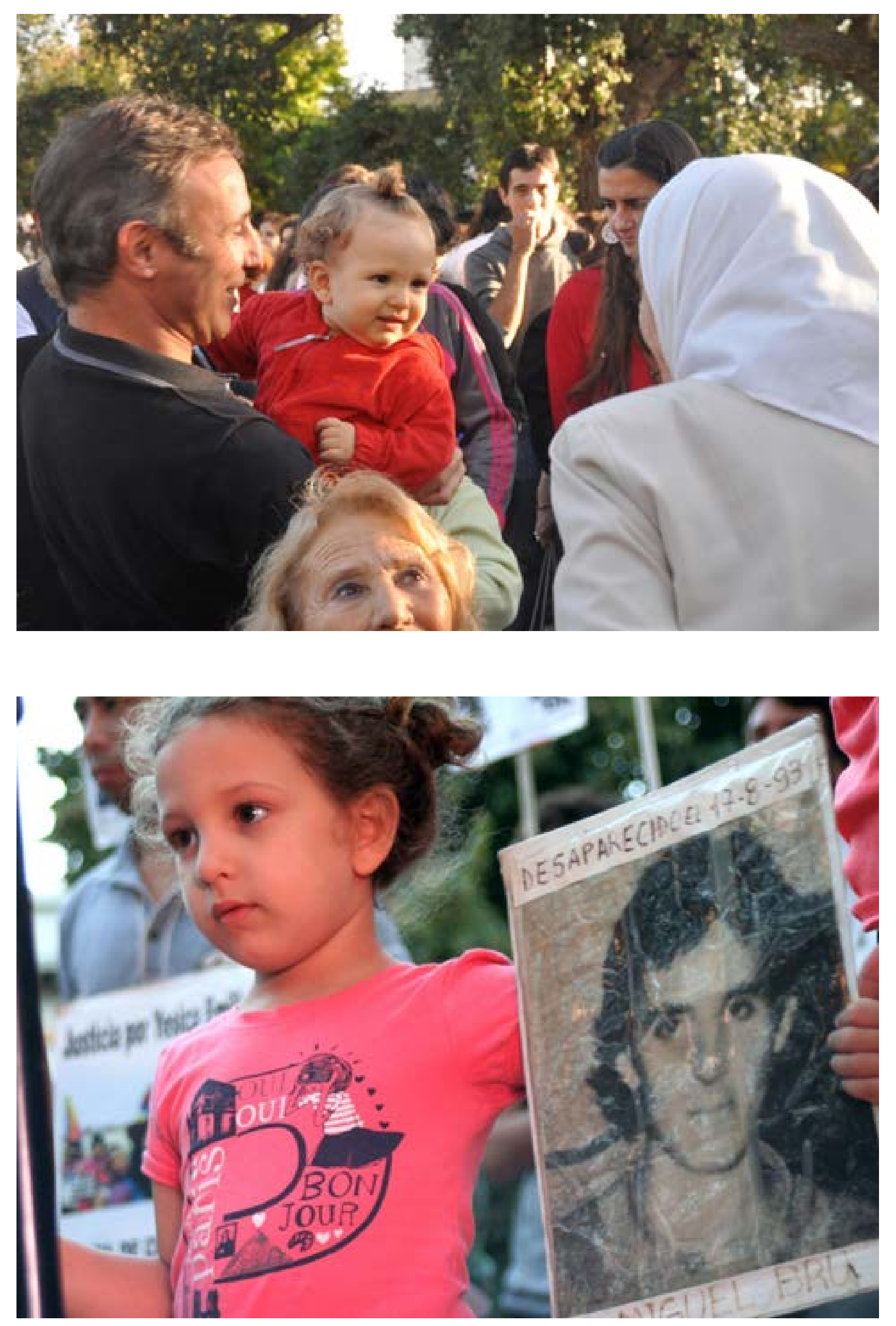

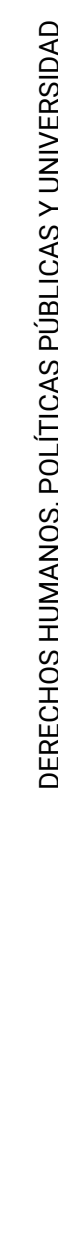



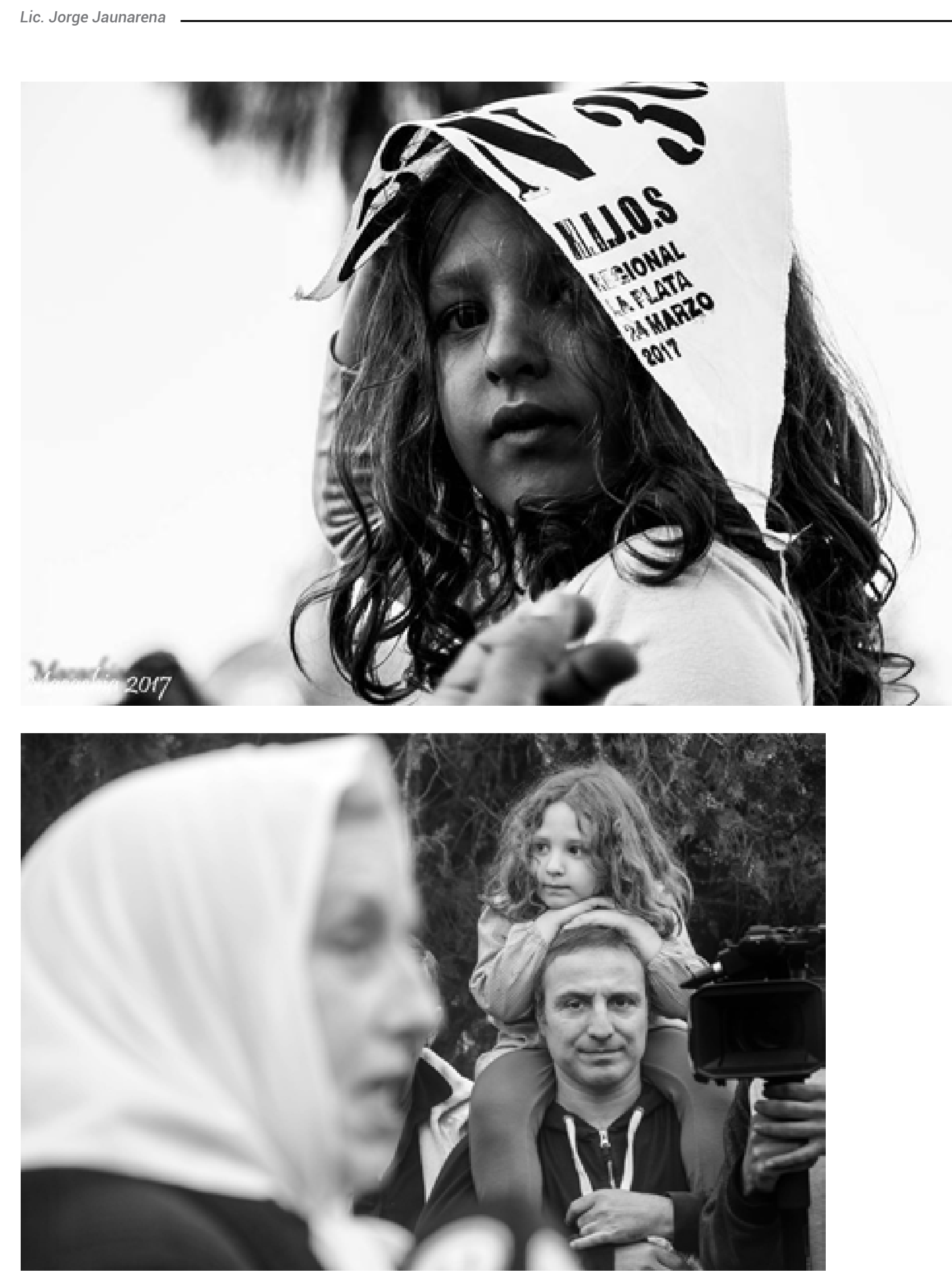

EL FUTURO

1.Mi hija Guadalupe Jaunarena mirándose con Adelina Alaye, Madre de Plaza de Mayo en la inauguración del monolito a los desaparecidos en la FP y CS. 2. Guadalupe, con la primer pancarta que hicimos por Miguel y que todavía conservo, en una manifestación. 3 y 4 Guadalupe en diversas marchas por memoria, verdad y justicia.
REFERENCIAS Y FUENTES

\section{Créditos por las fotografías}

Las fotografías fueron cedidas por la Facultad de Periodismo y Comunicación Social (FPyCS) de la UNLP y por su Secretaría de Derechos Humanos; por la familia Bru, la Asociación Civil Miguel Bru (AMB), la Asociación de Docentes de la Universidad de La Plata (ADULP) y la Mesa por los Derechos Humanos de la Plata, Berisso y Ensenada. También se incluyen algunas fotografías tomadas de google imágenes solo para este fin académico.

Federico Araneta, Eva Cabrera, Gabriela Hernández, Laura Sottile, Alberto Mendoza Padilla, María Isabel Peysse, Pablo Piovano y alumnes del Taller de foto que coordinó la AMB en Isla Maciel son algunes de les autores de las fotografías que se reproducen en esta tesis.

Varias fueron donadas solidariamente, a través de los años, por distintas personas sobre las que, en muchos casos, no quedó registro certero de su autoría.

¡Agradezco enormemente a todes su generosa colaboración!

\section{Obras referidas}

Abramovich, V. (2006). Una aproximación al enfoque de derechos en las estrategias y políticas de desarrollo. Revista de la Cepal, (88), 35-50. Recuperado de https://www. cepal.org/es/publicaciones/11102-aproximacion-al-enfoque-derechos-estrategiaspoliticas-desarrollo

Aguilar Villanueva, L. (1993). La hechura de la política. Ciudad de México, México: Miguel Ángel Porrúa.

Argumedo, A. (1996). Los silencios y las voces en América Latina: notas sobre el pensamiento nacional y popular. Ciudad Autónoma de Buenos Aires, Argentina: Colihue.

Arrúa, V. (2006). La producción de conocimiento desde los «diálogos de saberes». Tram[p] as de la comunicación y la cultura, (44), 23-27. Recuperado de http://sedici.unlp.edu. ar/handle/10915/32925

Barba, F. (1998). La Universidad Nacional de La Plata en su centenario (1897-1997). La Plata, Argentina: Universidad Nacional de la Plata y Banco Municipal de La Plata.

Calveiro, P. (2005). Antiguos y nuevos sentidos de la política y la violencia. En Lucha Armada, (4).

Ciappina, C. (2015). Facultad de Periodismo y Comunicación Social: una historia de formación y política, 1934-1998 (Tesis de Doctorado). La Plata, Argentina: Facultad 
de Periodismo y Comunicación Social, Universidad Nacional de La Plata. https://doi. org/10.35537/10915/45674

Comisión Nacional sobre la Desaparición de Personas (CONADEP). (1984). Nunca Más. Informe de la Comisión Nacional sobre Desaparición de Personas. Ciudad Autónoma de Buenos Aires, Argentina: Eudeba.

Díaz, C. (1998). El ciclo de las políticas públicas locales. Notas para su abordaje y reconstrucción. En J. Venesia (Coord.), Políticas públicas y desarrollo local (pp. 67107). Rosario, Argentina: Facultad Latinoamericana de Ciencias Sociales (FLACSO) y Fundación Instituto de Desarrollo Regional.

De Sousa Santos, B. (2005a). El milenio huérfano. Ensayos para una nueva cultura política. Madrid, España: Trotta.

De Sousa Santos, B. (2005b). La Universidad del Siglo XXI, para una reforma democrática y emancipadora de la Universidad. Ciudad de México, México: Centro de Investigaciones Interdisciplinarias en Ciencias y Humanidades, Universidad Autónoma de México.

De Sousa Santos, B. (2006). Renovar la teoría crítica y reinventar la emancipación social (encuentros en Buenos Aires). Ciudad Autónoma de Buenos Aires, Argentina: Consejo Latinoamericano de Ciencias Sociales (CLACSO).

Duhalde, E. L. (2007). Políticas públicas en derechos humanos. Defender los derechos humanos es construir ciudadanía. Tram[p]as de la comunicación y la cultura, (53), 30-34. Recuperado de http://sedici.unlp.edu.ar/handle/10915/36618

Federación Universitaria de la Revolución Nacional (FURN). (1973). Bases para la Nueva Universidad.

Fernández, A. (2006). Las políticas públicas. En M. Caminal Badia (Coord.), Manual de ciencia política (pp. 495-517). Madrid, España: Tecnos.

Gras, M. T. (2011). Estado y Derechos Humanos ¿ herramientas de planificación? Trabajo presentado en el VI Congreso Argentino de Administración Pública, Gobernabilidad Democrática y Desarrollo Económico con Equidad Social. Resistencia, Argentina.

Jara Holliday, O. (2018). La sistematización de experiencias: práctica y teoría para otros mundos posibles. Bogotá, Colombia: Centro Internacional de Educación y Desarrollo Humano (CINDE).

Jaunarena, J. (2005). Un recorrido por la violencia institucional en la Argentina. Oficios Terrestres, (17), 73-87. Recuperado de http://sedici.unlp.edu.ar/handle/10915/4660

Jelin, E. (2013). Memoria y democracia. Una relación incierta. Política. Revista de Ciencia Política, 51(2), 129-144. 10.5354/0716-1077.2013.30162.

Naciones Unidas (2005). Resoluciones y decisiones aprobadas por la Comisión en su $60^{\circ}$ período de sesiones. Ginebra, Suiza: Comisión de Derechos Humanos. Recuperado de https://undocs.org/pdf?symbol=es/E/2005/23(PARTI)

Oszlak, O. y O' Donnell, G. (1976). Estado y políticas estatales en América Latina: hacia una estrategia de investigación. Redes, 2(4), 99-128. Recuperado de http://repositorio. cedes.org/handle/123456789/3332

Pagani, M. L. y Manuele, M. (2020). La mirada organizacional: enfoques y metodología para el análisis. La Plata, Argentina: EDULP.

Pollak, M. (1989). Memoria, olvido, silencio. Revista de Estudios Históricos, 2(3), 3-15.

Reguillo, R. (1998). Un malestar invisible: derechos humanos y comunicación. Chasqui: Revista Latinoamericana de Comunicación, (64), 18-23. Recuperado de https://cutt. ly/2n20792

Retola, G. (2018). Paraíso. Construcción de conocimientos basados en diálogos de saberes entre la universidad y el pueblo. La Plata, Argentina: EDULP.

Saintout, F. y Varela, A. (2014). Los saberes académicos en contextos de compromiso. La epistemología del barro Oficios Terrestres, (30), 109-117. Recuperado de https:// perio.unlp.edu.ar/ojs/index.php/oficiosterrestres/article/view/2276

Universidad Nacional de La Plata (UNLP). (2009). Estatuto. Recuperado de https://unlp. edu.ar/frontend/media/20/120/722e7f1b616ac158e02d148aaeb762aa.pdf

Universidad Nacional de La Plata (UNLP). Nómina de integrantes de la comunidad Universitaria víctimas del Terrorismo de Estado. Recuperado de https://cutt.ly/In6RQC4

Vestfrid, P. (noviembre de 2005). Cambios curriculares en la Escuela Superior de Periodismo y Comunicación Social de la Universidad Nacional de La Plata durante la última dictadura. Trabajo presentado en las IV Jornadas de Sociología de la UNLP. Recuperado de http://www.memoria.fahce.unlp.edu.ar/trab_eventos/ev.6575/ ev.6575.pdf

Vestfrid, P. y Guillermo, G. (2007). La formación de periodistas y comunicadores durante la dictadura. El caso de la Escuela Superior de Periodismo y Comunicación Social de la UNLP durante 1976-1981. La Plata, Argentina: EDULP.

\section{Obras consultadas}

Acuña, C. y otros (1995). Juicios, castigos, memorias. Derechos Humanos y justicia en la política argentina. Ciudad Autónoma de Buenos Aires, Argentina: Nueva Visión.

Ageitos, S. M. (2002). Historia de la impunidad. De las Actas de Videla a los indultos de Menem, Ciudad Autónoma de Buenos Aires, Argentina: Adriana Hidalgo.

Argumedo, A. (1984). Los laberintos de la crisis. Ciudad Autónoma de Buenos Aires, Argentina: Puntosur. 
Barcesat, E. (1994). X Conferencia Continental de la Asociación Americana de Juristas. Bases Jurídicas para la Democracia, el Desarrollo y la Justicia Social en América. Chile, Santiago de Chile.

Bayer, O. (2010). Historia de la Crueldad Argentina. Julio A. Roca y el genocidio de los Pueblos Originarios. Ciudad Autónoma de Buenos Aires, Argentina: Red de Investigadores en Genocidio y Política Indígena en Argentina (RIGPI).

Beauvoir, S. (1949). El segundo sexo. Paris, Francia: Gallimard.

Blaustein, E. y Zubieta, M. (1998). Decíamos ayer. La prensa argentina bajo el proceso. Ciudad Autónoma de Buenos Aires, Argentina: Colihue.

Calloni, S. (2006). Operación Cóndor: pacto criminal. La Habana, Cuba: Editorial Ciencias Sociales.

Campana, G. (2020). Néstor Kirchner. No les tengo miedo. El militante que respetó su pasado. Ciudad Autónoma de Buenos Aires, Argentina: Colihue.

De Sousa Santos, B. (2014). Derechos humanos, democracia y desarrollo. Bogotá, Colombia: Centro de Estudios de Derecho, Justicia y Sociedad. Recuperado de https://cutt.ly/Mn24TIM

Devoto, J. (2020). Néstor: el hombre que cambió todo. Ciudad Autónoma de Buenos Aires Argentina: Planeta.

Elizalde, S. (2005). La otra mitad. Subjetividades peligrosas. Género y juventud en la Argentina contemporánea. (Tesis de Doctorado). Ciudad Autónoma de Buenos Aires, Argentina: Facultad de Filosofía y Letras, Universidad de Buenos Aires.

Feld, C. (2002). Del estrado a la pantalla: las imágenes del juicio a los ex comandantes en Argentina. España, Madrid: Siglo XXI.

Filmus, D. (1986). Educación, autoritarismo y democracia. Ciudad Autónoma de Buenos Aires, Argentina: Facultad Latinoamericana de Ciencias Sociales (FLACSO).

Forastelli, F. (1999). Políticas de la restitución. Identidades políticas y luchas homosexuales en la Argentina. En J. Triquell y F. Forastelli (Eds.), Las marcas del género: configuraciones de la diferencia en la Argentina. Córdoba, Argentina: Universidad de Córdoba y Universidad de Nottingham.

Ginzburg, C. (1999). The Judge and the Historian. Marginal Notes on a Late Twentieth Century Miscarriage of Justice. Reino Unido, Londres: Verso.

Gómez, M. R. (2008). Territorios en disputa: monumentos, museos y sitios de memoria. Ramona, (78). Recuperado de https://cutt.ly/Un24AN2

Jara Holliday, O. (1994). Para sistematizar experiencias: una propuesta teórica y práctica. Costa Rica, San José de Costa Rica: Alforja.
Jaunarena, J. y otros (2016). Guardianas de la memoria colectiva. Relatos de Madres y Abuelas de Plaza de Mayo. La Plata, Argentina: EDULP.

Nikken, P. (1987). El concepto de derechos humanos. Madrid, España: Civitas / Instituto Interamericano de Derechos Humanos.

Piccone, V. M. (2010). HUELLAS. Semblanzas de vida de detenidos desaparecidos y asesinados por el terrorismo de Estado pertenecientes a la Universidad Nacional de La Plata. La Plata, Argentina: EDULP.

Secretaria de Derechos Humanos del Ministerio de Justicia y Derechos Humanos de la Nación (2012). TENEMOS PATRIA. Argentina, un país con derechos. Ciudad Autónoma de Buenos Aires, Argentina: Cooperativa de Trabajo Artes Gráficas El Sol.

Valko, P. (2010). Pedagogía de la desmemoria. Crónicas y estrategias del genocidio invisible. Ciudad Autónoma de Buenos Aires, Argentina: Ediciones Madres de Plaza de Mayo.

Wainfeld, M. (2016). Kirchner. El tipo que supo. Ciudad Autónoma de Buenos Aires Argentina: Siglo veintiuno.

Zaffaroni, E. R. (2012). La cuestión criminal. Ciudad Autónoma de Buenos Aires, Argentina: Planeta.

\section{Normativas}

Ley Nacional 20654 (1974). Universidades Nacionales.

Boletín Oficial de la República Argentina. Buenos Aires, 01/04/1974.

Recuperado de http://servicios.infoleg.gob.ar/infolegInternet/verNorma.do?id=195302

Ley Nacional 23492 (1986). Fuerzas Armadas. Extinción de Acciones Penales a Fuerzas Armadas.

Boletín Oficial de la República Argentina. Buenos Aires, 29/12/1986.

Recuperado de http://servicios.infoleg.gob.ar/infolegInternet/verNorma.do?id=21864

Ley Nacional 23521 (1987). Fuerzas Armadas. Delimita Alcances del Deber de Obediencia Debida.

Boletín Oficial de la República Argentina. Buenos Aires, 09/06/1987.

Recuperado de http://servicios.infoleg.gob.ar/infolegInternet/verNorma.do?id=21746

Ley Nacional 24521 (1995). Educación Superior.

Boletín Oficial de la República Argentina. Buenos Aires, 10/08/1995

Recuperado de http://servicios.infoleg.gob.ar/infoleglnternet/verNorma.do?id=25394

Ley Nacional 25633 (2002). Conmemoraciones. Día Nacional de la Memoria por la Verdad. Boletín Oficial de la República Argentina. Buenos Aires, 23/08/2002

Recuperado de http://servicios.infoleg.gob.ar/infoleglnternet/verNorma.do?id=77081

Ley Nacional 25864 (2003). Educación. Ciclo Lectivo Anual. 
Boletín Oficial de la República Argentina. Buenos Aires, 15/01/2004.

Recuperado de http://servicios .infoleg.gob.ar/infolegInternet/verNorma.do?id=91819

Ley Nacional 26061 (2005). Ley de Protección Integral de los Derechos de las Niñas, Niños y Adolescentes. Disposiciones Generales.

Boletín Oficial de la República Argentina. Buenos Aires, 26/10/2005.

Recuperado de http://servicios .infoleg.gob.ar/infolegInternet/verNorma.do?id=110778

Ley Nacional 26160 (2006). Comunidades indígenas. Emergencia en Materia de Posesión y Propiedad de Tierras.

Boletín Oficial de la República Argentina. Buenos Aires, 29/11/2006.

Recuperado de http://servicios.infoleg.gob.ar/infoleglnternet/verNorma.do?id=122499

Ley Nacional 26206 (2006). Ley de Educación Nacional.

Boletín Oficial de la República Argentina. Buenos Aires, 28/12/2006.

Recuperado de http://servicios. infoleg.gob.ar/infoleglnternet/verNorma.do?id=123542

Ley Nacional 26485 (2009). Ley de Protección Integral a las Mujeres. Ley para Prevenir, Sancionar y Erradicar la Violencia.

Boletín Oficial de la República Argentina. Buenos Aires, 14/04/2009.

Recuperado de http://servicios. . infoleg.gob.ar/infoleglnternet/verNorma.do?id=152155

Ley Nacional 26618 (2010). Matrimonio Civil.

Boletín Oficial de la República Argentina. Buenos Aires, 22/07/2010.

Recuperado de http://servicios.infoleg.gob.ar/infoleglnternet/verNorma.do?id=169608

Ley Nacional 26743 (2012). Ley de identidad de género. Derecho de las personas.

Boletín Oficial de la República Argentina. Buenos Aires, 24/05/2012.

Recuperado de http://servicios.infoleg.gob.ar/infoleglnternet/verNorma.do?id=197860

Ley Nacional 26811 (2012). Día Nacional de la Lucha contra la Violencia Institucional.

Boletín Oficial de la República Argentina. Buenos Aires, 21/01/2013.

Recuperado de http://servicios.infoleg.gob.ar/infoleglnternet/verNorma.do?id=207586

Resolución Nacional 40 (1979).

Boletín Oficial de la República Argentina. Buenos Aires, 01/10/1970.

Resolución 155 (1955).

Universidad Nacional de La Plata. Recuperado de https://perio.unlp.edu.ar/archivoperio/ node/4156

Resolución 88 (2004). Designación Director de Derechos Humanos (2004/2007)

Facultad de Periodismo y Comunicación Social, Universidad Nacional de La Plata.

Resolución 87 (2007). Designación Secretario de Derechos Humanos (2007/2010).

Facultad de Periodismo y Comunicación Social, Universidad Nacional de La Plata.

\section{Notas periodísticas}

Amílcar Vara fue destituido como magistrado y será investigado (13 de mayo de 1998).
La Nación. Recuperado de https://www.lanacion.com.ar/sociedad/amilcar-vara-fuedestituido-como-magistrado-y-sera-investigado-nid96437/

Bautizaron la Facultad de Periodismo con el nombre de Miguel (17 de agosto de 2005). Casa de Cultura y Oficios. Recuperado de https://asociacionmiguelbru.org.ar/la-facultadde-periodismo-se-llama-miguel-bru/

Entregaron título a la familia de una egresada desaparecida (16 de diciembre de 2007). El Día. Recuperado de

https://www.eldia.com/nota/2007-12-16-entregaran-titulo-a-familia-de-una-egresadadesaparecida

Entregaron diploma a la familia de Liliana Molteni (17 de diciembre de 2007). La campana. Recuperado de

http://lacampanaweb.blogspot.com/2007/12/entregaron-diploma-la-familia-de.html 
Entregaron título a una periodista desaparecida en 1976 (18 de diciembre de 2007). Perfil. Recuperado de

https://www.perfil.com/noticias/sociedad/entregaron-titulo-a-una-periodista-

desaparecida-en-1976-20071218-0062.phtml

Emotivo homenaje a 20 años de la desaparición de Miguel Bru (4 de agosto de 2013). Hoy en la noticia. Recuperado de

https://diariohoy.net/trama-urbana/emotivo-homenaje-a-20-anos-de-la-desaparicion-demiguel-bru-13853

Rodríguez, C. (17 de agosto de 2013). Miguel Bru, a veinte años de su muerte. Página/12. Recuperado de https://www.pagina12.com.ar/diario/sociedad/3-226973-2013-08-17.html

Se inauguró el edificio «Néstor Kirchner» de la Facultad de Periodismo y Comunicación Social (12 de marzo de 2014). ANDigital. Recuperado de https://andigital.com.ar/interesgeneral/item/13546-se-inaugur-oacute-el-edificio-n-eacute-stor-kirchner-de-la-facultad-deperiodismo-y-comunicaci-oacute-n-social

Cómo funciona el sistema educativo en las cárceles argentinas (13 de marzo de 2015). La Nación. Recuperado de https://www.lanacion.com.ar/sociedad/como-funciona-el-sistemaeducativo-en-las-carceles-argentinas-nid1774947/

Entrevista realizada por los alumnxs de periodismo de la Casa de Cultura y Oficios ( 14 de junio de 2015). Casa de Cultura y Oficios. Recuperado de

https://asociacionmiguelbru.org.ar/entrevista-realizada-por-los-alumnxs-de-periodismode-la-casa-de-cultura-y-oficios/

Honoris Causa: Sra. Rosa Schoenfeld de Bru (10 de mayo de 2018). Universidad Nacional de La Plata. Recuperado de https://unlp.edu.ar/honoris_causa/rosa_schoenfeld_de_bru_ honoris_causa-2803

A 23 años de la Asamblea Universitaria que terminó en una brutal represión, el recuerdo (20 de febrero de 2019). 0221.com.ar. Recuperado de https://www.0221.com.ar/ nota/2019-2-20-17-9-0-a-23-anos-de-la-asamblea-universitaria-que-termino-en-una-brutalrepresion-el-recuerdo

Proyectan documental sobre el estudiante de periodismo desaparecido Miguel Bru ( $15 \mathrm{de}$ mayo de 2020). Télam. Recuperado de https://www.telam.com.ar/notas/202005/464319documental-miguel-bru-facultad-de-periodismo-de-la-plata.html

Con una jornada cultural se recordó a Miguel Bru (s/f). Facultad de Periodismo y

Comunicación Social. Recuperado de https://perio.unlp.edu.ar/archivoperio/node/3457

Realizarán la $1^{\circ}$ Muestra de Cine Indígena (s/f). Facultad de Periodismo y Comunicación Social. Recuperado de https://perio.unlp.edu.ar/archivoperio/node/2550

\section{Producciones audiovisuales}

Gardinetti, L. y Jaunarena, J. (2011). Comunicación en cárceles, una herramienta para el cambio [Documental audiovisual].
Jaunarena, J. (Director). (2011). Madres y Abuelas de Plaza de Mayo. Relatos del futuro [Producción audiovisual]. Recuperado de https://cutt.ly/MnOlia9

Jure, C. y Cartoy Díaz, E. (Directores). (2010). La guerra por otros medios [Documental audiovisual]

Jure, C. (Director). (2012). 10 veces venceremos [Documental audiovisual].

Torello, P. (Director). (2006). Historias de aparecidos. Los vuelos de la muerte [Documental audiovisual].

Torello, P. y Jaunarena, J. (Directores). (2000). ¿Dónde está Miguel? [Documenta audiovisual]. Documentales de la memoria, Canal Encuentro.

Torello, P. y Jaunarena, J. (Directores). (2013). Rosa Bru, 20 años de lucha [Documental audiovisual].

Vitola, F. (Director). (2008). Un grito sagrado [Documental audiovisual]. 
comunicación locales y nacionales, y también el intercambio de experiencias y articulaciones de trabajo con otras instituciones académicas, organizaciones gubernamentales, no gubernamentales y comunitarias.

En este sentido, el P.F.DD.HH. apuntará a la articulación de los trabajos de las cátedras, organizaciones estudiantiles y ámbitos de investigación. A través de un relevamiento entre docentes, estudiantes e investigadores/as mapearemos el abordaje ya existente en nuestra Facultad, para en una etapa posterior poder realizar un diagnóstico o estado de la cuestión en el que podamos caracterizar y proyectar necesidades académicas en la materia.

El P.F.DD.HH. se realizará en las siguientes etapas:

- Diagnóstico sobre el abordaje de derechos humanos en la carrera.

- Análisis de las necesidades académicas sobre la materia.

- Diseño de un programa de articulación con especialista y organizaciones gubernamentales y no gubernamentales en función del diagnóstico y el análisis.

- Puesta en marcha de cursillos de formación y conferencias.

El público objetivo del P.F.DD.HH. serán estudiantes, docentes, investigadores/as y no docentes.

Si bien el contenido de los cursillos y conferencias serán establecidos a partir del diagnóstico y del análisis, las evaluaciones intuitivas previas y el contexto político nos hace pensar como necesario avanzar en temas de actualidad con los que los profesionales y futuros/as profesionales egresados/as de nuestra Facultad se deberán enfrentar.

EI P.F.DD.HH. se implementará en el segundo cuatrimestre del año 2004. Para esto pensamos en los siguientes plazos:

- Diagnóstico: 1 mes

- Análisis: 15 días

- Diseño: 15 días

y otras formas de represión en el marco de la democracia. También creemos necesario ténén sexual, minorías culturales, entre otras cuestiones. La Universidad como espacio educativo dedicado a la enseñanza, investigación y extensión, posee, por su propia naturaleza, una conexión directa con los derechos humanos (civiles, políticos, económicos, sociales y culturales), que debe recrearse en abordajes substancialmente más integrales que los hasta ahora intentados, estableciendo una línea académica sobre la educación y articulación cívica, como política de la institución.

Esta capacitación se realizará en una primera instancia a través de un módulo al que denominaremos Programa de Formación (P.F.DD.HH.): realización de jornadas, seminarios, congresos de capacitación y conferencias concernientes a los temas antes mencionados, los que serán abordados por profesionales y actores sociales específicos en cada tema, para luego poder articular estos conocimientos desde la Dirección hacia las distintas secretarías de nuestra institución, para un trabajo interno y externo en esta materia. En este sentido propiciaremos un trabajo interclaustro que asegure una amplia transversalidad en el abordaje de los temas y de la "inscripción" de los mismos en nuestra Facultad.

Esta dirección también ve como fundamental la sistematización y difusión de todos los módulos trabajados, tanto en los órganos de difusión interna, como en los medios de 
La puesta en marcha se hará de manera inmediata luego de los dos meses de trabajo. En este sentido creemos conveniente trabajar desde principios de agosto.

El P.F.DD.HH. será monitoreado a través de un informe luego de cada etapa y un informe final. También se invitará a las organizaciones participantes a que señalen puntos débiles y fortalezas del programa.

Al finalizar el primer cuatrimestre, crearemos una red de organizaciones, investigadores/as y docentes interesados/as en los temas tratados para general bimensualmente una reunión de actualización. También crearemos un directorio de especialistas para los medios de comunicación y organizaciones gubernamentales y no gubernamentales que requieran de intervenciones de estudiantes, docentes e investigadores/as de nuestra facultad.

También invitaremos a las organizaciones gubernamentales y no gubernamentales a donar distintos materiales a nuestra facultad, con el objetivo de crear una sección de DD.HH. en la biblioteca, la hemeroteca y la videoteca.

EI P.F.DD.HH. desembocará en un Programa de Transferencia (P.T.) por medio del cual nuestra facultad podrá transferir conocimientos y estrategias de manera gratuita a organizaciones de base y pensar en contratos de trabajo con organizaciones no gubernamentales (básicamente, fundaciones) y órganos de gobierno. En este sentido, pensamos en la posibilidad de formar en cuestiones antidiscriminatorias a docentes secundarios, agentes de salud, entre otros/as.

Y en una tercera etapa, pensamos en un Programa de Intervenciones (P.I.), es decir, a partir de la creación del directorio de especialistas en el P.F.DD.HH., será posible intervenir como parte en la redacción de proyectos legislativos, observaciones a políticas públicas y procesos de amicus curiae en el ámbito de la justicia. 